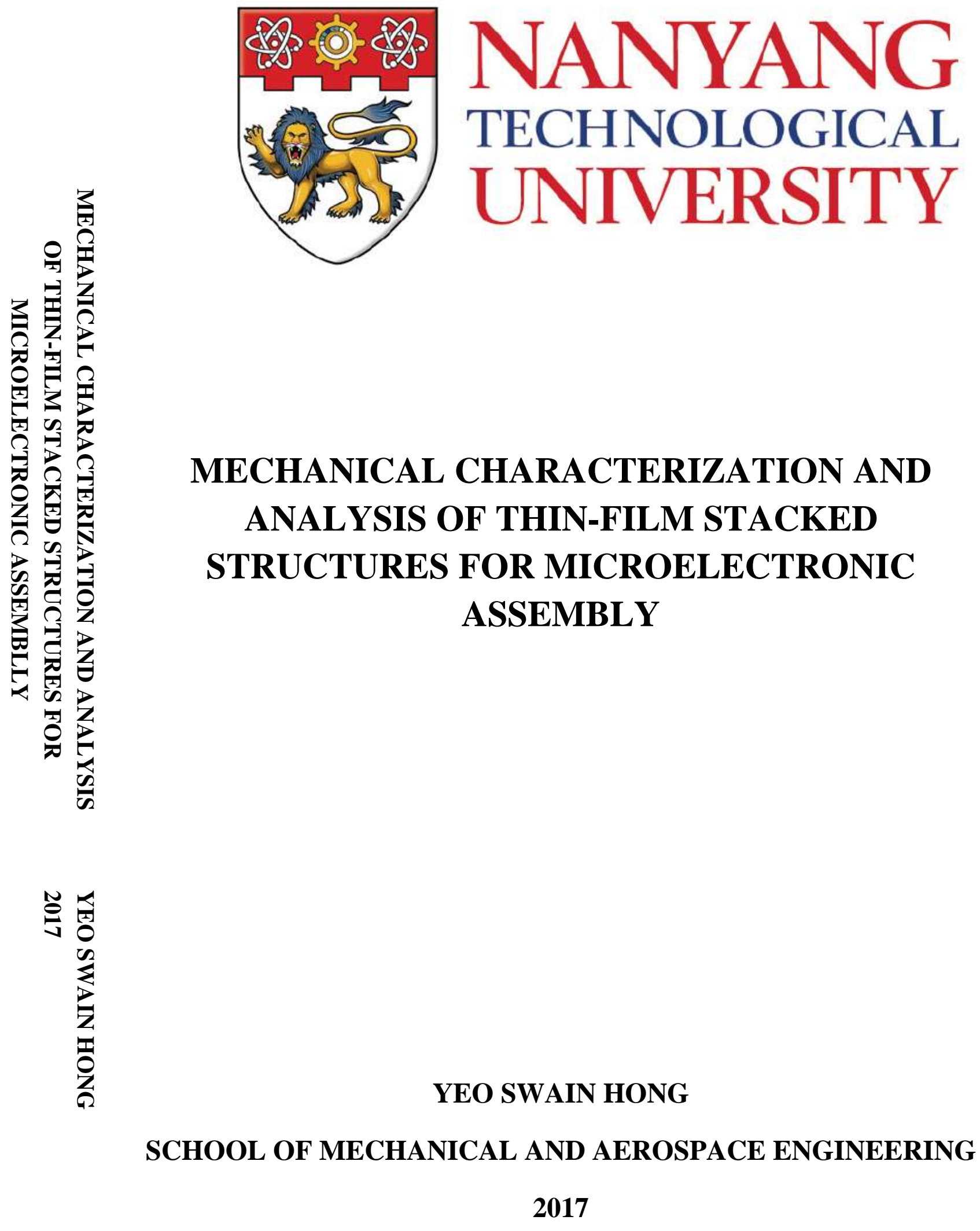




\section{MECHANICAL CHARACTERIZATION AND ANALYSIS OF THIN-FILM STACKED STRUCTURES FOR MICROELECTRONIC ASSEMBLY}

\section{YEO SWAIN HONG}

\section{SCHOOL OF MECHANICAL AND AEROSPACE ENGINEERING}

A thesis submitted to the Nanyang Technological University in partial fulfilment of the requirement for the degree of

Doctor of Philosophy 


\section{Acknowledgements}

I would like to express my sincere gratitude and appreciation to Assistant Professor Zhou Kun, my supervisor, for his guidance, patience and encouragement for the past over four years. This research would not have been possible without his help and guidance. I have immensely benefitted from his strict training on scientific thinking and writing. His dedication and enthusiasm for research has been exemplary and motivating. His rigorous and serious attitude towards scientific research has impressed me greatly.

My appreciation also goes to Dr. Chan Yuen Sing and Dr. Yang Kai from Infineon Technologies, and Dr. Che Faxing from Institution of Microelectronics. The technical discussions with them have been fruitful and helpful.

Last but not least, I would like to express my heartfelt gratefulness to my family for their continuous support, understanding and encouragement that really mean a lot to me. 



\section{Table of Content}

Acknowledgements ....................................................................................................................

Table of Content ......................................................................................................II

List of Figures.................................................................................................... VII

List of Tables .......................................................................................................................... XVII

Abstract....................................................................................................................................XVIII

Chapter 1 Introduction.......................................................................................................................... 1

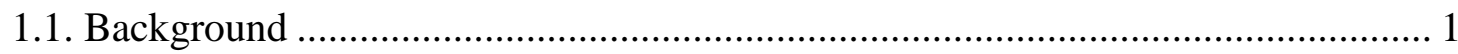

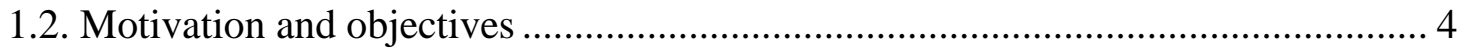

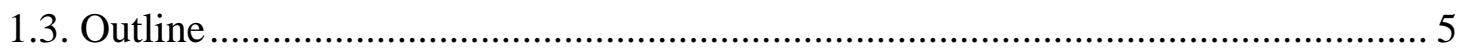

Chapter 2 Literature Review ............................................................................................. 6

2.1 Interaction mechanism between the integrated circuit chip and backend assembly 6

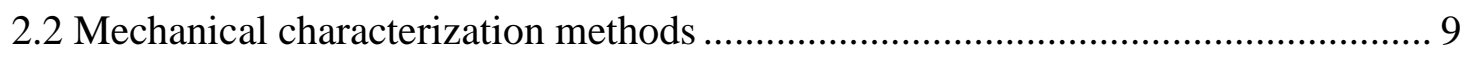

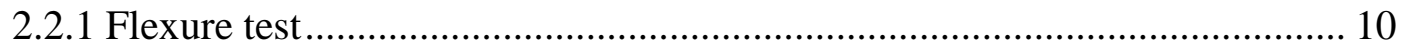

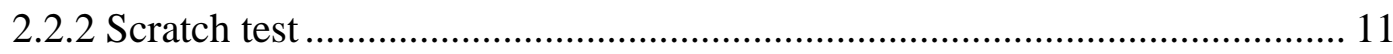

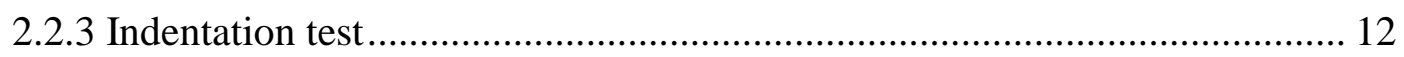

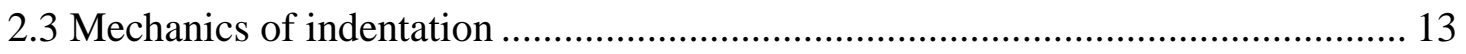

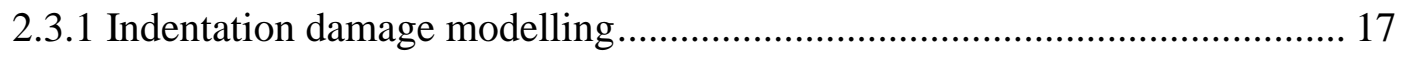

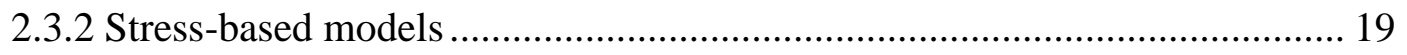

2.3.3 Energy-based models ............................................................................. 21 
2.4 Physical damage detection techniques .......................................................... 24

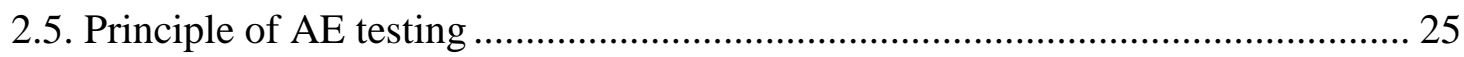

Chapter 3 Development of Indentation Damage Test Methodology .............................. 30

3.1 Integration of indentation testing with acoustic emission monitoring ................... 30

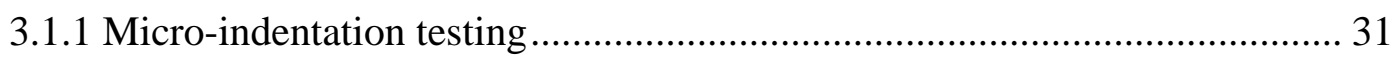

3.1.2 Acoustic emission event sensing and detection ......................................... 33

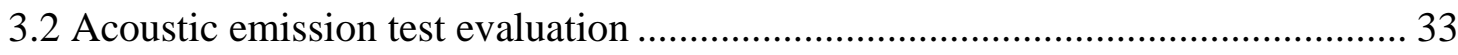

3.2.1 Effect of coupling medium between specimen and AE sensor....................... 36

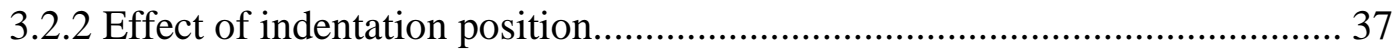

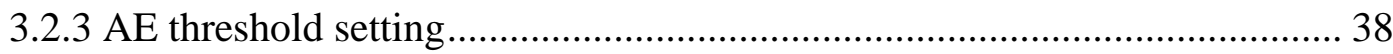

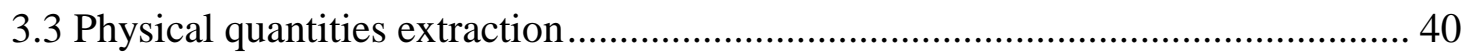

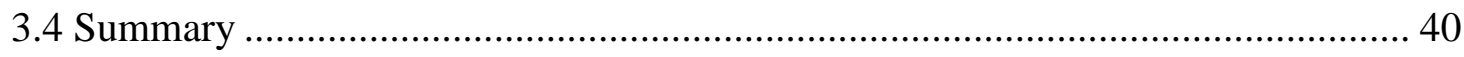

Chapter 4 Indentation Damage Evaluation of Si Dies.......................................................... 42

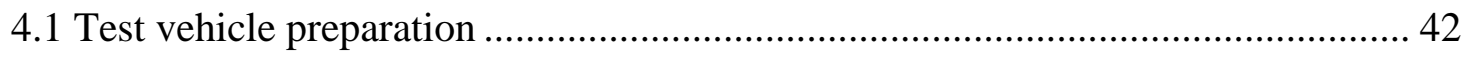

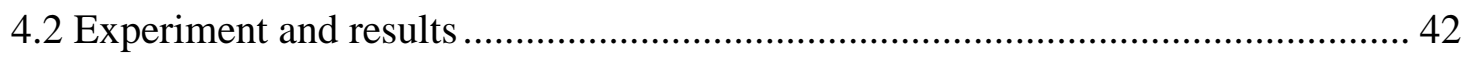

4.2.1 Indentation damage test on the Si (100) die............................................... 44

4.2.2 Indentation damage test on the Si (111) die.............................................. 49

4.3 Finite element modelling and simulation results...............................................5 54

4.3.1 Indentation hardness and modulus ............................................................... 56

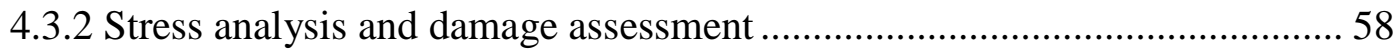

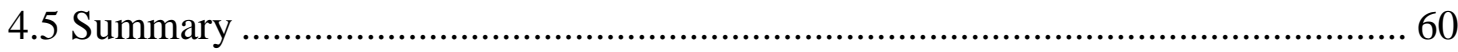


Chapter 5 Indentation Damage Evaluation of Thin-film Stacked Structures 61

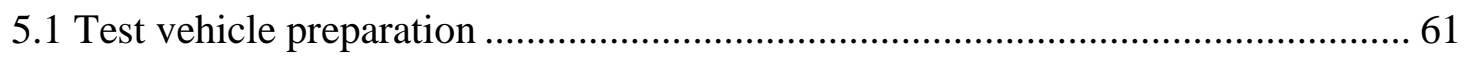

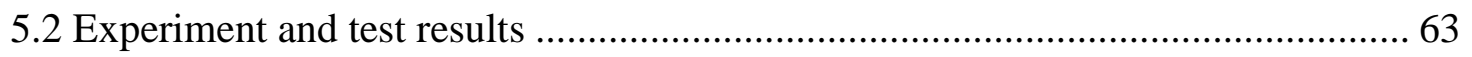

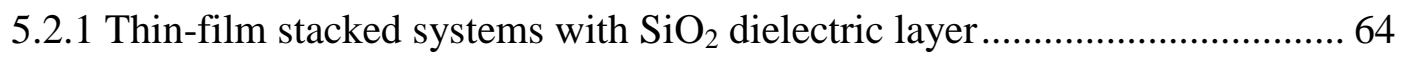

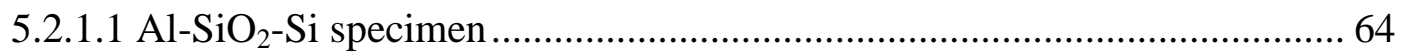

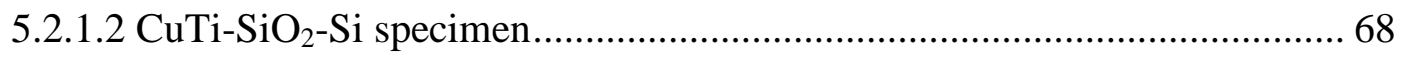

5.2.2 Thin-film stacked systems with $\mathrm{Si}_{3} \mathrm{~N}_{4}$ dielectric layer ........................... 75

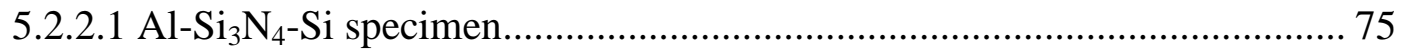

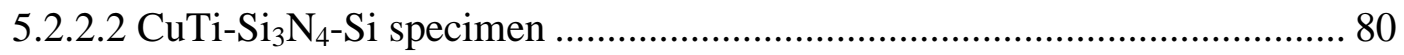

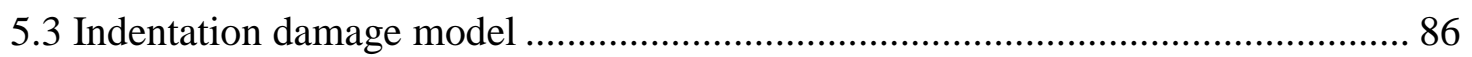

5.4 Finite element modelling and simulation results.......................................... 92

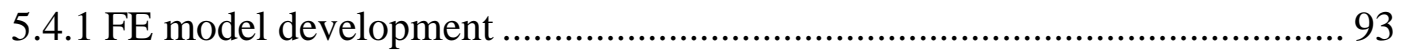

5.4.2 Stress analysis and damage assessment ........................................... 96

5.4.2.1 Metal-coated $\mathrm{SiO}_{2}-\mathrm{Si}$ specimens................................................. 97

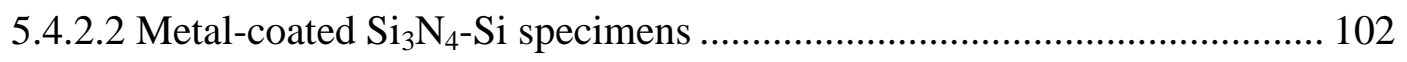

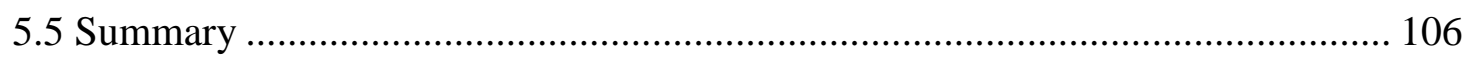

Chapter 6 Analysis of Indentation Work and Acoustic Emission Energy ................ 109

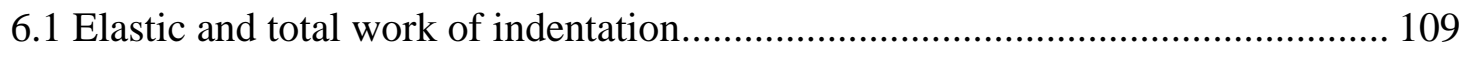

6.2 Work of indentation damage and fracture ............................................... 113

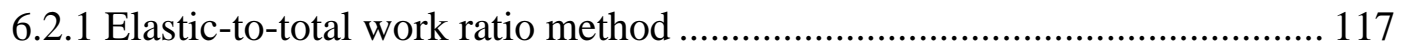

6.2.2 Integration of the unloading $F-d$ curve method ................................. 119 
6.3 Acoustic emission energy measurements.................................................... 121

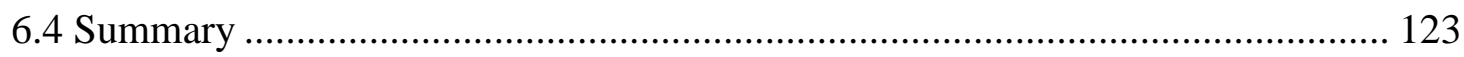

Chapter 7 Conclusions and Recommendations....................................................... 125

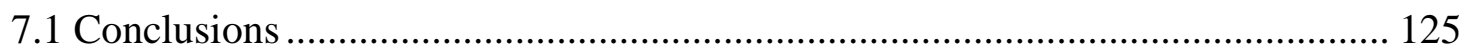

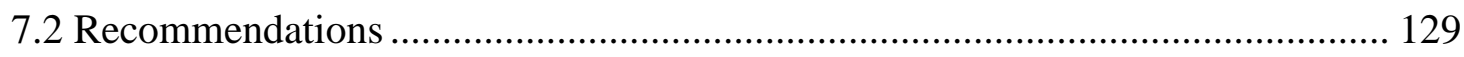

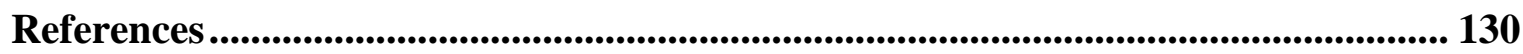

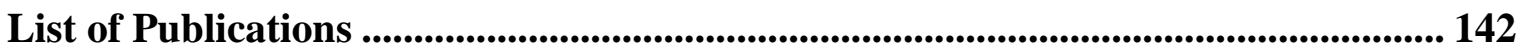




\section{List of Figures}

Fig. 1.1: Examples of the wire bond related failures on the bond pads of the IC chips. Sources: (a) Jeon et al. [12]; (b) courtesy of Infineon Technologies Asia Pacific Pte. Ltd.; (c) courtesy of Globalfoundries. 3

Fig. 2.1: An illustration of the wire bond process with an insert showing the scanning electron microscopy (SEM) imagine of a wire ball bond: (1) melting of the wire to form the $\mathrm{Au}$ or $\mathrm{Cu}$ ball; (2) the wire is retracted so that the ball is positioned against the bottom of the capillary; (3) the $\mathrm{Au}$ or $\mathrm{Cu}$ ball makes contact with the bond pad where heat, force and ultrasonic energy are applied; (4) the tool is raised after the bonded ball is formed; (5) the wire loop is formed and the tool is moved to the package bond pad position; (6) the stitch bond is formed with the applied heat, force and ultrasonic energy [3]................. 8

Fig. 2.2: Optical imaging of the wire bond failure modes after the ball shear test: (a) a lifted ball that shows a interfacial separation at the bonding pad with little or no intermetallic formation present on the pad surface, (b) fractography of a bonded ball shear, with wire material residue and inter-metallic formation on the pad surface, (c) bond pad cratering that shows metal and dielectric layers, and/or Si been chip-out, and (d) lifted metal pad that shows a separation between the top metal and underlying layer, with bonding surface metal remained attached to the ball bond [36] ................................ 9

Fig. 2.3: An illustration of the flexure test method in a three-point bend configuration... 11

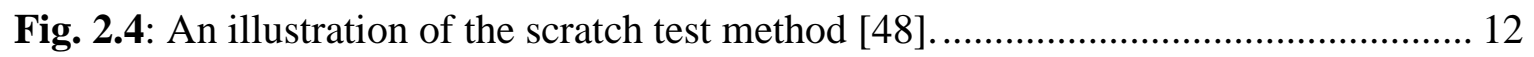

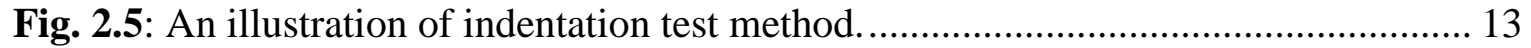

Fig. 2.6: The various indentation hardness test methods with different indenters [77]..... 14 
Fig. 2.7: The $F$ - $d$ curve of an indentation loading-unloading process [61]................... 16

Fig. 2.8: An illustration of the indentation crack formation: (a) cone, (b) lateral, (c) radial, (d) median, and (e) radial-median or half-penny radial crack [78-86]

Fig. 2.9: (a) Nano-indentation fracture of the thin-film coating and the corresponding $F-d$ curve observed with the associated energy release; (b) the model developed by Li et al.

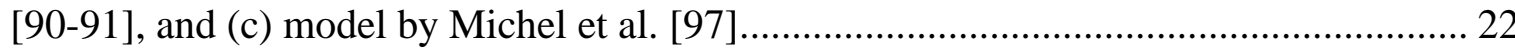

Fig. 2.10: An AE event in a stressed structure and its signal process chain [128] .......... 26

Fig. 2.11: Features of AE transient signal in time domain [129]. ............................... 28

Fig. 3.1: The experimental set-up of the indentation damage test............................... 31

Fig. 3.2: An indentation damage test system consists of an Instron micro-mechanical tester integrated with an $\mathrm{AE}$ sensor. 32

Fig. 3.3: An indentation damage test system consists of an Antor Paar CSM micromechanical tester integrated with an $\mathrm{AE}$ sensor. 33

Fig. 3.4: An illustration of the pulser testing method set-up. ...................................... 35

Fig. 3.5: A comparison of the AE transient signals for both cases with and without the $\mathrm{Si}$ die specimens: (a) voltage vs frequency, and (b) amplitude vs frequency. 35

Fig. 3.6: A comparison of AE transient signals for both cases with and without couplant medium: (a) voltage vs frequency waveform, and (b) amplitude vs frequency waveform.

Fig. 3.7: A comparison of AE transient signals measured at different positions for both cases with and without couplant medium, (a) peak voltage $V_{\mathrm{s}}$, and (b) amplitude $A$....... 37 
Fig. 3.8: A comparison of AE transient signals measured at different positions on top of the AE sensor: (a) voltage vs frequency waveform, and (b) amplitude vs frequency waveform. 38

Fig. 3.9: A comparison of $\mathrm{AE}$ transient signals measured at different positions on the $\mathrm{Si}$ die: (a) voltage vs frequency waveform, and (b) amplitude vs frequency waveform. ...... 38 Fig. 3.10: A comparison of $A E$ transient signals measured at different positions for both cases with and without the Si die: (a) peak voltage $V_{\mathrm{s}}$, and (b) amplitude $A \ldots \ldots \ldots \ldots \ldots \ldots . . . . . . .39$

Fig. 3.11: The result of $\mathrm{AE}$ continuous signal monitored throughout the indentation loading and unloading cycle, at the maximum load of $0.1 \mathrm{~N}$ and dwelling for 1 min...... 39

Fig. 4.1: The measurement procedure of the indentation damage test methodology....... 43

Fig. 4.2: The shape of the sphero-conical indenter: (a) optical imaging, (b) SEM imaging, and (b) surface profiling imaging. 43

Fig. 4.3: The $F$ - $d$ curve of the Si (100) die specimen after the indentation damage test... 44 Fig. 4.4: The results of $F$ and AE parameters for the Si (100) die after the indentation damage test: (a) $A$, (b) $t_{\mathrm{r}}$, (c) $t_{\mathrm{d}}$, and (d) $E_{\mathrm{AE}}$ plotted against $t$ 45

Fig. 4.5: The failure modes of the Si (100) die specimen after the indentation damage test:

(a) surface optical images and (b) cross-sectional SEM images 46

Fig. 4.6: The probability plots for the $\mathrm{Si}(100)$ die specimen: (a) $F_{\mathrm{c}}$, and (b) $d_{\mathrm{c}}$. 47

Fig. 4.7: The $F-d$ curve of the $\mathrm{Si}(100)$ die specimen obtained from the indentation verification test $\left(F_{\mathrm{m}}=1 \mathrm{~N}\right)$. 47

Fig. 4.8: The physical examination of the Si (100) die specimen after the verification test: (a) surface optical images, and (b) cross-sectional SEM images 47 
Fig. 4.9: The results of the AE parameters for the $\mathrm{Si}$ (100) die specimen after the indentation damage test: (a) $A$, (b) $t_{\mathrm{r}}$, (c) $t_{\mathrm{d}}$, and (d) $E_{\mathrm{AE}}$ plotted against $F_{\mathrm{c}}$. 48

Fig. 4.10: The $F-d$ curve of the $\mathrm{Si}(111)$ die specimen after the indentation damage test. 49

Fig. 4.11: The results of $F$ and AE parameters for the $\mathrm{Si}$ (111) die specimen after the indentation damage test: (a) $A$, (b) $t_{\mathrm{r}}$, (c) $t_{\mathrm{d}}$, and (d) $E_{\mathrm{AE}}$ plotted against $t$. 50

Fig. 4.12: The failure modes of the Si (111) die specimen after the indentation damage test: (a) surface optical imaging, and (b) surface, and (c) cross-sectional SEM imaging.. 51

Fig. 4.13: The probability plots of the $\mathrm{Si}(111)$ die specimen: (a) $F_{\mathrm{c}}$, and (b) $d_{\mathrm{c}} \ldots \ldots \ldots \ldots . \ldots 2$ Fig. 4.14: The $F$ - $d$ curve of the $\mathrm{Si}$ (111) die specimen obtained from the indentation verification test $\left(F_{\mathrm{m}}=1.2 \mathrm{~N}\right)$. 52

Fig. 4.15: The physical examination of the $\mathrm{Si}(111)$ die specimen after the verification test: (a) surface optical images, (b) surface and (c) cross-sectional SEM images. 53

Fig. 4.16: The results of AE parameters for the $\mathrm{Si}$ (111) die specimen after the indentation damage test: (a) $A$, (b) $t_{\mathrm{r}}$, (c) $t_{\mathrm{d}}$, and (d) $E_{\mathrm{AE}}$ plotted against $F_{\mathrm{c}}$. 54

Fig. 4.17: The bilinear stress-strain curve for elastic-plastic material modelling. ........... 56

Fig. 4.18: The FE model of the indentation test on the Si die. .................................. 56

Fig. 4.19: The experimental results of (a) $H_{\mathrm{IT}}$, and (b) $E_{\mathrm{IT}}$ for the $\mathrm{Si}(100)$ die. .............. 57

Fig. 4.20: The comparison of the experimental and modelling results for the $1.2-\mu \mathrm{m}$ indentation test on the Si die. 58

Fig. 4.21: The stress contour plots at the loading condition $d_{\mathrm{c}}=1.2 \mu \mathrm{m}$ : (a) the principal stress $\sigma_{1}$, and (b) shear stress $\tau_{13}$ 59

Fig. 5.1: (a) The wafer processing for the thin-films stacked specimens, and the crosssectional SEM images: (b) the Al-coated specimens and (c) the $\mathrm{Cu}$-coated specimens. .. 62 
Fig. 5.2: The $F-d$ curve of the $\mathrm{Al}-\mathrm{SiO}_{2}-\mathrm{Si}$ specimen after the indentation damage test.... 65

Fig. 5.3: The results of $F$ and $\mathrm{AE}$ parameters plotted against $t$ for the $\mathrm{Al}-\mathrm{SiO}_{2}-\mathrm{Si}$ specimen after the indentation damage test: (a) $A$, (b) $t_{\mathrm{r}}$, (c) $t_{\mathrm{d}}$, and (d) $E_{\mathrm{AE}}$.

Fig. 5.4: The failure modes of the $\mathrm{Al}-\mathrm{SiO}_{2}-\mathrm{Si}$ specimen after the indentation damage test: (a) surface optical images, and (b) cross-sectional SEM images 66

Fig. 5.5: The probability plots of the $\mathrm{Al}-\mathrm{SiO}_{2}-\mathrm{Si}$ specimen: (a) $F_{\mathrm{c}}$, and (b) $d_{\mathrm{c}}$ 67

Fig. 5.6: The $F-d$ curve of the $\mathrm{Al}-\mathrm{SiO}_{2}-\mathrm{Si}$ specimen after the verification test.

Fig. 5.7: The physical examination of the $\mathrm{Al}-\mathrm{SiO}_{2}-\mathrm{Si}$ specimen after the verification test: (a) surface optical images, and (b) cross-sectional SEM images. 68

Fig. 5.8: The first $\mathrm{AE}$ event results of the $\mathrm{Al}-\mathrm{SiO}_{2}-\mathrm{Si}$ specimen plotted against $F_{\mathrm{c}}$ during the indentation loading stage: (a) $A$, (b) $t_{\mathrm{r}}$, (c) $t_{\mathrm{d}}$, and (d) $E_{\mathrm{AE}}$. 69

Fig. 5.9: The second $\mathrm{AE}$ event results of the $\mathrm{Al}-\mathrm{SiO}_{2}-\mathrm{Si}$ specimen plotted against $F_{\mathrm{c}}$ during the indentation unloading stage: (a) $A$, (b) $t_{\mathrm{r}}$, (c) $t_{\mathrm{d}}$, and (d) $E_{\mathrm{AE}}$. 70 Fig. 5.11: The results of $F$ and $\mathrm{AE}$ parameters plotted against $t$ for the $\mathrm{CuTi}^{-\mathrm{SiO}_{2}-\mathrm{Si}}$ specimen after the indentation damage test: (a) $A$, (b) $t_{\mathrm{r}}$, (c) $t_{\mathrm{d}}$, and (d) $E_{\mathrm{AE}}$. 71

Fig. 5.12: The failure modes of the $\mathrm{CuTi}-\mathrm{SiO}_{2}-\mathrm{Si}$ specimen after the indentation damage test: (a) surface optical images, and (b) cross-sectional SEM images. 72

Fig. 5.13: The probability plots of the $\mathrm{CuTi}-\mathrm{SiO}_{2}-\mathrm{Si}$ specimen: (a) $F_{\mathrm{c}}$, and (b) $d_{\mathrm{c}}$. 73

Fig. 5.14: The $F$ - $d$ curve of the $\mathrm{CuTi}-\mathrm{SiO}_{2}-\mathrm{Si}$ specimen after the verification test... 73

Fig. 5.15: The physical examination of the $\mathrm{CuTi}-\mathrm{SiO}_{2}-\mathrm{Si}$ specimen after the verification test: (a) surface optical images, and (b) cross-sectional SEM images. 73

Fig. 5.16: The first $\mathrm{AE}$ event results of the $\mathrm{CuTi}-\mathrm{SiO}_{2}-\mathrm{Si}$ specimen plotted against $F_{\mathrm{c}}$ during the indentation loading stage: (a) $A$, (b) $t_{\mathrm{r}}$, (c) $t_{\mathrm{d}}$, and (d) $E_{\mathrm{AE}}$. 74 
Fig. 5.17: The second $\mathrm{AE}$ event results of the $\mathrm{CuTi}-\mathrm{SiO}_{2}-\mathrm{Si}$ specimen plotted against $F_{\mathrm{c}}$ during the indentation unloading stage: (a) $A$, (b) $t_{\mathrm{r}}$, (c) $t_{\mathrm{d}}$, and (d) $E_{\mathrm{AE}}$. 75

Fig. 5.18: The $F-d$ curve of the $\mathrm{Al}-\mathrm{Si}_{3} \mathrm{~N}_{4}-\mathrm{Si}$ specimen after the indentation damage test. 76

Fig. 5.19: The results of $F$ and $\mathrm{AE}$ parameters plotted against $t$ for the $\mathrm{Al}_{-} \mathrm{Si}_{3} \mathrm{~N}_{4}-\mathrm{Si}$ specimen after the indentation damage test: (a) $A$, (b) $t_{\mathrm{r}}$, (c) $t_{\mathrm{d}}$, and (d) $E_{\mathrm{AE}}$. 77

Fig. 5.20: The failure modes of the $\mathrm{Al}-\mathrm{Si}_{3} \mathrm{~N}_{4}-\mathrm{Si}$ specimen after the indentation damage test: (a) surface optical images, and (b) cross-sectional SEM images. 78

Fig. 5.21: The probability plots of the Al- $\mathrm{Si}_{3} \mathrm{~N}_{4}-\mathrm{Si}$ specimen: (a) $F_{\mathrm{c}}$, and (b) $d_{\mathrm{c}} \ldots \ldots \ldots \ldots .78$

Fig. 5.22: The $F-d$ curve of the $\mathrm{Al}-\mathrm{Si}_{3} \mathrm{~N}_{4}-\mathrm{Si}$ specimen after the verification test............ 79

Fig. 5.23: The physical examination of the $\mathrm{Al}-\mathrm{Si}_{3} \mathrm{~N}_{4}-\mathrm{Si}$ specimen after the verification test: (a) surface optical images, and (b) cross-sectional SEM images. 79

Fig. 5.24: The first $\mathrm{AE}$ event results of the $\mathrm{Al}-\mathrm{Si}_{3} \mathrm{~N}_{4}-\mathrm{Si}$ specimen plotted against $F_{\mathrm{c}}$ during the indentation loading stage: (a) $A$, (b) $t_{\mathrm{r}}$, (c) $t_{\mathrm{d}}$, and (d) $E_{\mathrm{AE}}$. 80

Fig. 5.25: The second $\mathrm{AE}$ event results of the $\mathrm{Al}-\mathrm{Si}_{3} \mathrm{~N}_{4}-\mathrm{Si}$ specimen plotted against $F_{\mathrm{c}}$ during the indentation unloading stage: (a) $A$, (b) $t_{\mathrm{r}}$, (c) $t_{\mathrm{d}}$, and (d) $E_{\mathrm{AE}}$ 81

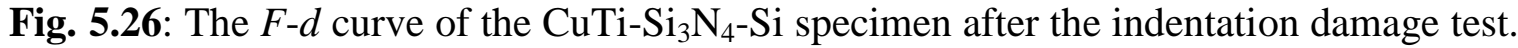

Fig. 5.27: The results of $F$ and $\mathrm{AE}$ parameters plotted against $t$ for the $\mathrm{CuTi}-\mathrm{Si}_{3} \mathrm{~N}_{4}-\mathrm{Si}$ specimen after the indentation damage test: (a) $A$, (b) $t_{\mathrm{r}}$, (c) $t_{\mathrm{d}}$, and (d) $E_{\mathrm{AE}}$. 82

Fig. 5.28: The failure modes of the $\mathrm{CuTi}-\mathrm{Si}_{3} \mathrm{~N}_{4}-\mathrm{Si}$ specimen after the indentation damage test: (a) surface optical images, and (b) cross-sectional SEM images. 83

Fig. 5.29: The probability plots of $\mathrm{CuTi}-\mathrm{Si}_{3} \mathrm{~N}_{4}-\mathrm{Si}$ specimen: (a) $F_{\mathrm{c}}$, and (b) $d_{\mathrm{c}} \ldots \ldots \ldots \ldots \ldots . \ldots 3$

Fig. 5.30: The $F-d$ curve of the $\mathrm{CuTi}-\mathrm{Si}_{3} \mathrm{~N}_{4}-\mathrm{Si}$ specimen after the verification test. ....... 84 
Fig. 5.31: The physical examination of the $\mathrm{CuTi}-\mathrm{Si}_{3} \mathrm{~N}_{4}-\mathrm{Si}$ specimen after the verification test: (a) surface optical images, and (b) cross-sectional SEM images. 84

Fig. 5.32: The first $\mathrm{AE}$ event results of the $\mathrm{CuTi}-\mathrm{Si}_{3} \mathrm{~N}_{4}-\mathrm{Si}$ specimen plotted against $F_{\mathrm{c}}$ during the indentation loading stage: (a) $A$, (b $t_{\mathrm{r}}$, (c) $t_{\mathrm{d}}$, and (d) $E_{\mathrm{AE}}$. 85

Fig. 5.33: The second $\mathrm{AE}$ event results of the $\mathrm{CuTi}-\mathrm{Si}_{3} \mathrm{~N}_{4}-\mathrm{Si}$ specimen plotted against $F_{\mathrm{c}}$ during the indentation unloading stage: (a) $A$, (b) $t_{\mathrm{r}}$, (c) $t_{\mathrm{d}}$, and (d) $E_{\mathrm{AE}}$. 86 Fig. 5.34: The indentation damage test results for the different thin-film stacked specimens: (a) $F_{\mathrm{c}}$, and (b) $d_{\mathrm{c}}$.... 87

Fig. 5.35: The failure modes of the $\mathrm{SiO}_{2}-\mathrm{Si}$ specimen after the indentation damage test: (a) surface and (b) cross-sectional SEM images. 88

Fig. 5.36: The failure modes of the $\mathrm{Si}_{3} \mathrm{~N}_{4}$ specimen after the indentation damage test: (a) surface and (b) cross-sectional SEM images. 89

Fig. 5.37: The indentation damage model for: (a) the metal-coated $\mathrm{SiO}_{2}$ dielectric, and (b) the metal-coated $\mathrm{Si}_{3} \mathrm{~N}_{4}$ dielectric on the $\mathrm{Si}$ substrate. 91

Fig. 5.38: The FE model of the thin-film stacked structure. 93 Fig. 5.39: The fitting criterion features in the $F$ - $d$ curve during the indentation testing... 94 Fig. 5.40: The comparison of the experiment and modelling results for a single dielectric layer on the $\mathrm{Si}$ substrate after the $1-\mu \mathrm{m}$ indentation test: (a) $\mathrm{SiO}_{2}-\mathrm{Si}$ and (b) $\mathrm{Si}_{3} \mathrm{~N}_{4}-\mathrm{Si}$ specimens. 95

Fig. 5.41: The comparison of the experimental and modelling results for a $\mathrm{Ti}$ adhesion layer and an intermediate dielectric layer on the Si substrate after the 1- $\mu \mathrm{m}$ indentation test: (a) $\mathrm{Ti}_{-} \mathrm{SiO}_{2}-\mathrm{Si}$ and (b) $\mathrm{Ti}-\mathrm{Si}_{3} \mathrm{~N}_{4}-\mathrm{Si}$ specimens 95 
Fig. 5.42: The comparison of the experiment and modelling results for a top $\mathrm{Al}$ layer and an intermediate dielectric layer on the Si substrate after the 1- $\mu$ m indentation test: (a) Al$\mathrm{SiO}_{2}-\mathrm{Si}$ and (b) $\mathrm{Al}-\mathrm{Si}_{3} \mathrm{~N}_{4}-\mathrm{Si}$ specimens. 96

Fig. 5.43: The comparison of the experiment and modelling results for a top $\mathrm{Cu}$ layer and an intermediate dielectric layer on the Si substrate after the 1- $\mu \mathrm{m}$ indentation test: (a)

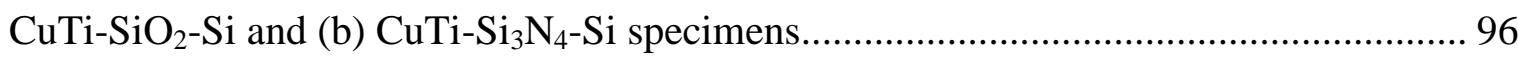
Fig. 5.44: A comparison of the experimental and modelling results after the indentation damage tests: (a) $\mathrm{Al}-\mathrm{SiO}_{2}-\mathrm{Si}$ and (b) $\mathrm{CuTi}-\mathrm{SiO}_{2}-\mathrm{Si}$ specimens. 98

Fig 5.45: (a) The cross-sectional $\mathrm{SEM}$ image of the $\mathrm{CuTi}-\mathrm{SiO}_{2}-\mathrm{Si}$ specimen after the indentation damage test. Stress contours obtained from FE modelling of the same specimen under the $d_{\mathrm{c}}$ loading: (b) principle stress $\sigma_{1}$ and (c) shear stress $\tau_{13}(\mathrm{MPa}) \ldots . . .99$ Fig. 5.46: (a) The cross-sectional $\mathrm{SEM}$ image of the $\mathrm{Al}-\mathrm{SiO}_{2}-\mathrm{Si}$ specimen after the indentation damage test. The stress contours from the modelling of the same specimen during the unloading stage at an indentation depth of $\sim 1.1 \mu \mathrm{m}$ : (b) shear stress $\sigma_{x y}$ and (c) normal stress $\sigma_{y}(\mathrm{MPa})$ 100

Fig. 5.47: The results of the displacement $d$ and $A$ plotted against $t$ after the indentation damage test for (a) $\mathrm{Al}-\mathrm{SiO}_{2}-\mathrm{Si}$, and (b) $\mathrm{CuTi}-\mathrm{SiO}_{2}-\mathrm{Si}$ specimens. 101

Fig. 5.48: The modelling results of $\sigma_{x y}$ and $\sigma_{y}$ components (extracted at Position C in Fig. 5.42) during the indentation loading-unloading cycle for both $\mathrm{Al}-\mathrm{SiO}_{2}-\mathrm{Si}$, and $\mathrm{CuTi}-\mathrm{SiO}_{2}-$ Si specimens. 102

Fig. 5.49: The comparison of the experimental and modelling results after the indentation damage tests: (a) $\mathrm{Al}-\mathrm{Si}_{3} \mathrm{~N}_{4}-\mathrm{Si}$ and (b) $\mathrm{CuTi}-\mathrm{Si}_{3} \mathrm{~N}_{4}-\mathrm{Si}$ specimens. 103 
Fig. 5.50: (a) The cross-sectional SEM image of the metal-coated $\mathrm{Si}_{3} \mathrm{~N}_{4}-\mathrm{Si}$ specimen after the indentation damage test, and (b) the contour plot of the shear stress $\tau_{13}(\mathrm{MPa})$ after the simulation of the same specimen under the $d_{\mathrm{c}}$ loading. 104

Fig. 5.51: (a) The cross-sectional SEM images of the metal-coated $\mathrm{Si}_{3} \mathrm{~N}_{4}-\mathrm{Si}$ specimens after the indentation damage test, and (b) the contour plots of the shear stress $\sigma_{x y}(\mathrm{MPa})$ after the simulation of the same specimen under an indentation loading of $d_{\mathrm{c}}$. 105

Fig. 5.52: The shear stress component $\sigma_{x y}$ of the intermediate $\mathrm{Si}_{3} \mathrm{~N}_{4}$ layer from right beneath the indentation centre to a length of the indenter radius for both $\mathrm{Al}-$ and $\mathrm{Cu}-$ $\mathrm{Si}_{3} \mathrm{~N}_{4}$-Si specimens at the $d_{\mathrm{c}}$ loading condition. 106

Fig. 6.1: The plots of $W_{\mathrm{el}} / W_{\mathrm{T}}$ against $F_{\mathrm{m}} / F_{\mathrm{c}}$ and $d_{\mathrm{m}} / d_{\mathrm{c}}$ for the Si die specimen. 110

Fig. 6.2: The plots of $W_{\mathrm{el}} / W_{\mathrm{T}}$ against $F_{\mathrm{m}} / F_{\mathrm{c}}$ and $d_{\mathrm{m}} / d_{\mathrm{c}}$ : (a) $\mathrm{Al}-\mathrm{SiO}_{2}-\mathrm{Si}$, (b) $\mathrm{CuTi}-\mathrm{SiO}_{2}-\mathrm{Si}$, (c) $\mathrm{Al}-\mathrm{Si}_{3} \mathrm{~N}_{4}-\mathrm{Si}$, and (d) CuTi-Si ${ }_{3} \mathrm{~N}_{4}-\mathrm{Si}$ specimens. 112

Fig. 6.3: The SEM images showing the deformed top metal layers after the indentation damage testing: (a) $\mathrm{Al}-\mathrm{SiO}_{2}-\mathrm{Si}$, and (b) $\mathrm{CuTi}-\mathrm{SiO}_{2}-\mathrm{Si}$ specimems. 112

Fig. 6.4: The associated work in the $F$ - $d$ curve after the indentation damage testing.... 113

Fig 6.5: The illustration of the $l$ measurement in the $F-d$ curve. 114

Fig. 6.6: The results of the $\mathrm{Si}$ die and thin-film stacked specimens after the indentation damage testing: (a) $F_{\mathrm{c}}$, (b) $l$ and (c) $W_{\mathrm{d}}$. 115 Fig. 6.7: The plots of $F$ and $d$ against $t$ for the $\mathrm{Al}_{-}-\mathrm{SiO}_{2}-\mathrm{Si}$ specimen during the indentation damage testing. 116

Fig. 6.8: The calculation of $W_{\mathrm{f}}$ by the elastic-to-total work ratio method. 118

Fig. 6.9: The results of $W_{\mathrm{f}}$ determined from the elastic-to-total work ratio method for the Si die and thin-film stacked specimens. 118 
Fig. 6.10: The calculation of $W_{\mathrm{f}}$ by integration of the unloading $F-d$ curve method. ..... 120 Fig. 6.11: The results of $W_{\mathrm{f}}$ determined from the integration of the unloading $F-d$ curve method for the Si die and thin-film stacked specimens........................................ 120 Fig. 6.12: A comparison of $W_{\mathrm{d}}$ and $W_{\mathrm{f}}$ for the Si die and thin-film stacked specimens.. 121 Fig. 6.13: The plots of $E_{\mathrm{AE}}$ against $W_{\mathrm{f}}$ calculated by (a) the elastic-to-total work method, and (b) the integration of $F-d$ curve method 


\section{List of Tables}

Table 5.1: The geometry specifications of the thin-film stacked specimens. 63

Table 5.2: Material properties of the thin-film stacked specimens obtained from the combined modelling and experiment methods.

Table 5.3: A summary of the indentation damage test results. 107

Table 6.1: A summary of $W_{\mathrm{f}}$ and $E_{\mathrm{AE}}$ results. 


\section{Abstract}

The trend towards cost reduction, improved reliability, and increased functionality and performance in the power electronic product leads to a continuous implementation of new designs, materials, processes, and evaluation methodologies for chip- and packagelevel interconnections. Due to such trend, the shrinking of integrated circuit (IC) features has raised a serious concern about the robustness of the thin-film stacked structure in the bond pad of an IC chip, especially on the wafer probe testing and wire bonding process in the chip-to-package interconnection. Furthermore, copper $(\mathrm{Cu})$ wires have started to replace gold $\mathrm{Au}$ ) wires in the wire interconnection due to their superb cost advantageous, and excellent thermal and electrical performances. However, this hard $\mathrm{Cu}$ material makes the wire bonding on the bond pad of an IC chip much more challenging, where excessive deformation and damage of sensitive structures underneath the bond pad could happen. Moreover, cracking normally occurs at a brittle hard dielectric layer underneath the top metallization pad, which is not visible and difficult to detect, and thus it is important to understand and predict the mechanical response of the thin-film stacked structure of the bond pad under the wire bonding process. Hence, this research aims to study the mechanical behaviors and damage mechanisms of the thin-film stacked structures under indentation loading through both experimental study and numerical simulation.

Firstly, an indentation damage test method is established using a micro-mechanical tester integrated with an acoustic emission (AE) sensor for crack detection in the specimen during the indentation loading-unloading cycle. The bulk $\mathrm{Si}$ die is first employed to investigate the integration of the indentation testing with the AE sensing, 
where the AE signal response is examined upon the occurrence of the onset cracking at the critical force $F_{\mathrm{c}}$ or displacement $d_{\mathrm{c}}$. The effects of the coupling medium between the specimen and $\mathrm{AE}$ sensor, and the specimen indentation position on the $\mathrm{AE}$ signal response are systematically studied.

Secondly, the indentation damage test is employed to evaluate the bulk Si die and different thin-film stacked systems consisting of a top metal layer (aluminium $\mathrm{Al}$ or copper-titanium $\mathrm{CuTi}$ ) and intermediate dielectric (silicon dioxide $\mathrm{SiO}_{2}$ or silicon nitride $\mathrm{Si}_{3} \mathrm{~N}_{4}$ ) layers on the $\mathrm{Si}$ substrate. During the indentation, the first $\mathrm{AE}$ event corresponds to the "pop-in" or plateau is observed in the $F-d$ curve, which is mainly due to the brittle cracking in the dielectric layer or/and Si substrate. Different failure modes are observed for different dielectric layers used in the thin-film stacked system, independent of the top metal layer materials. Besides the first $\mathrm{AE}$ event, a second or more $\mathrm{AE}$ events are also detected during the unloading stage due to the elastic recovery of the specimen, which lead to further crack propagation and delamination within the thin-film layers. A finite element model is established to simulate the loading-unloading process of the indentation on the bulk Si and the thin-film stacked system. The stress analysis is performed and correlated to the cracking of the specimens subjected to the indentation test, in which the damage mechanisms are uncovered.

Thirdly, the work of indentation damage and fracture on the specimen are investigated. An indentation energy-based approach is proposed to determine the work of indentation fracture $W_{\mathrm{f}}$ based on the difference in elastic strain recovery between a damaged and a non-damaged specimen from the same maximum force, where the unloading begins. Two different techniques are developed to estimate $W_{\mathrm{f}}$, namely the elastic-to-total work ratio 
and the integration of the unloading $F-d$ curve. The relationship of the calculated $W_{\mathrm{f}}$ and the measured $E_{\mathrm{AE}}$ is analyzed and discussed.

In summary, this $\mathrm{PhD}$ study contributes to the understanding of the deformation, damage and cracking behavior of the thin-film stacked system subjected to the indentation loading-unloading cycle. This is essential in the processes of the wafer probing and wire bonding on the bond pad of an IC device, where the damage-sensitive pad can be identified and handled with care. Furthermore, the methodology can be used to optimize the structural robustness of the bond pad design, or implement as a mechanical screening tool for wafer quality check, which provides guidance in achieving optimal design for manufacturing reliable and durable microelectronic devices. 


\section{Chapter 1 Introduction}

A power semiconductor device or integrated circuit (IC) is commonly used as a switch or rectifier in power electronics, where its structural configuration and materials are often altered to accommodate for the increase in current density, power dissipation, and/or reverse breakdown voltage. However, the steady advancement in the power electronics technology can never be achieved without overcoming the various quality and reliability issues in the IC chips and packages. In many cases, such challenges exist not only in the IC chip or package, but also in the interaction between them, especially in the chip-topackage interconnection and packaging, where the IC chip is connected to the external circuits.

In this chapter, IC chip packaging processes and their related failures are first introduced. Then, the motivation and objectives of the study on the mechanical characterization and analysis of the thin-film stacked structures are illustrated, which is related to the wire bonding on the bond pad during IC packaging. Finally, the organization of the thesis is presented.

\subsection{Background}

An IC is a microelectronic chip in which miniaturized active (e.g., transistors and diodes) and passive (e.g., capacitors and resistors) devices along with their interconnections are built up on a thin substrate of semiconductor material (e.g., silicon $\mathrm{Si}$ ). The IC undergoes various processes or steps, such as the front-end wafer fabrication 
followed by the back-end chip assembly before it can be used in the electronic system as an amplifier, oscillator, timer, microprocessor, or even computing memory.

In the back-end assembly, an IC chip is mechanically and electrically connected to the chip-carrier to form an IC package, where the signal and power distributions are communicated to and from in the electronic system. The wire bonding process is widely used as a first level or chip-to-package interconnection method in the power packaging. Due to its extensive infrastructure, it is impossible to replace the wire bonding by any other first-level interconnection method, such as the flip chip bonding in the foreseeable future [1-3]. Furthermore, the availability of the vast reliability data and extensive knowledge on the wire bonding process technology has deterred the industrial players from replacing it completely in their products [3-12].

In the recent years, there is a rapid increase of interest in understanding the interaction process between the IC chips and the back-end assembly. Furthermore, the reduction of the system size and the introduction of new material systems to enhance the IC performance have raised a serious concern about the mechanical robustness of the bond pad in an IC chip, especially in the processes of the wafer probing and wire bonding on those bond pads [13-23].

Recently, copper $(\mathrm{Cu})$ wires have been used as a substitute material to gold $(\mathrm{Au})$ wires in the wire bonding process due to their superb cost advantageous and excellent thermal and electrical performances [24-28]. However, the process of $\mathrm{Cu}$ wire bonding on the bond pad of an IC chip is much more challenging due to its high hardness as compared to that of $\mathrm{Au}$. It has shown that $\mathrm{Cu}$ wire bonding can lead to excessive pad deformation, 
cracking of oxide and dielectric layers, and degradation of the sensitive structures under the bond pads (Fig. 1.1) [29-34].

(a)

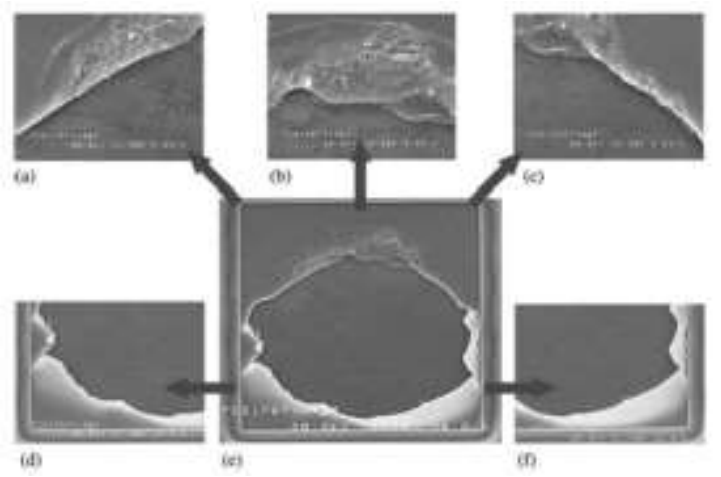

(c)
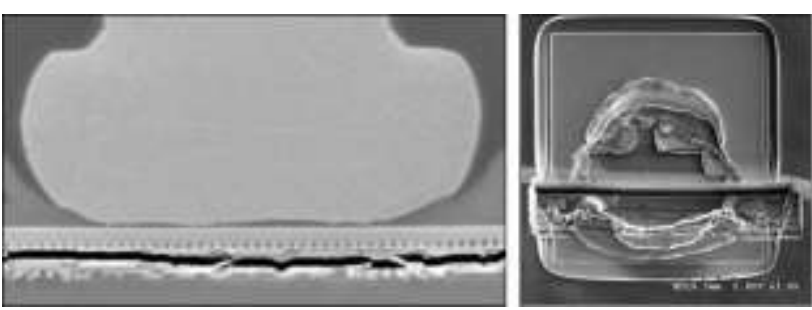

(b)
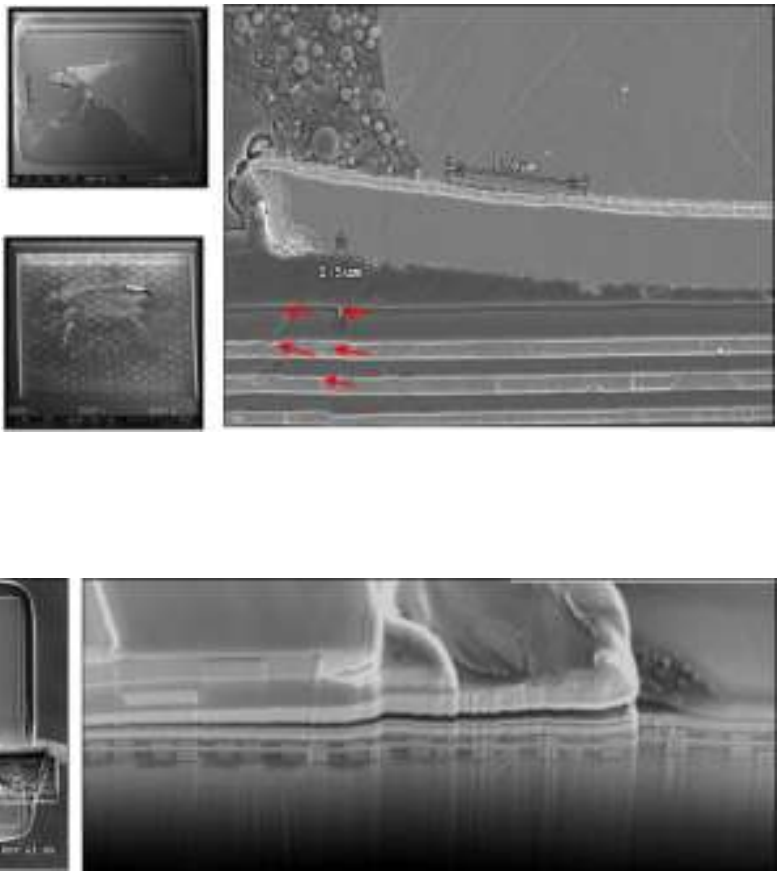

Fig. 1.1: Examples of the wire bond related failures on the bond pads of the IC chips. Sources: (a) Jeon et al. [12]; (b) courtesy of Infineon Technologies Asia Pacific Pte. Ltd.; (c) courtesy of Globalfoundries.

The current approach to access the mechanical robustness of the thin-film stacked structure in the bond pad is mainly empirical via tedious and large wire bonding evaluation matrix, with extensive wire bond pull and shear tests, followed by numerous failure analyses [35-37]. It is a time-consuming process and can affect both the development cost and time to market. In order to facilitate a smooth development and implementation of new-generation IC chip technology, an alternate approach is needed to assess the mechanical integrity of the bond pad during the design phase. Various mechanical characterization methods such as bending, tensile and indentation testing can be employed to study the cracking behavior during the development phase. However, 
cracking normally occurs at the brittle dielectric layer underneath the top ductile metal layer during the wire bonding on the bond pad of an IC chip, which is not visible and difficult to detect. Furthermore, as the material systems and geometry in the bond pad are rather complex, it is challenging to predict the failure and understand the damage behavior of those thin-film stacked structures in the bond pad. Therefore, a systematic assessment methodology and delicate experimental set-up is required to characterize and understand the mechanical response and damage behavior of the thin-film stacked structure, which is able to predict its mechanical performance during the wire bonding on the bond pad of an IC chip.

\subsection{Motivation and objectives}

This research aims to establish an indentation damage test system with a systematic assessment methodology to investigate the mechanical behavior and damage mechanisms of the thin-film stacked structure during the indentation test. Specifically, the main objectives are set as follow:

- Establish an indentation damage test methodology using a micro-mechanical tester integrated with an acoustic emission (AE) sensor for crack detection of the underlying layer in the thin-film stacked structure during the indentation testing;

- Examine the force-displacement $(F-d)$ and $\mathrm{AE}$ signal responses during the indentation process of the bulk Si die, and various thin-film stacked structures with respect to the deformation and damage behavior;

- Develop an indentation damage model to characterize the cracking behavior in the thin-film stacked specimen during the indentation loading-unloading cycle; 
- Establish a numerical model to simulate the indentation damage test, and understand the damage mechanism corresponding to the cracking observed on the bulk Si and the thin-film stacked specimens;

- Develop an energy-based method to determine the work of indentation fracture related to the specimen cracking, and the corresponding measured AE energy $\left(E_{\mathrm{AE}}\right)$ during the indentation test.

\subsection{Outline}

This $\mathrm{PhD}$ dissertation is organized into seven chapters. Following this introduction chapter, a comprehensive literature review on the interaction mechanism between the bond pad of an IC chip and the wire bonding process, the mechanical characterization methods and the indentation damage models are given in Chapter 2. The development of an indentation damage test system and experimental set-up are presented in Chapter 3. The experimental and modelling study of the indentation damage test on the Si dies are provided in Chapter 4. Chapter 5 deals with the investigation of indentation damage test and modelling on the thin-film stacked structure, where indentation damage models are discussed. An energy-based approach to determine the work of indentation fracture is proposed and discussed with the measured $E_{\mathrm{AE}}$ in Chapter 6. In Chapter 7, conclusions are drawn and future works are recommended. 


\section{Chapter 2 Literature Review}

In this Chapter, an overview of the interaction mechanism between the wire bonding process and the bond pad of an IC chip is presented. The different experimental techniques used to characterize the mechanical and damage behaviour of the thin-film stacked structure of the bond pad are briefly reviewed. Afterwards, the mechanics of the indentation is presented, where both the stress- and energy-based indentation damage models are discussed. Finally, the principle of AE testing used for the crack detection of the thin-film stacked structure is presented.

\subsection{Interaction mechanism between the integrated circuit chip and}

\section{backend assembly}

Due to the different product demands and performance requirements, there is a great variety of the thin-film stacked schemes in the bond pad, which comprises of one or several metallic and dielectric layers, and may include interlayers. These interlayers often serve as an adhesion layer, diffusion barrier or mechanical strengthener.

A metallic film such as aluminium ( $\mathrm{Al}$ ) or $\mathrm{Cu}$ is usually used as the bond pad surface material owing to their low electrical resistance property. The major purpose of the metal bond pad is to provide an area that can be contacted through an interconnection technique, i.e., wire bonding and flip chip soldering, thus providing a low-ohmic electrical connection between the chip and the chip-carrier or another chip. Besides that, the metal bond pad is also used to dissipate heat away from the chip surface in the power semiconductors. The metallic films can be deposited by physical vapor deposition (PVD), 
chemical vapor deposition (CVD), electrochemical deposition (ECD) or electroless deposition techniques.

The non-metallic film such as dielectric layer is usually used as an electric insulator, chemical and moisture diffusion barrier, stress compensation, or adhesion layer. These non-metallic films are usually deposited by CVD, evaporation or sputtering techniques.

Wire bonding is basically an interconnection process between the bond pad of an IC chip and the lead terminal of a leadframe using a metal wire with a combination of heat, force and/or ultrasonic energy (Fig. 2.1). It is a solid-phase welding process whereby two metallic materials, i.e., wire and bond pad surfaces, are brought into close contact so that electron sharing or inter-diffusion of atoms can take place to form a metallurgy joint. During this process, the bonding force will cause the material to deform and subsequently break up the surface contamination layer and smooth out any surface asperity. The application of the ultrasonic energy and heat enhances the contacting area and accelerates the inter-atomic diffusion for the bond formation [3].

The quality of the wire bonding process is usually first assessed by the non-destructive methods such as visual inspection and dimensional measurement of the wire interconnections. Next, the destructive methods such as the bonded ball shear and wire pull tests are carried out to assess the mechanical integrity of the wire interconnection to ensure that the minimum force or strength be met with a preferred failure mode [35-37]. The delayering of the bond pad metallization using chemical etchant, and the crosssectioning of the wire interconnection are also performed to check for any micro-cracks. 


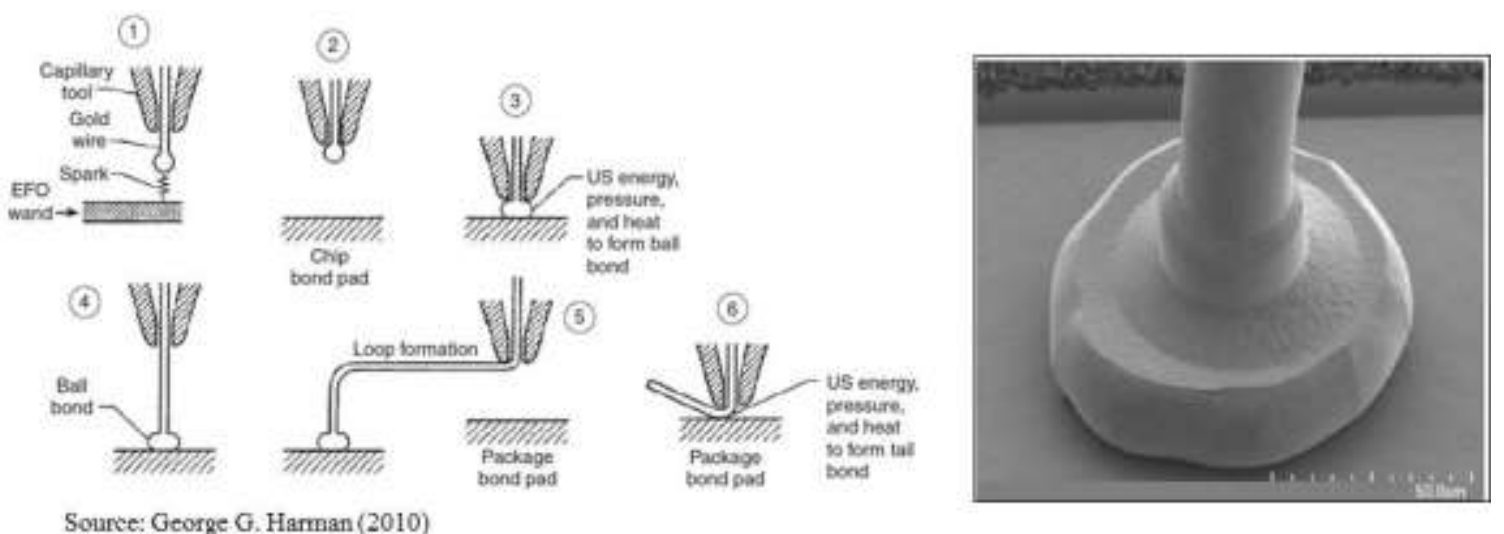

Fig. 2.1: An illustration of the wire bond process with an insert showing the scanning electron microscopy (SEM) imagine of a wire ball bond: (1) melting of the wire to form the $\mathrm{Au}$ or $\mathrm{Cu}$ ball; (2) the wire is retracted so that the ball is positioned against the bottom of the capillary; (3) the $\mathrm{Au}$ or $\mathrm{Cu}$ ball makes contact with the bond pad where heat, force and ultrasonic energy are applied; (4) the tool is raised after the bonded ball is formed; (5) the wire loop is formed and the tool is moved to the package bond pad position; (6) the stitch bond is formed with the applied heat, force and ultrasonic energy [3].

The wire pull test is inadequate as it provides very limited information on the strength and overall quality of the interface between the bonded wire and bond pad surface [37]. When the minimum ball shear force or strength criterion is achieved, a desirable interfacial bonding will usually result in a ball lift or shear and the failure mode is dependent on the materials involved in the test system (Fig. 2.2). In the event of undesirable interfacial bonding, the bond pad cratering or metallization lift will be observed. Therefore, the optimizations of the wire bonding process and the mechanical integrity of the thin-film stacked structure of the bond pad have to be re-examined.

Studies have revealed that the out-of-plane stress induced in the bond pad is mainly contributed by the bonding force, while the in-plane stress is related to the ultrasonic energy [32-34]. The former stress component usually measures a much larger magnitude than the latter one, and thus the high bonding force may be the driving damage 
mechanism to trigger the crack in the thin-film stacked structure of the bond pad. The damage can be further aggravated by the applied ultrasonic energy. However, some studies have reported that the ultrasonic energy is the main driving mechanism for the bond pad damage, and responsible for the bond pad peeling [32-33]. This can be depending on the design of the bond pad, which is either sensitive to the out-of-plane (brittle cracking of the dielectric layer) or in-plane (layer peeling or delamination) stress.

(a)

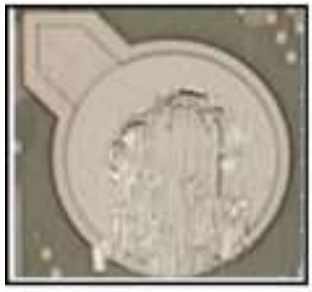

(c)

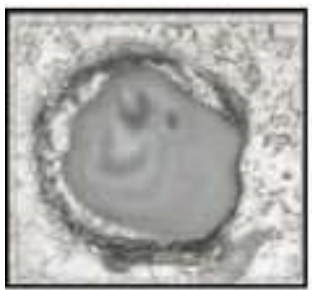

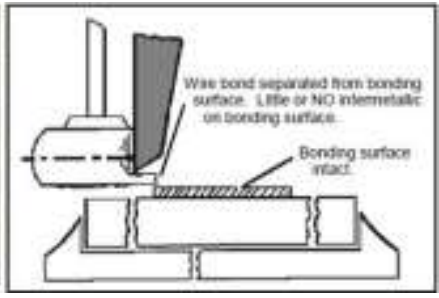

(b)

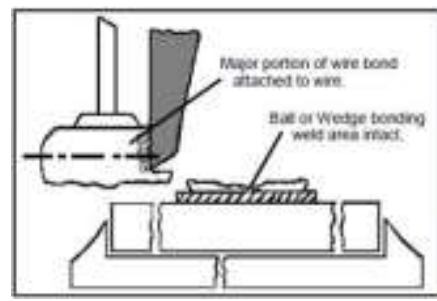

(d)

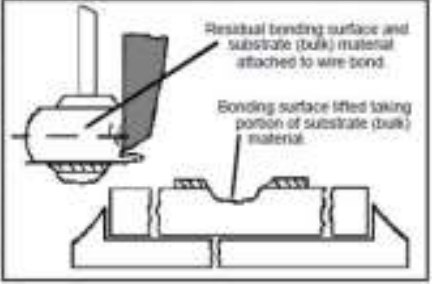

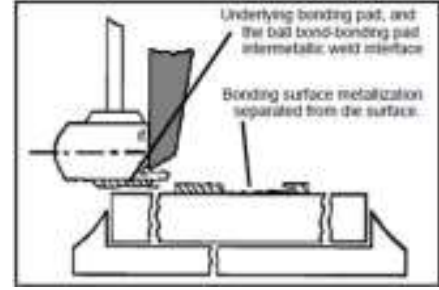

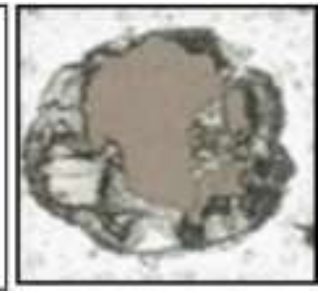

Fig. 2.2: Optical imaging of the wire bond failure modes after the ball shear test: (a) a lifted ball that shows a interfacial separation at the bonding pad with little or no intermetallic formation present on the pad surface, (b) fractography of a bonded ball shear, with wire material residue and inter-metallic formation on the pad surface, (c) bond pad cratering that shows metal and dielectric layers, and/or Si been chip-out, and (d) lifted metal pad that shows a separation between the top metal and underlying layer, with bonding surface metal remained attached to the ball bond [36].

\subsection{Mechanical characterization methods}

Thin-film materials are the key elements of continued technological advances made in the fields of microelectronic, optoelectronic, photonic and magnetic devices. The 
processing of the materials into thin films allows easy integration into the various types of devices for specific applications. With the rapid change in material systems and reduced feature size in the microelectronic device, the thin-film microstructure and its mechanical properties have become the critical parameters for the manufacturing quality and the product reliability. Hence, the knowledge of the thin-film constitutive mechanical behavior is required and is often different from those of the bulk materials, due to its nano- or micro-structure and also the influences of the substrate.

\subsubsection{Flexure test}

The flexure test is also known as the transverse beam or bend test, where the specimen is positioned horizontally over two contact points (lower support span) and then a force is applied to the top of the specimen through either one or two contact points (upper loading span) until the specimen fails (Fig. 2.3). The specimen subjected to the flexural loading will experience three fundamental stresses, namely the tensile, compressive and shear stresses. Therefore, the flexural properties of a specimen are strongly influence by the combined effect of all the three stresses, and also the geometry of the specimen and the applied loading rate.

A flexure test produces tensile and compressive stresses in the convex and concave sides of the specimen respectively, inducing the shear stresses along the midline. The shear stress must be minimized in order to ensure that the primary failure come from tensile or compressive stresses. Many researchers and engineers have employed this test method to evaluate the fracture risk of a Si die as a function of its thickness, surface and side-wall quality that may be affected by the wafer thinning and dicing processes [38-40]. 
Some works also used the flexure test method for adhesion studies of thin films, whereby a pre-crack was first introduced at the top plate and subsequently the mechanical loading was applied to induce delamination at the interface of interest [41-42].

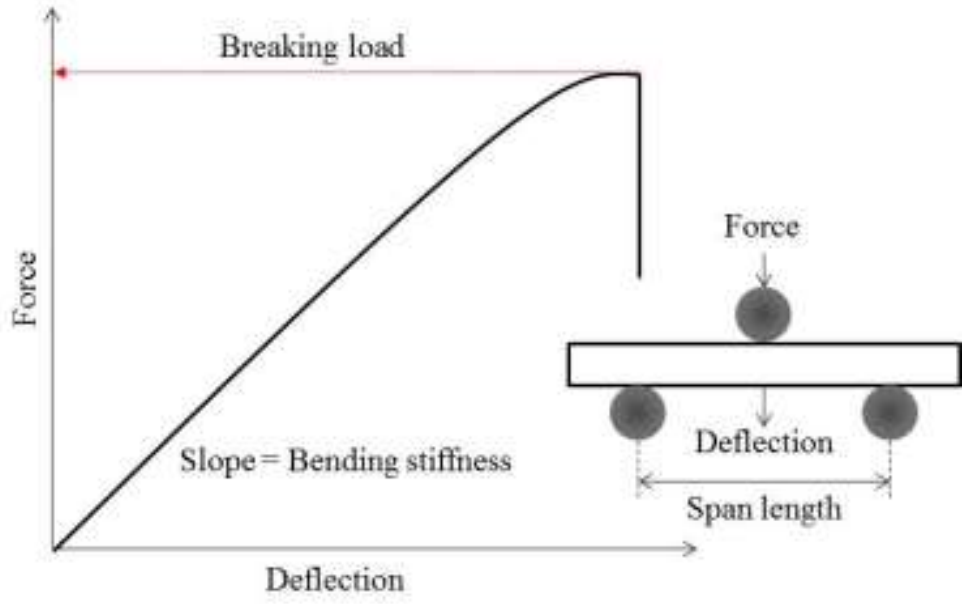

Fig. 2.3: An illustration of the flexure test method in a three-point bend configuration.

\subsubsection{Scratch test}

Surface engineering of the material plays a significant role in a variety of functional applications, ranging from decorative appearance to protecting the substrates from wear, corrosion and other forms of attacks. An important factor that determines the quality and service lifetime of the coatings is their cohesive and adhesive strength. Scratch testing method is widely used to characterize the thin film-substrate systems, to quantify parameters such as adhesive strength and friction force. The scratch testing is a fast and effective method, where the critical load related to the adhesion properties of the coating can be readily determined.

A sphero-conical stylus is first positioned normally on the specimen surface, and subsequently moves horizontally with a constant or progressive normal load until the 
failure occurs at a critical load (Fig. 2.4). When a constant normal load test is performed, the critical load corresponds to a force at which a regular occurrence of such failure along the track is observed. In the case of a progressive normal load test, the critical load is defined as the smallest force at which a recognizable failure occurs. Generally, the critical load is defined as the lateral force that corresponds to the failure event, which is related to the practical adhesion strength and/or the damage resistance of the thin film-substrate system [43-47].

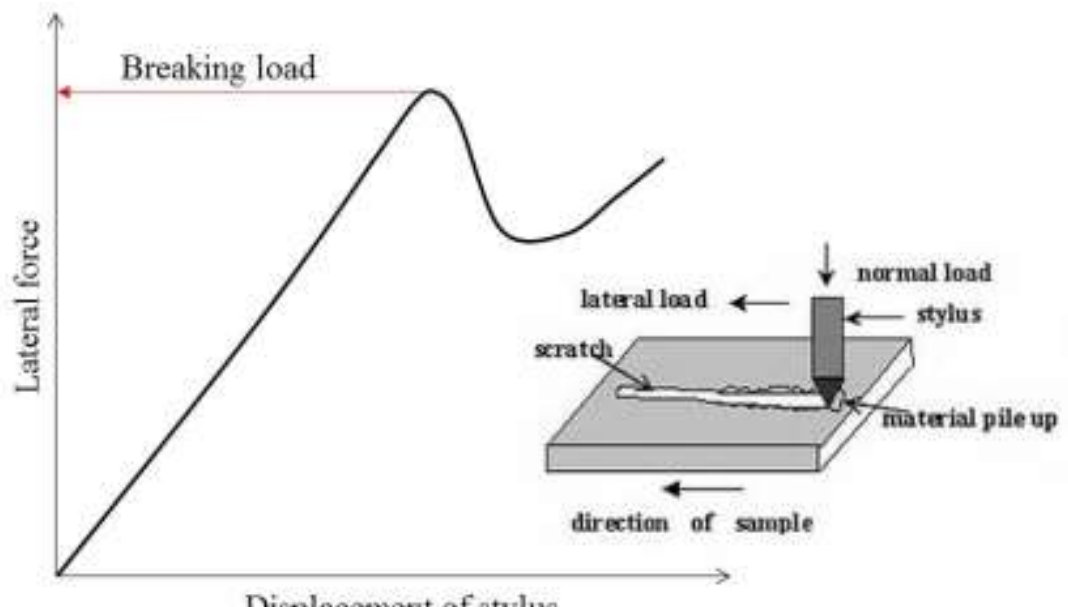

Displacement of stylus

Fig. 2.4: An illustration of the scratch test method [48].

\subsubsection{Indentation test}

The objective of the majority of the indentation tests is to extract the elastic modulus and the hardness of the material from the $F-d$ measurement [49-76]. The test is conducted using an indenter tip with a known geometry penetrates normally onto the specimen surface with an increasing force till a pre-set condition or failure. The force and displacement are recorded simultaneously during the indentation loading and unloading cycle (Fig. 2.5). Numerous works have also been carried out using the indentation test 
method to evaluate the fracture behavior and toughness for the bulk materials [78-89] and the coating or thin-film materials [90-105]. However, the indentation loading on the coating-substrate structure yields a rather complex multitude of failure modes, and the substrate effect poses a challenge to determine the fracture property of the coating accurately [67].

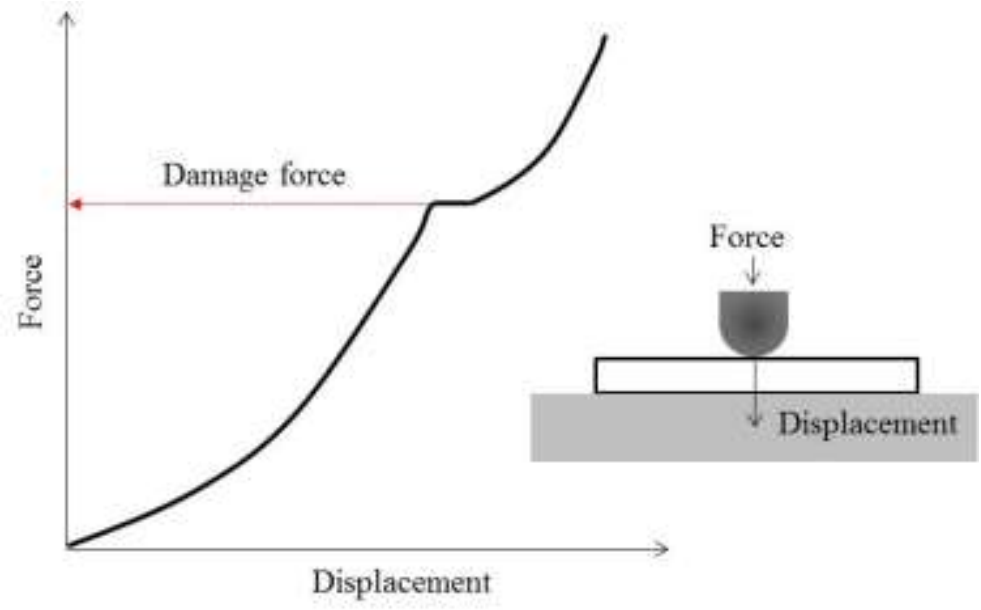

Fig. 2.5: An illustration of indentation test method.

In order to attain mechanical device stability, the elastic, plastic and fracture properties are important for the thin-film characterization. Among all the three mechanical methods, an indentation test is the most suitable technique to evaluate the mechanical behavior of the thin-film stacked structure related to the application of the wire bonding on the bond pad of an IC chip. In addition, this test method requires no special specimen preparation process, in which the test can be performed rapidly and inexpensively.

\subsection{Mechanics of indentation}

The aim of any general mechanical description of a contact problem is to characterize the deformation and fracture processes of the materials to the appropriate material 
parameters, such as the elastic modulus $E$, hardness $H$, and toughness $K_{\mathrm{c}}[60,76]$. The most commonly used indentation hardness test method is related to the geometry and shape of the indenter used (Fig. 2.6). The test involves the size measurement of the residual plastic impression in the specimen as a function of the indenter load, which is also known as the mean contact pressure $[60,75-76]$. This provides the contact area of the residual indentation $A_{\mathrm{r}}$ for a given load $P_{\mathrm{m}}$, whereby $H=P_{\mathrm{m}} / A_{\mathrm{r}}$.

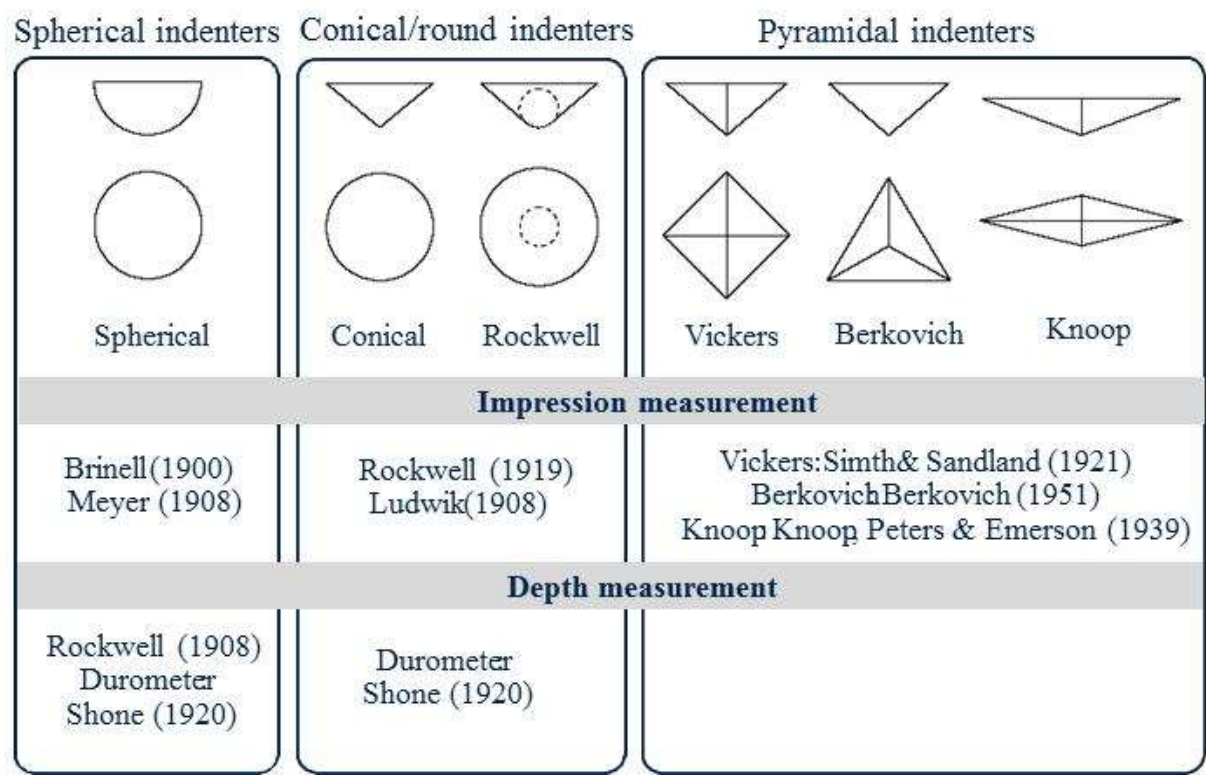

Fig. 2.6: The various indentation hardness test methods with different indenters [77].

The hardness can also be obtained from the depth-sensing indentation without imaging the residual indentation of the specimen surface. For a spherical and conical indenter, the load-displacement relationships are non-linear and the contact area changes continuously during the loading and unloading stages. The total indentation depth $h_{\mathrm{T}}$ measures both the elastic displacement $h_{\mathrm{el}}$ and plastic displacement $h_{\mathrm{pl}}$ of the material (Fig. 2.7). At any time in the unloading stage, the total displacement $h_{\mathrm{T}}=h_{\mathrm{s}}+h_{\mathrm{c}}$, where $h_{\mathrm{s}}$ is the elastic displacement of the surface at the perimeter of the contact, and $h_{\mathrm{c}}$ is the contact depth or 
vertical distance along which the contact is made [76]. Assuming the pile-up is negligible, $h_{\mathrm{s}}$ is given by [61]

$$
h_{s}=\varepsilon \frac{P_{m}}{S},
$$

where $P_{\mathrm{m}}$ is the maximum load and $\varepsilon$ is a constant that depends on the indenter geometry, i.e., 0.72 for conical, 0.75 for spherical, and 1.0 for flat punch [61]. The depth at which contact is made between the indenter and the specimen is expressed as (Fig. 2.7)

$$
h_{c}=h_{T}-\varepsilon \frac{P_{m}}{S} .
$$

With the knowledge of the indenter geometry, the projected contact area $A_{\mathrm{c}}$ can be calculated from the contact depth $h_{\mathrm{c}}$, and the hardness is obtained from $H=P_{\mathrm{m}} / A_{\mathrm{c}}$. This hardness calculation is based on the projected contact area under load, which may deviate from the conventional hardness obtained using the residual indentation area, if the material experiences significant elastic recovery during the unloading stage [61].

The most significant contribution in the analysis of the $F-d$ curves measured by a depth-sensing indentation system is based on the work by Doerner and Nix [51], and Oliver and Pharr [52]. Their analyses are in turn based upon the relationships developed by Sneddon [49] for the penetration of a flat elastic half space by different axisymmetric indenters, e.g., flat-ended cylindrical, spherical, and conical punches. These elasticitybased analyses are normally applied to the unloading data of an indentation measurement, assuming the material is characterized by elastic recovery.

The indentation $F$ - $d$ curve is then analyzed according to

$$
S=\frac{d P}{d h}=\frac{2}{\sqrt{\pi}} E_{e f f} \sqrt{A_{c}},
$$


where $S$ is the experimentally measured stiffness of the upper portion of the unloading data (Fig. 2.7), and $E_{\text {eff }}$ is the effective elastic modulus that is defined by

$$
\frac{1}{E_{\text {eff }}}=\frac{1-v^{2}}{E}+\frac{1-v_{i}^{2}}{E_{i}}
$$

The $E_{\text {eff }}$ takes into account of the elastic displacements for both the specimen and the indenter, with the elastic constants of $E$ and $E_{i}$, and Poisson's ratios $v$ and $v_{i}$, respectively. From the indentation experiments, the stiffness $S$ and the projected contact area $A_{\mathrm{c}}$ can be obtained, and thus $E$ can be calculated if $v$ is known. Originally, Eq. (2.3) is derived for elastic contact only [52], but it has been applied equally well to elastic-plastic contact [55]. Furthermore, it is also unaffected by pile-up and sink-in [61].

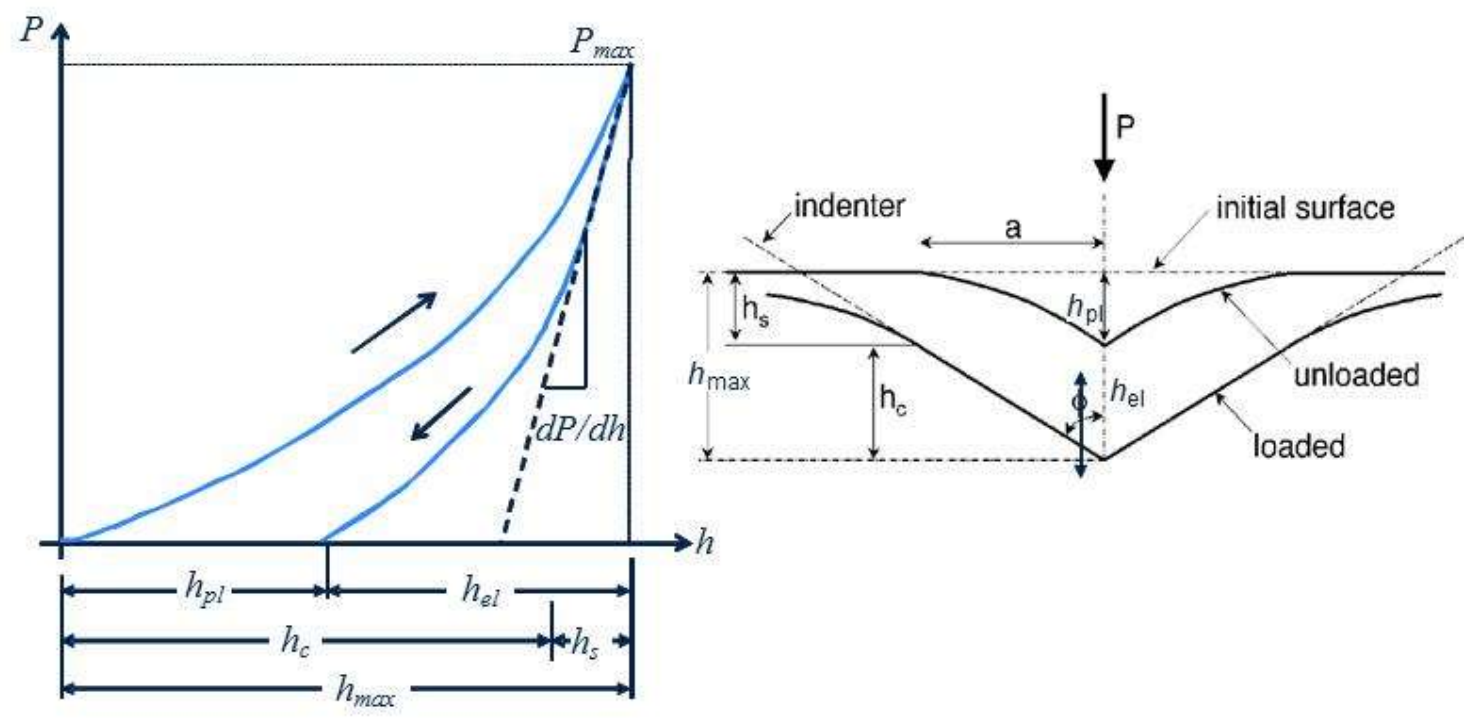

Fig. 2.7: The $F-d$ curve of an indentation loading-unloading process [61]. 


\subsubsection{Indentation damage modelling}

The indentation method can be extended to evaluate the damage behaviour or fracture toughness of the materials and interfaces in a manner similar to that conventionally used in the larger scale testing. This technique has become popular for measuring the fracture toughness properties of the thin-film or coating material due to its simplicity and expediency of experiments [93-105]. When subjected to the indentation loading, the specimen usually shows complex crack characteristics, depending on its structure and composition, geometry of the indenter, load and environment conditions. The indentation stress field is usually dominated by the shear and hydrostatic components and may contain a small amount of tension, and thus the potential for fracture exists in any contact event [50]. The five major types of indentation cracks on the bulk brittle materials and/or thick coatings are summarized in Fig. 2.8 [78-86].
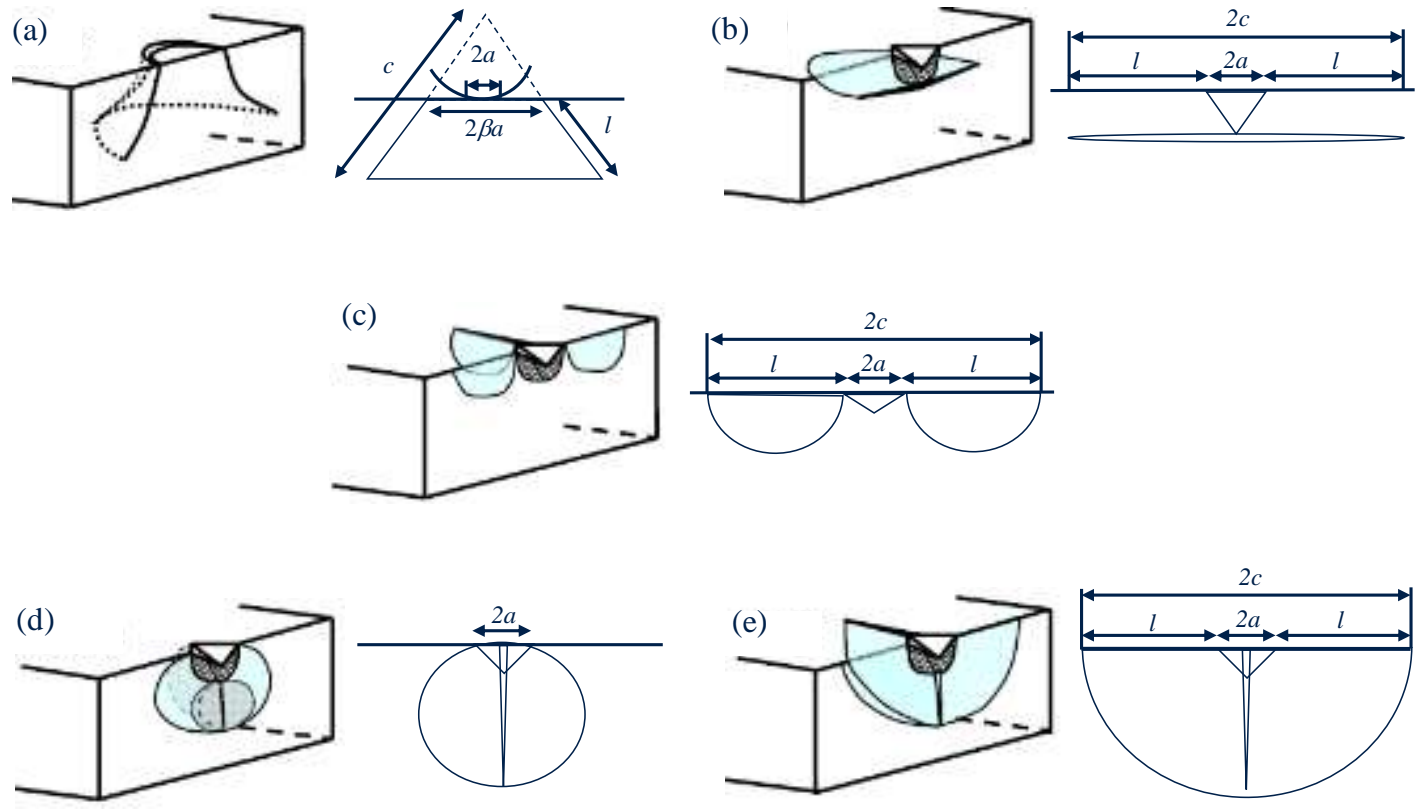

Fig. 2.8: An illustration of the indentation crack formation: (a) cone, (b) lateral, (c) radial, (d) median, and (e) radial-median or half-penny radial crack [78-86]. 
The conical cracks are typically generated by the flat punch or spherical indenter, whereby a ring crack is initiated at the high tensile stress region near the edge of the contact (Fig. 2.8(a)). The lateral cracks are "horizontal" ones that occur beneath the surface and are symmetrical along the loading axis generated by the pyramidal indenters (Fig. 2.8(b)). They are produced by the tensile stress and often extend to the surface during the unloading process of indentation, resulting in a surface ring that may lead to chipping of the surface of the specimen. The radial cracks are "vertical" half penny-type ones that occur on the surface of the specimen at the corners of the residual impression, and outside the plastic zone when the specimen is penetrated with sharp or blunt indenters at high loads (Fig 2.8(c)). These cracks, also known as Palmqvist radial cracks, are formed by tensile hoop stress that extend downward into the specimen and are usually quite shallow. The median cracks are "vertical" circular penny cracks that form beneath the surface along the loading axis outside the plastic zone, and have a direction aligned with the corners of the residual impression by pyramidal indenters (Fig 2.8(d)). The halfpenny cracks are also known as radial-median cracks, which can be initiated from the surface radial cracks to the median cracks, from the median cracks to the surface radial cracks, or a mixture of both, and thus forming the two half-penny cracks that intersect the surface, as shown in Fig. 2.8(e). These types of cracks are usually initiated from the unloading stage of the indentation. The exact sequence of crack initiation is sensitive to the experimental conditions. 


\subsubsection{Stress-based models}

The fracture toughness of a material is a measure of its stress resistance to fracture in the presence of a flaw. It is typically measured by the flaw size $c$, and the applied load $P$. For such a specimen, the stresses around the crack tip are given by [87]

$$
\sigma_{i j}=\frac{K}{\sqrt{2 \pi r}} f_{i j}(\theta),
$$

where $r$ and $\theta$ are polar coordinates relative to the crack tip, and the stress intensity factor is given by [87]

$$
K=\beta P \sqrt{c},
$$

where $\beta$ is the geometry factor. The fracture toughness $K_{c}$ is defined as the stress intensity factor of a critical load needed to propagate the crack.

Hertzian cone cracks have been studied widely in the silicate glass, single crystal ceramics and some hard fine-grained polycrystalline ceramics, using a spherical indenter. The usage of a spherical indenter is able to provide insights to the entire evolution of damage process, as a progressive transition from initial elasticity to full plasticity. A Hertzian cone crack begins as a surface ring crack outside the elastic contact and when a critical load is exceeded, it will propagates downward and flares outward within a modest tensile field into a truncated cone configuration as shown in Fig. 2.8(a). For a welldeveloped cone crack, the fracture toughness is given by [50]

$$
K_{c}=\chi \frac{P}{c^{1.5}},
$$

where $\chi$ is the function of Poisson's ratio, and $c$ is the extend crack length as shown in Fig. $2.8(a)$. 
For the semi-circular radial crack, the crack length $l$ varied as a linear function of the indentation load $P$, and the fracture toughness was given by [96-97]

$$
K_{c}=k\left(\frac{E}{H}\right)^{m} \frac{P}{a l^{0.5}},
$$

where $a$ is the semi-diagonal of the residual imprint as shown in Fig. 2.8(b) and $k$ is the empirical calibration constant. The empirical exponent $m$ takes a value of 2/5.

Lawn et al. [81] formulated a different relationship for a fully formed median-radial crack:

$$
K_{c}=k\left(\frac{E}{H}\right)^{m} \frac{P}{c^{3 / 2}},
$$

where $c$ is measured from the centre of contact to the end of the corner radial crack and $m$ $=1 / 2$.

Various researchers have reported different values of $k$ and $m$ based on their indentation experiments and observations $[81,96]$. The parameter $k$ is dependent on the indentation deformation, crack pattern and indenter geometry, and $m$ is found to be between $2 / 5$ and $2 / 3[81,96]$. The residual stress after indentation is also responsible for the extension of the cracks or damage during unloading. Hence, an additional term is usually included to the fracture toughness equation to account for the residual stress effect [83-84].

The crack has to be distinct and well developed, i.e., $l \gg 2 a$, for all the methods discussed above, and therefore a high indentation load is required. However, for the thin coating, large penetration into the coating at a higher load will result in the plastic deformation in the substrate, and thus the stress field and the crack shape can be 
influenced by the substrate effect. Therefore, a sharp indenter like a cube corner tip is used to induce cracks at a lower load $[86,92,99]$. If the substrate plays an important role, a shape factor is introduced to the facture toughness to account for the crack shape modification [87].

Field et al. proposed a measurement method of fracture toughness for those hardly visible cracks using the depth-sensing indentation approach [93]. In this method, it was recognized that cracking was accompanied by an increase in penetration depth as shown in the $F$ - $d$ response. This "pop-in" event corresponded to the nucleation of a median crack at the boundary of the plastic zone below the point of contact with the indenter. The difference between the maximum actual penetration depth (with pop-in) and the anticipated penetration depth (with no pop-in) was used to determine the crack length, which was later used for the fracture toughness calculation.

\subsubsection{Energy-based models}

With the development of the complex coating or multi-layered thin-film systems and the presence of variable crack patterns, the application of stress-analysis-based approaches has become challenging. Hence, the energy-based models have been established to deal with the various crack patterns in complex stack thin-film systems. During nanoindentation, circumferential cracking and spallation can be used to characterize the peeling of the coating around the indentation. A pop-in or plateau can also be observed in the $F-d$ curve, and it can be used to provide a quantitative estimate of the coating fracture toughness (Fig. 2.9) [90-91, 99, 103]. 
Li et al. [90-91] proposed a widely used energy-based model, which is based on the extrapolating of the loading curve at the point of 'pop-in' induced by a through-thickness crack. The model assumes that the onset of fracture occurs from the start point A to its end point B as illustrated in Fig. 2.9(b), and the difference between the extrapolated curve and the measured curve is denoted as the fracture dissipated energy $U_{f}$, i.e., the area $\mathrm{ABC}$. The fracture toughness is related to the released elastic strain energy $U_{f}$ during fracture, the $E$ and $v$ of the film and the crack area $2 \pi C_{R} t$, and is given by

$$
K_{c}=\sqrt{\frac{U_{f} E}{\left(1-v^{2}\right) 2 \pi C_{R} t}},
$$

where $C_{\mathrm{R}}$ is the radius of circumferential through-thickness crack formed around the indenter, and $t$ is the effective film thickness.

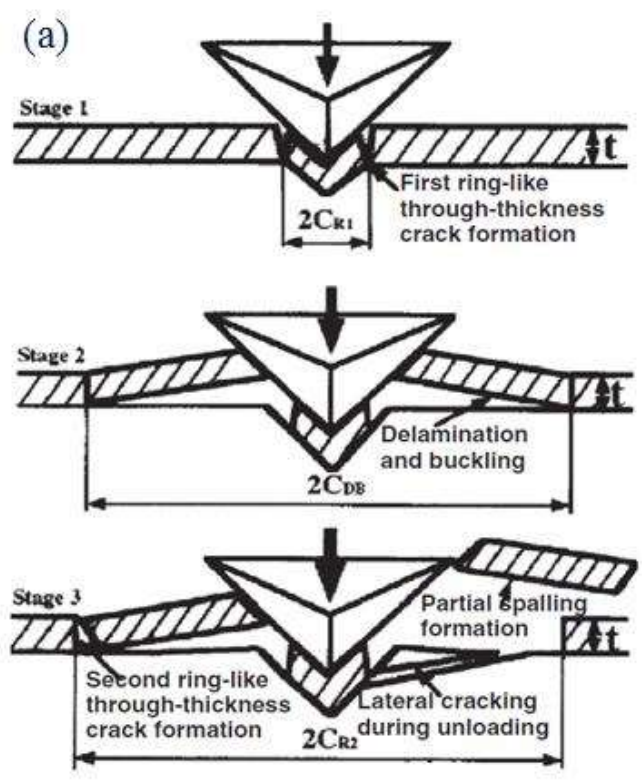

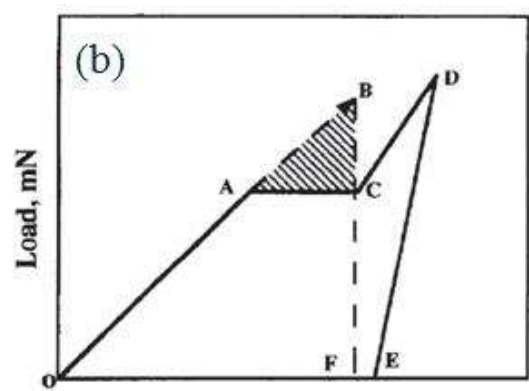

Displacement, $\mathbf{n m}$

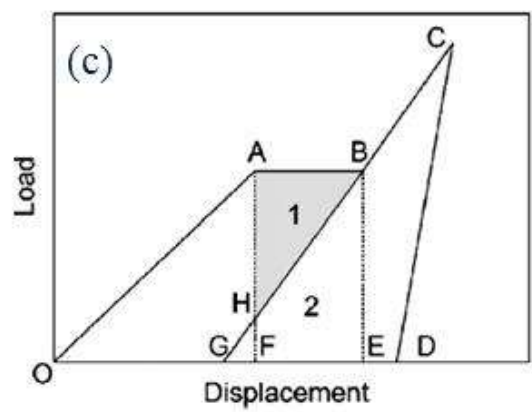

Fig. 2.9: (a) Nano-indentation fracture of the thin-film coating and the corresponding $F-d$ curve observed with the associated energy release; (b) the model developed by Li et al. [90-91], and (c) model by Michel et al. [97]. 
Michel et al. [97] realized that the total work of the indenter should include the fracture energy of the coating and the energy consumed in substrate deformation. Hence, they proposed the area ABEF (Fig. 2.9(c)) as the total work of the indenter during circumferential cracking and spallation of the coating. Thus, areas 1 and 2 represent the fracture energy of the coating and the elastic energy of Si deformation, respectively. The segment BG denotes a partial loading curve of the Si substrate.

However, in the event of fracture that does not always cause a "pop-in" or plateau in the $F$ - $d$ curve, which typically occurs in the hard coating on a soft substrate. Thus, another energy-based method to estimate the coating toughness in the event of the absence of "pop-in" in the $F$ - $d$ curve was proposed by Chen et al using the irreversible work difference approach [100-101]. The work of indentation can be written in the following form:

$$
W_{\mathrm{T}}=W_{\mathrm{el}}+W_{\mathrm{pl}}+U_{\mathrm{f}}+W_{\mathrm{other}}
$$

where $W_{\mathrm{T}}$ is the total work, $W_{\mathrm{el}}$ is the work of elastic deformation, $W_{\mathrm{pl}}$ is the work of plastic deformation, $U_{\mathrm{f}}$ is the fracture dissipated energy, and $W_{\text {other }}$ represents the friction and heat dissipated during indentation. The reversible plastic behavior is ignored, and the sum of all the other terms except $W_{\mathrm{el}}$ is considered as the irreversible energy. In the indentation experiments, $W_{\mathrm{T}}$ and $W_{\mathrm{el}}$ can be measured, and if $W_{\mathrm{pl}}$ and $W_{\text {other }}$ are be determined, the fracture dissipated energy $U_{\mathrm{f}}$ can obtained [58, 74, 100-101]. 


\subsection{Physical damage detection techniques}

Damage is defined as the changes to the material and/or geometric properties of a structural system, which can adversely affect the intended function or performance of the system. During the process development phase, engineers are able to evaluate the cause of the damage and improve their processes from the real-time damage monitoring information on the time, load condition, or other conditions at which damage occurs. Hence, it is important to choose the most suitable damage detection technique to be used in the thin-film stacked structure during the indentation loading. Damage detection can be performed using an active sensing method that requires an external electrical power source (e.g., ultrasonic sensor, piezo-resistor, and electrical resistance measurement) or a passive sensing approach that generates its own electrical output signal without requiring external voltages or currents (e.g., AE sensor, strain gauge and thermocouple).

Electrical resistance measurement is an active sensing technique, which serves as an effective method to monitor the structural failure or damage during external mechanical loading. The electrical resistance $R$ of a given object depends primarily on the material such as its electrical resistivity $\rho$, and its structure (cross-sectional area $A$ and length $L$ ), for which $R=\rho A / L$, and is defined as the ratio of voltage $V$ to the current $I$ flowing through the object, which is governed by the Ohm's law, i.e. $R=V / I$. Any failure that occurs in the structure will result in an increase in $R$. However, the implementation of resistance monitoring technique requires the structure to be conductive; delicate wiring or connection is necessitated to enable an accurate measurement, and hence a four-point probe technique is usually employed [106-110]. There are a number of applications using this technique to study the electrical resistivity of the metallic thin film as a function of 
film thickness [106-107] or to examine the deterioration of the coated metal under mechanical loading [108-109].

AE testing is a passive and receptive technique that analyses the ultrasound pulses emitted by a defect at the moment of its occurrence. When the structure is subjected to an external stimulus, it experiences stress and strain. If the stress exceeds the mechanical strength limit of the structure, cracking occurs and the structure releases the energy that travels in a form of high-frequency stress waves to the AE sensor. The detection and analysis of the AE voltages and waveforms provide valuable information regarding the origin and importance of a discontinuity or damage in a stressed structure. The application of the AE testing to detect and monitor defect formation and failures in structural materials can be divided into the three categories: the material study [111-118], the examination of structures [111-112, 119-123] and the process control of the manufacturing processes [124-126].

The common failure mode observed in the bond pad of an IC chip during the wire bonding process is usually the dielectric cracking underneath the top metal layer, and this dielectric layer is a non-electrical conductive material, and therefore the electrical resistance measurement method is not a suitable approach for the crack event monitoring. Hence, AE testing is employed in this study.

\subsection{Principle of AE testing}

The origination of the AE testing is attributed to J. Kaiser in 1950s, and subsequently the scientific investigation on the sounds emitted during crack initiation and growth began in the 1960s [127]. The AE signal process chain consists of four main elements: (a) the 
source where the $E_{\mathrm{AE}}$ is released, (b) the wave propagation in the structure from the source to the sensor, (c) the detection of $\mathrm{AE}$ wave by the sensor and (d) the signal conditioning and analysis. Each element has a controlling influence on the size and shape of the measured AE signal, and thus the final signal will be completely different from the original motion at the source (Fig. 2.10) [128].
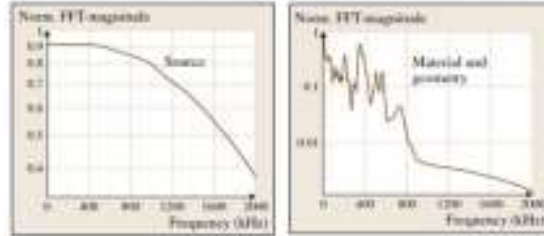

Source, $\mathrm{H}_{3}$
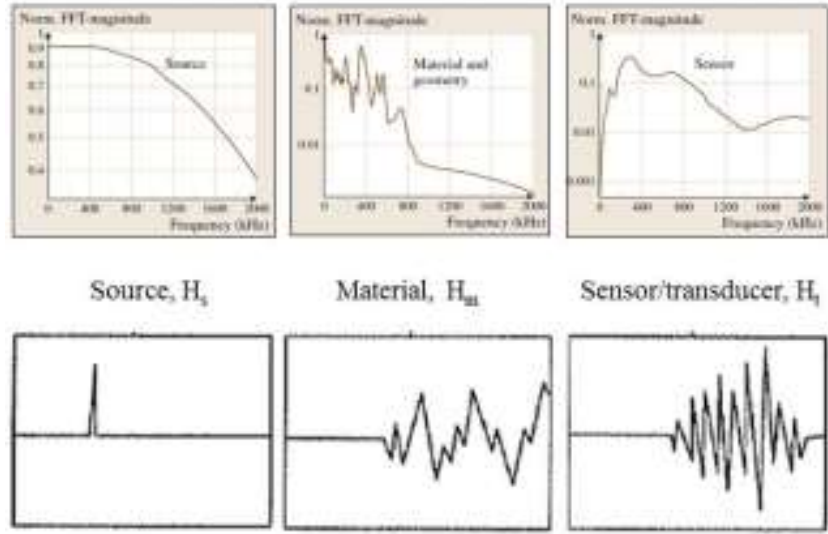

Sensoritransducer, $\mathrm{H}_{1}$
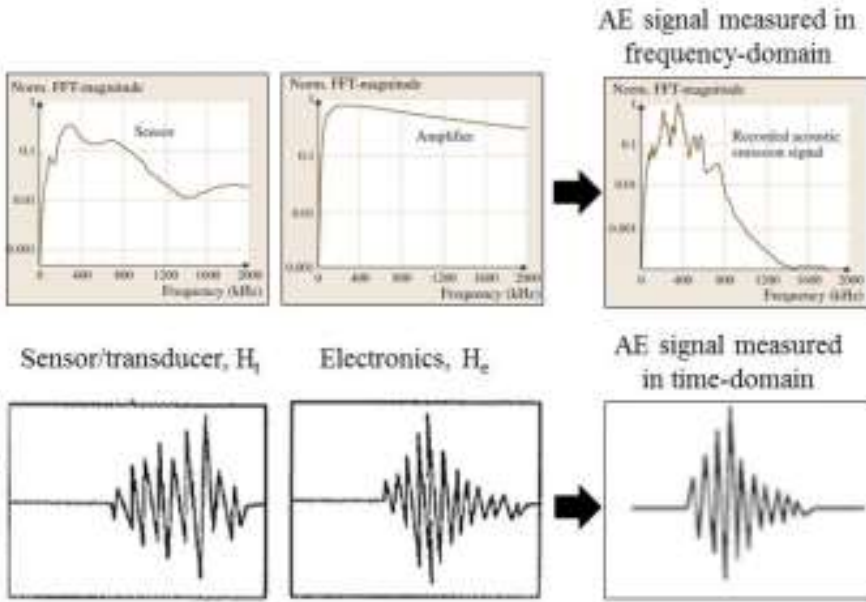

AE signal measured

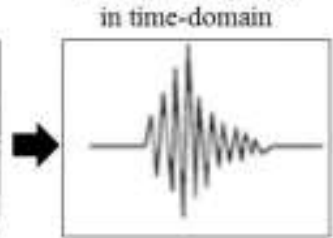

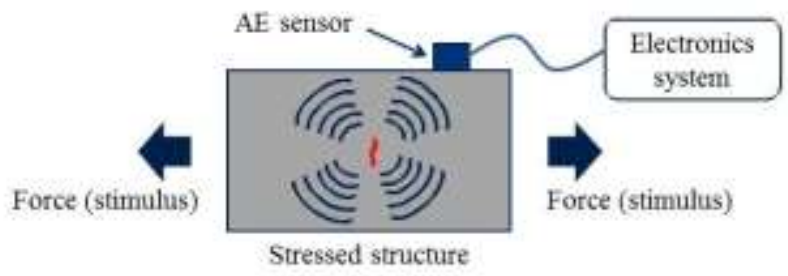

Fig. 2.10: An AE event in a stressed structure and its signal process chain [128].

All signals can be analyzed as "sine wave" frequency components using Fourier analysis methods, which can be expressed by the characteristic or transfer functions of the source $H_{\mathrm{s}}$, propagation medium $H_{\mathrm{m}}$, sensor or transducer $H_{\mathrm{t}}$, and electronics $H_{\mathrm{e}}$ [128]. In the frequency domain, the transfer function of the $\mathrm{AE}$ signal, $H_{\mathrm{AE}}$, is given by the product of the four transfer functions:

$$
H_{\mathrm{AE}}(w)=H_{\mathrm{s}}(w) H_{\mathrm{m}}(w) H_{\mathrm{t}}(w) H_{\mathrm{e}}(w)
$$


where $w$ represents the frequency in hertz. In the time domain, the source function of a crack is the force or displacement versus the time history, describing the normal displacement of the crack of the area. This is combined using a convolution integral with the impulse response of the mechanical system (or Green's function) to represent a source, and is determined by integral over Fourier transforms:

$$
h_{\mathrm{AE}}(t)=\int_{-\infty}^{\infty} H_{\mathrm{AE}}(\mathrm{w}) e^{i w t} d w
$$

with

$$
H_{\mathrm{AE}}(w)=\int_{-\infty}^{\infty} h_{\mathrm{AE}}(\mathrm{t}) e^{-i w t} d t
$$

The AE signal produced by the sensor is amplified and filtered (signal conditioning), followed by detection and evaluation (data analysis) through an AE electronic system. Basically, there are two types of AE signals, namely transient and continuous signals. The transient signal is also known as burst, where the start and end points deviate clearly from background noise (Fig. 2.11), whereas the continuous signal shows the non-stop variations of the amplitudes and frequencies during the AE testing. The most commonly used features in an AE transient signal are as follows [129-131]:

(a) Peak amplitude: the maximum measured voltage in a waveform that is measured in decibels $(\mathrm{dB})$. This is an important parameter in AE inspection because it determines the detectability of the signal.

(b) Rise-time: the time interval between the first threshold crossing and the signal peak. This parameter is related to the propagation of the wave between the source of the AE event and the sensor. Therefore, the rise time is used for qualification of signals and as a criterion for noise filter. 


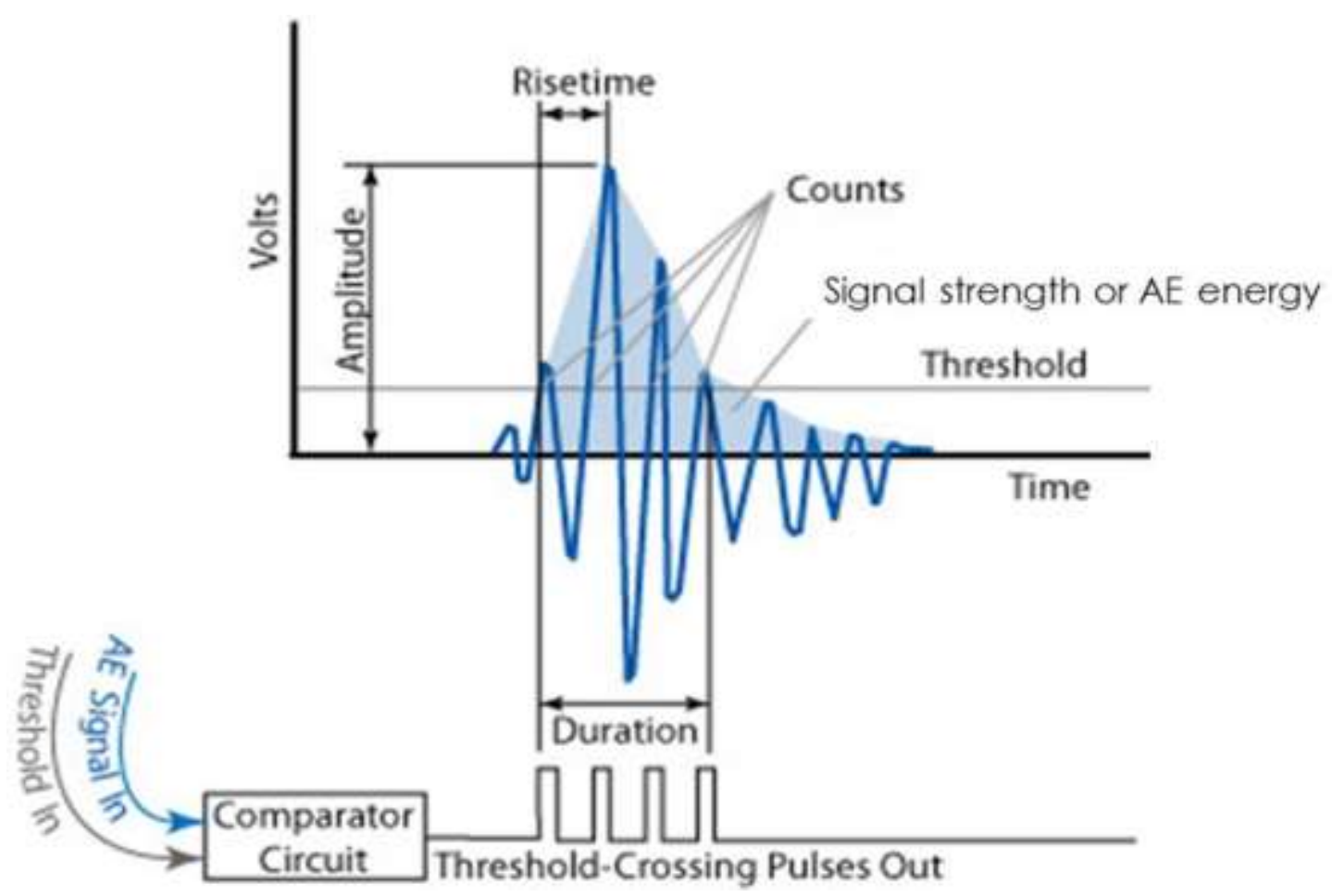

Fig. 2.11: Features of AE transient signal in time domain [129].

(c) Signal duration: the time difference between the first and last threshold crossings. The duration can be used to identify different types of sources and to filter out the noise. This parameter relies upon the magnitude of the signal and the acoustics of the material, like the number of threshold crossings.

(d) Number of threshold crossings or counts $(N)$ : the number of pulses emitted by the measurement circuitry if the signal amplitude is greater than the pre-determined threshold. A hit may produce one or many counts, which depends on the magnitude of the AE event and the characteristics of the material. However, this is a relatively simple parameter to collect, and usually need to be combined with amplitude and/or duration measurements to provide quality information about the shape of a signal. 
(e) Signal strength or $E_{\mathrm{AE}}$ : the measure of the area under the envelope of the rectified linear voltage time signal from the transducer. The energy is processed in either the signal strength mode that is calculated by integrating the absolute value of AE signal during the signal duration, or the so-called true energy mode, which is calculated by integrating the square of the digitized AE signal (voltage $V_{\mathrm{i}}$ ) during the signal duration, and then divided by a reference resistance $R$ :

$$
E_{\mathrm{i}}=\int V_{i}(t)^{2} d t / R
$$

The $E_{\mathrm{AE}}$ is sensitive to the amplitude and duration of the signal, but independent of the frequencies and counts. Sometimes, AE bursts may not be related to the defects of interest and can originate from the background noises. Therefore, it is very important to determine those characteristics that distinguish the right burst signal from the unwanted ones [117123]. 


\section{Chapter 3 Development of Indentation Damage Test Methodology}

In this chapter, the development of an indentation damage test methodology that consists of an instrumented micro-mechanical tester and a piezo-electric AE sensor is presented. An AE pulser test method is proposed to investigate the signal-to-noise ratio and the measurement sensitivity for the different test condition set-ups. Subsequently, the measured AE signals and waveforms are further discussed.

\subsection{Integration of indentation testing with acoustic emission monitoring}

An instrumented micro-mechanical tester is employed to study the mechanical strength and behaviour of a thin-film stacked structure that is similar to the bond pad of an IC chip. A quasi-static load is first applied normally on the surface of the specimen, and any damage or cracking induced by the indentation load is detected by the AE sensor placed underneath the specimen. Besides the $F-d$ response obtained from the indentation tester, the AE sensor offers the additional physical quantities such as the AE peak voltage, energy, rise and duration times, and waveform, which may provide an in-sight exploration to the structural evolution and damage behaviour with respect to the mechanical loading.

The integration is established by connecting the AE sensor module to the instrumented micro-mechanical tester, whereby both the mechanical $F-d$ and AE signal responses are synchronized (Fig. 3.1). 


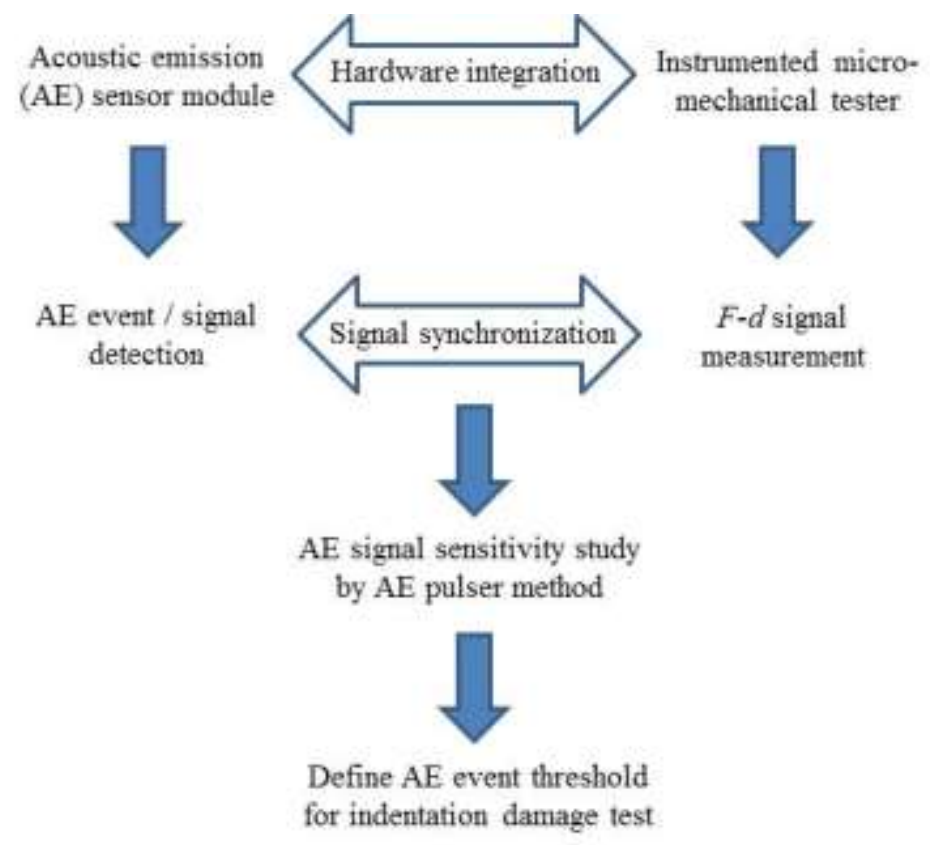

Fig. 3.1: The experimental set-up of the indentation damage test.

\subsubsection{Micro-indentation testing}

The most fundamental measurements made by any micro-mechanical tester are the force $F$ and displacement $d$. The two measurements are typically coupled in the system through the support springs. When the AE sensor is integrated with the micro-mechanical tester, the accuracy of the $F-d$ measurement can be affected significantly. The integration of the micro-mechanical tester and $\mathrm{AE}$ sensor is analogous to a mechanical representation of two springs connected in series (Fig. 3.2).

During the indentation test, the total indentation displacement $d_{\mathrm{T}}$ is the sum of the displacement $d_{0}$ due to the hardware or system compliance $C_{0}$ and the actual indentation displacement $d_{\mathrm{s}}$ of the specimen, i.e., $d_{\mathrm{T}}=d_{\mathrm{s}}+d_{0}$. The overall finite stiffness or total compliance $C_{\mathrm{T}}$ in an indentation test comprises the load-frame of the tester integrated mechanically with an $\mathrm{AE}$ sensing element (customized fixture and $\mathrm{AE}$ sensor) $C_{0}$ and the 
specimen $C_{\mathrm{s}}$, i.e., $C_{T}=\sum_{i=1}^{n} C_{i}=C_{0}+C_{\mathrm{S}}=d_{T} / F=\sum_{i=1}^{n} d_{i} / F$. In order to measure the $F-d$ response of the specimen accurately, $C_{0}$ must be established precisely and compensated accordingly, i.e., $C_{\mathrm{s}}=C_{\mathrm{T}}-C_{0}$. Hence, before the indentation damage test is conducted, a compliance test (without the specimen) is required. A second-order polynomial function is used to fit the measured $F$ - $d$ curve response that is able to handle both the linear and nonliner behaviors of $C_{0}$.

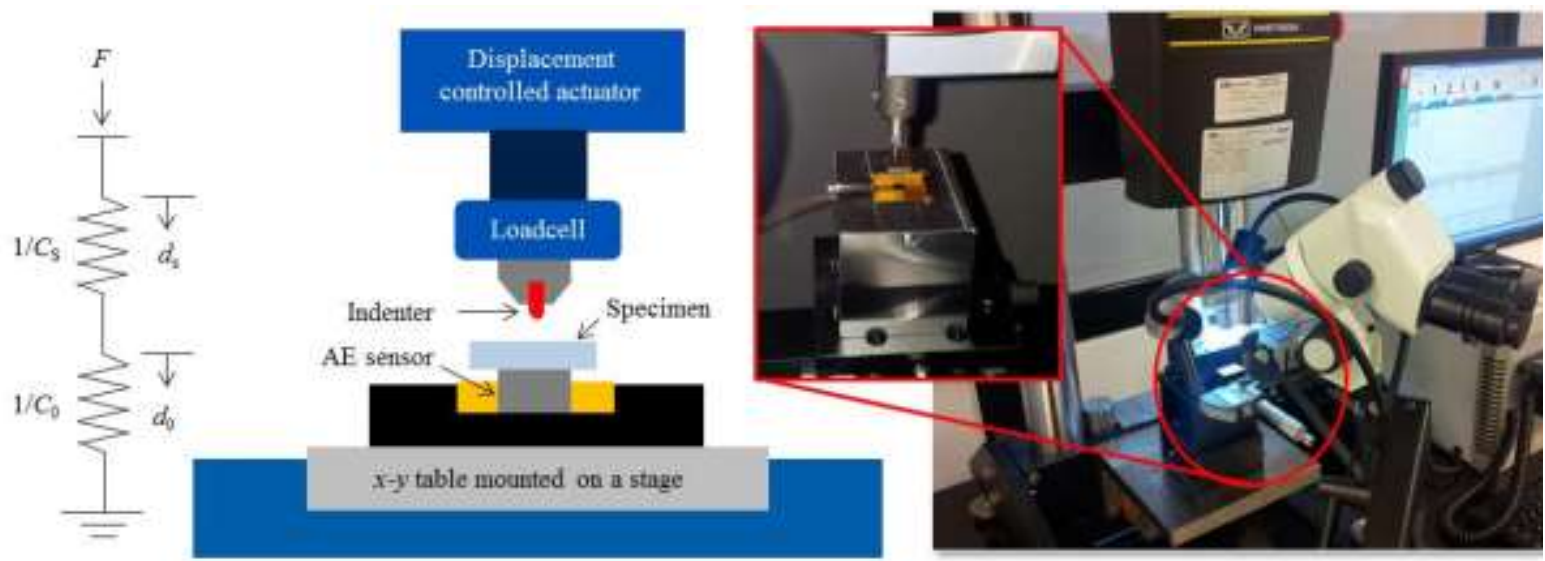

Fig. 3.2: An indentation damage test system consists of an Instron micro-mechanical tester integrated with an AE sensor.

Alternatively, an Antor Paar CSM micro-mechanical (or micro-hardness) tester that requires no compliance compensation is preferred (Fig. 3.3). This tester is incorporated with a reference point which encompasses the indenter and provides a constant reference for the amount of penetration made into the specimen. Furthermore, this design feature also helps to reduce the thermal drift on the depth signal. In this set-up, a fine setting mode is selected in the CSM tester that provided a normal load range of 0.05 to $10 \mathrm{~N}$ at a maximum depth of $100 \mu \mathrm{m}$. The load and depth resolution is $0.3 \mathrm{mN}$ and $0.3 \mathrm{~nm}$, respectively. The data acquisition rate or sampling frequency used in this study is $20 \mathrm{~Hz}$. 


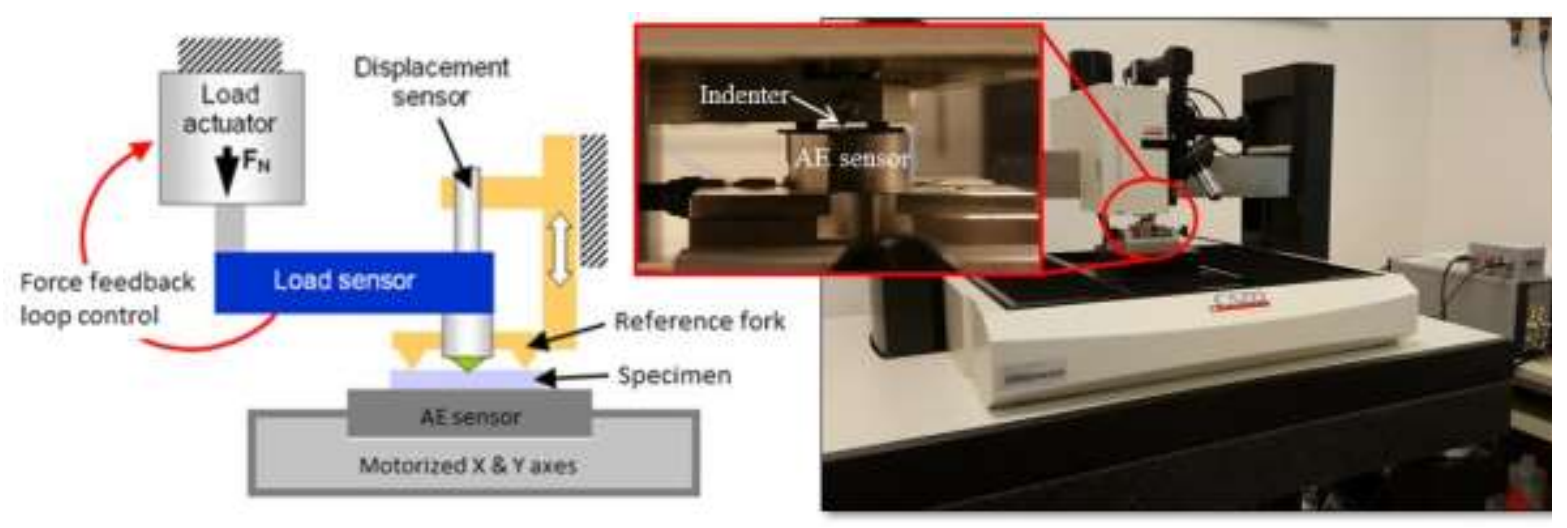

Fig. 3.3: An indentation damage test system consists of an Antor Paar CSM micromechanical tester integrated with an AE sensor.

\subsubsection{Acoustic emission event sensing and detection}

Most AE sensors rely on the piezo-electric effect to transform a surface motion or displacement into an electrical signal, and these sensors are usually very sensitive and do not saturate. In this study, a resonant type of the AE sensor (VS150-L) with a working frequency range of $100-450 \mathrm{kHz}$ is connected to the Vallen AMSY-6 system for signal processing and analysis [131]. The data acquisition rate or sampling frequency is $10 \mathrm{MHz}$, and the digital filter is set to be $95-850 \mathrm{kHz}$. The AE sensor is positioned firmly in a fixture on the universal adapter, which is mounted on the $x-y-z$ motorized stage of the micro-mechanical tester, to detect any damage occurrence in the specimen during the indentation loading-unloading cycle.

\subsection{Acoustic emission test evaluation}

A wideband type of the AE sensor (M31) is employed as a pulser for AE source generation, in order to evaluate the measurement response of the AE sensor (VS150-L). 
This M31 pulser has a relative flat frequency response of $250-1200 \mathrm{kHz}$, which is able to transform an electrical pulse to an abrupt surface movement generated by a capacitor in the Vallen AMSY-6 system [131]. The pulser test method is realized by coupling the M31 pulser face-to-face (using nail polish) with the VS150-L sensor, which is then stimulated by a short burst under the room temperature condition $\left(25^{\circ} \mathrm{C}\right)$. A dead-load of $50 \mathrm{gf}$ is placed on top of the M31 pulser to maintain the mechanical contact with the sensor. The method is extended to evaluate the thickness effect of the Si die $(250$ and $500 \mu \mathrm{m})$ that is placed in between the pulser and the sensor (Fig 3.4).

When an electrical pulse is generated, a single AE event is detected by the VS150-L sensor and the parameters like voltage (peak) $V_{\mathrm{s}}$, energy $E_{\mathrm{AE}}$, rise time $t_{\mathrm{r}}$ and duration time $t_{\mathrm{d}}$ can be extracted from the transient waveform in the time domain. The logarithmic amplitude scale is used to address the large magnitude range of the AE transient signals, and thus the amplitude $A$ of an AE signal in decibels (dB) can be derived by

$$
A=20 \log \frac{V_{\mathrm{s}}}{V_{\text {ref }}}
$$

where $V_{\text {ref }}=1 \mu \mathrm{V}$ that is the output reference voltage of the AE sensor. Furthermore, the properties of the logarithmic function allow gain and attenuation values to be easily calculated by the addition and subtraction, respectively.

Besides analyzing the waveforms in the time domain, the Fast Fourier Transform (FFT) is used to convert these data in the time domain into the frequency domain by the software. Basically, this is done by breaking down the original time-based waveform into a series of sinusoidal terms, each with a unique magnitude, frequency, and phase. Hence, the AE transient signals like $V_{\mathrm{s}}$ and $A$ in the time domain are denoted as $V_{\mathrm{s}} . S$ and $A . s$ in the frequency-domain, respectively. 


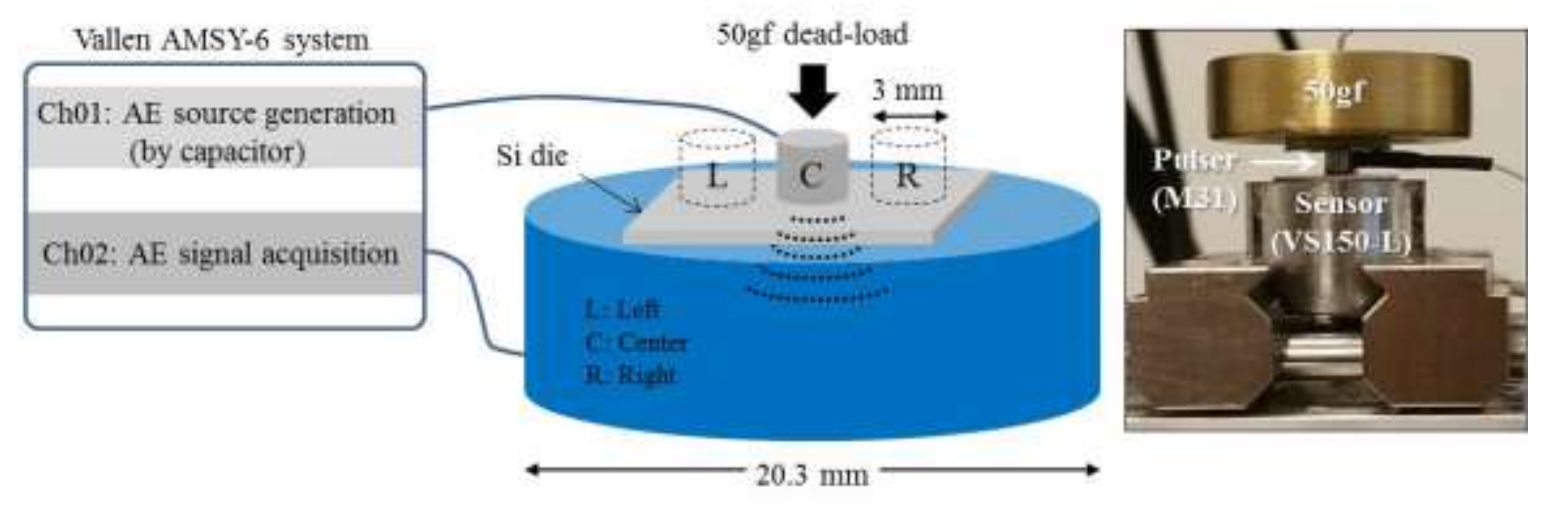

Fig. 3.4: An illustration of the pulser testing method set-up.

Figure 3.5 compares the AE transient signals obtained from the pulser tests with and without the Si die, and for both the 250 and $500 \mu \mathrm{m}$-thick Si dies in the frequency domain. The AE source emitted by the pulser is represented by the dotted-line waveform (Ch01), while the measured AE signals $(\mathrm{Ch} 02)$ is observed to have comparable waveforms for those cases without the Si die, and with the Si die of 250 and $500 \mu \mathrm{m}$ thicknesses (Fig 3.5(a)). It is also found that the VS150-L sensor is sensitive at a frequency range of 150$450 \mathrm{kHz}$, which is in agreement with the product specification.

(a)

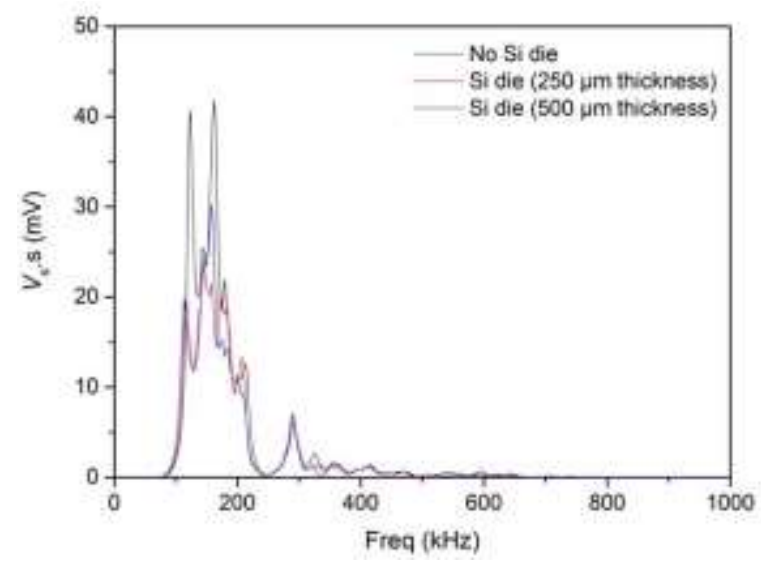

(b)

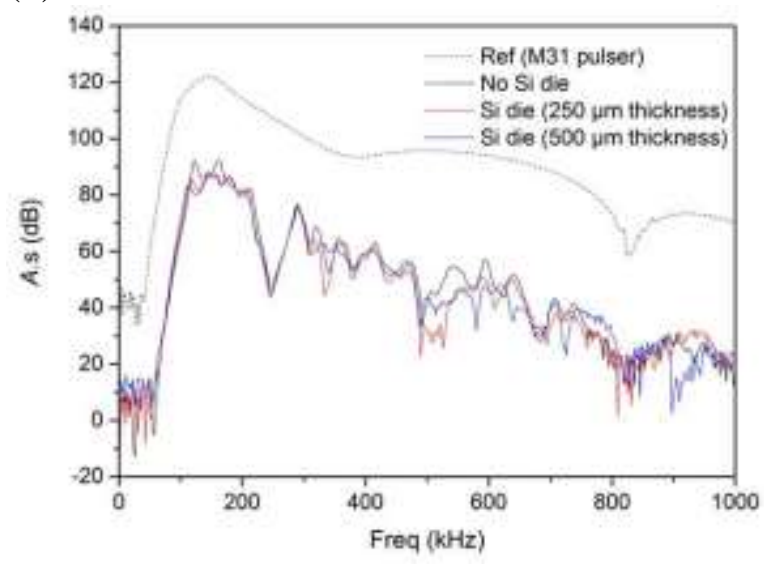

Fig. 3.5: A comparison of the AE transient signals for both cases with and without the $\mathrm{Si}$ die specimens: (a) voltage vs frequency, and (b) amplitude vs frequency. 


\subsubsection{Effect of coupling medium between specimen and AE sensor}

Ideally, a couplant medium (between the specimen and the AE sensor) should be easily applied and removed from the sensor without affecting the loading process, while possessing excellent acoustic impedance, and thus providing a good signal-to-noise $(S / N)$ ratio. Nail polish that consists of a film-forming polymer dissolved in a volatile organic solvent is chosen as the couplant medium in this study. The pulser test method is used to investigate the effect of the nail polish as a couplant medium between the AE sensor and Si die $(500 \mu \mathrm{m})$ on the $S / N$ ratio.

Figure 3.6 presents the $\mathrm{AE}$ transient signals for both cases with and without the nail polish couplant on the AE sensor. In the presence of the couplant, the $S / N$ ratio is improved by $\sim 60 \%$ for the peak voltage $V_{\mathrm{s}}$ detection (or $\sim 10 \mathrm{~dB}$ ). The improvement in the $S / N$ ratio can also be observed at different positions for the case with the couplant (Fig. 3.7). Generally, when a couplant medium is used, the acoustic wave can be transmitted effectively from the pulser (source) to the AE sensor through the Si die specimen.

(a)

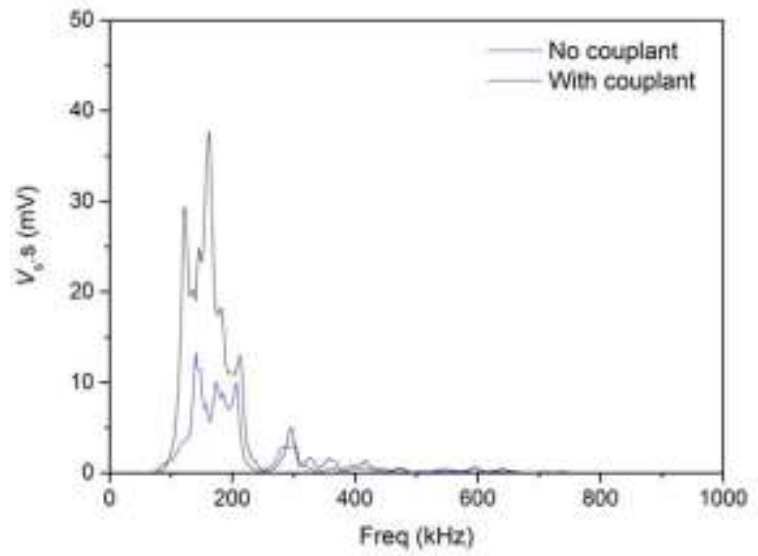

(b)

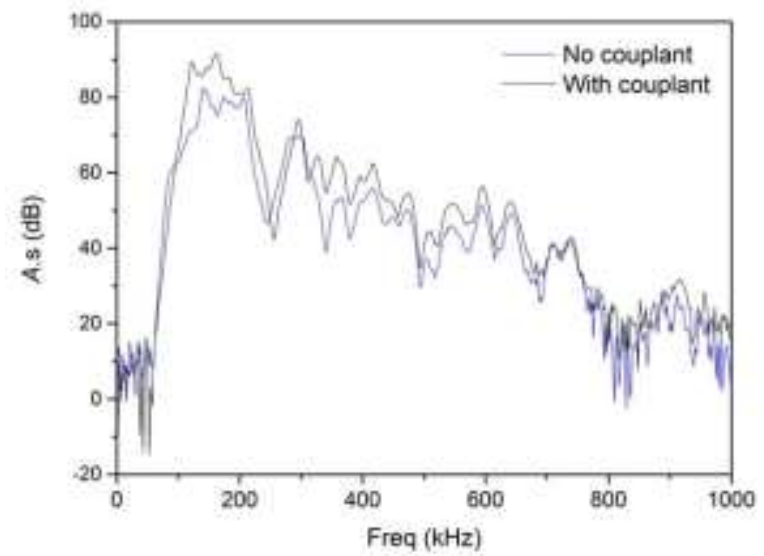

Fig. 3.6: A comparison of AE transient signals for both cases with and without couplant medium: (a) voltage vs frequency waveform, and (b) amplitude vs frequency waveform. 
(a)

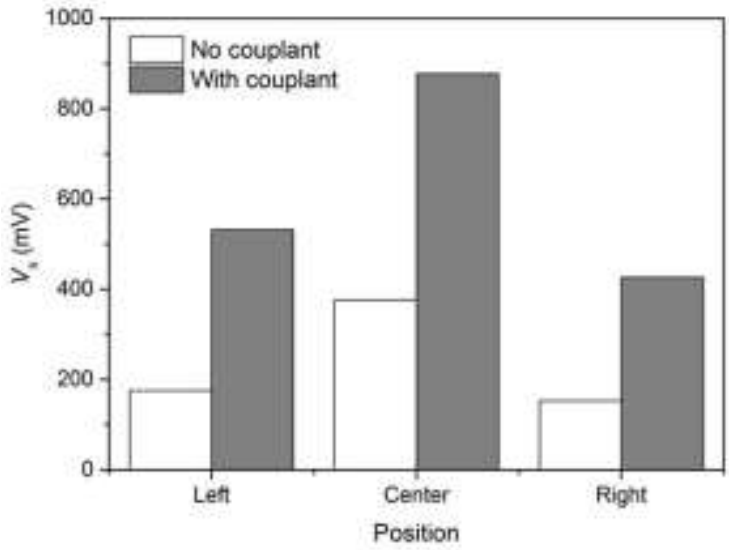

(b)

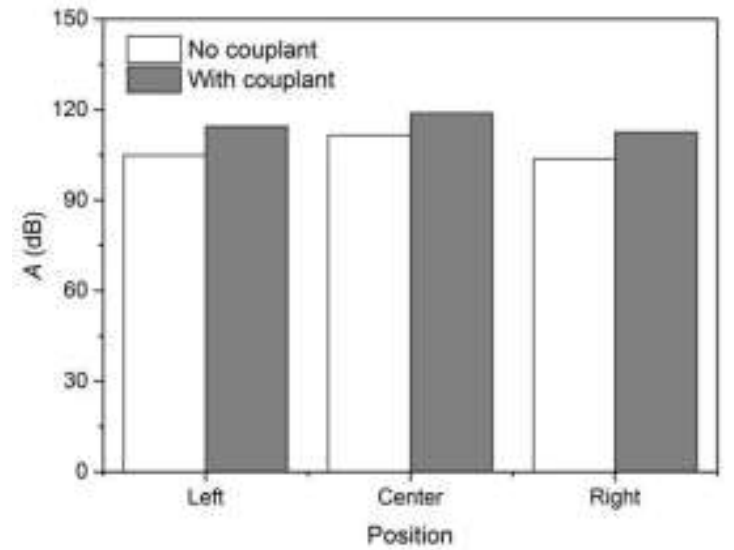

Fig. 3.7: A comparison of AE transient signals measured at different positions for both cases with and without couplant medium, (a) peak voltage $V_{\mathrm{s}}$, and (b) amplitude $A$.

\subsubsection{Effect of indentation position}

Usually the specimen size is much smaller than the AE sensor, i.e., $20 \mathrm{~mm}$ diameter, the detection and sensitivity of the AE signal is strongly dependent on the position of the specimen placed on the surface of the sensor. Hence, it is important to characterize the sensitivity of the AE signal with respect to the different locations of the AE source generated. The investigation is carried out by placing the M31 sensor (pulser) at different positions on the surface of the AE sensor (Fig 3.8), and on the $500 \mu \mathrm{m}$-thick Si die specimen (Fig. 3.9). It is observed that the signal is further attenuated as the position of the pulsar moved away from the centre of the AE sensor or specimen. The AE signals detected at the centre position provide the best $\mathrm{S} / \mathrm{N}$ ratio, for both the cases with and without the Si die (Figs. 3.10). Generally, the improvement of $\mathrm{S} / \mathrm{N}$ ratio is $\sim 60 \%$ for the peak voltage $V_{\mathrm{s}}$ measured (or $\sim 15 \mathrm{~dB}$ ) at the centre of the $\mathrm{AE}$ sensor or specimen as compare to other positions. 
(a)

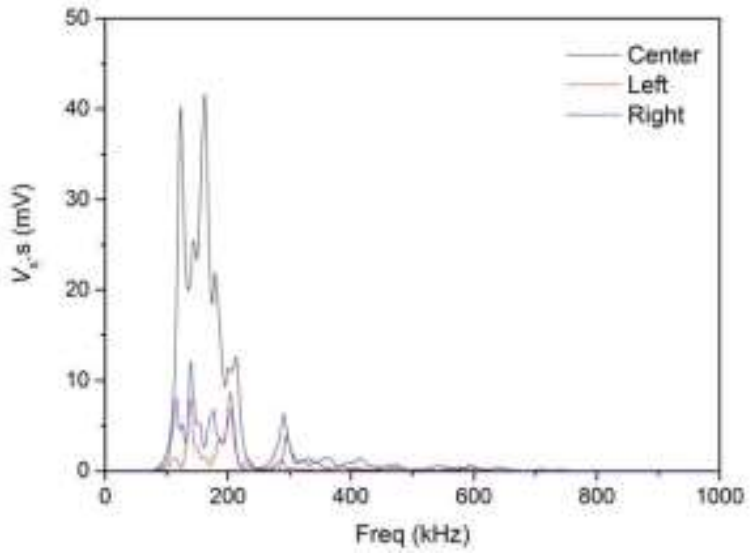

(b)

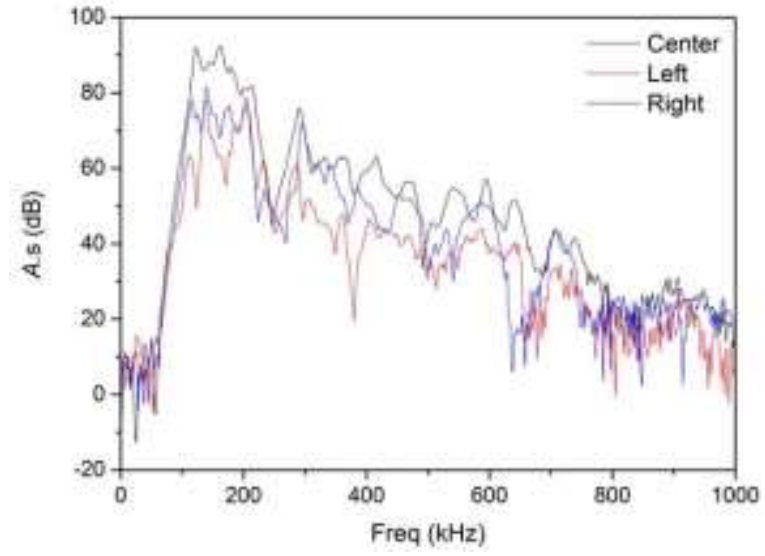

Fig. 3.8: A comparison of AE transient signals measured at different positions on top of the AE sensor: (a) voltage vs frequency waveform, and (b) amplitude vs frequency waveform.

(a)

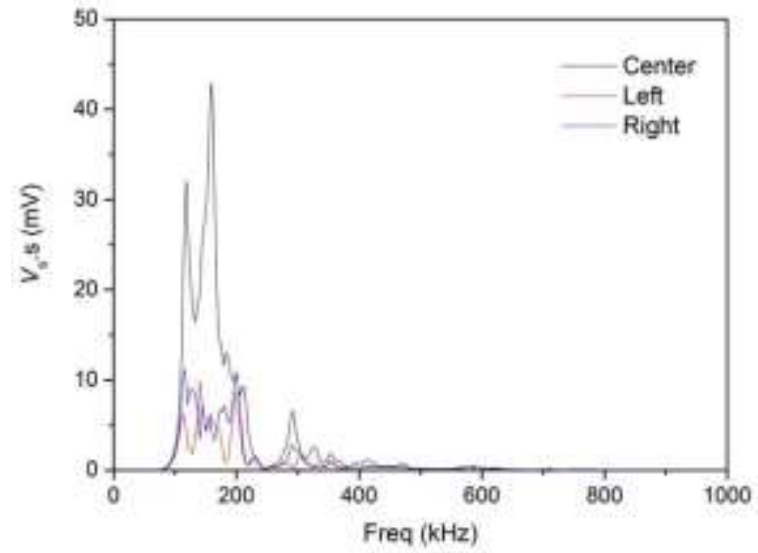

(b)

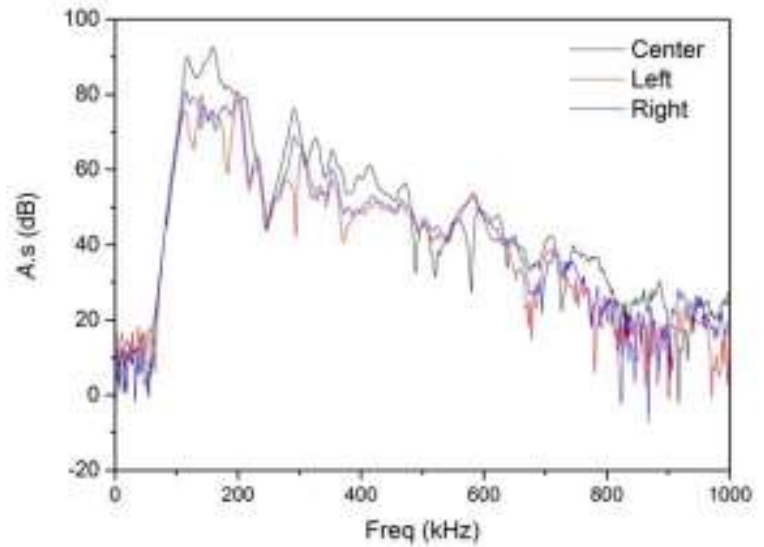

Fig. 3.9: A comparison of AE transient signals measured at different positions on the Si die: (a) voltage vs frequency waveform, and (b) amplitude vs frequency waveform.

\subsubsection{AE threshold setting}

The AE threshold setting is determined by monitoring the continuous signal before, during and after applying a small indentation load on the $500 \mu \mathrm{m}$-thick Si die with a diamond sphero-conical indenter. The maximum indentation load is $0.1 \mathrm{~N}$ and dwells for 
1 min, where no damage will be induced on the Si die. It is found that the maximum background noise recorded is $\sim 57 \mathrm{~dB}$ and this will be defined as the threshold voltage used in the AE testing (Fig. 3.11).

(a)

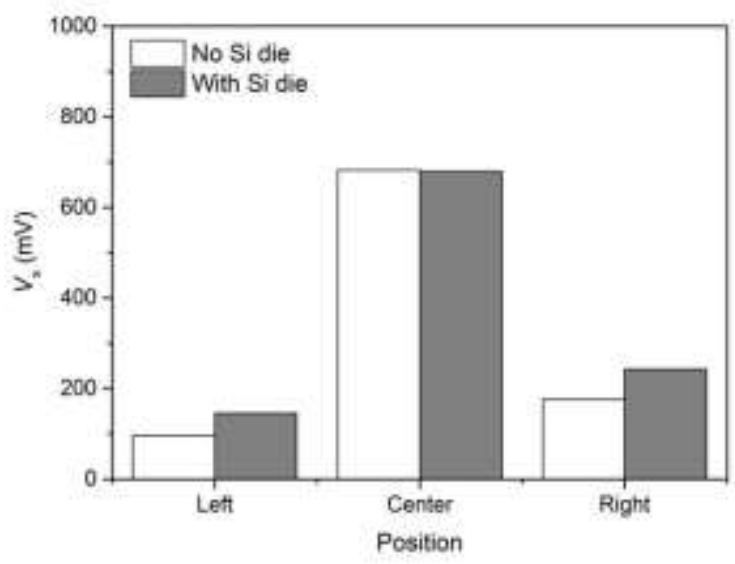

(b)

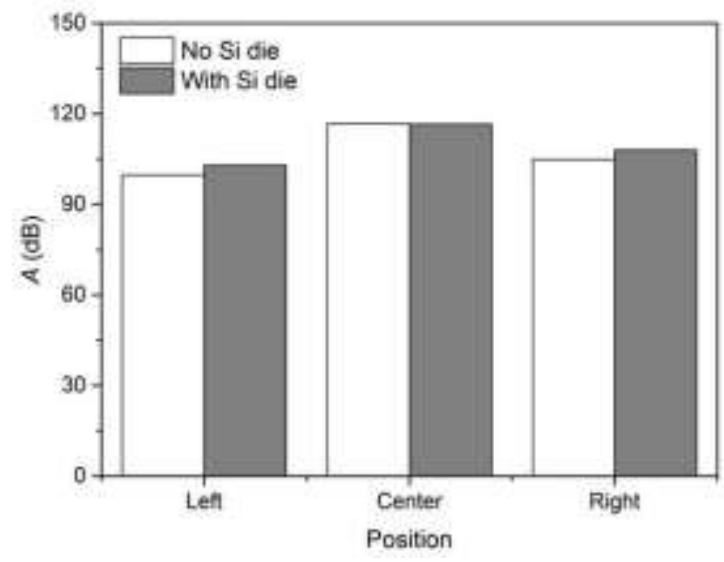

Fig. 3.10: A comparison of $A E$ transient signals measured at different positions for both cases with and without the Si die: (a) peak voltage $V_{\mathrm{s}}$, and (b) amplitude $A$.

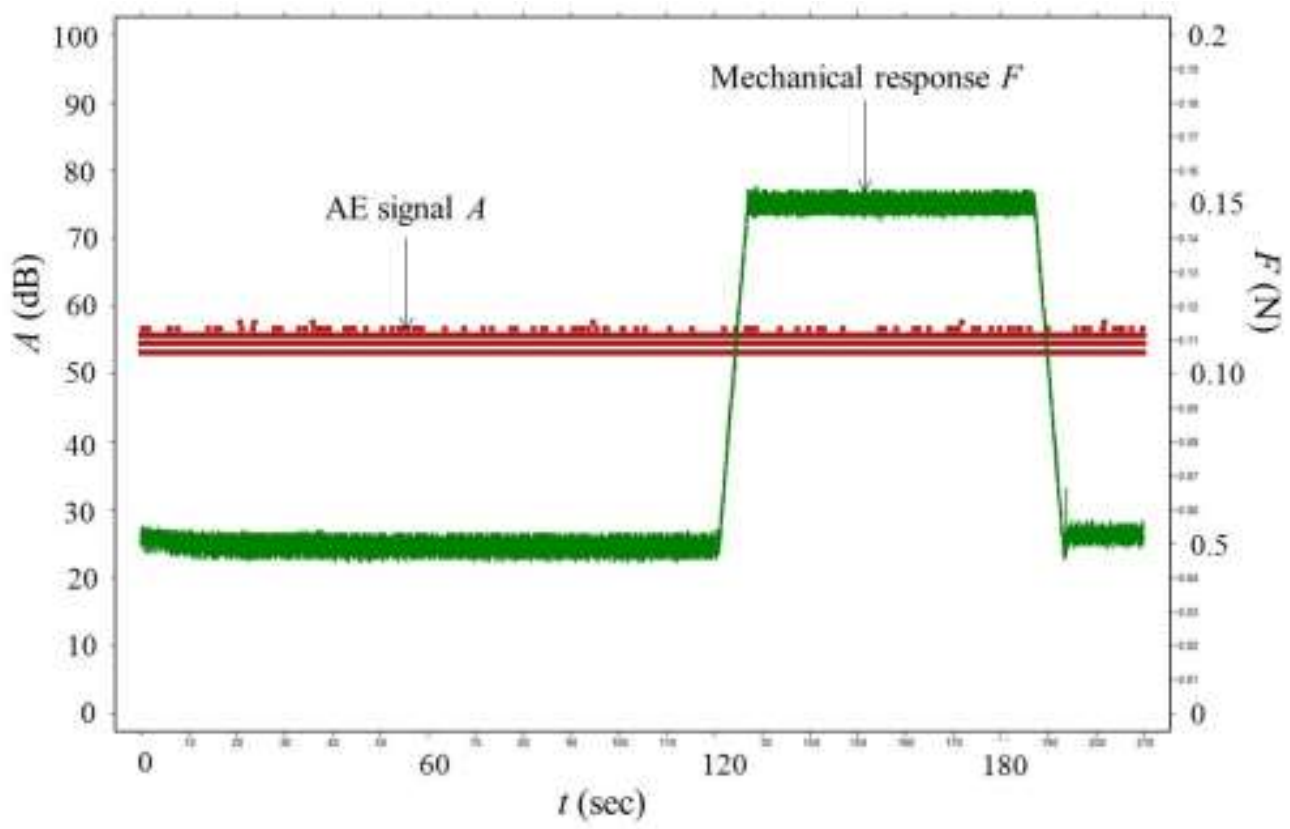

Fig. 3.11: The result of $\mathrm{AE}$ continuous signal monitored throughout the indentation loading and unloading cycle, at the maximum load of $0.1 \mathrm{~N}$ and dwelling for $1 \mathrm{~min}$. 


\subsection{Physical quantities extraction}

The mechanical signal of $F-d$ measurement from the micro-mechanical tester is integrated and synchronized with the AE signals in the Vallen AMSY-6 system. Both the mechanical and AE signals are monitored continuously during the indentation loadingunloading cycle. In addition, an algorithm is developed so that the indentation loading would stop immediately and then retract to its original position, when an $\mathrm{AE}$ event is detected, i.e. above the AE threshold setting. Hence, the determined onset damage parameters can be related to the cracking observed on the specimen.

The AE signal is monitored throughout the loading-unloading cycle, where the transient and continuous data are recorded. The AE parameters like $V_{\mathrm{s}}, A, E_{\mathrm{AE}}, t_{\mathrm{r}}$ and $t_{\mathrm{d}}$ are usually extracted from the transient signal, and plotted together with the mechanical response. The $E_{\mathrm{AE}}$ calculation employed in this work will be based on the so-called true energy mode, and is given in energy units (eu), where $1 \mathrm{eu}=10^{-14} \mathrm{~V}^{2} \mathrm{~s}$ or $10^{-18} \mathrm{~J}$. The $E_{\mathrm{AE}}$ is determined by integrating the square of the digitized $\mathrm{AE}$ signal during the signal duration (Eq. 2.15). In addition, the $F$ and $d$ corresponding to the detected AE event are known as the critical or onset crack force $F_{\mathrm{c}}$ and displacement $d_{\mathrm{c}}$, respectively, if specimen damage or cracking is observed.

\subsection{Summary}

In this chapter, the integration of an instrumented micro-mechanical tester with a piezo-electric AE sensor is presented. The AE pulser test method is used to study the sensitivity of the AE signal during the test set-up, and then optimized for the indentation testing. A nail polish is used as a couplant medium between the AE sensor and specimen, 
where the $S / N$ ratio is found to be improved by $\sim 10 \mathrm{~dB}$. It is observed that the AE signal is attenuated if the position of the pulsar is located away from the centre of the AE sensor. The improvement of the $S / N$ ratio is $\sim 15 \mathrm{~dB}$ when the pulsar is positioned at the centre of the AE sensor or specimen over other locations. Hence, the indentation position on the specimen must be kept within a diameter of $\sim 3 \mathrm{~mm}$ from the centre of the $\mathrm{AE}$ sensor. The preliminary threshold amplitude of $57 \mathrm{~dB}$ is determined, and will be employed in the indentation damage test and evaluated with the actual damage observed. The measurement of the $F$ - $d$ curve in the micro-mechanical tester is synchronized with the $\mathrm{AE}$ signals that are monitored in real time in the Vallen AMSY-6 system during the indentation loading-unloading cycle. 


\section{Chapter 4 Indentation Damage Evaluation of Si Dies}

In this chapter, the Si crystals with the orientations of (100) and (111) are investigated by indentation testing using a diamond sphero-conical indenter. The AE sensor is used to detect any crack occurrence, and the corresponding onset crack force $F_{\mathrm{c}}$ and displacement $d_{\mathrm{c}}$ are recorded. Finally, finite element (FE) simulation is performed, in which the stress analysis and the damage assessment of the $\mathrm{Si}(100)$ die are conducted.

\subsection{Test vehicle preparation}

Both the $\mathrm{Si}$ (100) and (111) wafers evaluated are $100 \mathrm{~mm}$ in diameter and $\sim 600 \mu \mathrm{m}$ in thickness. These wafers are mechanically sawn into a die size of $10 \mathrm{~mm}$ x $10 \mathrm{~mm}$ using a DISCO machine at a feed rate of $20 \mathrm{~mm} / \mathrm{s}$ and a spindle revolution speed of $45000 \mathrm{rpm}$. The Si die is then manually picked from those singulated wafers and placed firmly on the top of the AE sensor coated with the nail polish.

\subsection{Experiment and results}

The measurement procedure of the indentation damage test is presented in Figure 4.1. Before performing the test, a cotton bud dipped in an isopropyl alcohol solution is used to remove any dirt or foreign particle on the tip of the diamond sphero-conical indenter (Fig. 4.2) and the surface of the $\mathrm{AE}$ sensor. A minimum of 30 indentation tests (five indentations per specimen) are performed at a room temperature of $25^{\circ} \mathrm{C}$. After the test, all the indented surfaces of the specimens are inspected by a high-magnification power 
scope. Subsequently, a focus ion beam (FIB) cut is performed and examined with a scanning electron microscopy (SEM) on the indented surfaces of the specimens.

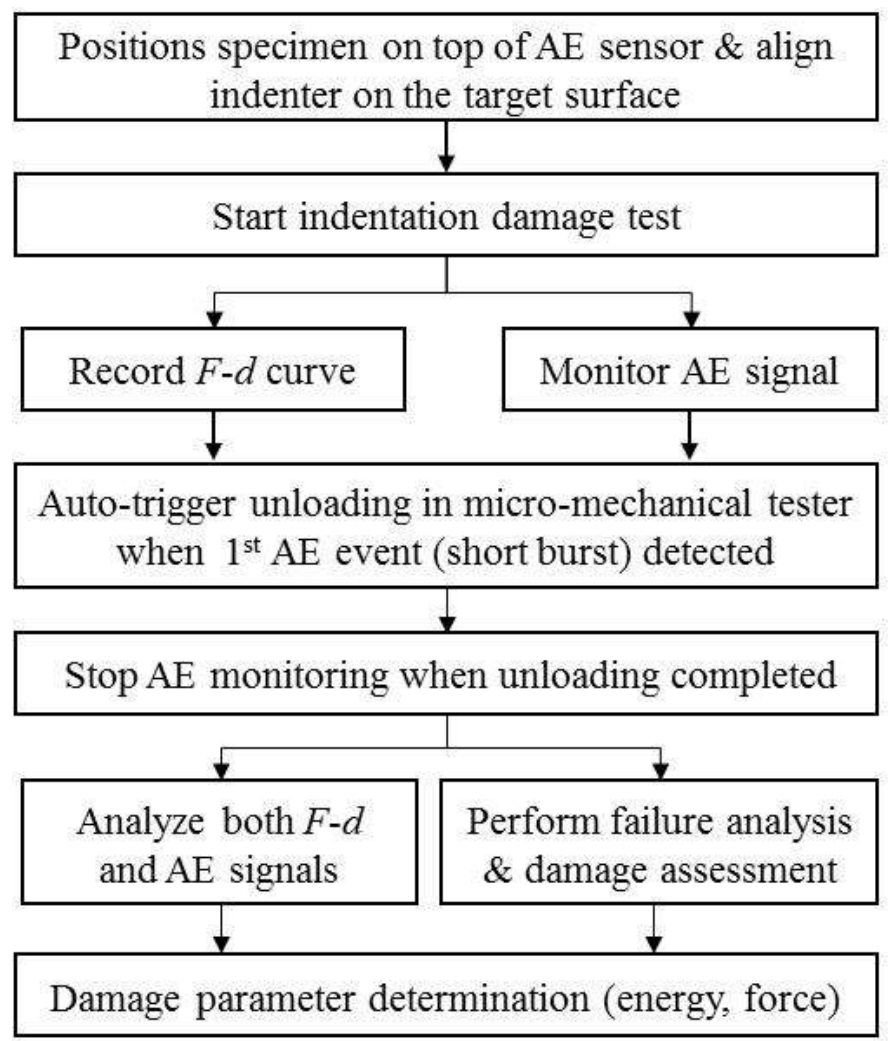

Fig. 4.1: The measurement procedure of the indentation damage test methodology.

(a)

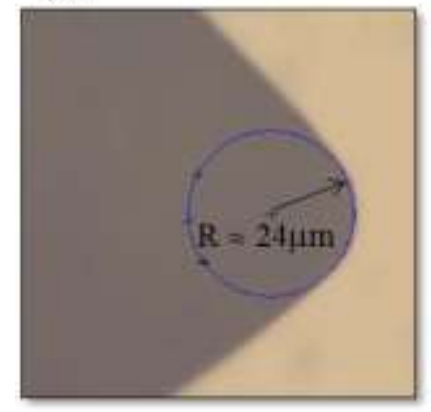

(b)

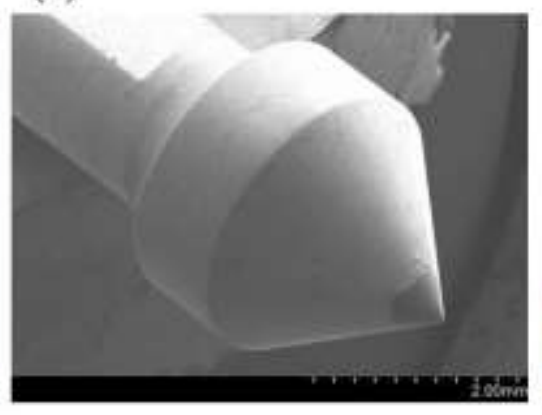

(c)

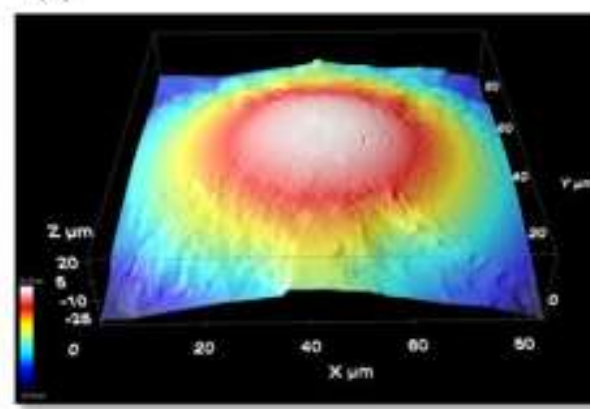

Fig. 4.2: The shape of the sphero-conical indenter: (a) optical imaging, (b) SEM imaging, and (b) surface profiling imaging. 
Different indentation loading (unloading) rates, i.e., $0.1,0.5$ and $1 \mathrm{~N} / \mathrm{min}$, are evaluated for the $\mathrm{Si}(100)$ die. It is found that the measured onset crack force $F_{\mathrm{c}}$ corresponds to the first $\mathrm{AE}$ event or peak voltage $V_{\mathrm{s}}$ is independent of the loading rates. Hence, a loading (unloading) rate of $1 \mathrm{~N} / \mathrm{min}$ will be employed for the subsequent tests.

\subsubsection{Indentation damage test on the $\mathrm{Si}(100)$ die}

During the indentation test of the $\mathrm{Si}(100)$ die specimen, the first $\mathrm{AE}$ event or peak voltage $V_{\mathrm{s}}$ detected corresponds to the plateau or 'pop-in' in the $F-d$ curve at $F_{\mathrm{c}}$ and $d_{\mathrm{c}}$ (Fig 4.3). The AE parameters and the indentation force $F$ are plotted against a common time axis $t$ for a single test (Fig. 4.4). This plateau in the $F$ - $d$ curve is due to the sudden increase in the distance travelled by the indenter when the crack is initiated and propagates till another resistance point is reached (for a force-controlled indentation).

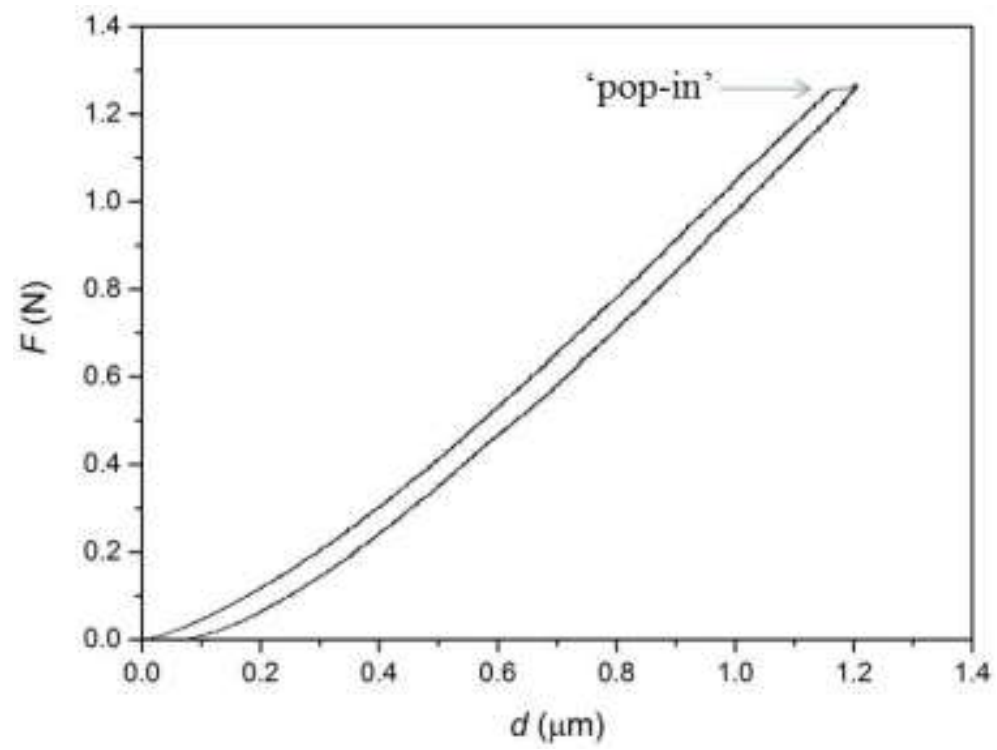

Fig. 4.3: The $F-d$ curve of the $\mathrm{Si}(100)$ die specimen after the indentation damage test. This suggests that the stored strain energy in the specimen as a result of the indentation work is released by the specimen fracture. At this instant, the specimen loses its structural 
integrity and stiffness. In some indents, more than one $\mathrm{AE}$ event is recorded near $F_{\mathrm{c}}$; however no AE event is detected during the unloading stage.

(a)

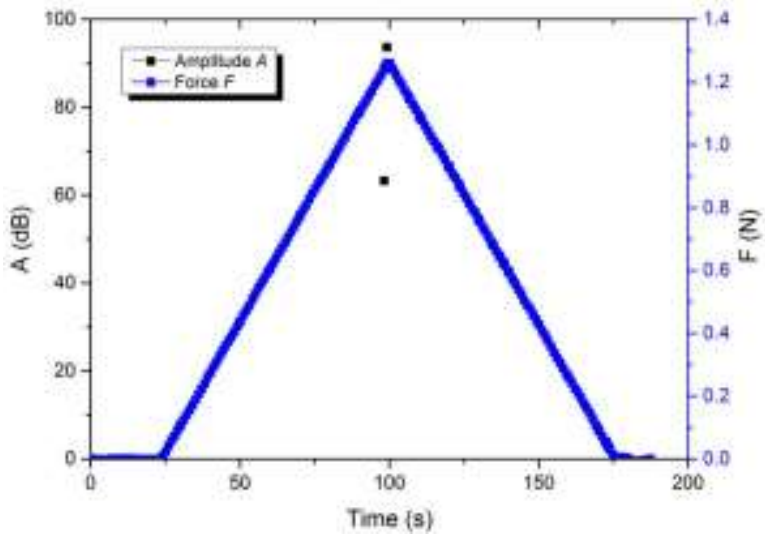

(c)

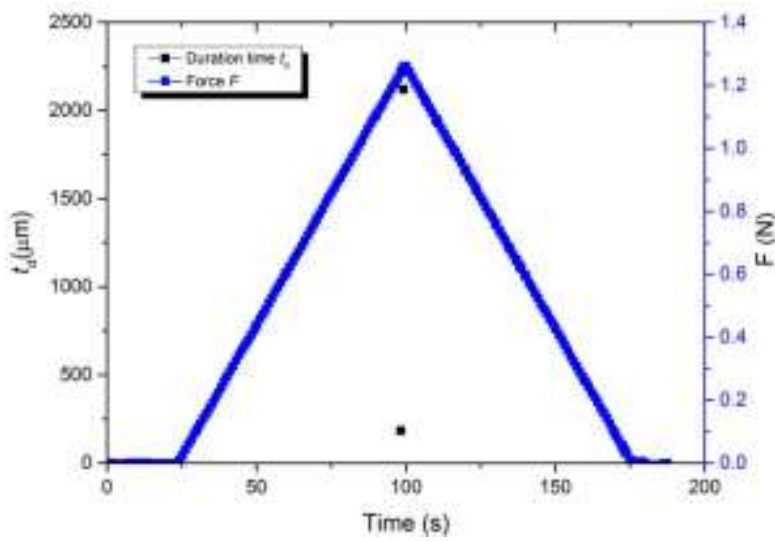

(b)

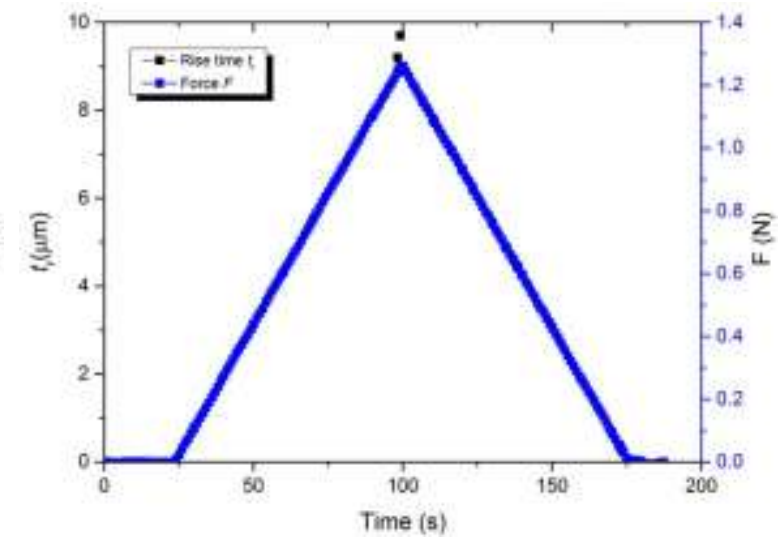

(d)

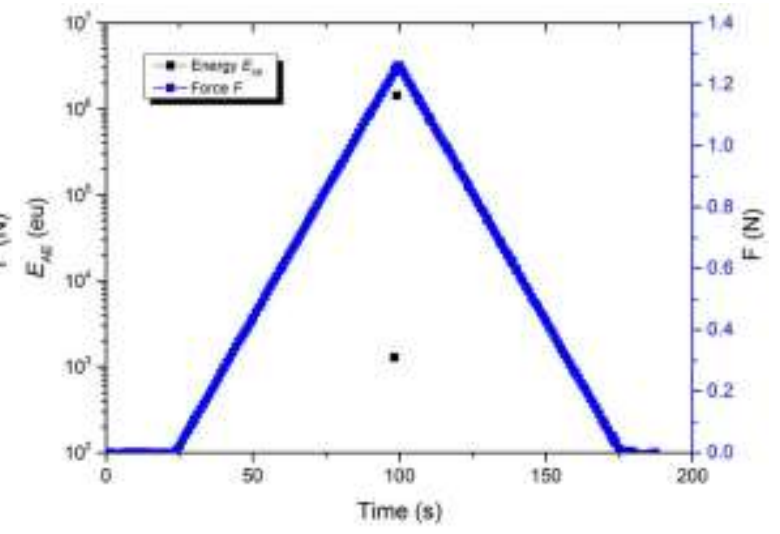

Fig. 4.4: The results of $F$ and AE parameters for the $\mathrm{Si}$ (100) die after the indentation damage test: (a) $A$, (b) $t_{\mathrm{r}}$, (c) $t_{\mathrm{d}}$, and (d) $E_{\mathrm{AE}}$ plotted against $t$.

It is observed that most of the indented surfaces show a residual round mark and/or ring crack, and occasionally radial crack (Fig. 4.5). The sub-surface lateral crack is also observed directly below the indented surface, as shown in Fig. 4.5(b). The multiple AE events that occur near $F_{\mathrm{c}}$ do not show any relations to the failure observation, i.e. number of cracks or crack length. 
(a)

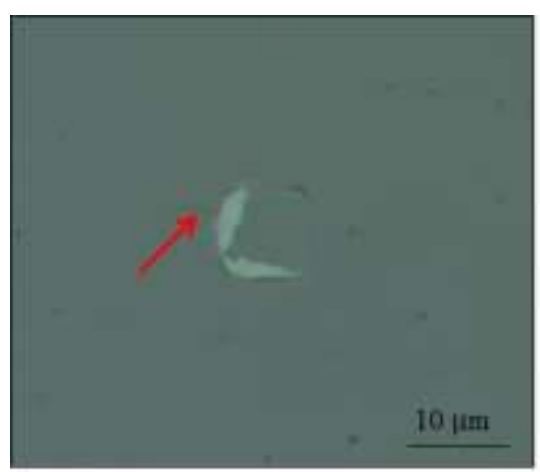

Ring and radial cracks

(b)

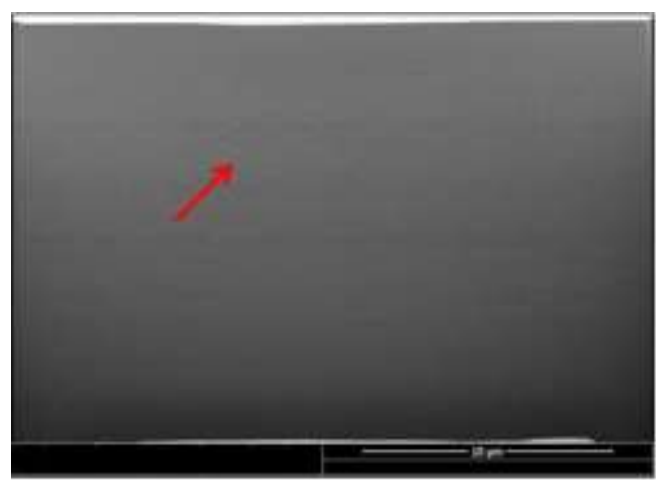

Sub-surface lateral crack

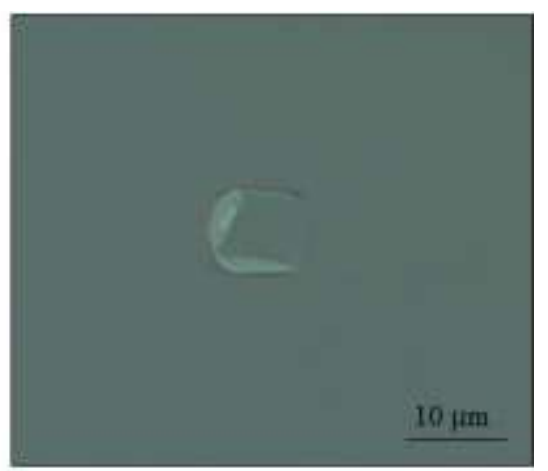

Ring crack only

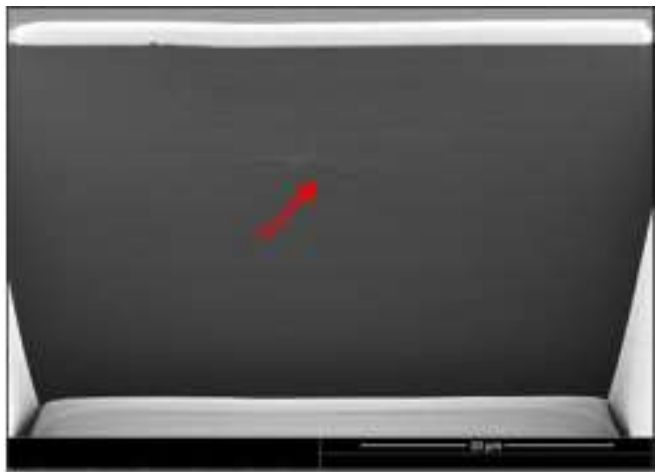

Sub-surface lateral crack

Fig. 4.5: The failure modes of the Si (100) die specimen after the indentation damage test: (a) surface optical images and (b) cross-sectional SEM images.

The mean values of $F_{\mathrm{c}}$ and $d_{\mathrm{c}}$ for the $\mathrm{Si}(100)$ die specimen are $\sim 1.16 \mathrm{~N}$ and $\sim 1.24 \mu \mathrm{m}$, respectively (Fig. 4.6). Further verification test is performed at the maximum indentation load $F_{\mathrm{m}}<F_{\mathrm{c}}, F_{\mathrm{m}}=1 \mathrm{~N}$, to examine for the presence of cracks in the specimen that the AE sensor has failed to detect (Fig. 4.7). As expected, no AE event is detected and no cracking is observed at the $F_{\mathrm{m}}$ loading condition, except for a faded round mark on the indented surface (Fig. 4.8). 
(a)

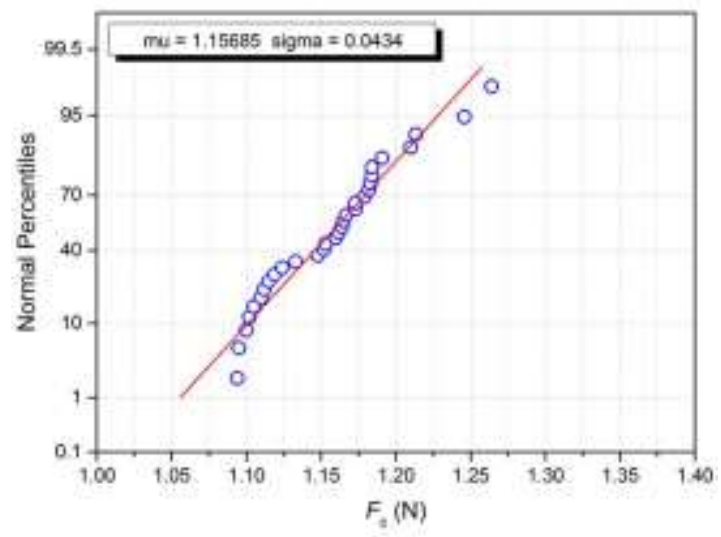

(b)

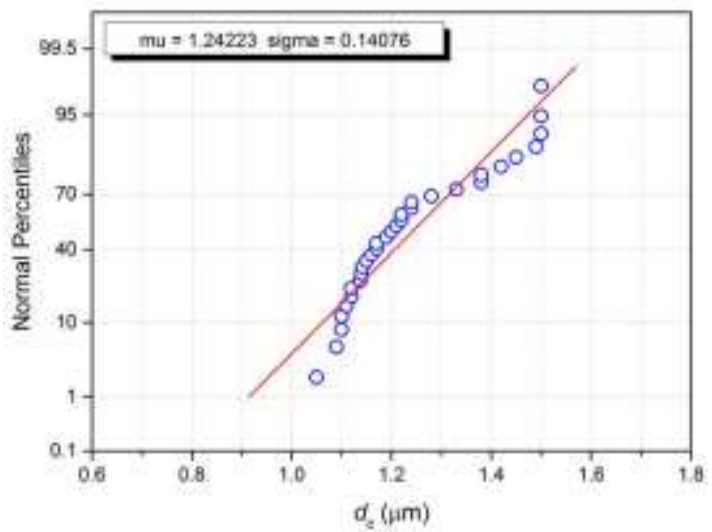

Fig. 4.6: The probability plots for the $\mathrm{Si}(100)$ die specimen: (a) $F_{\mathrm{c}}$, and (b) $d_{\mathrm{c}}$.

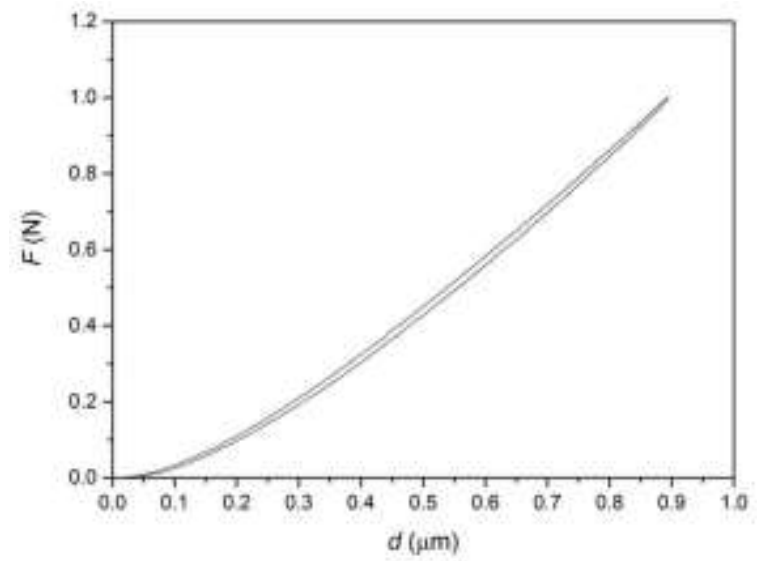

Fig. 4.7: The $F$ - $d$ curve of the $\mathrm{Si}(100)$ die specimen obtained from the indentation verification test $\left(F_{\mathrm{m}}=1 \mathrm{~N}\right)$.

(a)

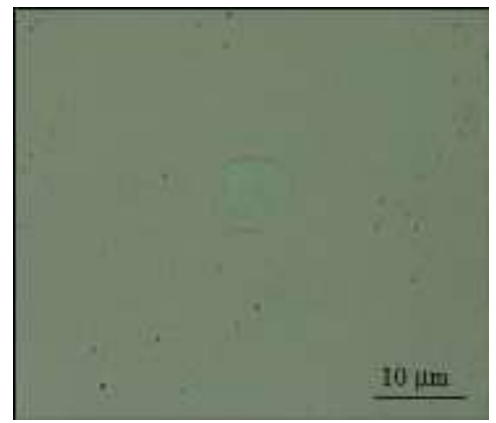

(b)

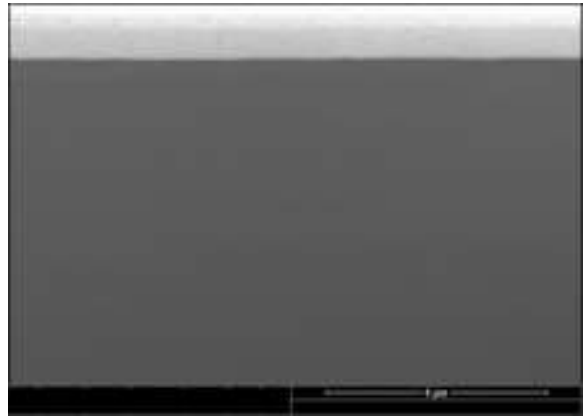

Fig. 4.8: The physical examination of the Si (100) die specimen after the verification test: (a) surface optical images, and (b) cross-sectional SEM images. 
The parameters of the first AE transient signal detected at the loading stage are plotted against $F_{\mathrm{c}}$ as shown in Fig. 4.9. The rise period $t_{\mathrm{r}}$ and duration period $t_{\mathrm{d}}$ of the transient AE signals recorded for all the $\mathrm{Si}(100)$ dies are $7-13 \mu$ s and $60-130 \mu$ s, respectively. It is found that the magnitudes of $A, t_{\mathrm{d}}$, and $E_{\mathrm{AE}}$ increase with $F_{\mathrm{c}}$. However, there is no correlation between this observation and the damage severity due to the difficulty in quantifying the crack length or area.

(a)

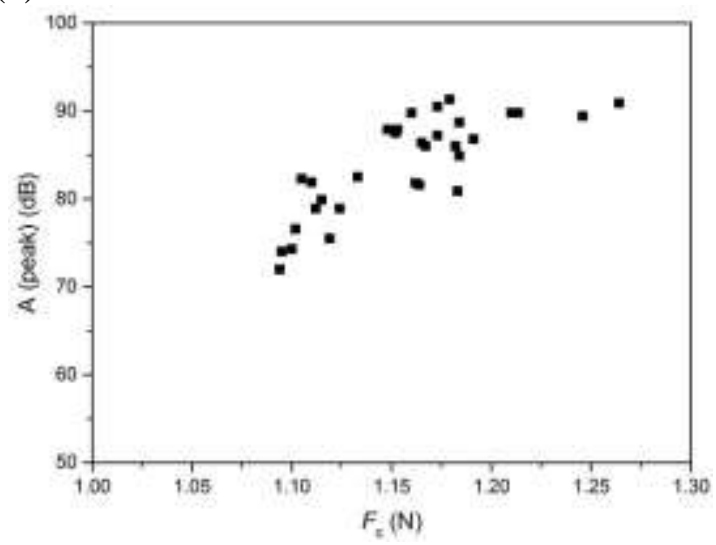

(c)

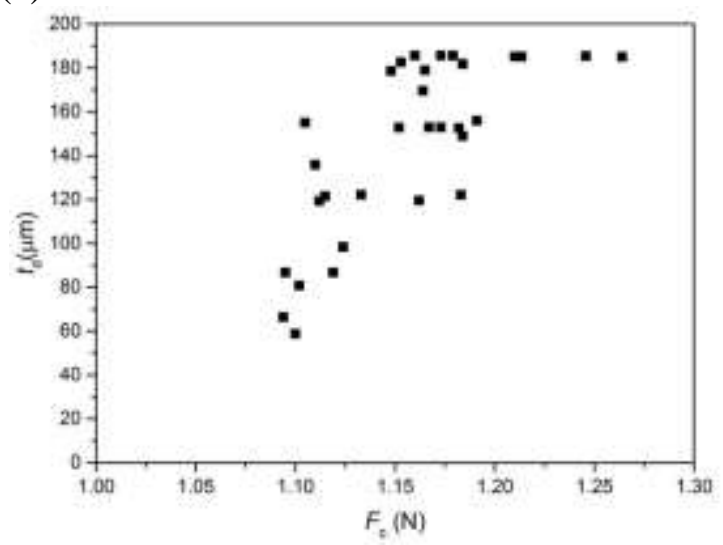

(b)

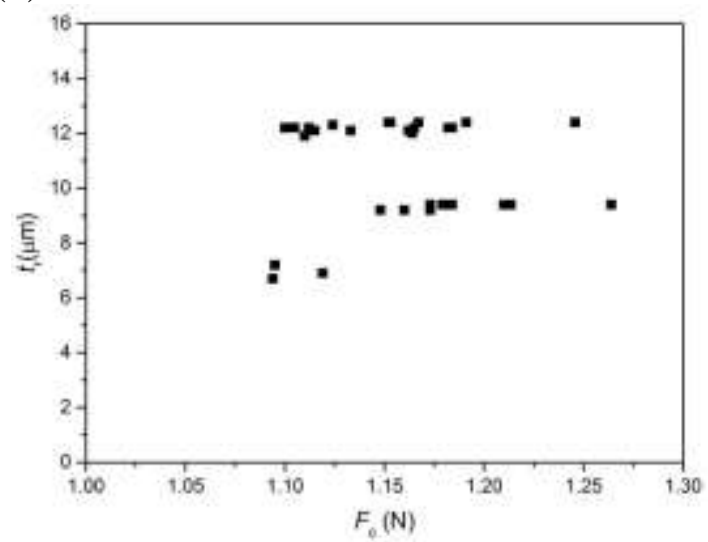

(d)

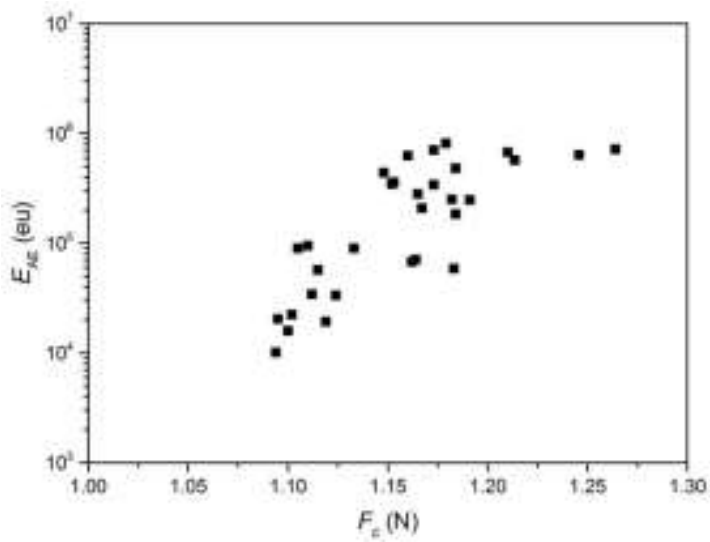

Fig. 4.9: The results of the $\mathrm{AE}$ parameters for the $\mathrm{Si}$ (100) die specimen after the indentation damage test: (a) $A$, (b) $t_{\mathrm{r}}$, (c) $t_{\mathrm{d}}$, and (d) $E_{\mathrm{AE}}$ plotted against $F_{\mathrm{c}}$. 


\subsubsection{Indentation damage test on the Si (111) die}

A 'pop-in' or plateau in the $F-d$ curve is observed when the first AE event or peak voltage $V_{\mathrm{s}}$ is detected during the indentation test on the Si (111) die specimen, and this corresponds to $F_{\mathrm{c}}$ or $d_{\mathrm{c}}$ (Fig. 4.10). The AE parameters and $F$ are plotted against a common time axis $t$ for one of the indents (Fig. 4.11). Similar to the observation of the Si (100) die specimen, this 'pop-in' is due to the sudden increase in the distance travelled by the indenter when the crack is initiated and propagates till another resistance point is reached. It is also observed that more than one $\mathrm{AE}$ event is detected near the $F_{\mathrm{c}}$ similar to that of the Si (100) die.

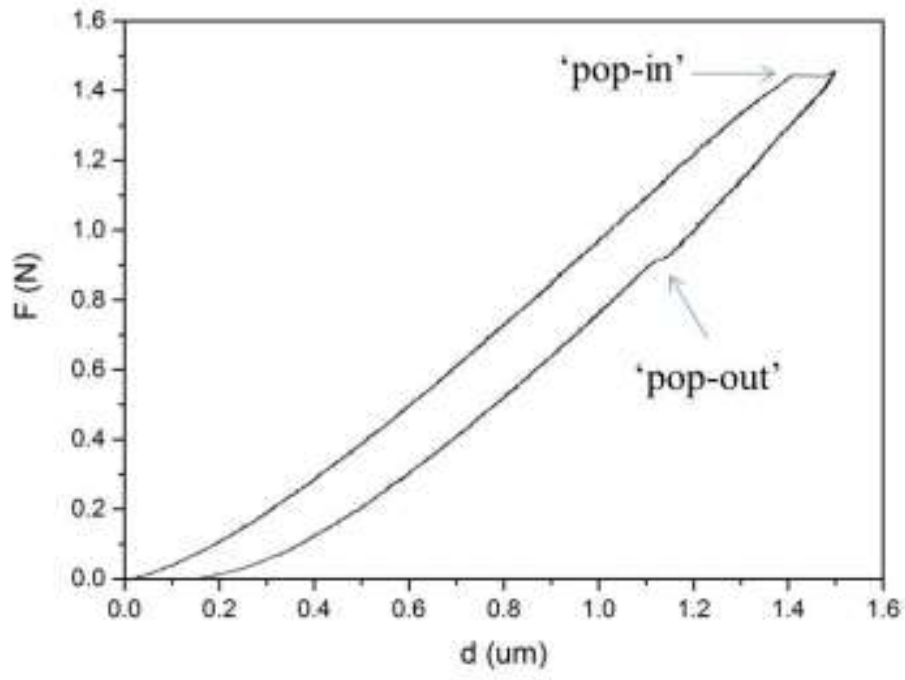

Fig. 4.10: The $F$ - $d$ curve of the Si (111) die specimen after the indentation damage test.

During the unloading stage, a second $\mathrm{AE}$ event is also detected in three of the indentations at a force of $0.05 \sim 0.09 \mathrm{~N}$, and this is not related to the 'pop-out' observed in the unloading $F$ - $d$ curve that happens at $0.8 \sim 1.1 \mathrm{~N}$ (Fig. 4.11). Chang and Zhang reported the "pop-out" observed in the unloading $F-d$ curve using a Berkovich indenter was due to the different evolution processes of the phase transformations in the monocrystalline $\mathrm{Si}$ 
[132]. This transformation occurred from Si-II to Si-III/Si-XII and/or to amorphous phases, thus reducing the volume of the residual Si-II zone. This phenomenon is also observed in the indentation damage test of the Si (111) die specimen, which experiences a higher indentation load and stress, as compared to the $\mathrm{Si}(100)$ die.

(a)

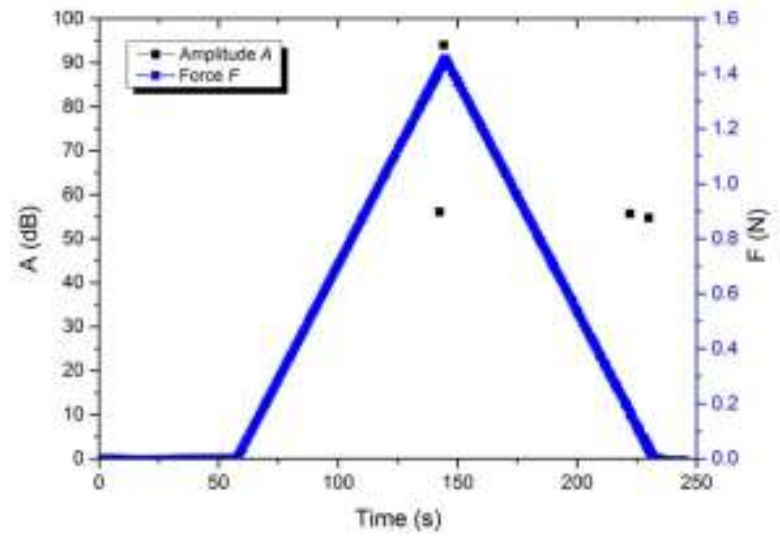

(c)

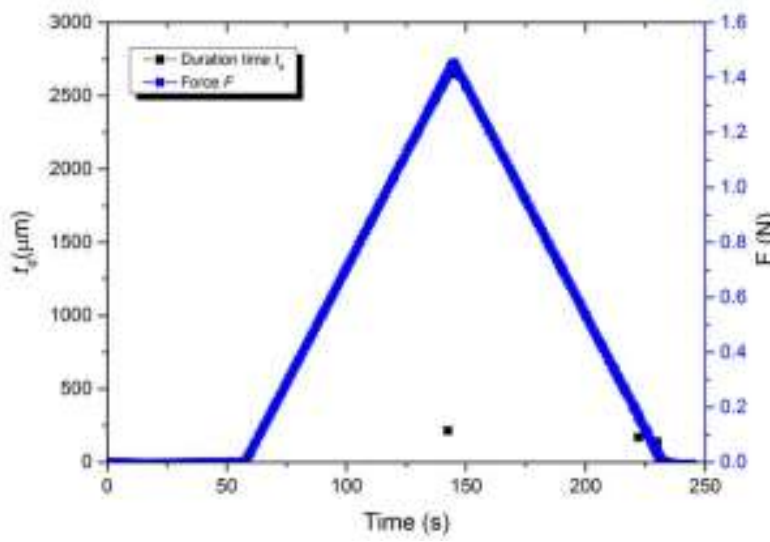

(b)

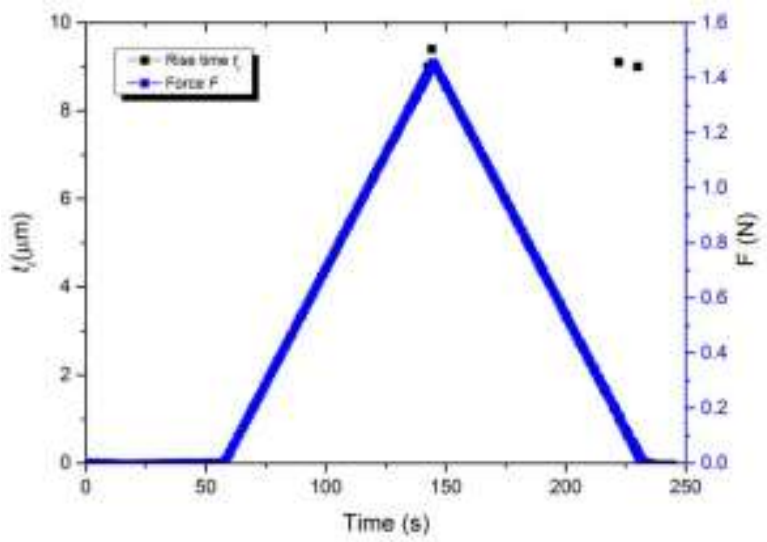

(d)

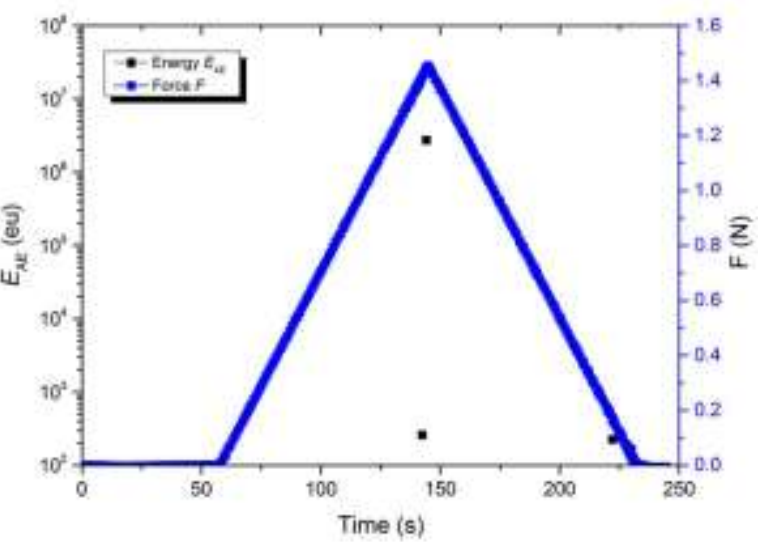

Fig. 4.11: The results of $F$ and AE parameters for the Si (111) die specimen after the indentation damage test: (a) $A$, (b) $t_{\mathrm{r}}$, (c) $t_{\mathrm{d}}$, and (d) $E_{\mathrm{AE}}$ plotted against $t$.

In most of the specimens, a residue round mark with ring and radial cracks is observed on the indented surfaces of the Si (111) die (Figs. 4.12(a) and (b)). Sub-surface lateral and cone cracks are also found directly beneath the indented surface, as shown in the crosssectional analysis (Fig. 4.12(c)). It is found that the severity of the crack is higher than those observed in the Si (100) die. It is highly possible that the AE events recorded during 
the unloading stage are attributed to the sliding of those crack surfaces or/and the chipping of the Si, as observed in Fig. 4.12(b).

(a)

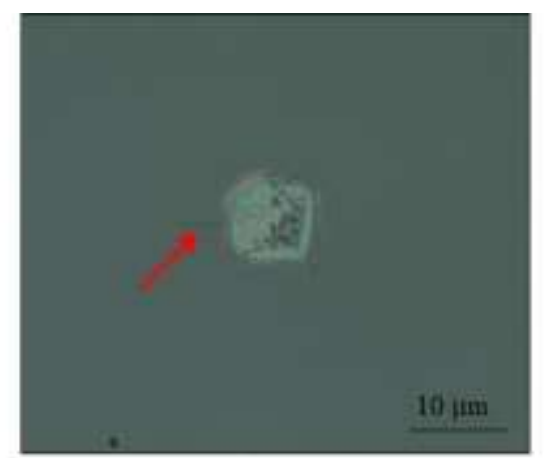

Low values of $F_{\mathrm{c}}$ measured related to single crack-line with shorter length

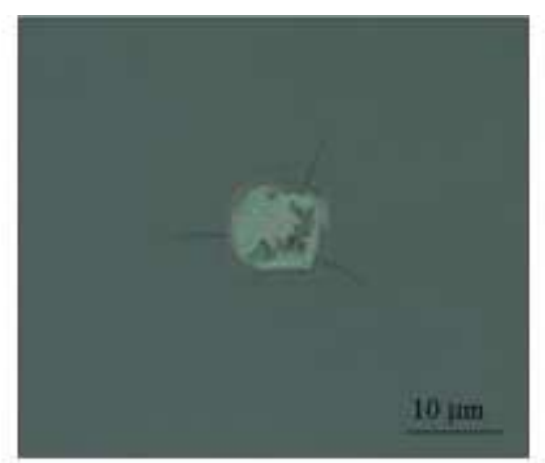

Large value of $F_{\mathrm{c}}$ measured related to multiple crack-line with longer length

(b)

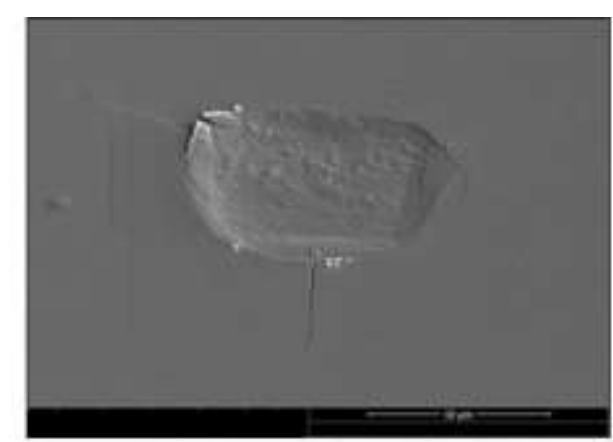

Ring and radial cracking, with Si chip-off

(c)

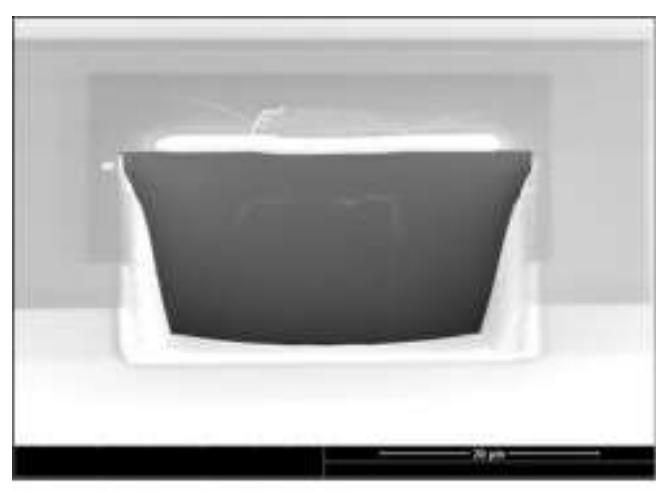

Sub-surface lateral crack

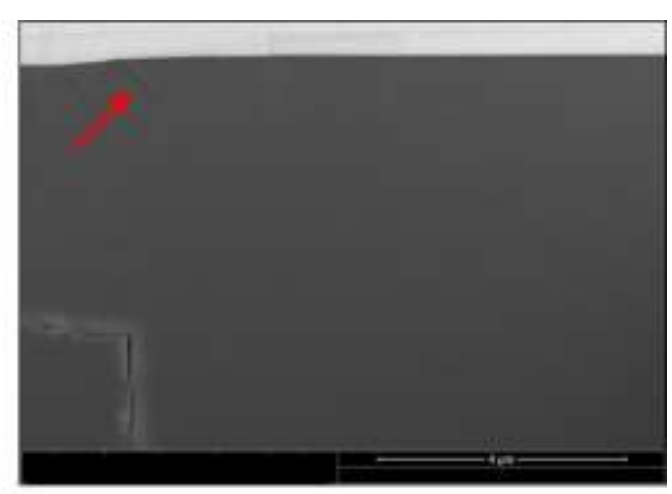

Sub-surface cone crack

Fig. 4.12: The failure modes of the $\mathrm{Si}$ (111) die specimen after the indentation damage test: (a) surface optical imaging, and (b) surface, and (c) cross-sectional SEM imaging. 
The mean values of $F_{\mathrm{c}}$ and $d_{\mathrm{c}}$ for the $\mathrm{Si}(111)$ die are $1.49 \mathrm{~N}$ and $1.47 \mu \mathrm{m}$, respectively (Fig. 4.13). The verification test is then performed at $F_{\mathrm{m}}<F_{\mathrm{c}}$, i.e., $F_{\mathrm{m}}=1.2 \mathrm{~N}$, to examine for any cracking induced in the specimen that the AE sensor has failed to detect (Fig. 4.14). There is no AE event detected and cracking at the $F_{\mathrm{m}}$ loading condition, except for a faded round mark on the indented surface (Fig. 4.15).

(a)

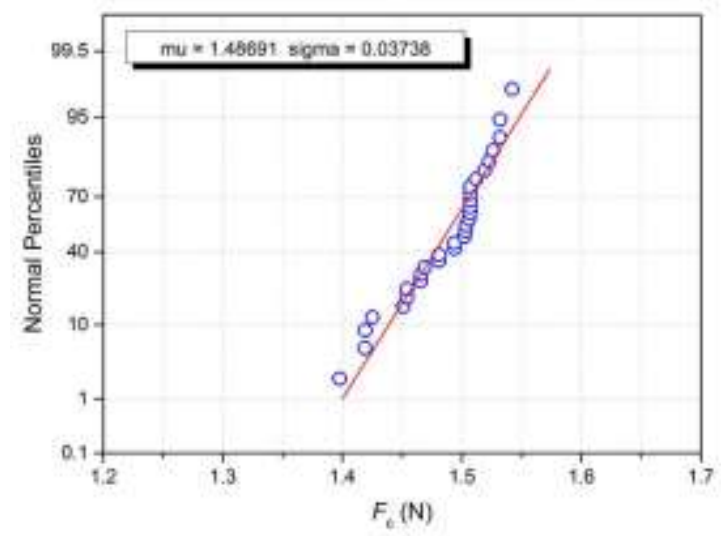

(b)

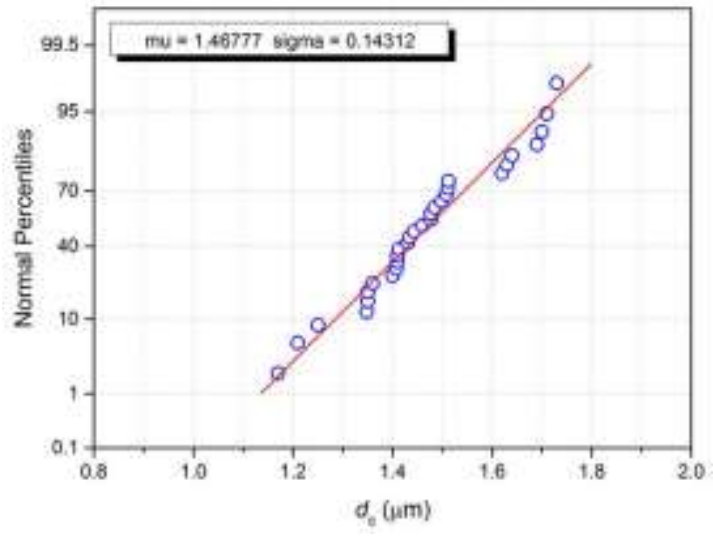

Fig. 4.13: The probability plots of the $\mathrm{Si}(111)$ die specimen: (a) $F_{\mathrm{c}}$, and (b) $d_{\mathrm{c}}$.

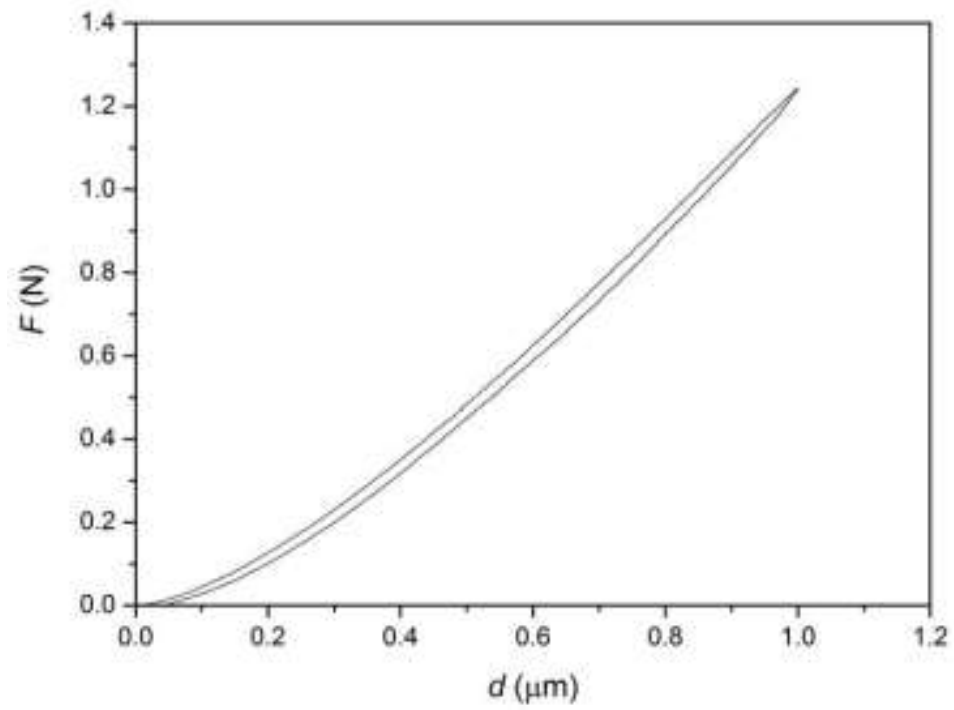

Fig. 4.14: The $F$ - $d$ curve of the $\mathrm{Si}(111)$ die specimen obtained from the indentation verification test $\left(F_{\mathrm{m}}=1.2 \mathrm{~N}\right)$. 
(a)

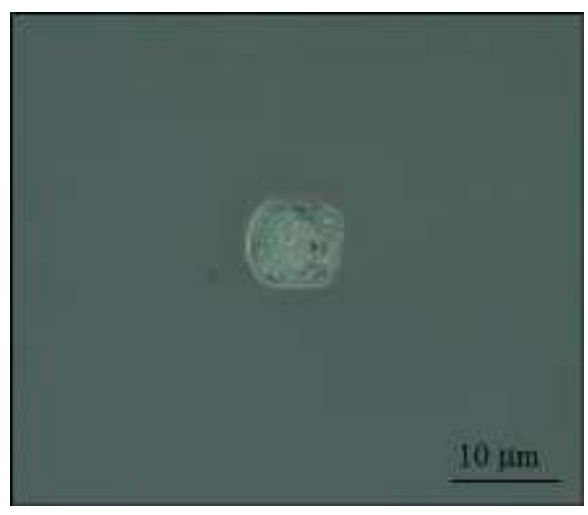

(b)

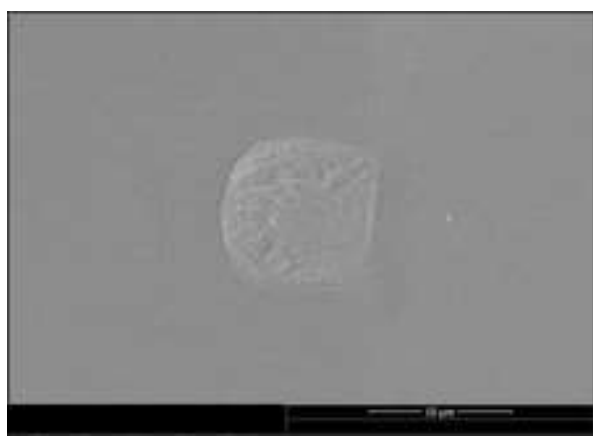

(c)

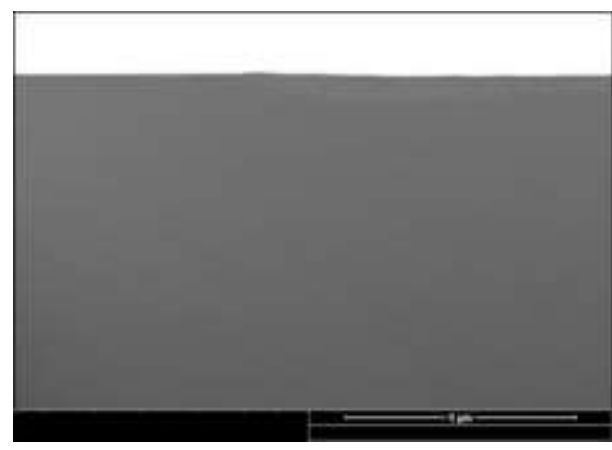

Fig. 4.15: The physical examination of the $\mathrm{Si}$ (111) die specimen after the verification test: (a) surface optical images, (b) surface and (c) cross-sectional SEM images.

The AE parameters of the first AE event or transient signal detected at the loading stage are plotted against $F_{\mathrm{c}}$, as shown in Fig. 4.16. It is observed that $A$ and $E_{\mathrm{AE}}$ increase with $F_{\mathrm{c}}$, The rise time $t_{\mathrm{r}}$ is comparable to that of the $\mathrm{Si}(100)$ die $(6-13 \mu \mathrm{s})$; however there are three indents recorded a duration time $t_{\mathrm{d}}>2500 \mu \mathrm{s}$. This suggests that the larger $t_{\mathrm{d}}$ is most likely due to the multiple AE signals from the cracking, recorded between the first and last threshold crossings at the $F_{\mathrm{c}}$. Furthermore, the multiple AE events or signals observed in the Si (111) die could be related to the several radial cracks and/or larger crack length observed in those specimens with higher $F_{\mathrm{c}}$ (Fig. 4.12). 
Generally, the $\mathrm{Si}$ (111) die records larger values of $F_{\mathrm{c}}, A$ and $E_{\mathrm{AE}}$ than the $\mathrm{Si}$ (100) die, and also has a higher severity of radial cracking during the indentation damage tests.

(a)

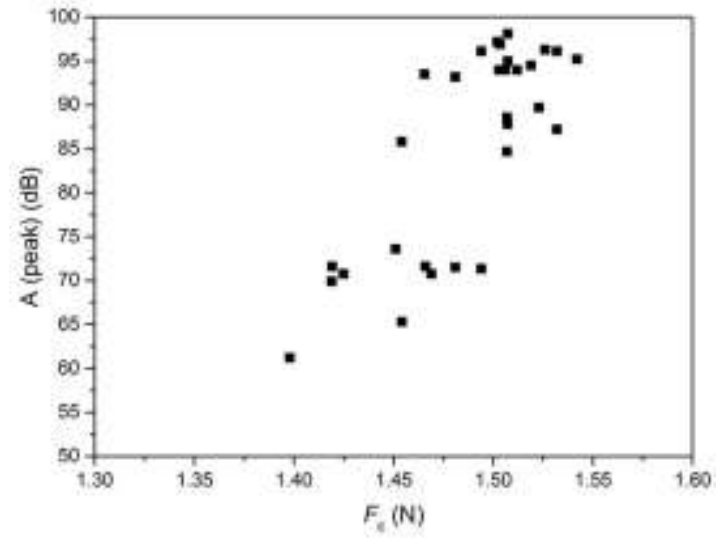

(c)

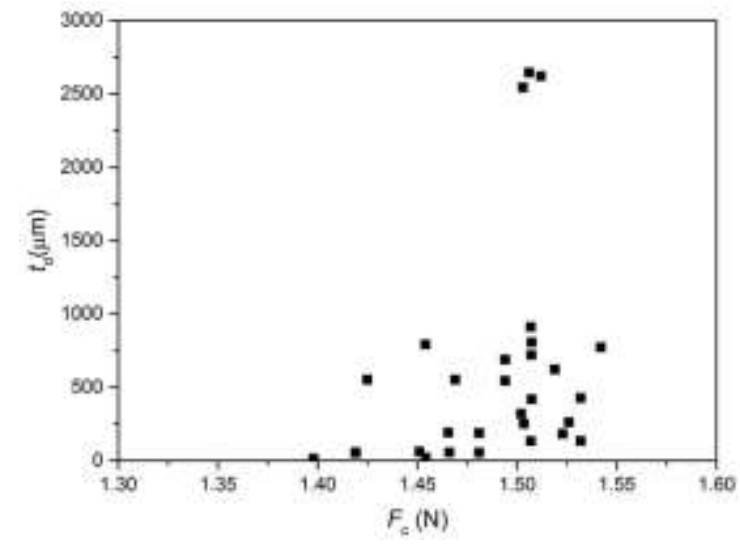

(b)

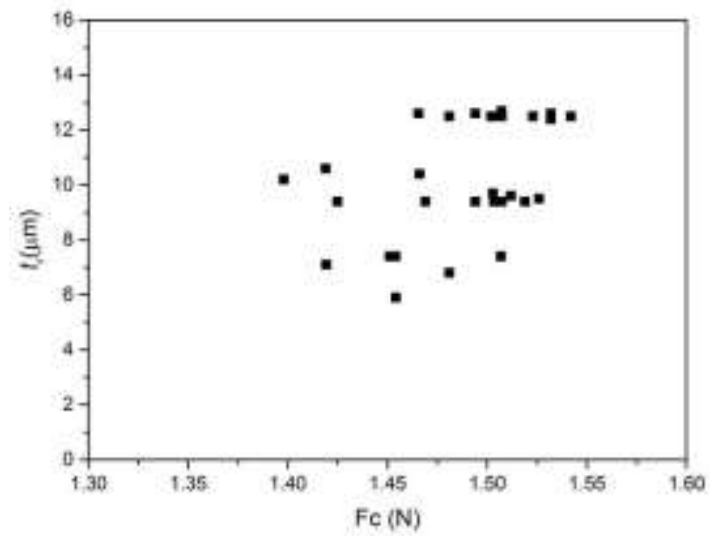

(d)

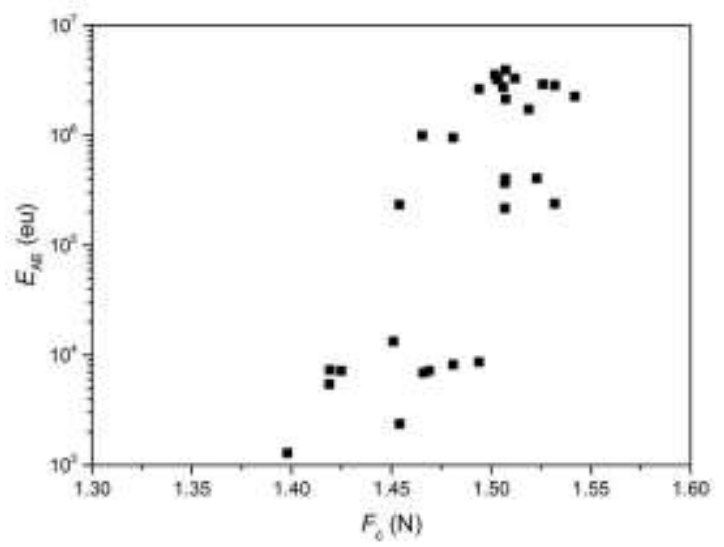

Fig. 4.16: The results of AE parameters for the $\mathrm{Si}$ (111) die specimen after the indentation damage test: (a) $A$, (b) $t_{\mathrm{r}}$, (c) $t_{\mathrm{d}}$, and (d) $E_{\mathrm{AE}}$ plotted against $F_{\mathrm{c}}$.

\subsection{Finite element modelling and simulation results}

An FE software ANSYS ${ }^{\circledR}$ is used to model the indentation test in a quasi-static approach without considering the time effect. The indentation loading-unloading process is simulated with a $50 \mu \mathrm{m}$-diameter sphero-conical diamond tip indenting on the surface of the Si (100) dies. The actual specimens have the dimensions of $10 \times 10 \mathrm{~mm}^{2}$ in the 
horizontal indentation plane. In the modelling, the dimensions of the model are set to be $500 \times 500 \mu \mathrm{m}^{2}$ such that the length is ten times as large as the diameter of the indenter for computational efficiency without influencing the results.

The diamond indenter is modelled as a linear-elastic behavior, where the elastic modulus $E$ and the Poisson's ratio $v$ are $1141 \mathrm{GPa}$ and 0.07 , respectively [52]. The indentation modulus $E_{\mathrm{IT}}$ and hardness $H_{\mathrm{IT}}$ determined experimentally are used to model the isotropic elastic-plastic behavior of the Si die, and assuming $v=0.28$ [133]. The yield strength $Y$ is related to the hardness $H$; for example, the relationship $Y \approx H / 3$ has been commonly used for most materials [53]. The tangent modulus that defines the slope of the stress-strain curve above the elastic proportional limit is given by $E_{\mathrm{t}}=a E$, where $a$ is the empirical strain hardening constant and is used to describe the hardening of the material (Fig. 4.17). For most practical materials, the parameter $a$ is usually in the range of $0 \sim 0.1$ [134]. If $a=0$, the material will be modelled as elastic-perfectly plastic. In this study, $a=$ 0.1 is assumed for the Si die. The frictional effect is not considered between the surfaces of the sphero-conical indenter and the specimen, as the contact friction will not have significant effect on the $F-d$ curve result [135].

A three-dimensional (3D) quarter model is built using the solid (SOLID185) and contact pair (TARGE170 and CONTA173) elements, with the applied boundary and displacement loading conditions (Fig. 4.18). The nodes at the symmetric axis ( $x=0$ and $z$ $=0$ ) can only move vertically and all the nodes at the bottom of the structure are fixed. The meshing density with a minimum mesh size of $0.3 \mu \mathrm{m}$ is selected to optimize computing efficiency and data output quality. 


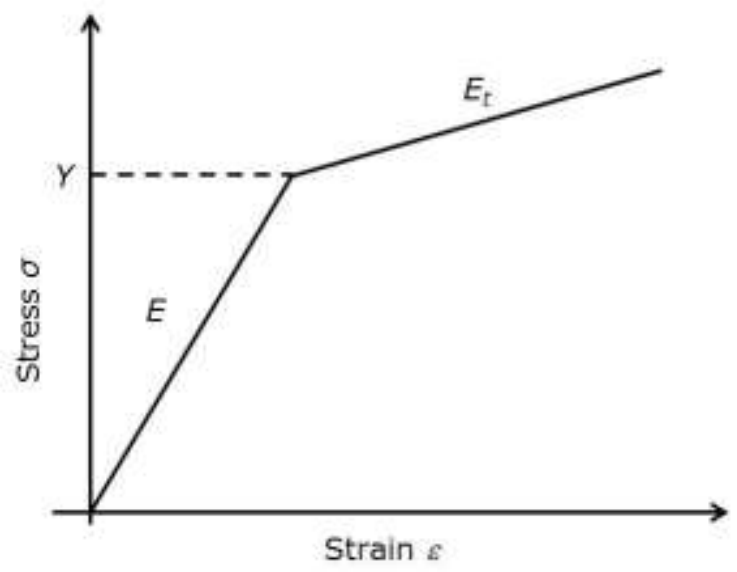

Fig. 4.17: The bilinear stress-strain curve for elastic-plastic material modelling.
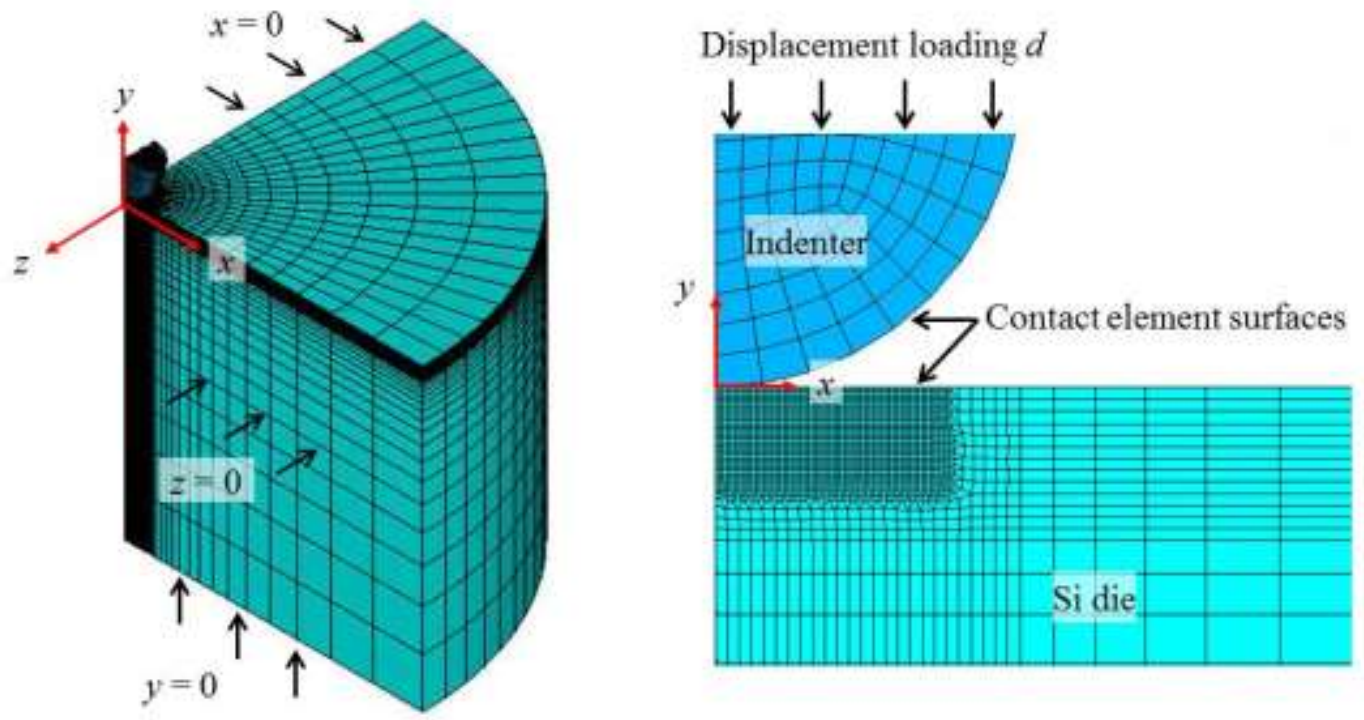

Fig. 4.18: The FE model of the indentation test on the Si die.

\subsubsection{Indentation hardness and modulus}

The $H_{\mathrm{IT}}$ and $E_{\mathrm{IT}}$ are determined from the verification test results $\left(F_{\mathrm{m},}=0.6,0.8\right.$ and 1 N) for the $\mathrm{Si}$ (100) die (Fig. 4.19). The $H_{\mathrm{IT}}$ of $\mathrm{Si}$ is determined from the maximum force $F_{\mathrm{m}}$ and the corresponding projected contact area:

$$
H_{\mathrm{IT}}=\frac{F_{m}}{2 \pi R d_{\mathrm{m}}}
$$


where $R$ is the indenter radius and $d_{\mathrm{m}}$ is the contact depth at $F_{\mathrm{m}}$. The effective modulus $E_{\text {eff }}$ that accounts for the elastic deformation of both the diamond indenter and the Si die is calculated by

$$
E_{\mathrm{eff}}=\frac{S}{2} \sqrt{\frac{1}{2 R d_{\mathrm{m}}}},
$$

where $S$ is the contact stiffness. The $E_{\mathrm{IT}}$ of the Si die is then obtained by

$$
\frac{1}{E_{e f f}}=\frac{1-v^{2}}{E_{I T}}+\frac{1-v_{i}^{2}}{E_{i}}
$$

where $v_{i}$ and $E_{i}$ are the Poisson's ratio and elastic modulus of the diamond tip, respectively.

(a)

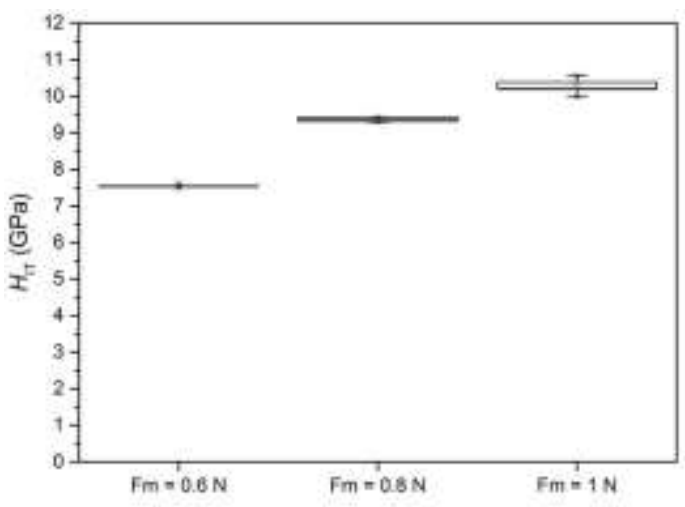

(b)

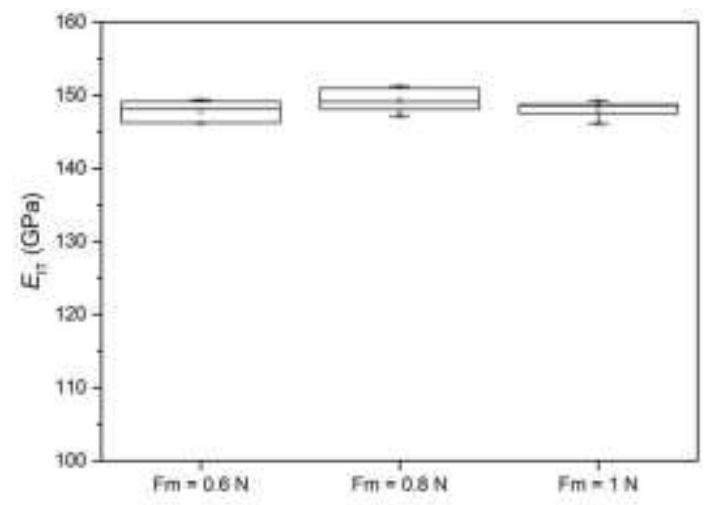

Fig. 4.19: The experimental results of (a) $H_{\mathrm{IT}}$, and (b) $E_{\mathrm{IT}}$ for the $\mathrm{Si}$ (100) die.

It is observed that $H_{\mathrm{IT}}$ increases with $F_{\mathrm{m}}$ due to the changing stress field condition under a spherical indentation as compared to a sharp tip indentation such as the Vickers or Berkovich indenter, under which the stress field remains constant. The $E_{\mathrm{IT}}$ of Si (100) is $\sim 150 \mathrm{MPa}$ and is found to be independent of the test conditions, as the elasticity of the material is characterized by the unloading stage of the indentation. 


\subsubsection{Stress analysis and damage assessment}

During the simulation of the indentation loading process, the load corresponding to the applied displacement $d$ is defined by the resistive force of the rigid indenter, which is also equivalent to the sum of the reaction forces at the bottom nodes of the specimen. The simulation of the unloading process is performed by returning the applied indenter to its original position by controlling the indenter depth or displacement. The $F-d$ of the indenter is then used to represent the material system response.

The simulation results of the $F-d$ curve are compared with the experimental results of the Si (100) die at a loading condition $d_{\mathrm{c}}=1.2 \mu \mathrm{m}$ (Fig. 4.6). It is observed that a good fitting is obtained between the simulation and experimental results of the $F-d$ curve for $Y$ $\approx 7.3 \mathrm{GPa}\left(Y=H_{\mathrm{IT}} / 1.5\right)$, which is close to the data published in [133, 136-137] (Fig 4.20). The calculated $F_{\mathrm{c}}=1.14 \mathrm{~N}$ is within the experimental results of $1.1-1.3 \mathrm{~N}$.

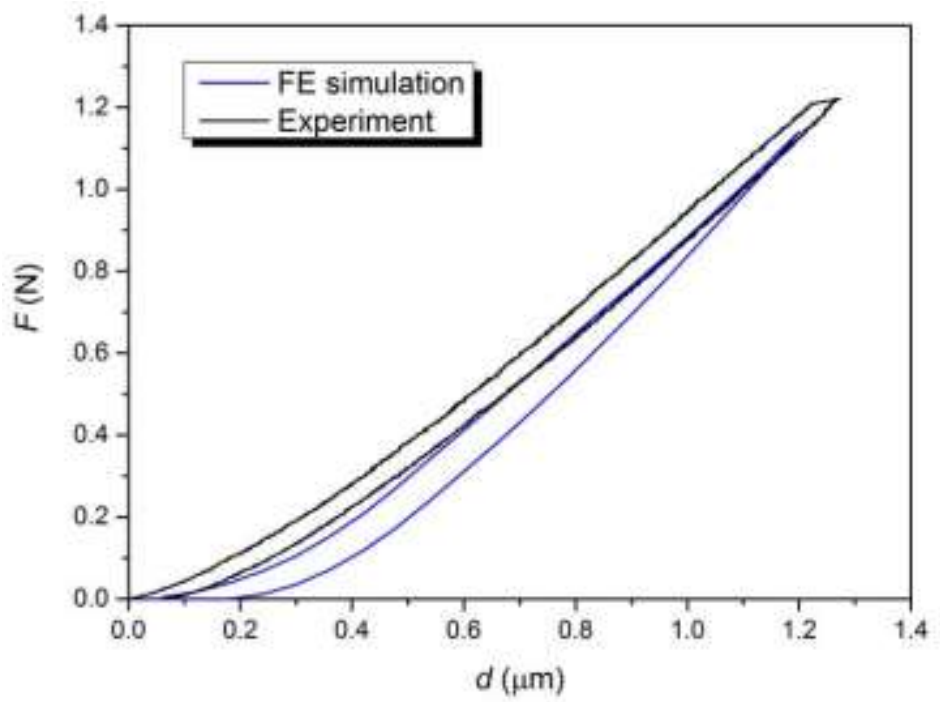

Fig. 4.20: The comparison of the experimental and modelling results for the $1.2-\mu \mathrm{m}$ indentation test on the Si die. 
The FE modelling results show that the maximum principal stress component $\sigma_{1}$ occurs at the region $\mathrm{A}$, which is located within the area outside the indentation contact surface (Fig. 4.21(a)). The region A corresponds to somewhere within the radial crack location as observed in Fig. 4.5a. It is conjectured that the maximum tensile stress in region A initiates a mode-I crack, which is then driven by the indentation loading to form the radial crack. The maximum shear stress component $\tau_{13}=0.5\left(\sigma_{1}-\sigma_{3}\right)$ occurs at regions $\mathrm{B}$ and $\mathrm{C}$, which are located round the perimeter of the indentation contact surface and $\sim 3 \mu \mathrm{m}$ below the surface of the Si die, respectively (Fig. 4.21b). In the SEM imaging, regions B and $\mathrm{C}$ correspond to somewhere within the ring and sub-surface lateral cracks, respectively (Fig. 4.5). This infers that the maximum shear stress regions at regions B and $\mathrm{C}$ are able to initiate a mode-II crack, which then propagates to form the ring and lateral cracks under the indentation loading, respectively.

(a)

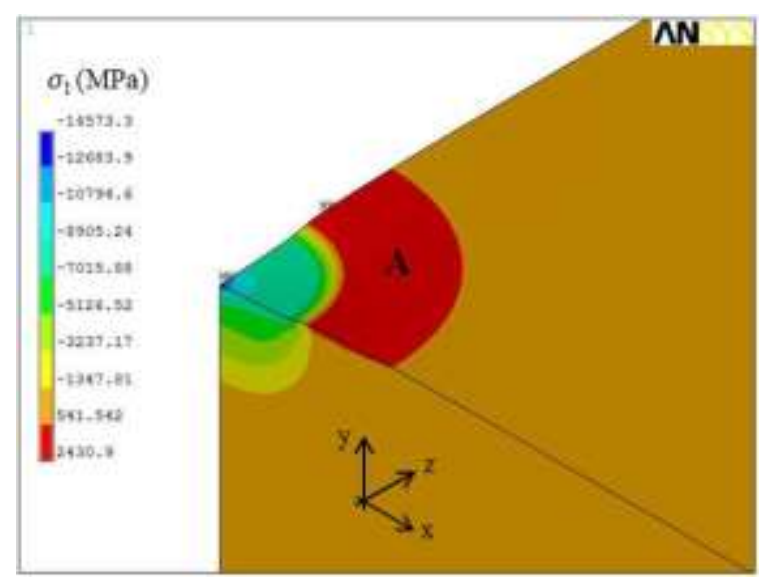

(b)

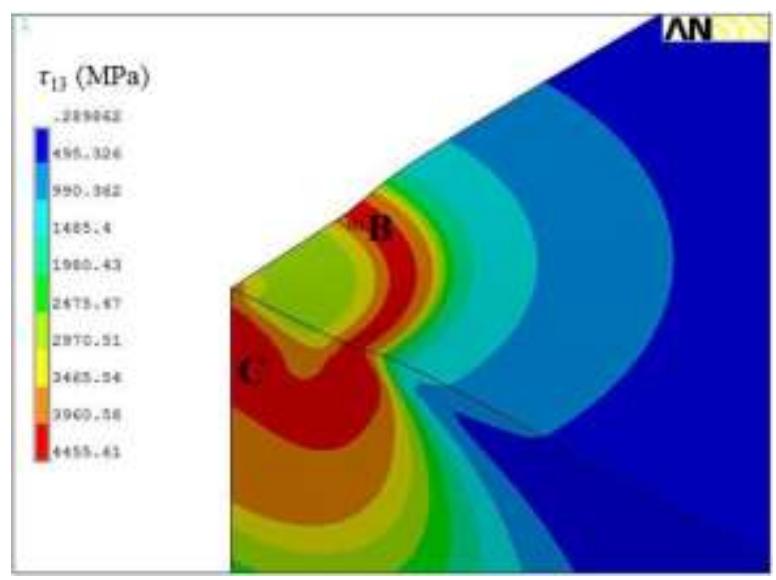

Fig. 4.21: The stress contour plots at the loading condition $d_{\mathrm{c}}=1.2 \mu \mathrm{m}$ : (a) the principal stress $\sigma_{1}$, and (b) shear stress $\tau_{13}$. 


\subsection{Summary}

In the indentation damage tests for both $\mathrm{Si}(100)$ and (111) die specimens, the first $\mathrm{AE}$ event detected corresponds to the 'pop-in' or plateau in the $F-d$ curve, at the onset crack force $F_{\mathrm{c}}$ and displacement $d_{\mathrm{c}}$. The mean values of $F_{\mathrm{c}}$ and $d_{\mathrm{c}}$ for the $\mathrm{Si}(100)$ die are $1.16 \mathrm{~N}$ and $1.24 \mu \mathrm{m}$, respectively, and $1.49 \mathrm{~N}$ and $1.47 \mu \mathrm{m}$ for the $\mathrm{Si}$ (111) die. In general, the larger values of $A$ and $E_{\mathrm{AE}}$ are recorded for those $\mathrm{Si}$ die specimens measured with the higher $F_{\mathrm{c}}$. The main failure mode of the Si (100) die is sub-surface lateral cracking; in some cases, the surface ring and radial cracks are also observed. However, for the $\mathrm{Si}$ (111) die, mixed surface ring and radial cracks including the sub-surface cone and lateral cracks are observed. Multiple AE events are detected near $F_{\mathrm{c}}$, and a larger $t_{\mathrm{d}}$ is recorded at $F_{\mathrm{c}}$ for the $\mathrm{Si}$ (111) die, which could be due to the multiple radial cracking observed.

The $H_{\mathrm{IT}}$ and $E_{\mathrm{IT}}$ of the $\mathrm{Si}(100)$ die are determined experimentally and applied in the FE modelling. The maximum principle stress component $\sigma_{1}$ occurs in the area within the radial crack region, as observed in the indentation damage test. Hence, the maximum tensile stress region is able to initiate a mode-I crack, which is then driven by the indentation loading to form the radial crack. The regions of the maximum shear stress component $\tau_{13}=0.5\left(\sigma_{1}-\sigma_{3}\right)$ correspond to the area within the ring and sub-surface lateral cracks. This implies that the maximum shear stress regions are able to initiate a mode-II crack, which then propagates to form the ring and lateral cracks under the indentation loading. Generally, the FE simulation has shown that the regions of the maximum principle stress and shear stress components correspond to somewhere within the cracking locations of those $\mathrm{Si}$ (100) die specimens under indentation testing. 


\section{Chapter 5 Indentation Damage Evaluation of Thin-film Stacked Structures}

In this chapter, the indentation damage test with a sphero-conical indenter is performed on the different thin-film stacked systems, which consist of a top metal layer (Al or copper-titanium $\mathrm{CuTi}$ ) and intermediate dielectric (silicon dioxide $\mathrm{SiO}_{2}$ or silicon nitride $\mathrm{Si}_{3} \mathrm{~N}_{4}$ ) layers on the $\mathrm{Si}(100)$ substrate. The mechanical responses and the $\mathrm{AE}$ signals from the indentation damage test are recorded, and investigated with the failure mode observed. The indentation damage model of these thin-film stacked system is also presented. Finite element (FE) model is developed to simulate the indentation loadingunloading process on the thin-film stacked system, and then compared with the experimental results. Finally, the stress analysis and damage assessment of those thin-film stacked structure are discussed.

\subsection{Test vehicle preparation}

The preparation of the thin-films stacked specimen in this work is carried out using the standard wafer fabrication process on a $100 \mathrm{~mm}$-diameter wafer. The Si wafer first goes through a plasma-enhanced chemical vapor deposition process, where a homogenous layer of the dielectric layer $\left(\mathrm{SiO} 2\right.$ or $\left.\mathrm{Si}_{3} \mathrm{~N}_{4}\right)$ is deposited on one side of the $\mathrm{Si}$ wafer surface. The $\mathrm{Al}$ or $\mathrm{Cu}$ metallization layer is then sputtered over the dielectric layer. In the case of the $\mathrm{Cu}$ deposition, a Ti layer is first sputtered for the adhesion purpose. Lastly, the wafer is sawn mechanically into a $10 \mathrm{~mm}$ x $10 \mathrm{~mm}$ die size. Figure 5.1 illustrates the sample preparation processes of the thin-films stacked specimens, including their cross- 
sectional SEM images. The voids in the $\mathrm{Cu}$ metal layer can affect the measured $F$ - $d$ response or the overall stiffness of the thin-film stacked specimen. However, the micromechanical system employed in this work may not be sensitive in characterizing those voids, and is not the scope of this study. The geometrical information of the specimens is presented in Table 5.1.

(a)

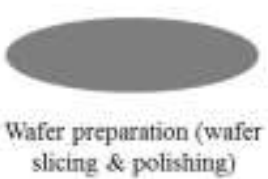
slicing \& polishing)

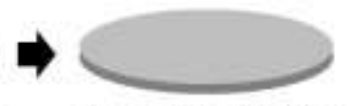

Plasma-enhanced chemical vapor deposition process of dielectric $\left(\mathrm{SiO}_{2}, \mathrm{Si}_{2} \mathrm{~N}_{4}\right)$
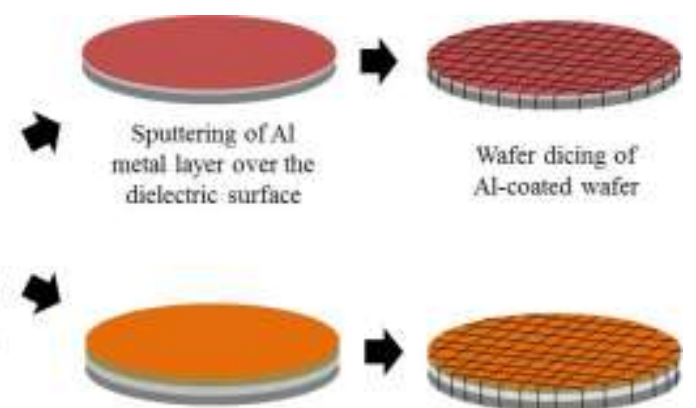

Sputtering of Ti \& Cu metal layer over the dielectric surface

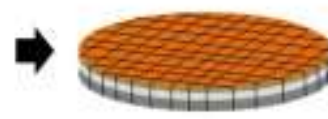

Wafer dicing of Cu-coated wafer

(b)
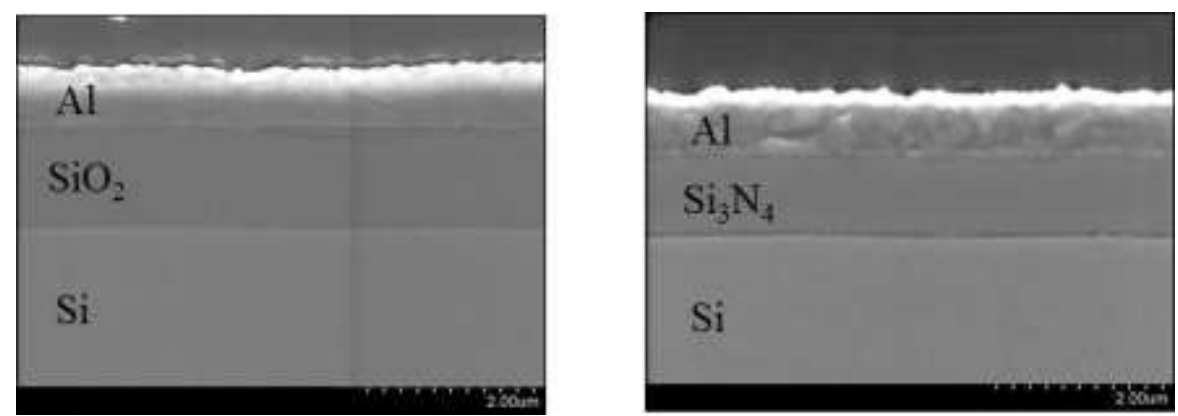

(c)
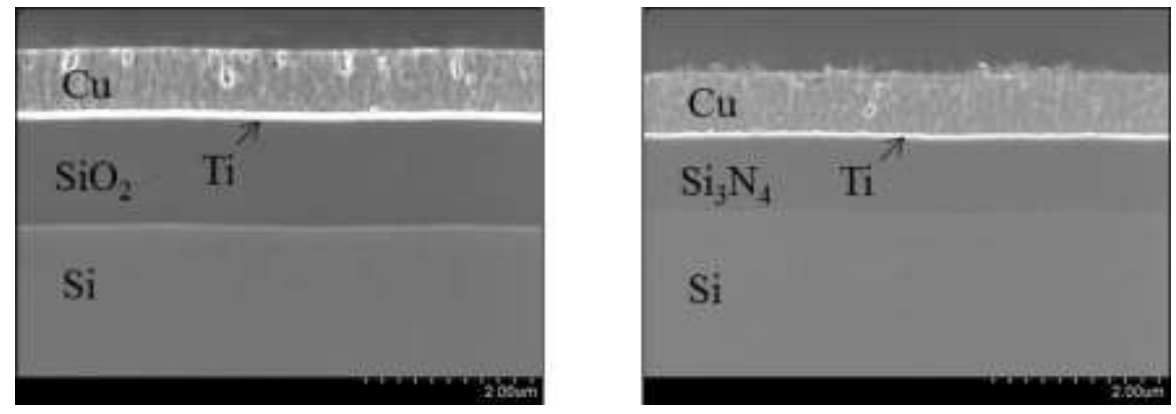

Fig. 5.1: (a) The wafer processing for the thin-films stacked specimens, and the crosssectional SEM images: (b) the Al-coated specimens and (c) the $\mathrm{Cu}$-coated specimens. 
Table 5.1: The geometry specifications of the thin-film stacked specimens.

\begin{tabular}{cccc}
\hline \hline Specimen & Metal thickness $(\mu \mathrm{m})$ & $\begin{array}{c}\text { Dielectric } \\
\text { thickness }(\mu \mathrm{m})\end{array}$ & $\begin{array}{c}\text { Substrate } \\
\text { thickness }(\mu \mathrm{m})\end{array}$ \\
\hline $\mathrm{Al}-\mathrm{SiO}_{2}-\mathrm{Si}$ & $0.6-0.9$ & $0.9-1.1$ & $\sim 500$ \\
$\mathrm{Al}-\mathrm{Si}_{3} \mathrm{~N}_{4}-\mathrm{Si}$ & $0.6-0.9$ & $0.8-1.0$ & $\sim 500$ \\
$\mathrm{Cu}(\mathrm{Ti})-\mathrm{SiO}_{2}-\mathrm{Si}$ & $\mathrm{Cu}: 0.7-0.9 ; \mathrm{Ti}: 0.07-0.08$ & $0.9-1.1$ & $\sim 500$ \\
$\mathrm{Cu}(\mathrm{Ti})-\mathrm{Si}_{3} \mathrm{~N}_{4}-\mathrm{Si}$ & $\mathrm{Cu}: 0.7-0.9 ; \mathrm{Ti}: 0.07-0.08$ & $0.8-1.0$ & $\sim 500$ \\
\hline \hline
\end{tabular}

\subsection{Experiment and test results}

A similar measurement procedure is employed as described in Chapter 4 (Fig 4.1). The indentation damage test is performed at the room temperature $\left(25^{\circ} \mathrm{C}\right)$ on the four different specimens listed in Table 5.1. A minimum of 30 indentation tests (five indentations per specimen) is conducted on each type of the specimen. Both the planar and the cross-sectional areas of the damaged specimens are examined in detail. The indented surface of the top metallization layer is usually removed by a wet chemical etchant (i.e. mixture of acids) to expose the dielectric $\mathrm{SiO}_{2}$ or $\mathrm{Si}_{3} \mathrm{~N}_{4}$ layer, and followed by rinsing the specimens with the de-ionized water. This delayering failure analysis technique only reveals the bulk material cracking or damage on the surface of the dielectric layer. In order to examine any interfacial crack or delamination within the stacked structure, the cross-sectioning approach using the focused ion beam (FIB) and scanning electron microscopy (SEM) technique are further carried out. 


\subsubsection{Thin-film stacked systems with $\mathrm{SiO}_{2}$ dielectric layer}

\subsubsection{1 $\mathrm{Al}-\mathrm{SiO}_{2}-\mathrm{Si}$ specimen}

During the indentation loading stage, the first AE event or peak voltage $V_{\mathrm{s}}$ detected is related to the 'pop-in' observation or plateau in the $F$ - $d$ curve, and corresponds to the onset crack force $F_{\mathrm{c}}$ and displacement $d_{\mathrm{c}}$ (Fig. 5.2). The AE parameters and the indentation force $F$ are plotted against a common time axis $t$ for one of the indents (Fig. 5.3). This "pop-in" is a result of the sudden increase in the distance travelled by the indenter when the cracking of the specimen occurs (for a force-controlled indentation) before reaching another resistance point. This suggests that the stored strain energy in the specimen converted from the work of indentation is released by fracture, and the specimen loses its structural integrity and stiffness at the instance of "pop-in" occurrence. A new stiffness or compliance is usually measured after the "pop-in" if the indenter continues the loading process on the damaged specimen. However, in this test set-up, the indenter is retracted immediately after the first AE event detection. During the unloading stage, a second $\mathrm{AE}$ event or $V_{\mathrm{s}}$ is detected but there is no abnormality or 'pop-out' observed in the unloading $F-d$ curve, as shown in Fig. 5.2. It is observed that $\sim 40 \%$ of the total indents experience this second AE event (Fig. 5.3). 


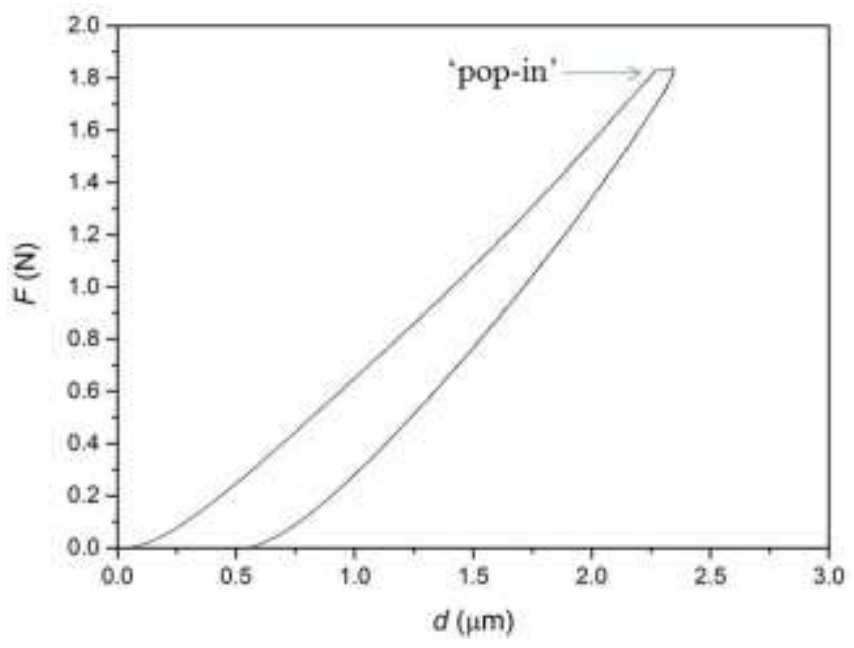

Fig. 5.2: The $F$ - $d$ curve of the $\mathrm{Al}-\mathrm{SiO}_{2}-\mathrm{Si}$ specimen after the indentation damage test.

(a)

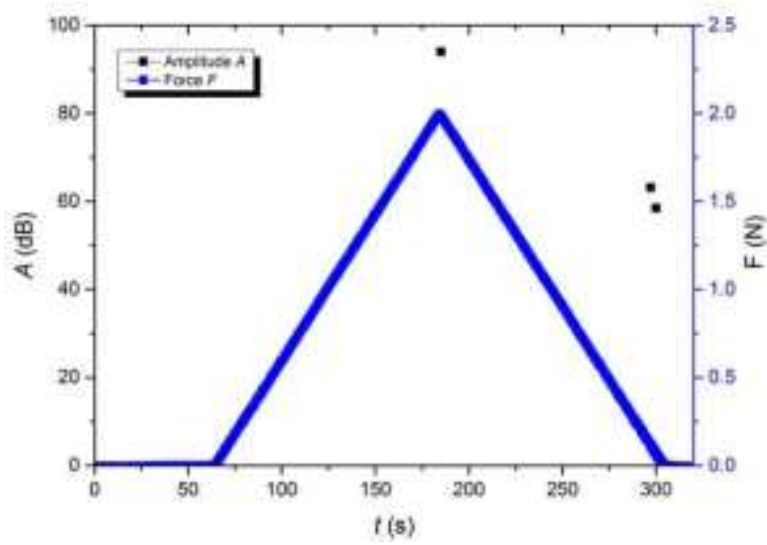

(c)

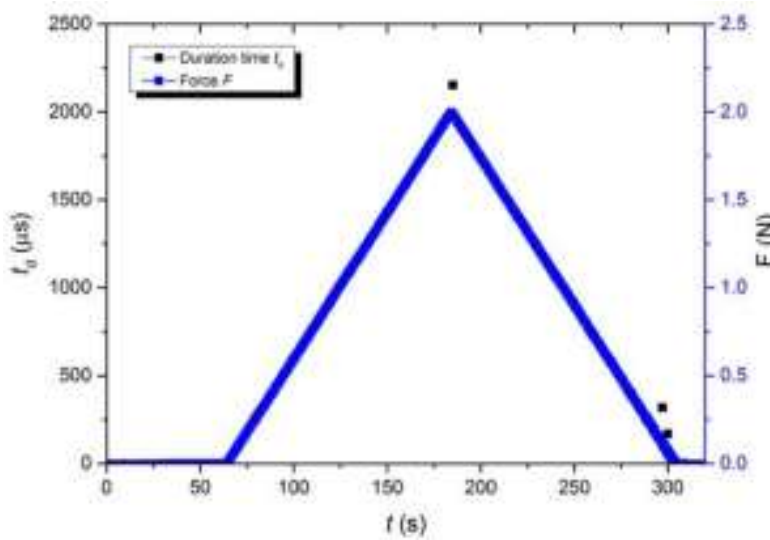

(b)

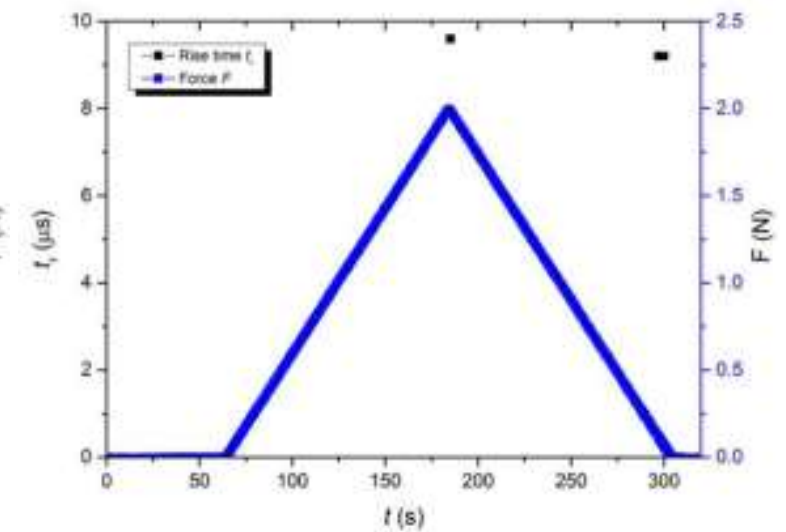

(d)

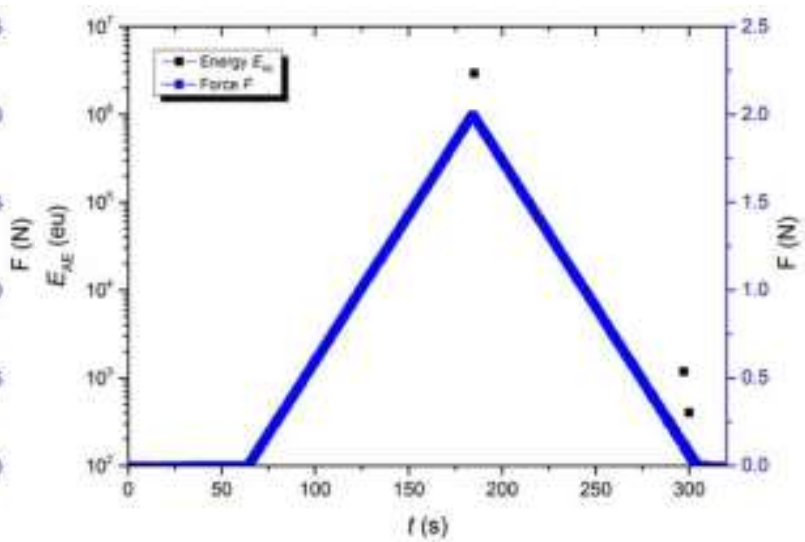

Fig. 5.3: The results of $F$ and $\mathrm{AE}$ parameters plotted against $t$ for the $\mathrm{Al}-\mathrm{SiO}_{2}-\mathrm{Si}$ specimen after the indentation damage test: (a) $A$, (b) $t_{\mathrm{r}}$, (c) $t_{\mathrm{d}}$, and (d) $E_{\mathrm{AE}}$. 
There is no cracking found on the top $\mathrm{Al}$ layers for all the $\mathrm{Al}-\mathrm{SiO}_{2}-\mathrm{Si}$ specimens, except a round indented mark and a pile-up around the indented area (Fig. 5.4(a)). However, the delayering of the top metal layer reveals the peeling, ring and radial cracking on the $\mathrm{SiO}_{2}$ surfaces. The cross-sectioning of the specimen is performed and subsequently examined by the SEM. The sub-surface cone and lateral cracks are found in the $\mathrm{Si}$ substrate, and delamination between the $\mathrm{SiO}_{2}$ and $\mathrm{Si}$ interface is also observed (Fig. 5.4(b)). Furthermore, a partial "white-ring" is observed at the perimeter of the imprinted $\mathrm{SiO}_{2}$ surface (Fig. 5.4(a)), which could be an indicator of the dielectric peeling or delamination during the unloading stage. Further evaluation will be discussed in the later section.

(a)

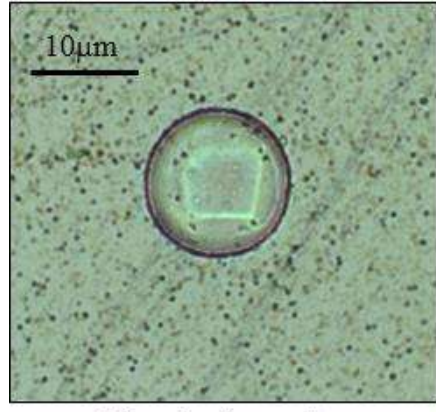

After indentation

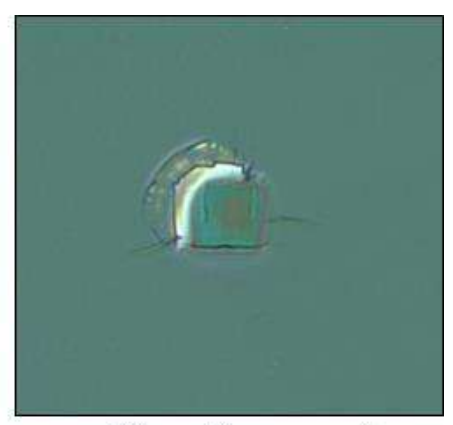

After Al removal

(b)
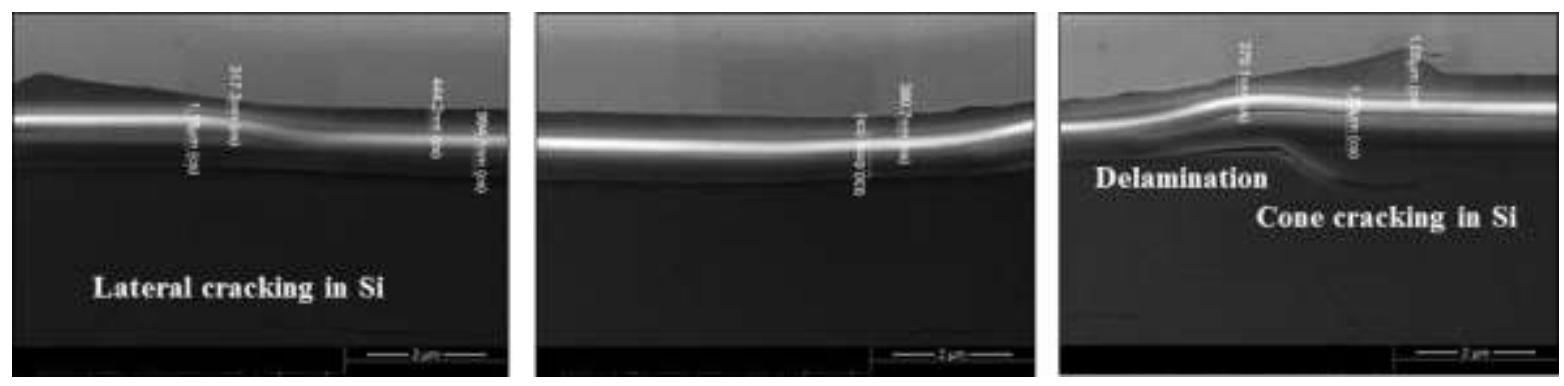

Fig. 5.4: The failure modes of the $\mathrm{Al}-\mathrm{SiO}_{2}-\mathrm{Si}$ specimen after the indentation damage test: (a) surface optical images, and (b) cross-sectional SEM images. 
The mean values of $F_{\mathrm{c}}$ and $d_{\mathrm{c}}$ for the $\mathrm{Al}-\mathrm{SiO}_{2}-\mathrm{Si}$ specimen are $1.93 \mathrm{~N}$ and $2.08 \mu \mathrm{m}$, respectively (Fig. 5.5). Further verification testing is performed at a maximum indentation load $F_{\mathrm{m}}<F_{\mathrm{c}}$, i.e., $F_{\mathrm{m}}=1.7 \mathrm{~N}$, to examine for the presence of any crack in the specimen that is undetected by the $\mathrm{AE}$ sensor (Fig. 5.6). There is no $\mathrm{AE}$ event and specimen cracking observed, except for a faded round mark on the indented surface (Fig. 5.7).

(a)

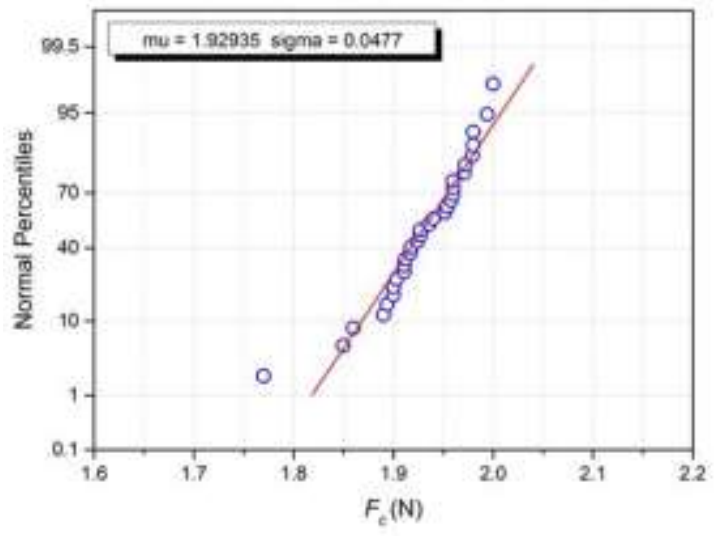

(b)

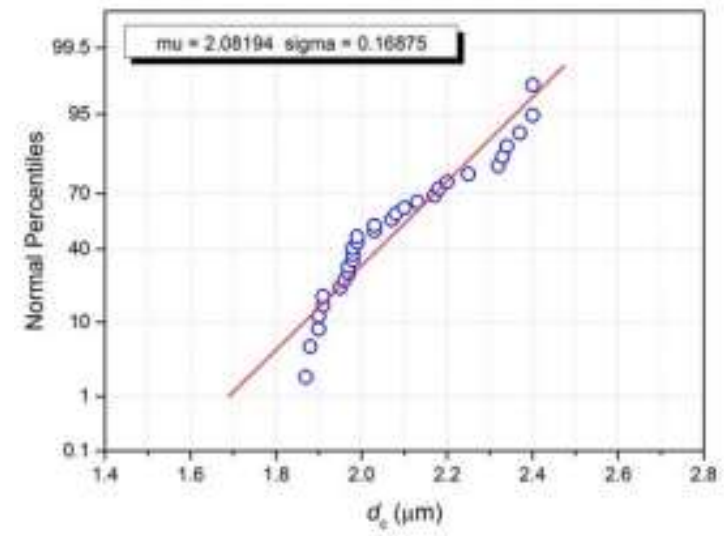

Fig. 5.5: The probability plots of the Al-SiO $2-S i$ specimen: (a) $F_{\mathrm{c}}$, and (b) $d_{\mathrm{c}}$.

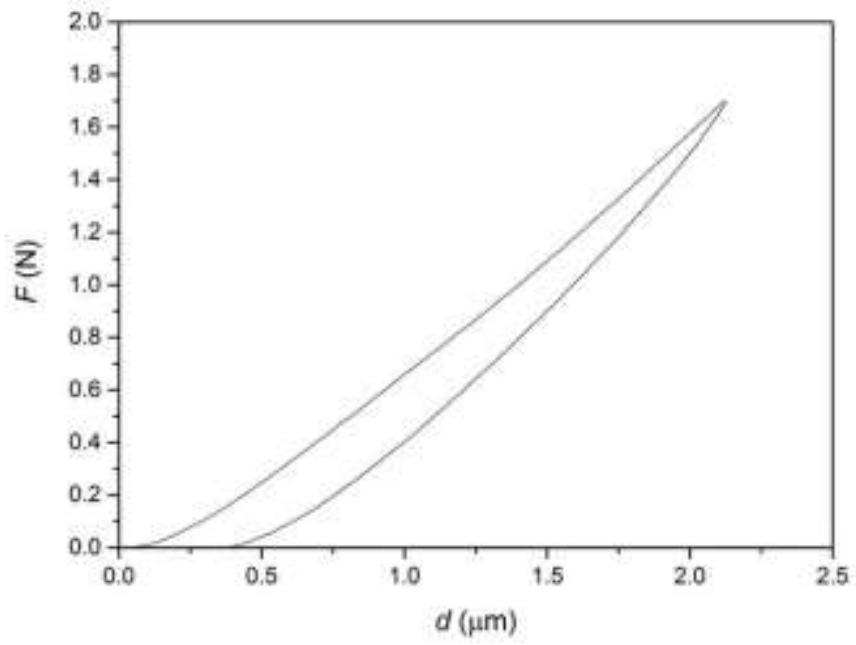

Fig. 5.6: The $F-d$ curve of the $\mathrm{Al}-\mathrm{SiO}_{2}-\mathrm{Si}$ specimen after the verification test. 
(a)

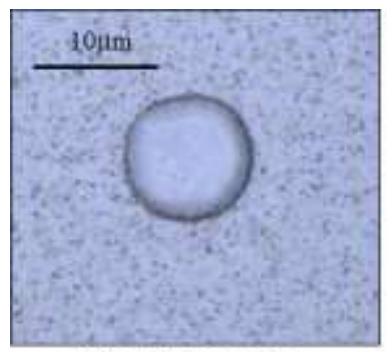

After indentation

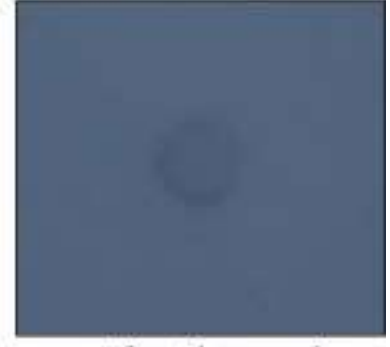

After Al removal (b)

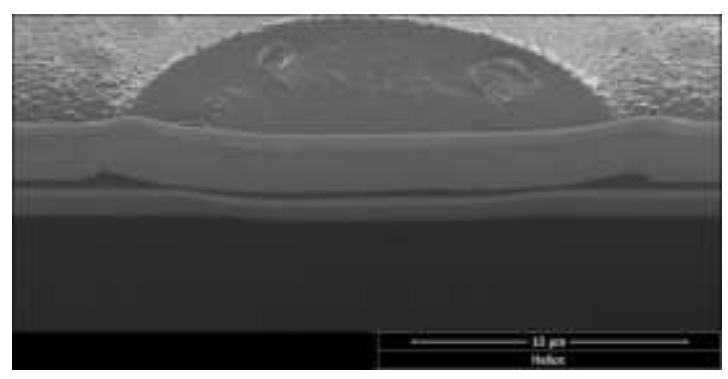

Fig. 5.7: The physical examination of the $\mathrm{Al}-\mathrm{SiO}_{2}-\mathrm{Si}$ specimen after the verification test: (a) surface optical images, and (b) cross-sectional SEM images.

The parameters of the first $\mathrm{AE}$ event or transient signal detected at the loading stage are plotted against $F_{\mathrm{c}}$, as shown in Fig. 5.8. The rise duration $t_{\mathrm{r}}$ is either $\sim 9$ or $\sim 13 \mu \mathrm{s}$, and it is observed that $A, t_{\mathrm{d}}$, and $E_{\mathrm{AE}}$ increase with $F_{\mathrm{c}}$. However, a correlation between these AE parameters with the damage severity or condition on the specimen is not established. This is because of the difficulty in quantifying the overall crack condition, especially in the sub-surface of Si substrate.

The parameters of the second AE transient signal detected during the unloading stage are plotted against $F_{\mathrm{c}}$, as shown in Fig. 5.9. During the unloading stage, the second $\mathrm{AE}$ event or $V_{\mathrm{s}}$ detected are within the range of 0.05-0.2 N, and are made up by $\sim 40 \%$ of the total indents. In general, the lower values of the AE parameters are recorded as compared to those obtained from the first AE event detected at the loading stage.

\subsubsection{2 $\mathrm{CuTi}-\mathrm{SiO}_{2}-\mathrm{Si}$ specimen}

Similar to that result of the $\mathrm{Al}-\mathrm{SiO}_{2}-\mathrm{Si}$ specimens, the first $\mathrm{AE}$ event or $V_{\mathrm{s}}$ detected during the loading stage is related to the 'pop-in' observation or plateau in the $F$ - $d$ curve, and corresponds to $F_{\mathrm{c}}$ and $d_{\mathrm{c}}$ (Fig. 5.10). Multiple AE events are detected near $F_{\mathrm{c}}$, which is 
also observed in the $\mathrm{Al}-\mathrm{SiO}_{2}-\mathrm{Si}$ specimen. The $\mathrm{AE}$ parameters and $F$ are plotted against a common time axis $t$ for one of the indents (Fig. 5.11). A second AE event is also detected during the unloading process, but there is no abnormality observed in the unloading $F-d$ curve. It is observed that $\sim 70 \%$ of the total indents experience a second AE event.

There is no cracking found on the top $\mathrm{Cu}$ layers for all the $\mathrm{CuTi}-\mathrm{SiO}_{2}-\mathrm{Si}$ specimens, except a round indented mark and a pile-up around the indented area (Fig. 5.12(a)).

(a)

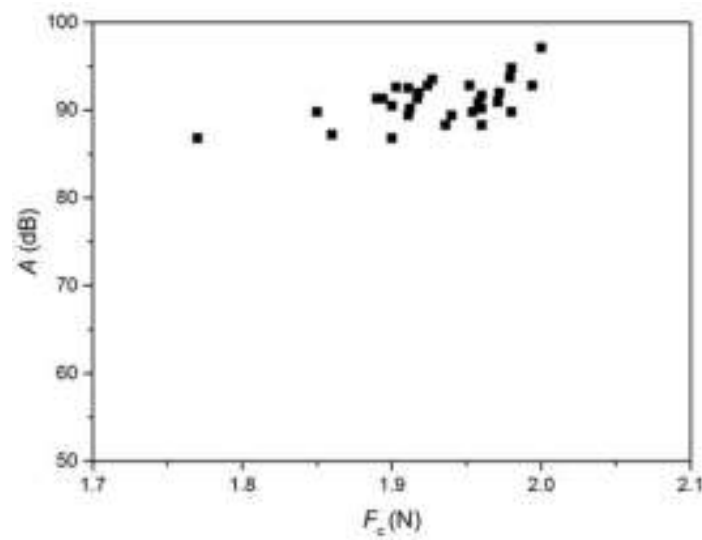

(c)

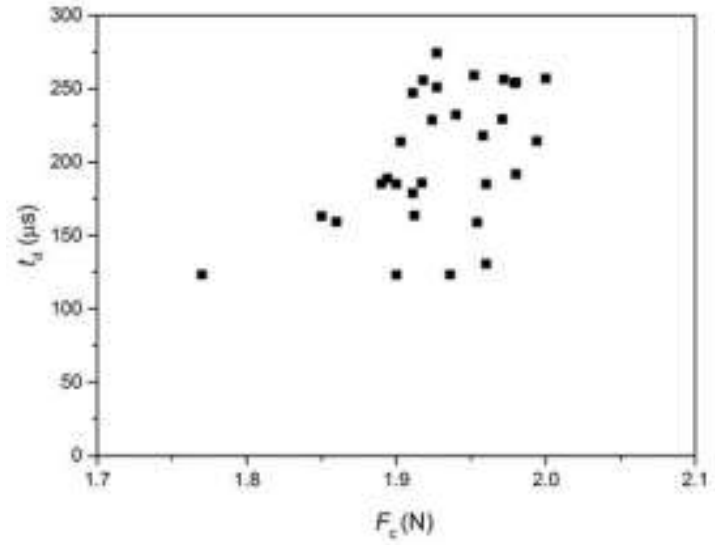

(b)

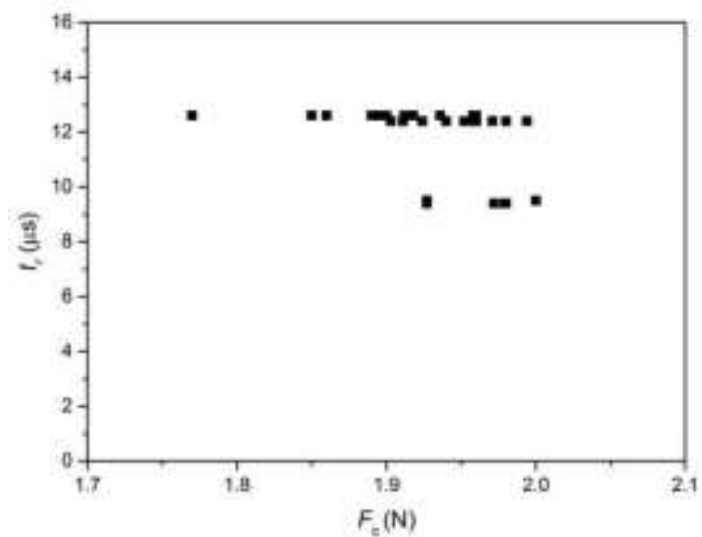

(d)

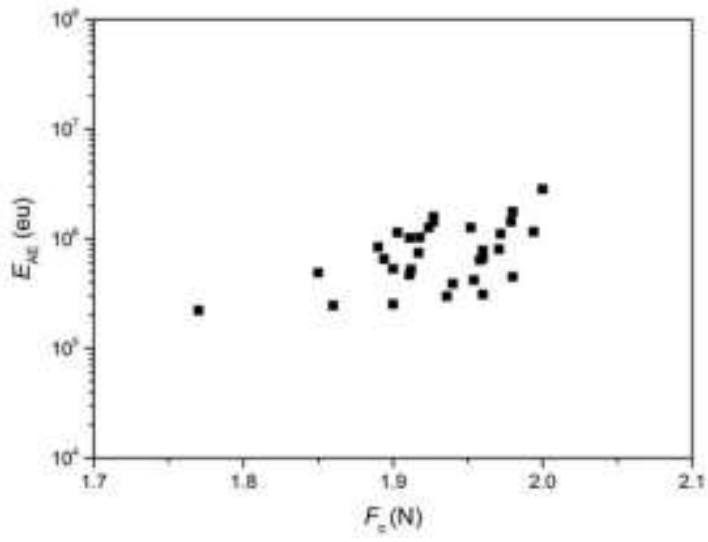

Fig. 5.8: The first $\mathrm{AE}$ event results of the $\mathrm{Al}-\mathrm{SiO}_{2}-\mathrm{Si}$ specimen plotted against $F_{\mathrm{c}}$ during the indentation loading stage: (a) $A$, (b) $t_{\mathrm{r}}$, (c) $t_{\mathrm{d}}$, and (d) $E_{\mathrm{AE}}$. 
(a)

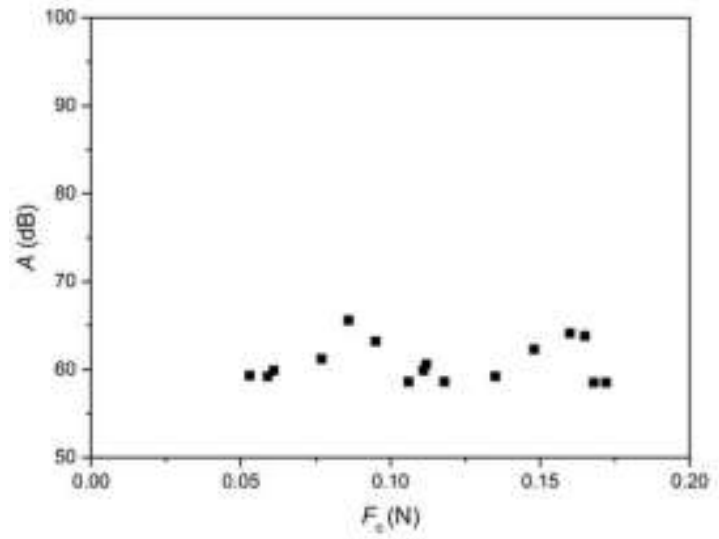

(c)

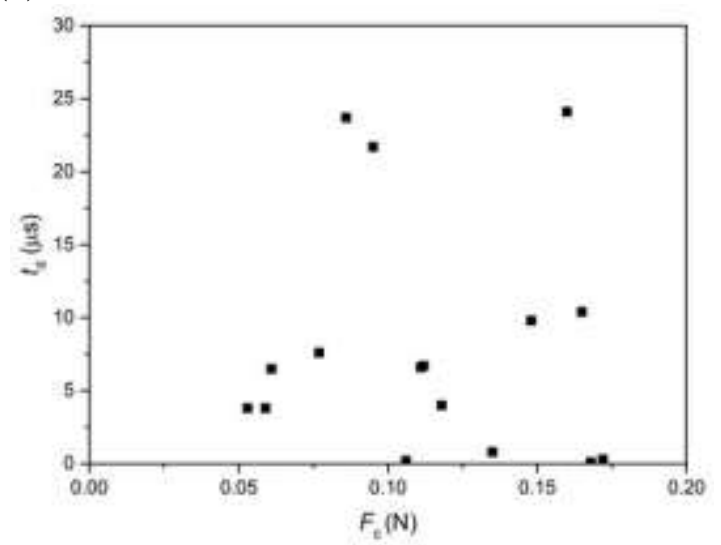

(b)

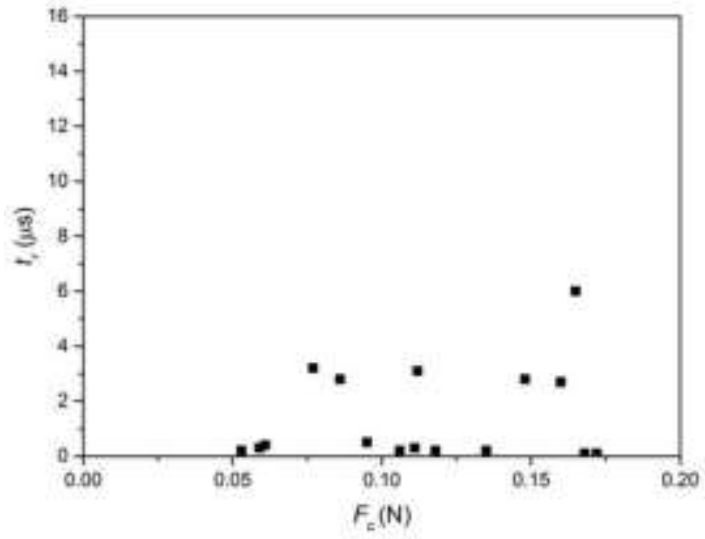

(d)

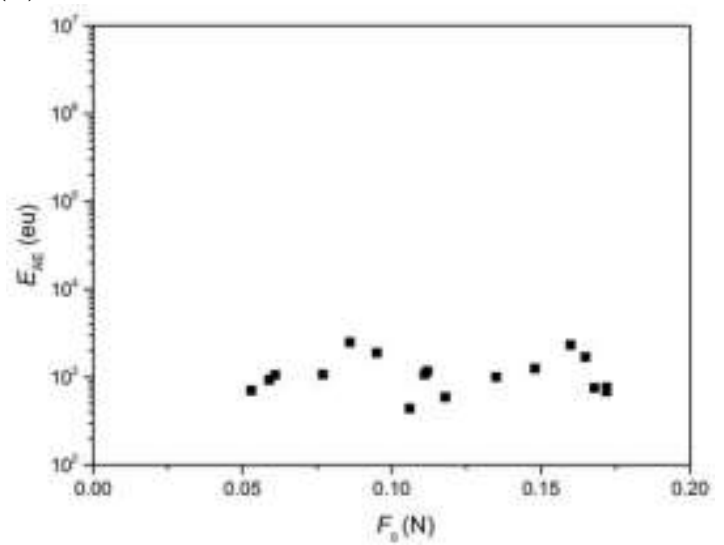

Fig. 5.9: The second $\mathrm{AE}$ event results of the $\mathrm{Al}-\mathrm{SiO}_{2}-\mathrm{Si}$ specimen plotted against $F_{\mathrm{c}}$ during the indentation unloading stage: (a) $A$, (b) $t_{\mathrm{r}}$, (c) $t_{\mathrm{d}}$, and (d) $E_{\mathrm{AE}}$.

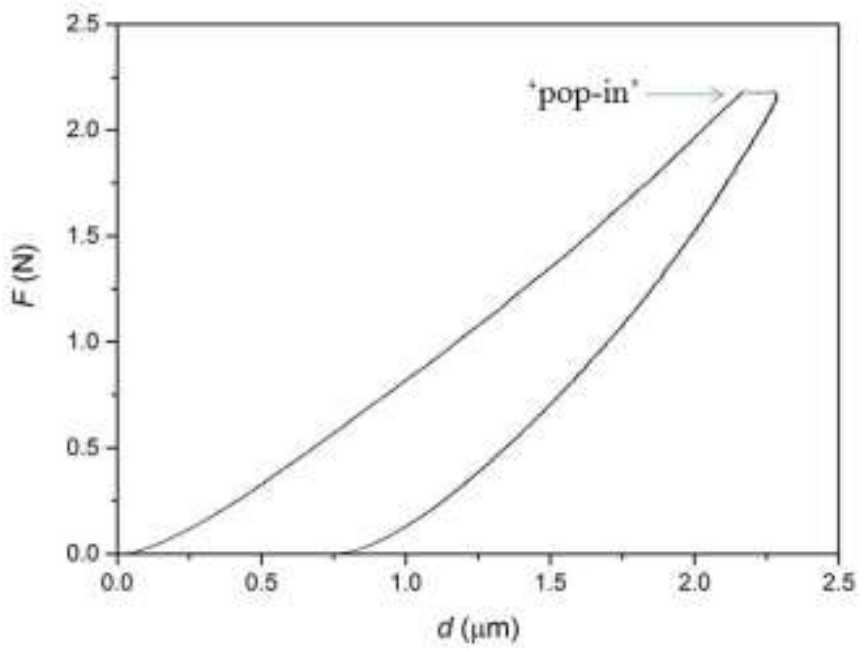

Fig. 5.10: The $F$ - $d$ curve of the CuTi-SiO2-Si specimen after the indentation damage test. 
(a)

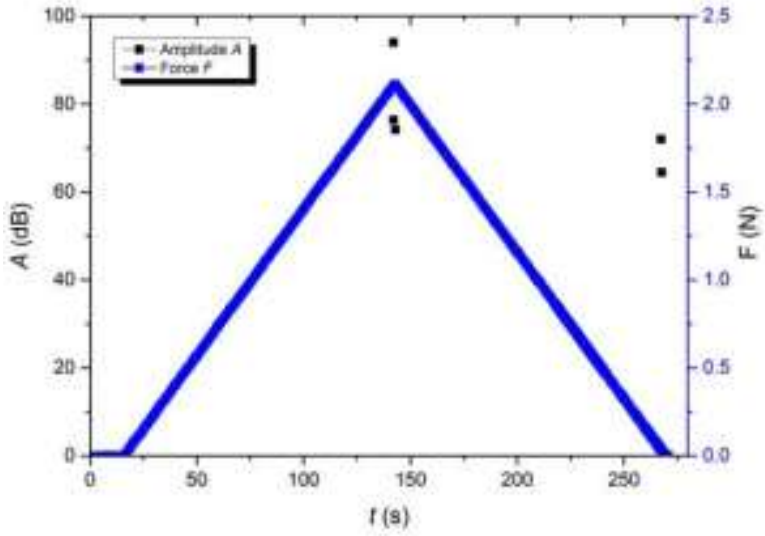

(c)

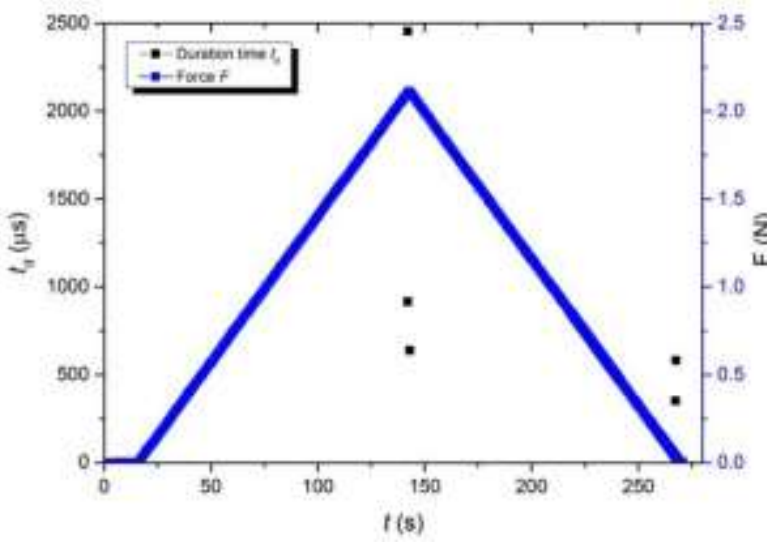

(b)

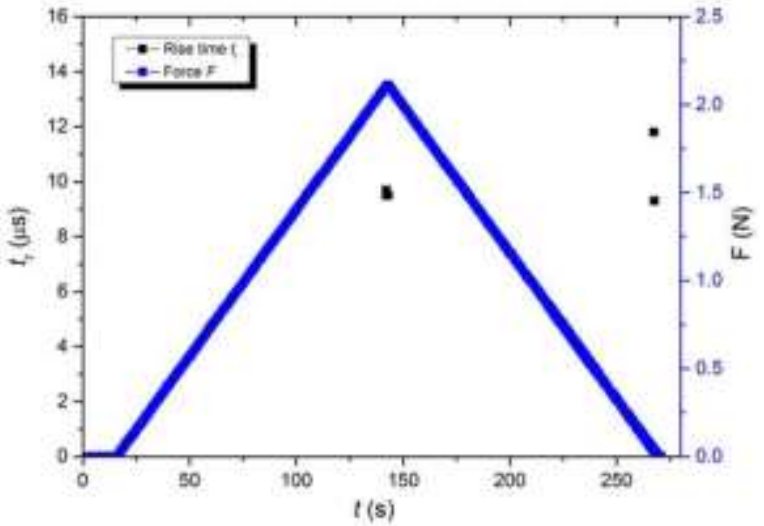

(d)

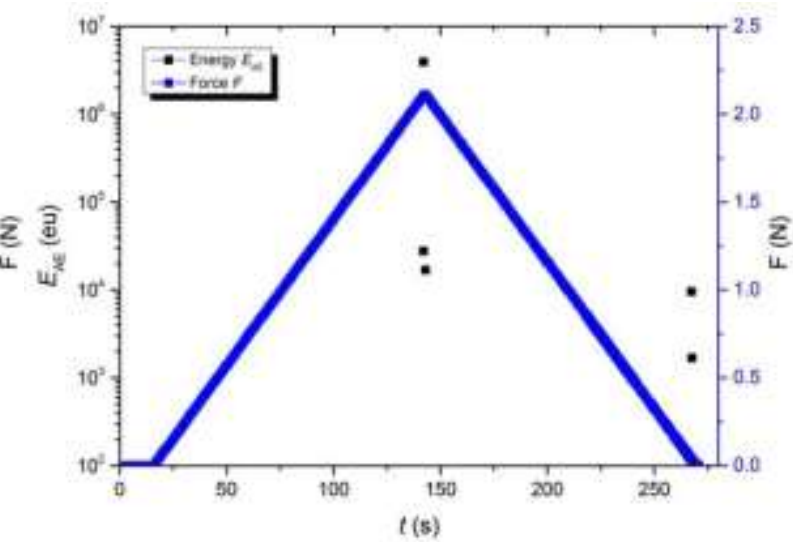

Fig. 5.11: The results of $F$ and $\mathrm{AE}$ parameters plotted against $t$ for the $\mathrm{CuTi}-\mathrm{SiO}_{2}-\mathrm{Si}$ specimen after the indentation damage test: (a) $A$, (b) $t_{\mathrm{r}}$, (c) $t_{\mathrm{d}}$, and (d) $E_{\mathrm{AE}}$.

Radial cracking on the Ti layer surface is revealed after the delayering of the top Cu layer, and a further removal of the $\mathrm{Ti}$ layer shows peeling, radial and median cracking on the $\mathrm{SiO}_{2}$ surfaces. The cross-sectioning (FIB and SEM) of the specimen exposes both the subsurface cone and lateral cracking in the $\mathrm{Si}$ substrate, and delamination between the $\mathrm{SiO}_{2}$ and Si interface (Fig. 5.12(b)). Furthermore, a partial "white-ring" is observed at the perimeter of the imprinted $\mathrm{SiO}_{2}$ surface as shown in Fig. 5.12(a), which could be an indicator of the dielectric peeling or delamination. This failure mode is similar to the observation in the $\mathrm{Al}-\mathrm{SiO}_{2}-\mathrm{Si}$ specimen, and further evaluation will be discussed in the later section. 
(a)

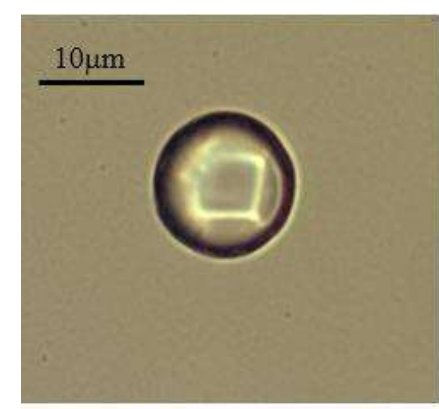

After indentation

(b)

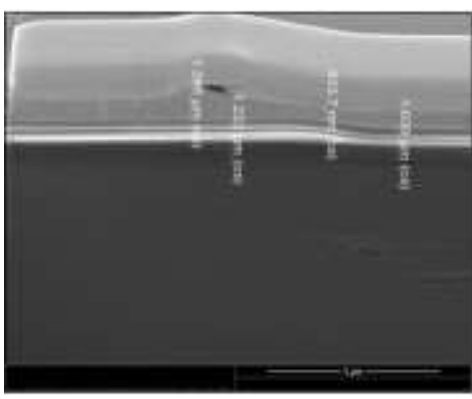

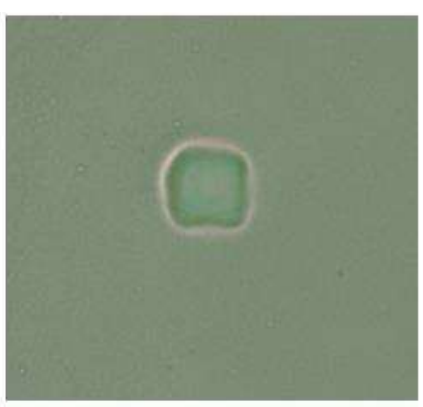

After $\mathrm{Cu}$ removal

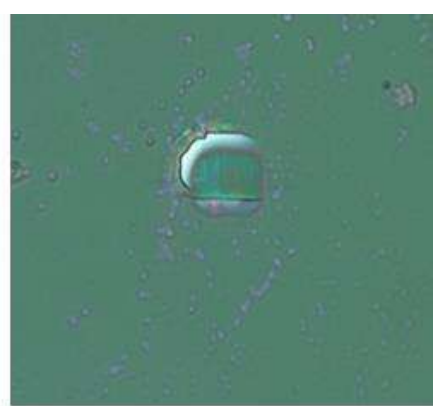

After Ti removal
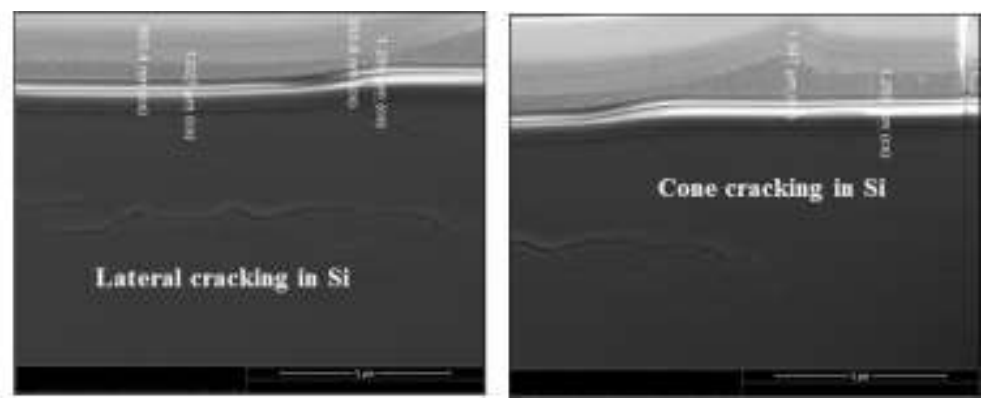

Fig. 5.12: The failure modes of the $\mathrm{CuTi}-\mathrm{SiO}_{2}-\mathrm{Si}$ specimen after the indentation damage test: (a) surface optical images, and (b) cross-sectional SEM images.

The mean values of $F_{\mathrm{c}}$ and $d_{\mathrm{c}}$ for the $\mathrm{CuTi}-\mathrm{SiO}_{2}-\mathrm{Si}$ specimen are $2.07 \mathrm{~N}$ and $2.12 \mu \mathrm{m}$, respectively (Fig. 5.13). Verification testing is conducted at $F_{\mathrm{m}}<F_{c}$, i.e., $F_{\mathrm{m}}=1.7 \mathrm{~N}$ (Fig. 5.14), and no AE event and specimen cracking are observed (Fig. 5.15). In addition, this shows that the metal and dielectric layers enhance the damage threshold of the Si (100) substrate.

The parameters of the first AE transient signal detected at the loading stage are plotted against the $F_{\mathrm{c}}$, as shown in Fig. 5.16. It is observed that the magnitudes of $A, t_{\mathrm{d}}$, and $E_{\mathrm{AE}}$ increase with $F_{\mathrm{c}}$, and $t_{\mathrm{r}}$ is either $\sim 9$ or $\sim 13 \mu \mathrm{s}$, which is also observed in the $\mathrm{Al}-\mathrm{SiO}_{2}-\mathrm{Si}$ specimen. 
(a)

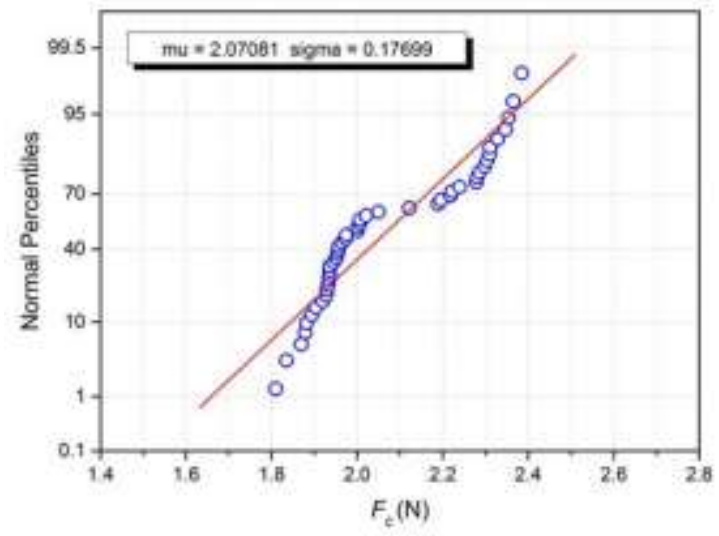

(b)

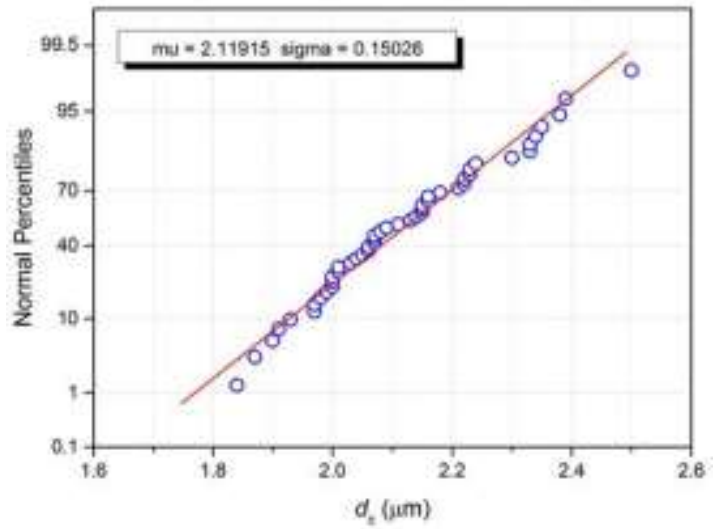

Fig. 5.13: The probability plots of the $\mathrm{CuTi}-\mathrm{SiO}_{2}-\mathrm{Si}$ specimen: (a) $F_{\mathrm{c}}$, and (b) $d_{\mathrm{c}}$.

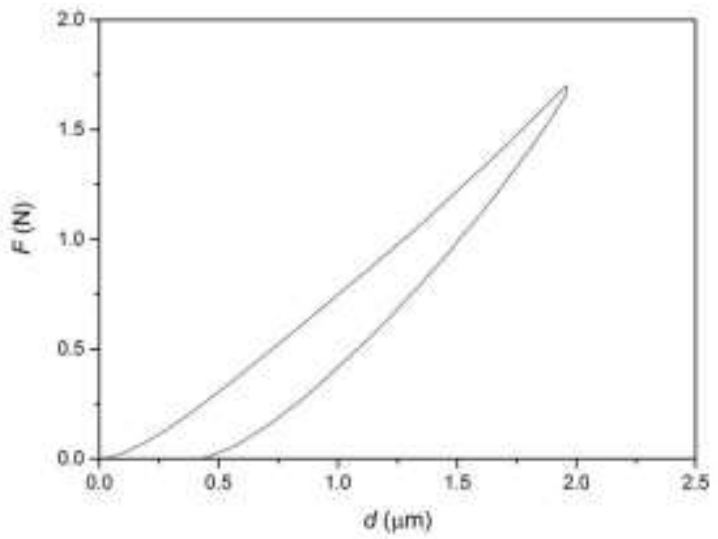

Fig. 5.14: The $F$ - $d$ curve of the $\mathrm{CuTi}_{-} \mathrm{SiO}_{2}-\mathrm{Si}$ specimen after the verification test.

(a)

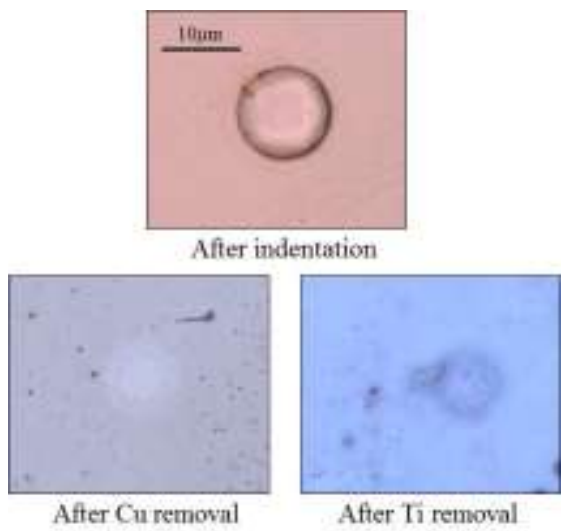

(b)

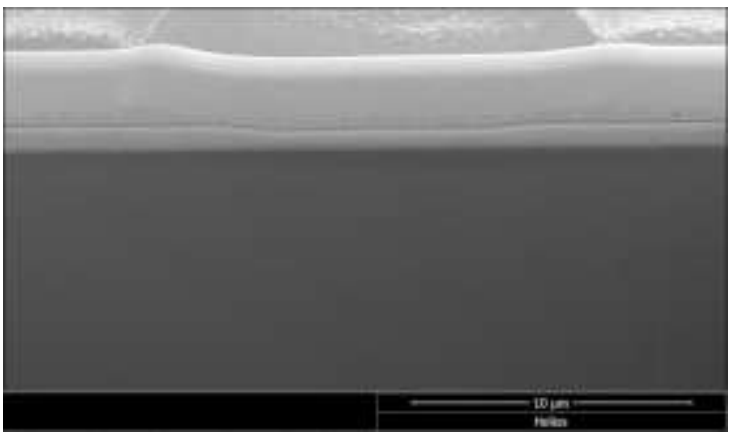

Fig. 5.15: The physical examination of the $\mathrm{CuTi}_{-} \mathrm{SiO}_{2}-\mathrm{Si}$ specimen after the verification test: (a) surface optical images, and (b) cross-sectional SEM images. 
Although both the Al- and $\mathrm{CuTi}_{-} \mathrm{SiO}_{2}$-Si specimens experience multiple $\mathrm{AE}$ events near $F_{\mathrm{c}}$, but a longer $t_{\mathrm{d}}$ is recorded in the latter specimen. Hence, this is unlikely due to the AE signals from the cracking recorded between the first and last threshold crossings at $F_{\mathrm{c}}$. It is suspected that the longer $t_{\mathrm{d}}$ includes the reflected signal from the original AE event, and the reflection plane could be the crack-free Ti layer (Fig 5.1 (c)).

(a)

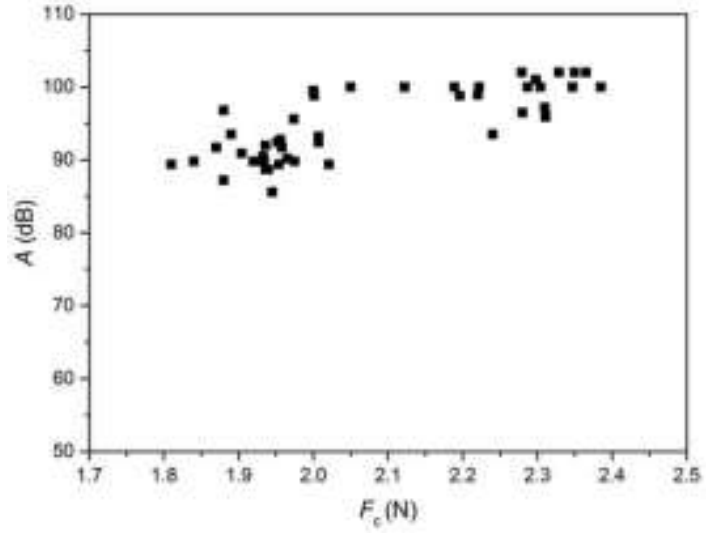

(c)

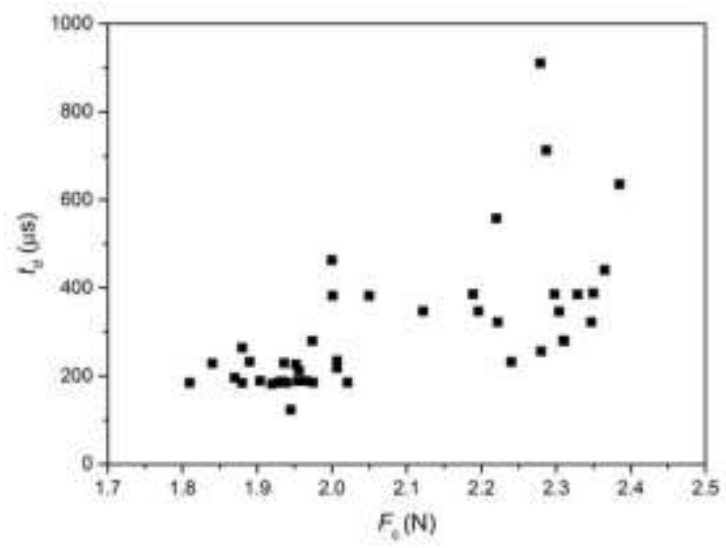

(b)

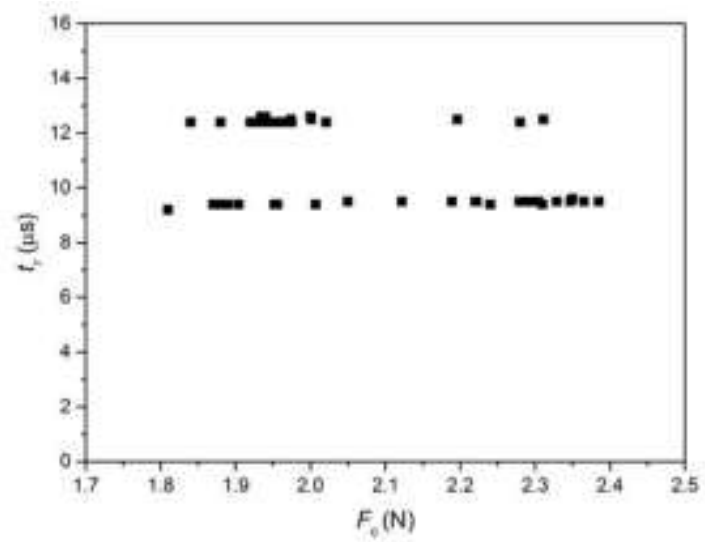

(d)

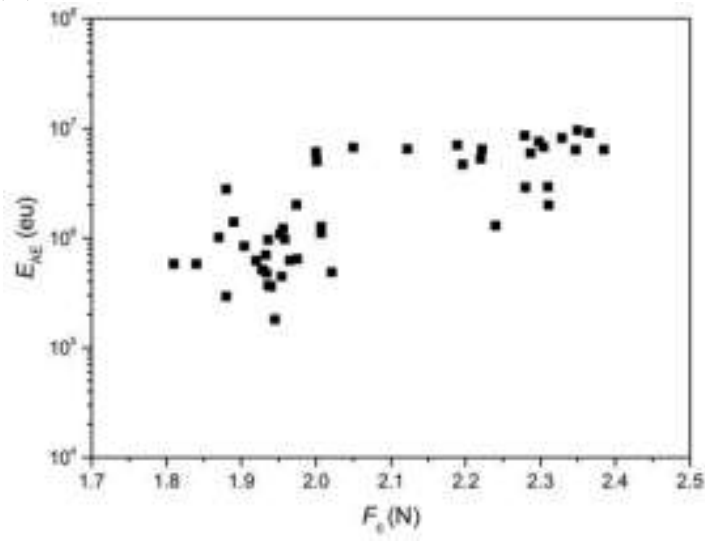

Fig. 5.16: The first $\mathrm{AE}$ event results of the $\mathrm{CuTi}-\mathrm{SiO}_{2}-\mathrm{Si}$ specimen plotted against $F_{\mathrm{c}}$ during the indentation loading stage: (a) $A$, (b) $t_{\mathrm{r}}$, (c) $t_{\mathrm{d}}$, and (d) $E_{\mathrm{AE}}$.

The parameters of the second $\mathrm{AE}$ transient event detected during the unloading stage are plotted against $F_{\mathrm{c}}$, as shown in Fig. 5.17. During the unloading stage, $\sim 70 \%$ of the total indents experience a second $\mathrm{AE}$ event at a range of $0.05-0.3 \mathrm{~N}$, except for the five indents that occurs at a higher $F$, i.e., 1.5-2.5 N. Generally, the lower value of $\mathrm{AE}$ 
parameters are recorded as compared to those obtained from the first $\mathrm{AE}$ event at the loading stage.

(a)

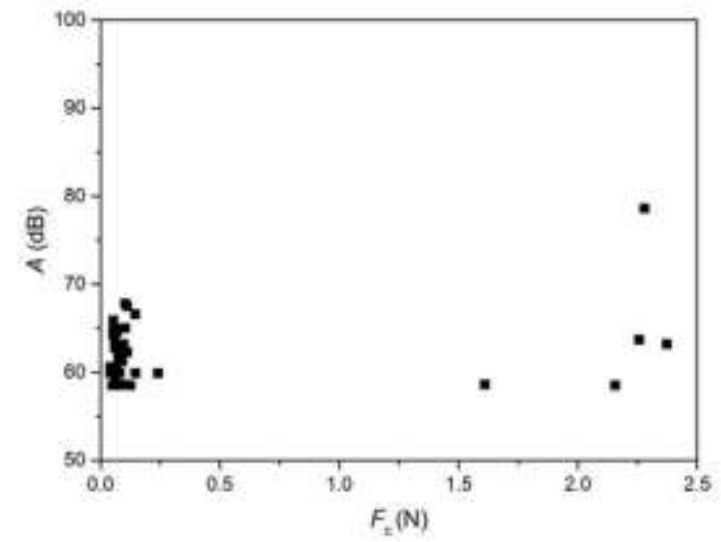

(c)

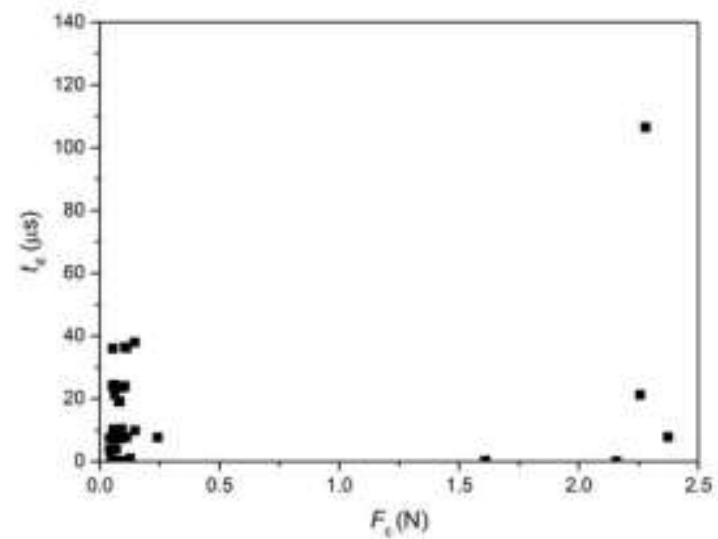

(b)

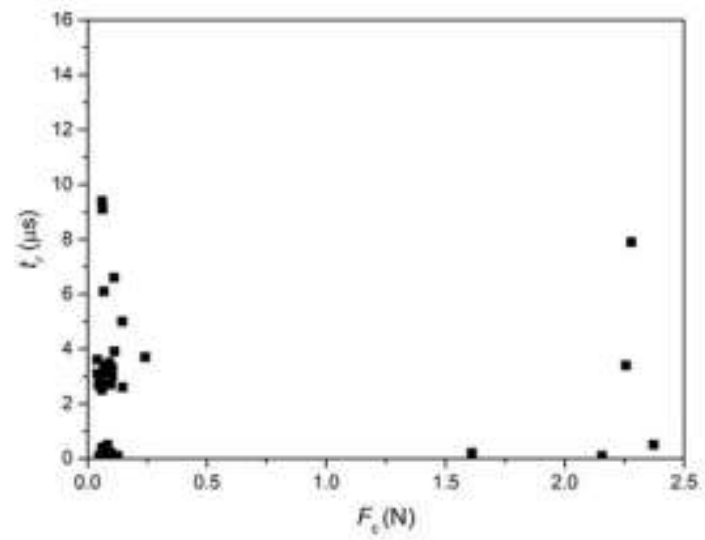

(d)

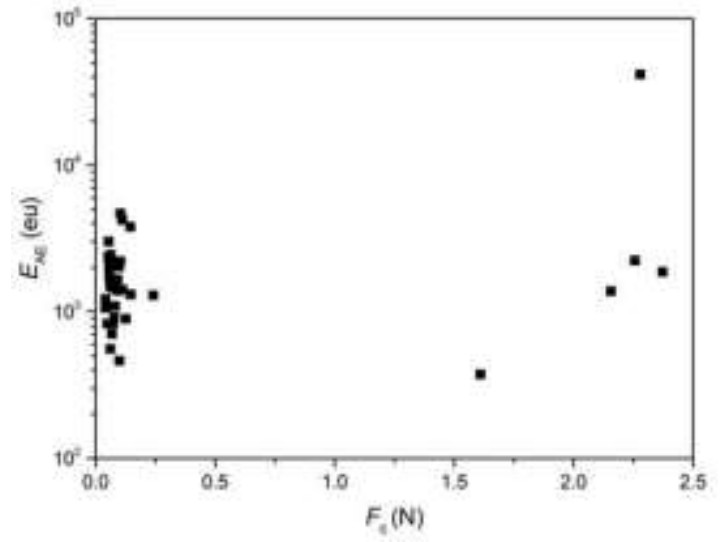

Fig. 5.17: The second $\mathrm{AE}$ event results of the $\mathrm{CuTi}-\mathrm{SiO}_{2}-\mathrm{Si}$ specimen plotted against $F_{\mathrm{c}}$ during the indentation unloading stage: (a) $A$, (b) $t_{\mathrm{r}}$, (c) $t_{\mathrm{d}}$, and (d) $E_{\mathrm{AE}}$.

\subsubsection{Thin-film stacked systems with $\mathrm{Si}_{3} \mathrm{~N}_{4}$ dielectric layer}

\subsubsection{Al- $\mathrm{Si}_{3} \mathrm{~N}_{4}-\mathrm{Si}$ specimen}

The first $\mathrm{AE}$ event or $V_{\mathrm{s}}$ detected during the loading stage is related to the 'pop-in' or plateau in the $F$ - $d$ curve, and corresponds to $F_{\mathrm{c}}$ and $d_{\mathrm{c}}$ (Fig. 5.18). Unlike the metal-coated $\mathrm{SiO}_{2}$-Si specimen, a very weak second $\mathrm{AE}$ event is detected during the unloading stage of 
the indentation, and the occurrence is only $<10 \%$ of the total indents. The AE parameters and $F$ are plotted against a common time axis $t$ for one of the indents (Fig. 5.19).

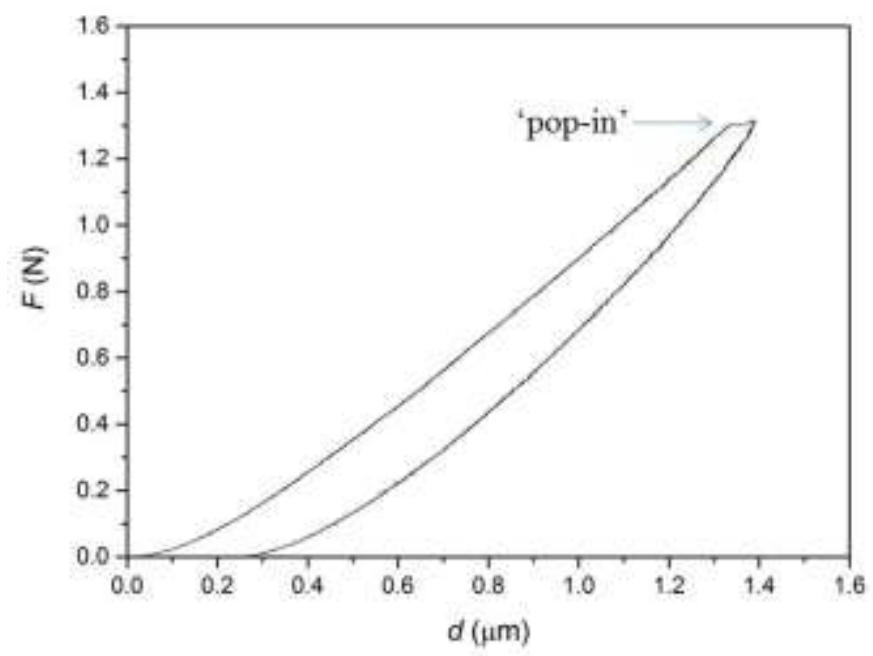

Fig. 5.18: The $F-d$ curve of the $\mathrm{Al}-\mathrm{Si}_{3} \mathrm{~N}_{4}-\mathrm{Si}$ specimen after the indentation damage test.

There is no cracking found on the top $\mathrm{Al}$ layers for all the $\mathrm{Al}-\mathrm{Si}_{3} \mathrm{~N}_{4}-\mathrm{Si}$ specimens, except for a round indented mark and a pile-up around the indented area (Fig. 5.20(a)). However, the delayering of the top $\mathrm{Al}$ layer reveals ring, median and radial cracking on the $\mathrm{Si}_{3} \mathrm{~N}_{4}$ surfaces. The cross-sectioning (FIB and SEM) of the specimen uncovers the through-thickness crack in the $\mathrm{Si}_{3} \mathrm{~N}_{4}$ dielectric layer and the sub-surface lateral cracking in the Si substrate (Fig. 5.20(b)).

The mean values of $F_{\mathrm{c}}$ and $d_{\mathrm{c}}$ for $\mathrm{Al}_{-} \mathrm{Si}_{3} \mathrm{~N}_{4}-\mathrm{Si}$ specimen are $1.26 \mathrm{~N}$ and $1.33 \mu \mathrm{m}$, respectively (Fig. 5.21). Verification testing is conducted at $F_{\mathrm{m}}<F_{\mathrm{c}}$, i.e., $F_{\mathrm{m}}=1 \mathrm{~N}$ (Fig. 5.22), and no AE event and specimen cracking are observed (Fig. 5.23). After the removal of the top $\mathrm{Al}$ layer, there is no visible mark observed on the $\mathrm{Si}_{3} \mathrm{~N}_{4}$ surface, unlike that of the metal-coated $\mathrm{SiO}_{2}-\mathrm{Si}$ specimen. 
(a)

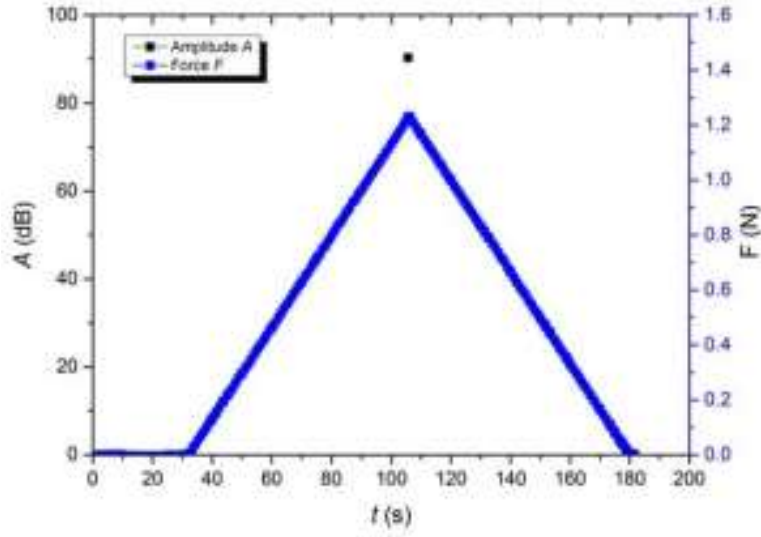

(c)

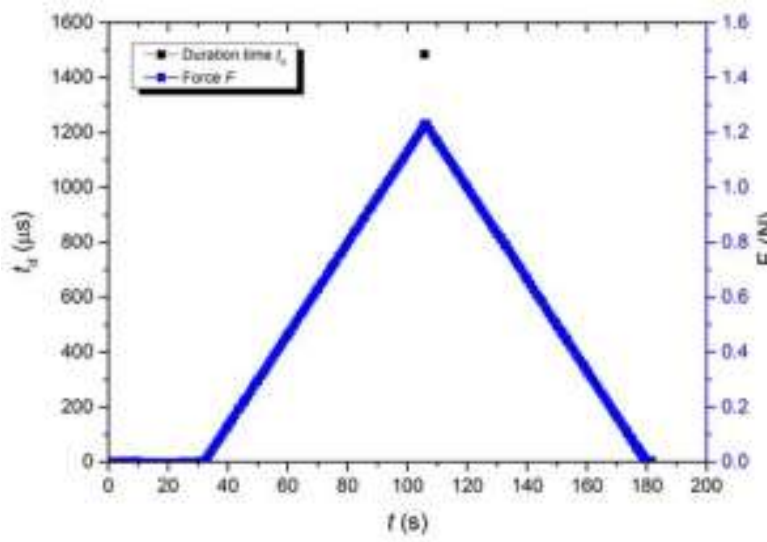

(b)

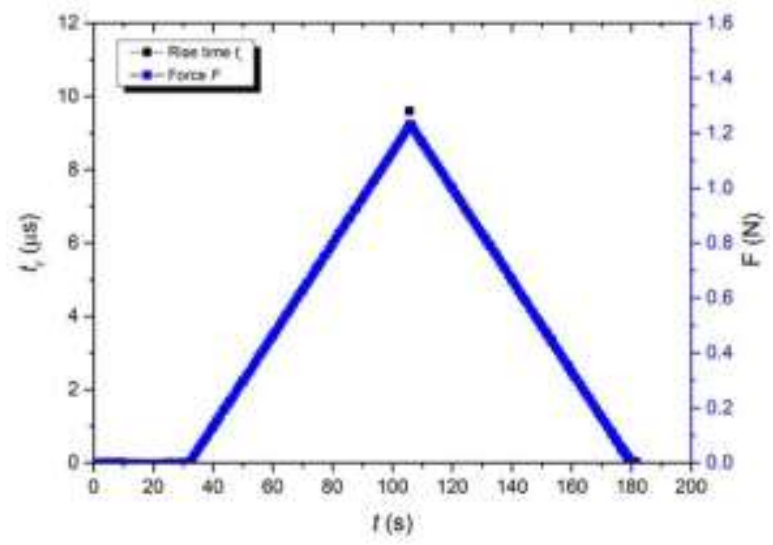

(d)

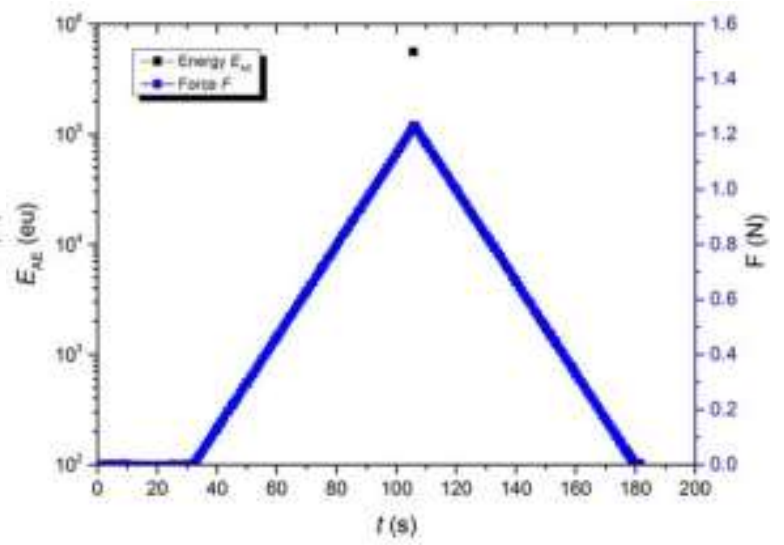

Fig. 5.19: The results of $F$ and $\mathrm{AE}$ parameters plotted against $t$ for the $\mathrm{Al}-\mathrm{Si}_{3} \mathrm{~N}_{4}-\mathrm{Si}$ specimen after the indentation damage test: (a) $A$, (b) $t_{\mathrm{r}}$, (c) $t_{\mathrm{d}}$, and (d) $E_{\mathrm{AE}}$.

The AE parameters of the first transient signal detected at the loading stage are plotted against $F_{\mathrm{c}}$, as shown in Fig. 5.24. The rise duration $t_{\mathrm{r}}$ is either $\sim 9$ or $\sim 12 \mu \mathrm{s}$, and it is observed that $A, t_{\mathrm{d}}$, and $E_{\mathrm{AE}}$ increase with $F_{\mathrm{c}}$. However, a correlation between these AE parameters with the damage severity or condition is not determined due to the difficulty in quantifying the geometry of the cracks, especially the sub-surface cracking in the $\mathrm{Si}$ substrate. 
(a)

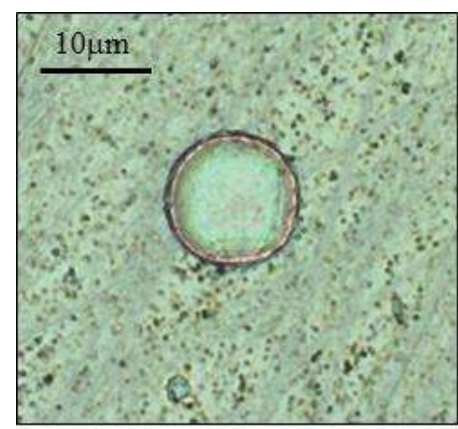

After indentation

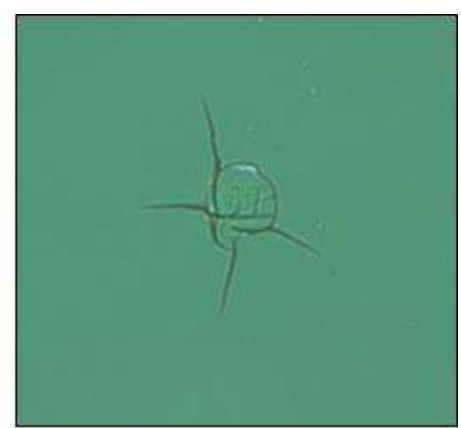

After Al removal

(b)
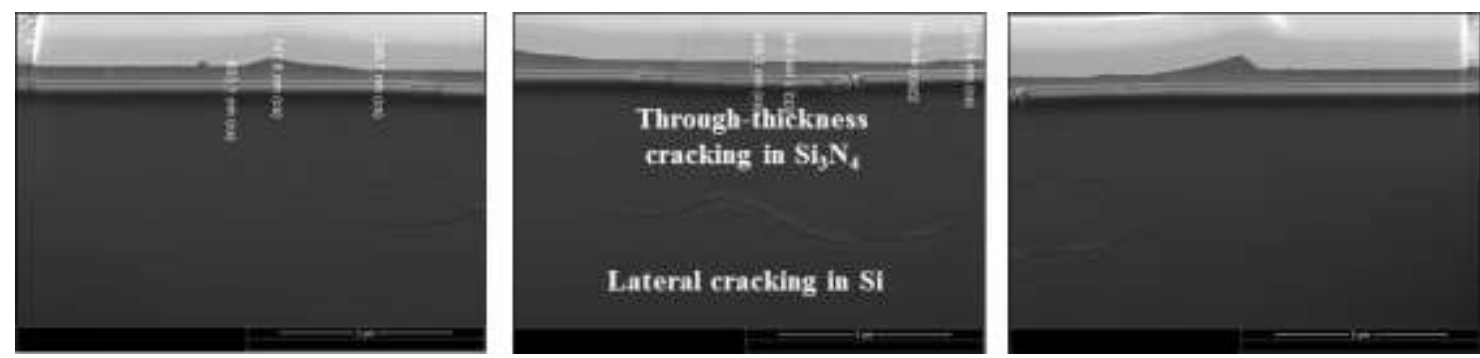

Fig. 5.20: The failure modes of the $\mathrm{Al}-\mathrm{Si}_{3} \mathrm{~N}_{4}-\mathrm{Si}$ specimen after the indentation damage test: (a) surface optical images, and (b) cross-sectional SEM images.

(a)

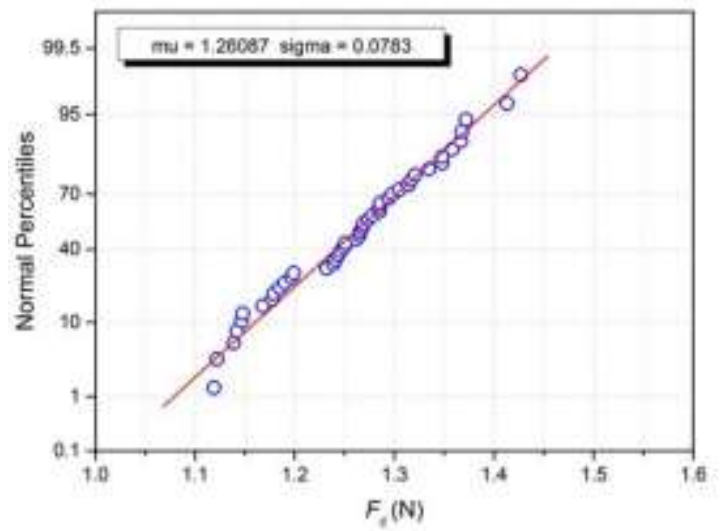

(b)

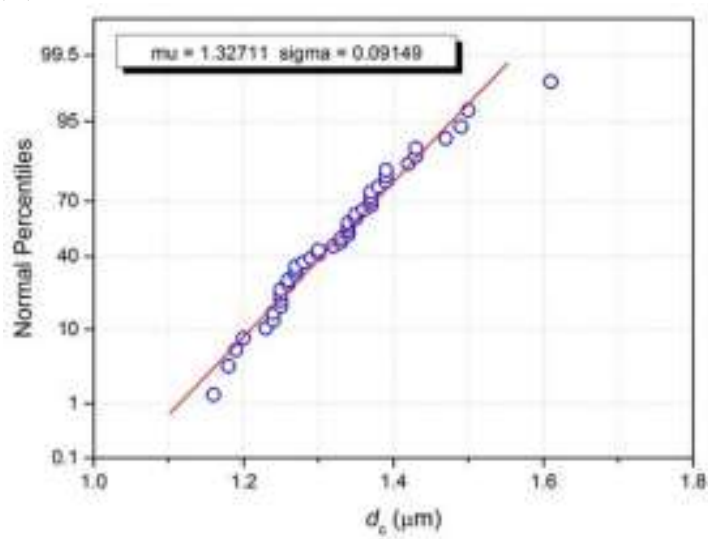

Fig. 5.21: The probability plots of the Al- $\mathrm{Si}_{3} \mathrm{~N}_{4}-\mathrm{Si}$ specimen: (a) $F_{\mathrm{c}}$, and (b) $d_{\mathrm{c}}$. 


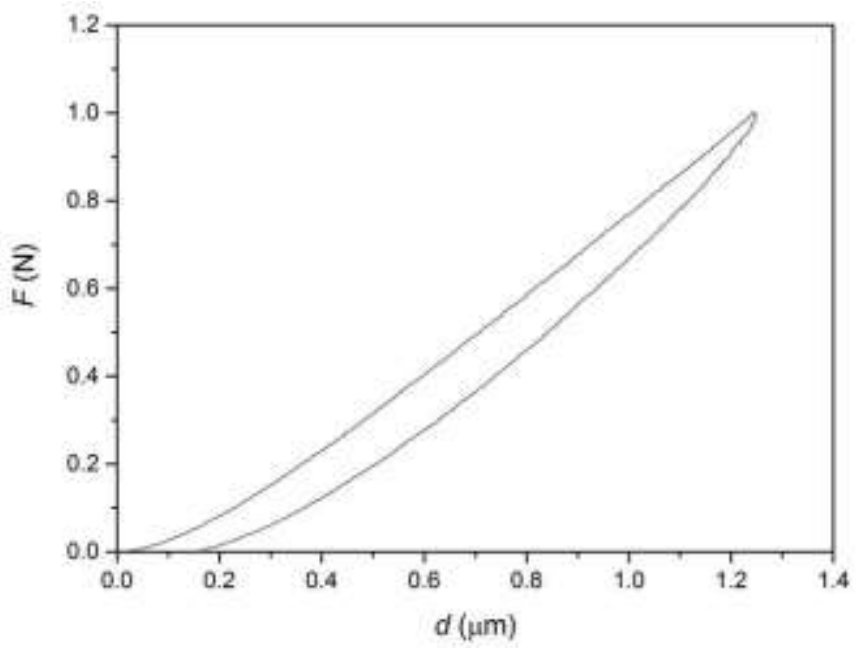

Fig. 5.22: The $F$ - $d$ curve of the $\mathrm{Al}-\mathrm{Si}_{3} \mathrm{~N}_{4}-\mathrm{Si}$ specimen after the verification test.

(a)

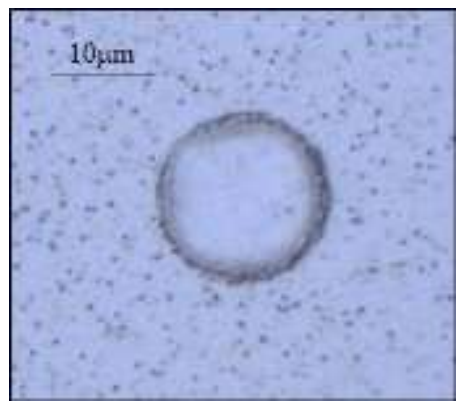

(b)

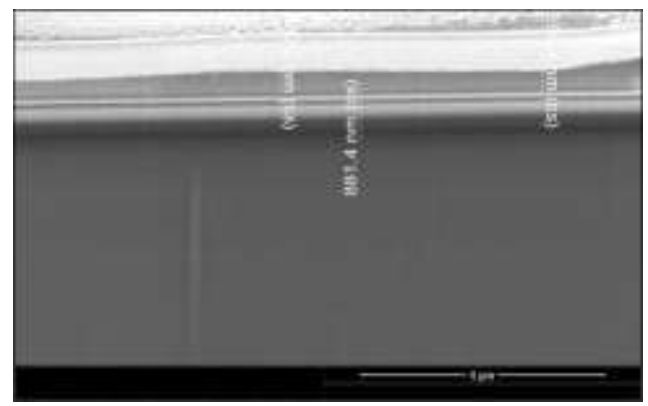

Fig. 5.23: The physical examination of the $\mathrm{Al}-\mathrm{Si}_{3} \mathrm{~N}_{4}-\mathrm{Si}$ specimen after the verification test: (a) surface optical images, and (b) cross-sectional SEM images.

The parameters of a second $\mathrm{AE}$ transient signal detected during the unloading stage are plotted against $F_{\mathrm{c}}$, as shown in Fig. 5.25. A second AE event is detected only the four indents during the unloading stage, within a range of $0.05-0.1 \mathrm{~N}$, except one that occurs at $0.8 \mathrm{~N}$. Generally, the lower values of the AE parameters are recorded in the unloading stage, as compared to those obtained in the loading stage (the first AE events). 
(a)

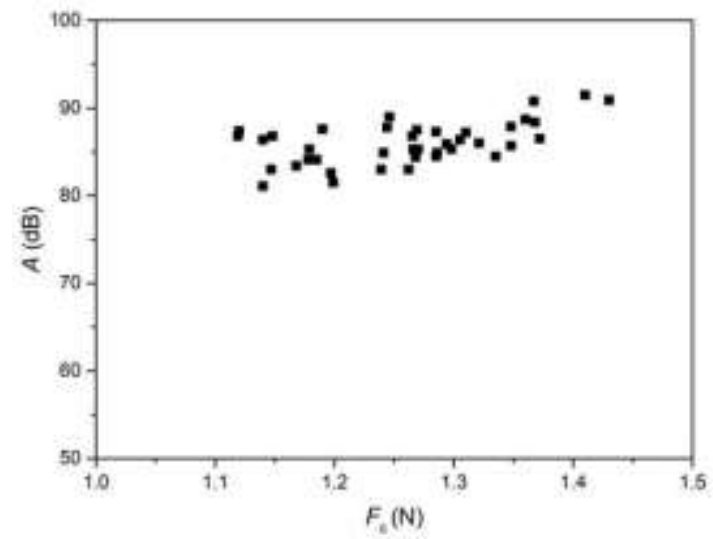

(c)

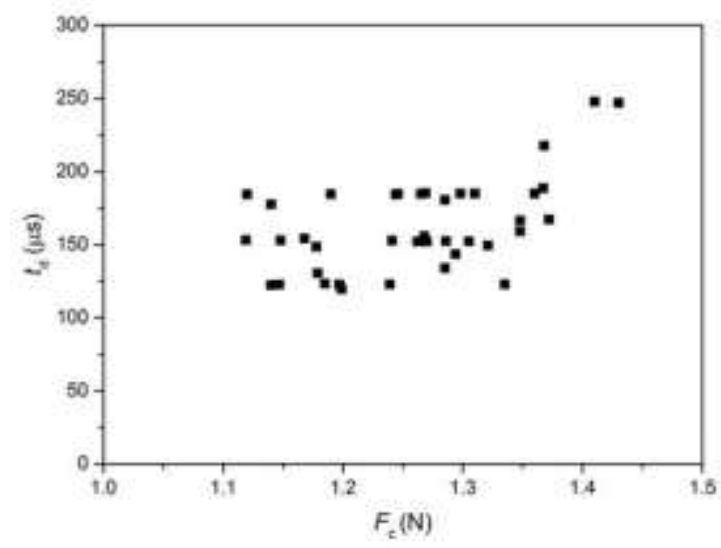

(b)

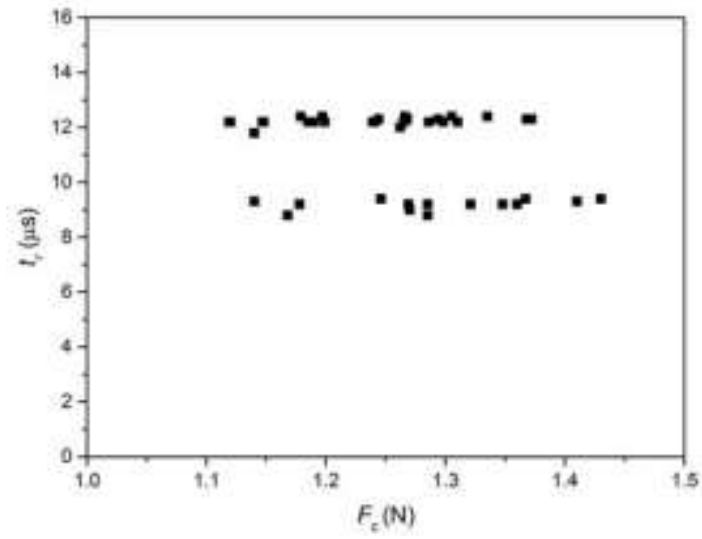

(d)

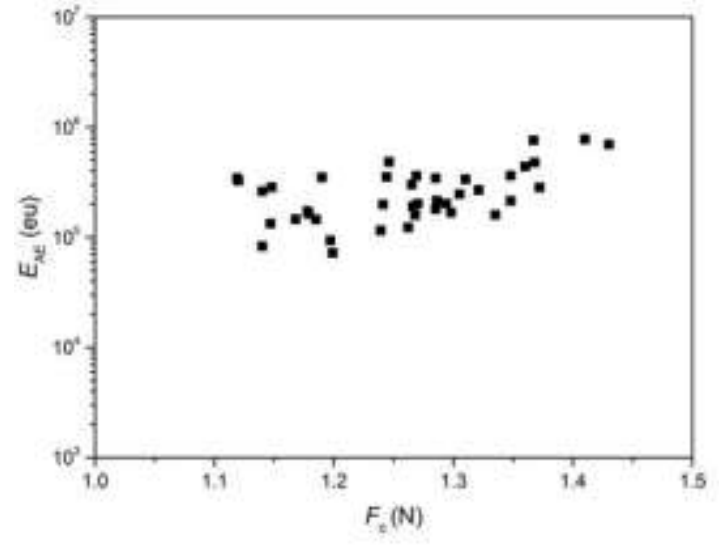

Fig. 5.24: The first $\mathrm{AE}$ event results of the $\mathrm{Al}-\mathrm{Si}_{3} \mathrm{~N}_{4}-\mathrm{Si}$ specimen plotted against $F_{\mathrm{c}}$ during the indentation loading stage: (a) $A$, (b) $t_{\mathrm{r}}$, (c) $t_{\mathrm{d}}$, and (d) $E_{\mathrm{AE}}$.

\subsubsection{2 $\mathrm{CuTi}-\mathrm{Si}_{3} \mathrm{~N}_{4}-\mathrm{Si}$ specimen}

Similar to that result of the $\mathrm{Al}-\mathrm{Si}_{3} \mathrm{~N}_{4}-\mathrm{Si}$ specimens, the first $\mathrm{AE}$ event detected during the loading stage is related to the 'pop-in' observation in the $F$ - $d$ curve, and corresponds to $F_{\mathrm{c}}$ and $d_{\mathrm{c}}$ (Fig. 5.26). It is observed that a very weak second AE event is also detected during the unloading stage, and the occurrence is only $<10 \%$ of the total indents. The AE parameters and $F$ are plotted against $t$ for one of the indents, as shown in Fig. 5.27. 
(a)

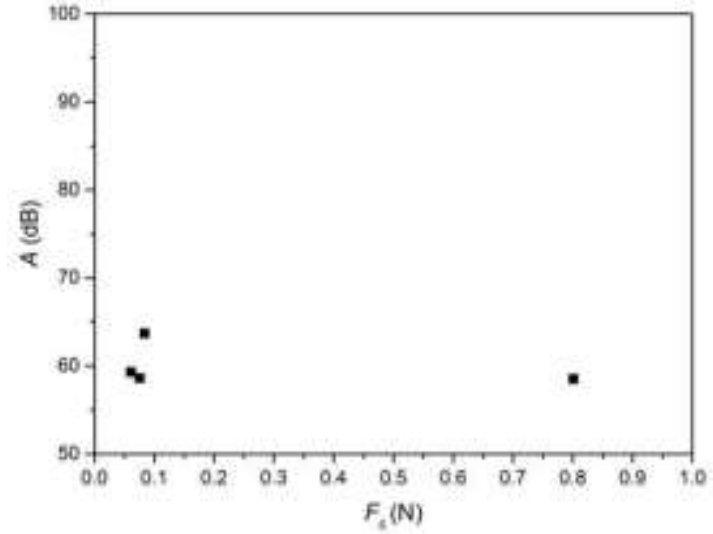

(c)

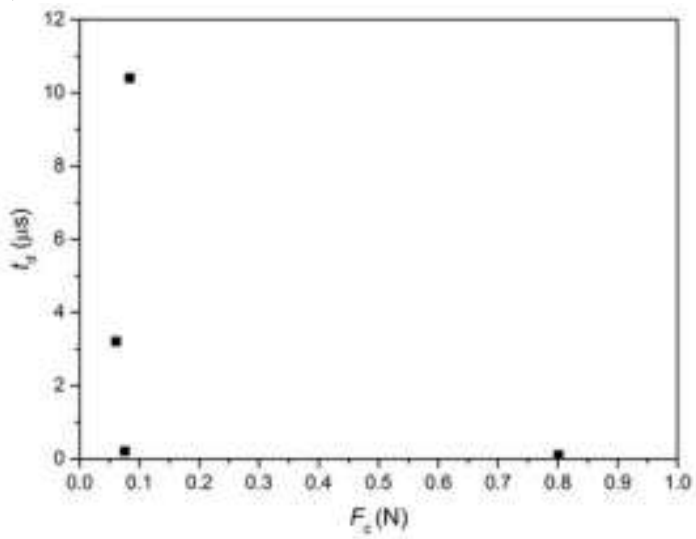

(b)

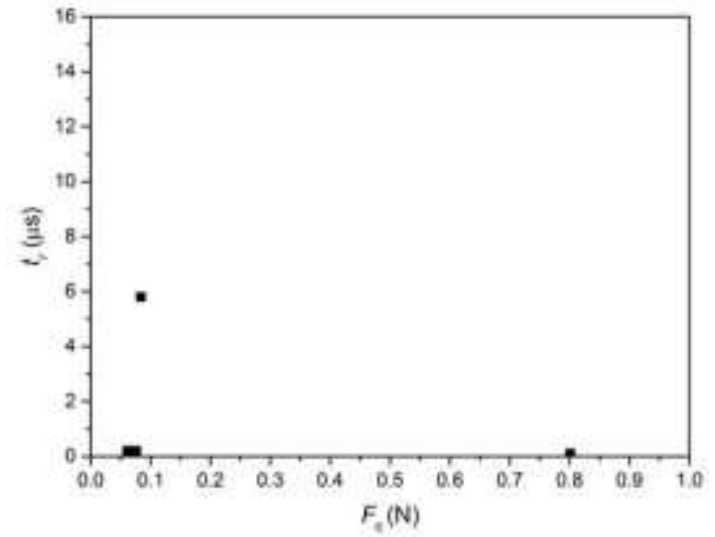

(d)

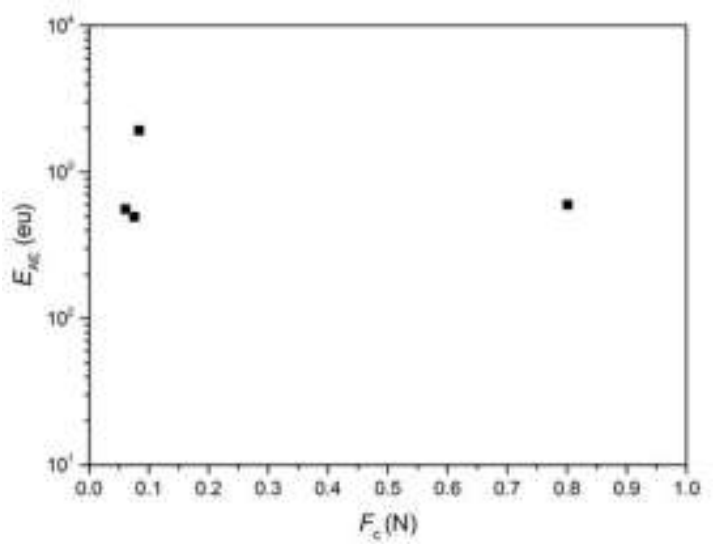

Fig. 5.25: The second $\mathrm{AE}$ event results of the $\mathrm{Al}-\mathrm{Si}_{3} \mathrm{~N}_{4}-\mathrm{Si}$ specimen plotted against $F_{\mathrm{c}}$ during the indentation unloading stage: (a) $A$, (b) $t_{\mathrm{r}}$, (c) $t_{\mathrm{d}}$, and (d) $E_{\mathrm{AE}}$.

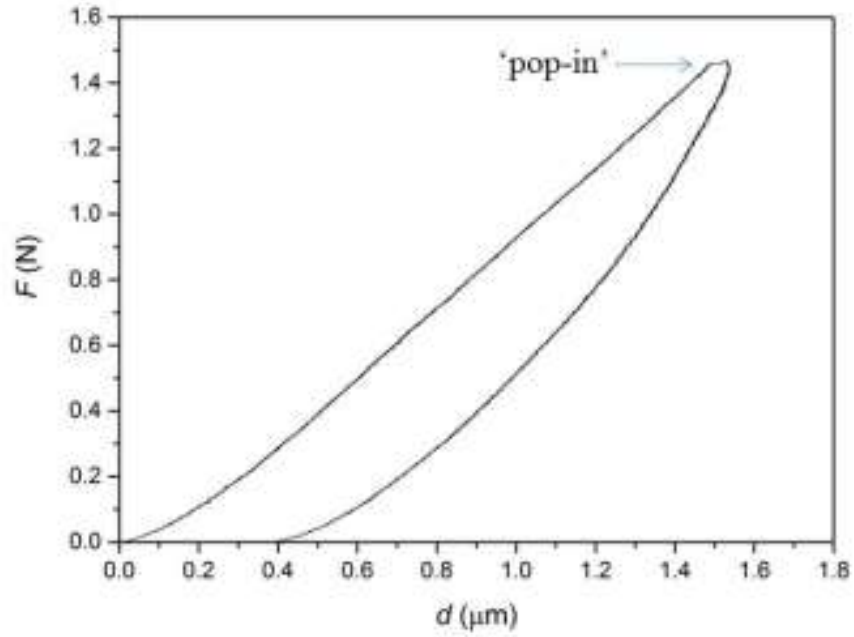

Fig. 5.26: The $F-d$ curve of the $\mathrm{CuTi}-\mathrm{Si}_{3} \mathrm{~N}_{4}-\mathrm{Si}$ specimen after the indentation damage test. 
(a)

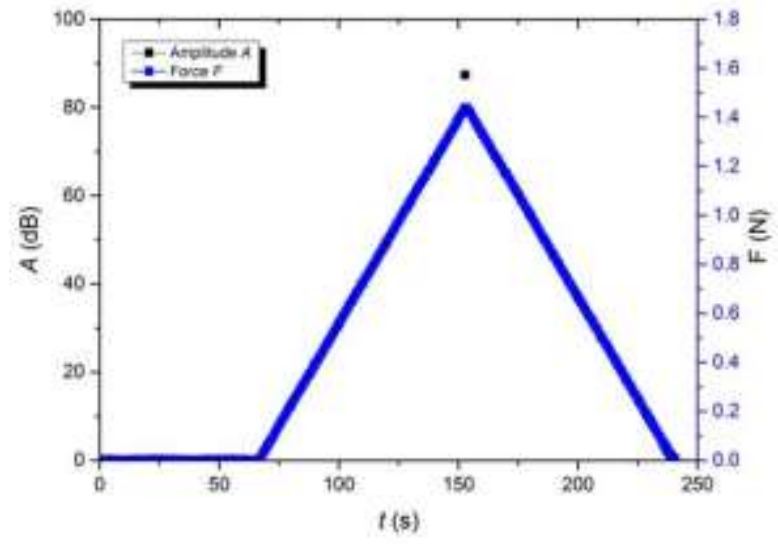

(c)

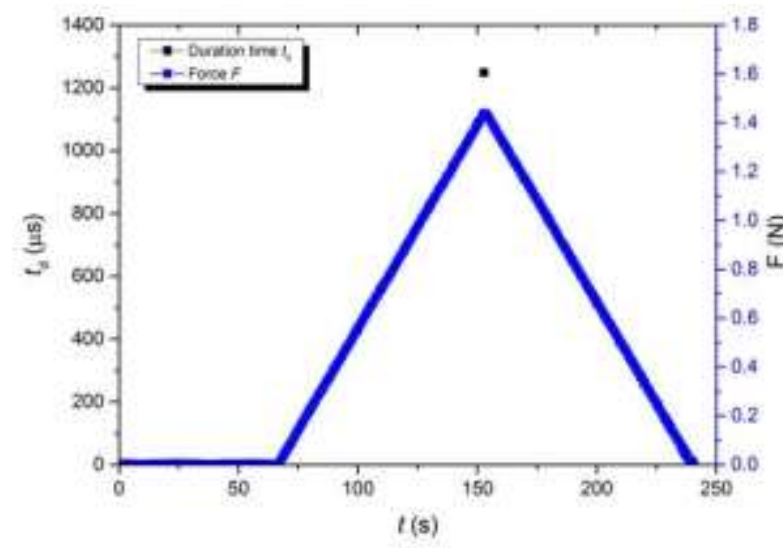

(b)

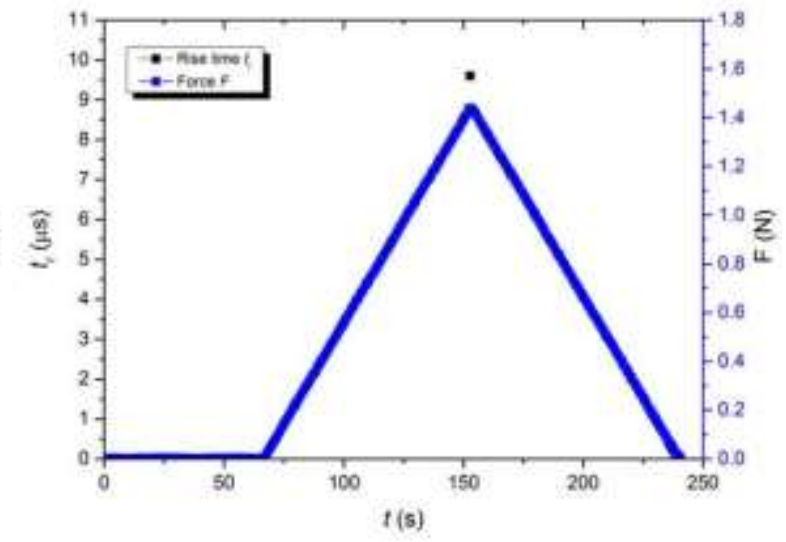

(d)

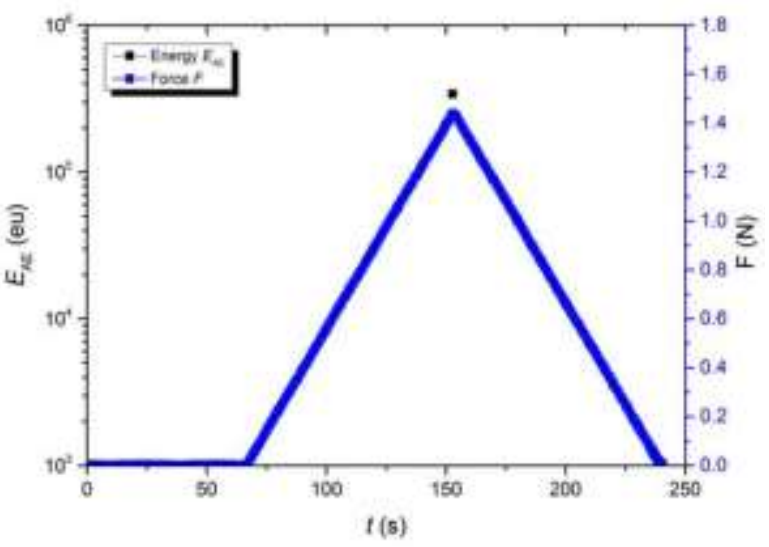

Fig. 5.27: The results of $F$ and $\mathrm{AE}$ parameters plotted against $t$ for the $\mathrm{CuTi}-\mathrm{Si}_{3} \mathrm{~N}_{4}-\mathrm{Si}$ specimen after the indentation damage test: (a) $A$, (b) $t_{\mathrm{r}}$, (c) $t_{\mathrm{d}}$, and (d) $E_{\mathrm{AE}}$.

There is no cracking observed on the top $\mathrm{Cu}$ layers for all the $\mathrm{CuTi}-\mathrm{Si}_{3} \mathrm{~N}_{4}-\mathrm{Si}$ specimens after the indentation damage test, except a round indented mark and a pile-up around the indented area (Fig. 5.28(a)). However, delayering of the top $\mathrm{Cu}$ layer reveals median and radial cracking on the Ti surfaces, and further removal of the Ti layer exposes ring, median and radial cracking on the $\mathrm{Si}_{3} \mathrm{~N}_{4}$ surfaces. The cross-sectioning (FIB and $\mathrm{SEM}$ ) of the specimen uncovers the through-thickness crack in the $\mathrm{Si}_{3} \mathrm{~N}_{4}$ dielectric layer and the sub-surface lateral cracking in the Si substrate (Fig. 5.28(b)). 
(a)

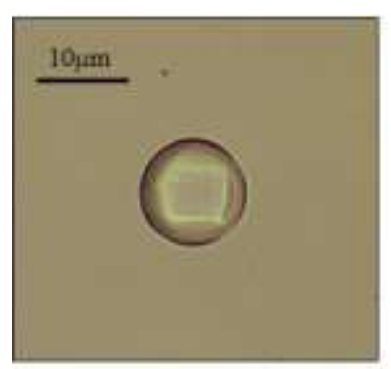

After indentation

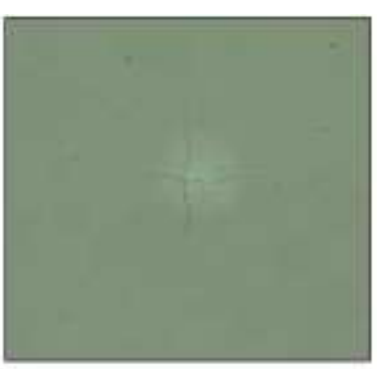

After Cu removal

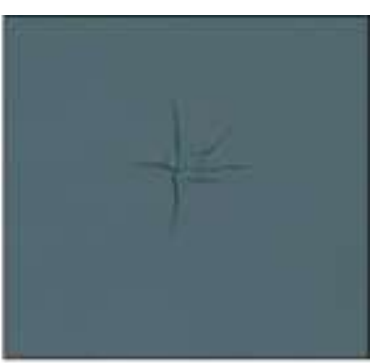

After Ti removal

(b)
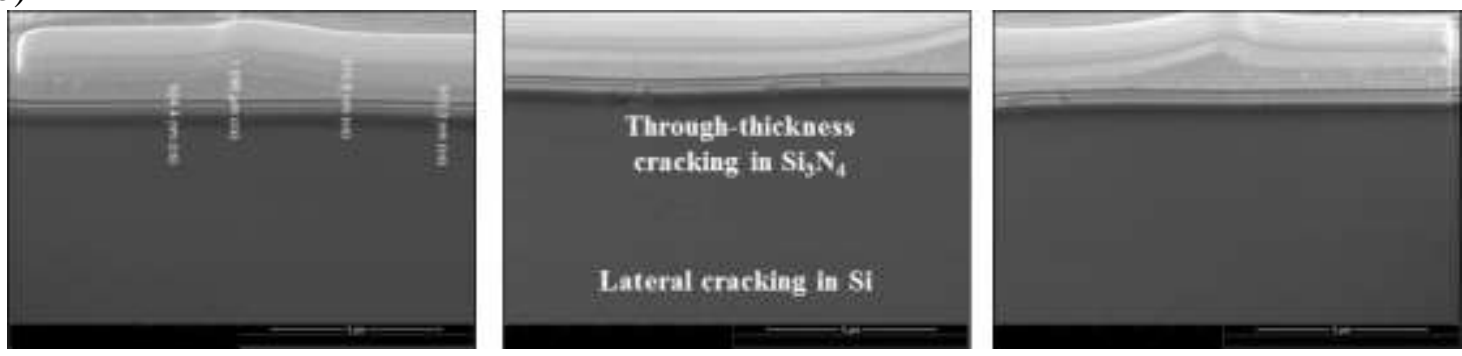

Fig. 5.28: The failure modes of the $\mathrm{CuTi}-\mathrm{Si}_{3} \mathrm{~N}_{4}-\mathrm{Si}$ specimen after the indentation damage test: (a) surface optical images, and (b) cross-sectional SEM images.

The mean values of $F_{\mathrm{c}}$ and $d_{\mathrm{c}}$ for $\mathrm{CuTi}-\mathrm{Si}_{3} \mathrm{~N}_{4}-\mathrm{Si}$ specimen are $1.48 \mathrm{~N}$ and $1.44 \mu \mathrm{m}$, respectively (Fig. 5.29). Verification testing is conducted at $F_{\mathrm{m}}=1 \mathrm{~N}$, which is smaller than $F_{\mathrm{c}}$ (Fig. 5.30), and no $\mathrm{AE}$ event and specimen cracking are observed (Fig. 5.31). Unlike the metal-coated $\mathrm{SiO}_{2}$-Si specimen, there is no visible mark detected on the $\mathrm{Si}_{3} \mathrm{~N}_{4}$ surface after the removal of the top CuTi layer.

(a)

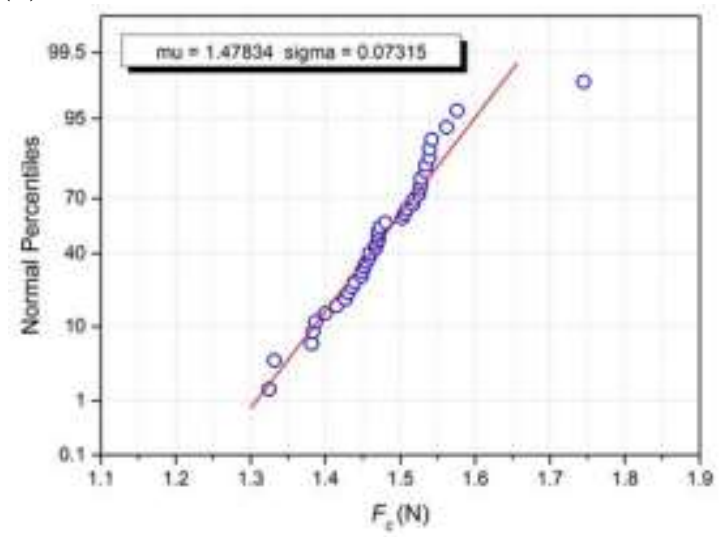

(b)

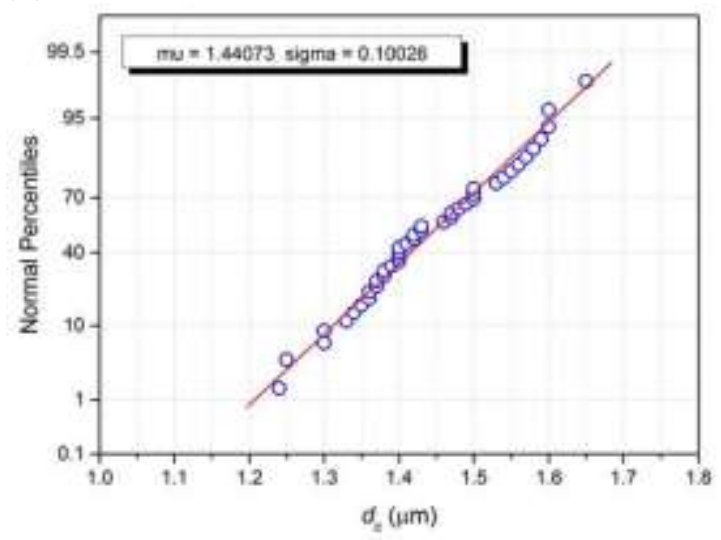

Fig. 5.29: The probability plots of CuTi-Si ${ }_{3} \mathrm{~N}_{4}-\mathrm{Si}$ specimen: (a) $F_{\mathrm{c}}$, and (b) $d_{\mathrm{c}}$. 


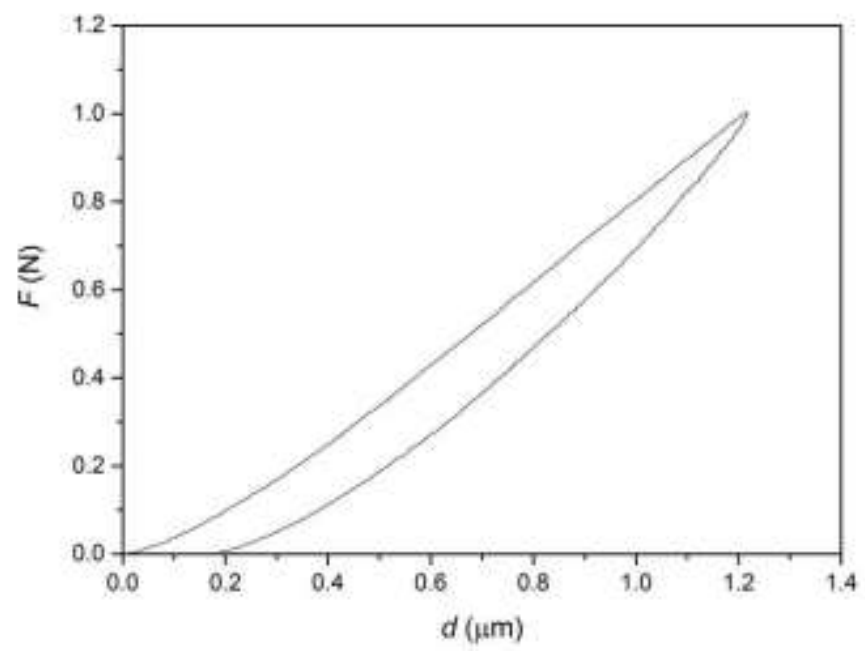

Fig. 5.30: The $F-d$ curve of the $\mathrm{CuTi}-\mathrm{Si}_{3} \mathrm{~N}_{4}-\mathrm{Si}$ specimen after the verification test.

(a)

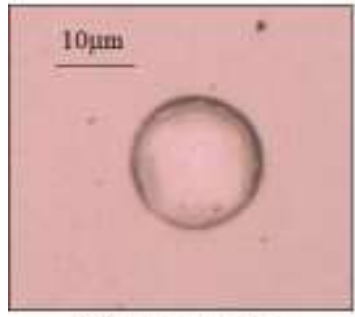

After indentation (b)

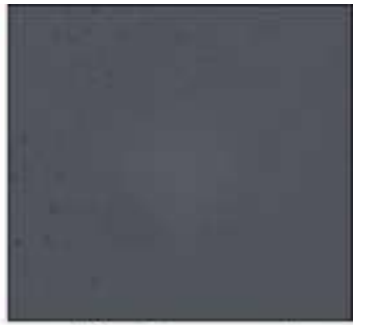

After Cu removal

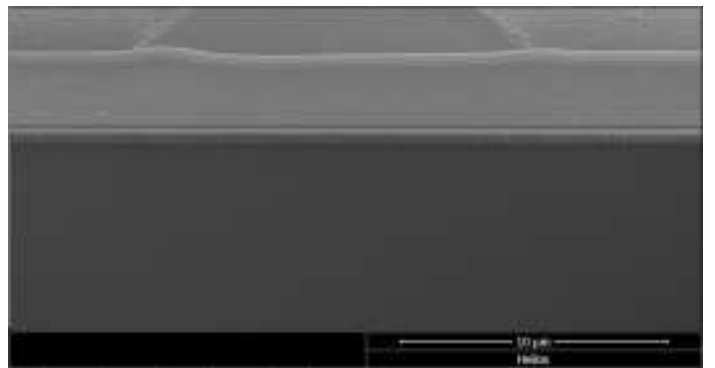

Fig. 5.31: The physical examination of the $\mathrm{CuTi}-\mathrm{Si}_{3} \mathrm{~N}_{4}-\mathrm{Si}$ specimen after the verification test: (a) surface optical images, and (b) cross-sectional SEM images.

The parameters of the first AE transient signal detected at the loading stage are plotted against $F_{\mathrm{c}}$, as shown in Fig. 5.32. The rise duration $t_{\mathrm{r}}$ is either $\sim 9$ or $\sim 12 \mu \mathrm{s}$, which is similar to that of the $\mathrm{Al}-\mathrm{Si}_{3} \mathrm{~N}_{4}-\mathrm{Si}$ specimen. However, the magnitudes of $A, t_{\mathrm{d}}$, and $E_{\mathrm{AE}}$ seem to be independent of $F_{c}$, in contrary to those results obtained for the $\mathrm{Al}-\mathrm{Si}_{3} \mathrm{~N}_{4}-\mathrm{Si}$ specimen. 
(a)

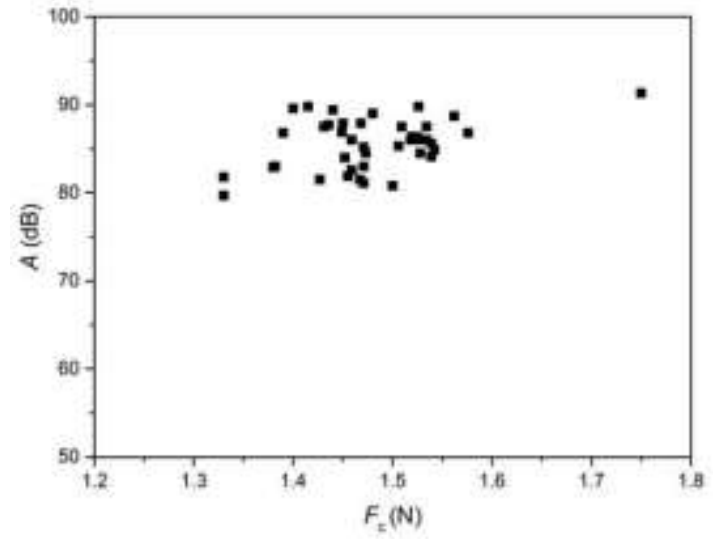

(c)

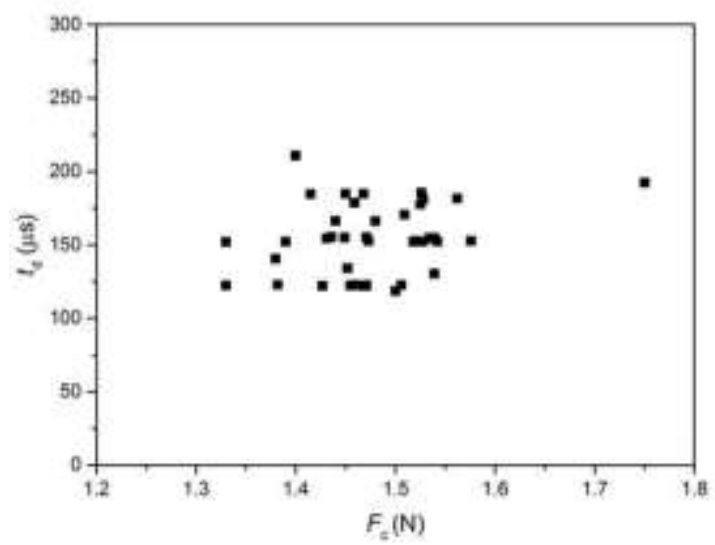

(b)

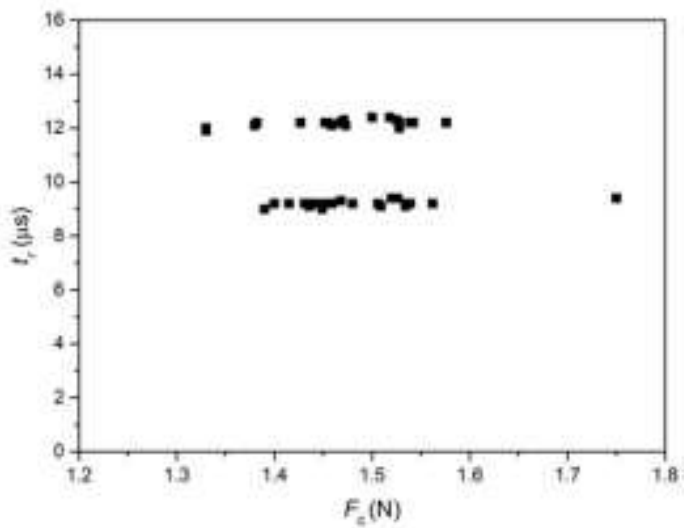

(d)

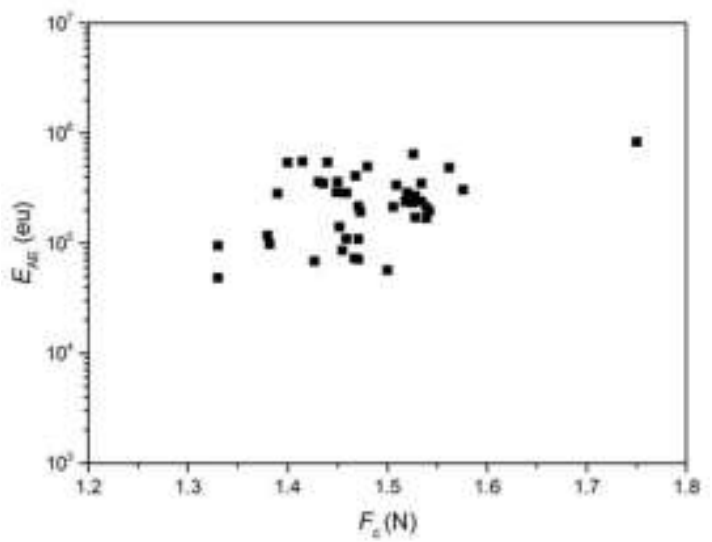

Fig. 5.32: The first $\mathrm{AE}$ event results of the $\mathrm{CuTi}-\mathrm{Si}_{3} \mathrm{~N}_{4}-\mathrm{Si}$ specimen plotted against $F_{\mathrm{c}}$ during the indentation loading stage: (a) $A$, (b $t_{\mathrm{r}}$, (c) $t_{\mathrm{d}}$, and (d) $E_{\mathrm{AE}}$.

The parameters of the second AE transient signal detected during the unloading stage are plotted against $F_{\mathrm{c}}$, as shown in Fig. 5.33. Similar to the observation in the $\mathrm{Al}-\mathrm{Si}_{3} \mathrm{~N}_{4}-\mathrm{Si}$ specimen, a second AE event is detected during the unloading stage within a range of 0.04-0.09 $\mathrm{N}$ for the four indents. Generally, the lower values of the AE parameters are recorded during the unloading stage, as compared to those obtained in the loading stage (the first AE events). 
(a)

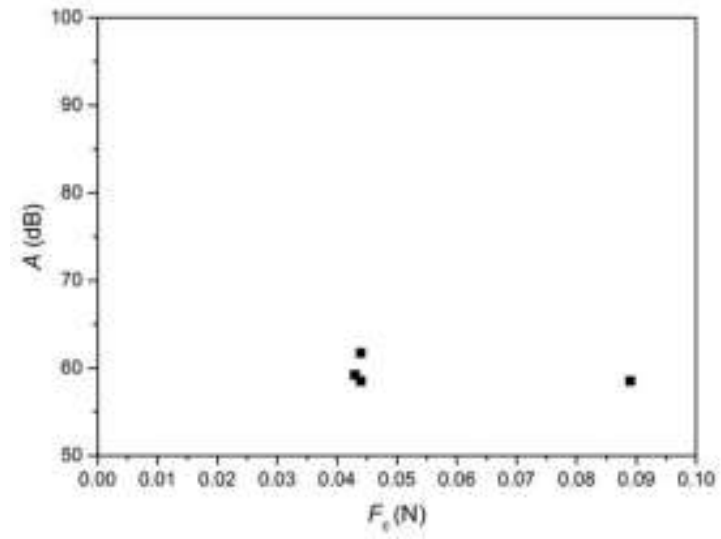

(c)

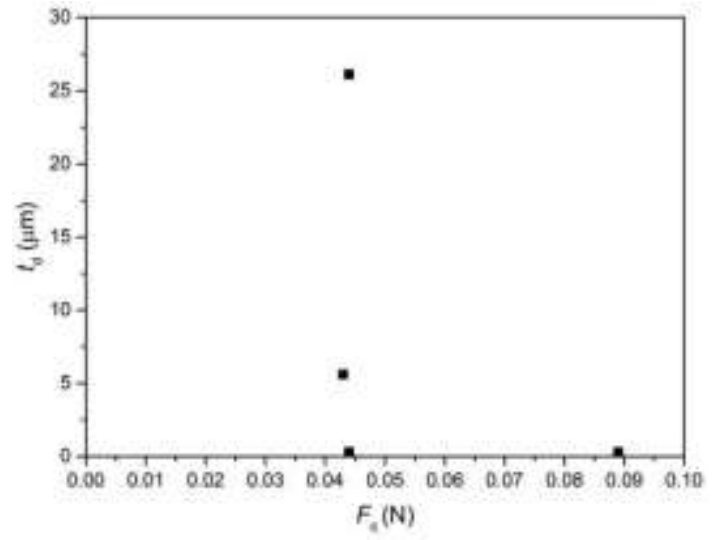

(b)

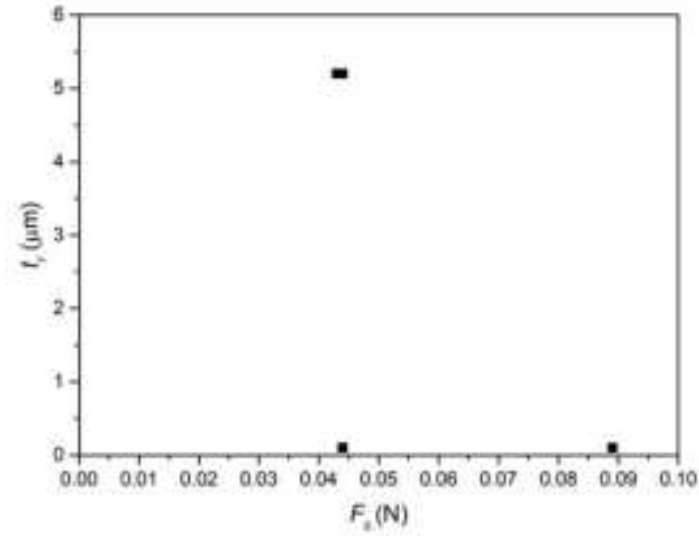

(d)

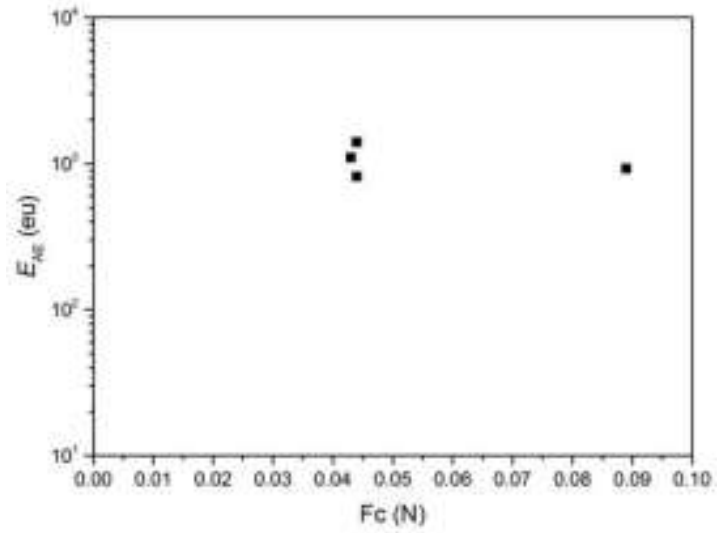

Fig. 5.33: The second $\mathrm{AE}$ event results of the $\mathrm{CuTi}-\mathrm{Si}_{3} \mathrm{~N}_{4}-\mathrm{Si}$ specimen plotted against $F_{\mathrm{c}}$ during the indentation unloading stage: (a) $A$, (b) $t_{\mathrm{r}}$, (c) $t_{\mathrm{d}}$, and (d) $E_{\mathrm{AE}}$.

\subsection{Indentation damage model}

In order to uncover the damage behavior during the unloading stage for the metalcoated $\mathrm{SiO}_{2}-\mathrm{Si}$ specimens, additional testing is conducted on those specimens after removing their top metal layers. First, the specimens are prepared by etching away the top Al layer to expose the dielectric $\left(\mathrm{SiO}_{2}\right.$ and $\left.\mathrm{Si}_{3} \mathrm{~N}_{4}\right)$ layers. The same loading and unloading rate of $1 \mathrm{~N} / \mathrm{min}$ is applied. Both $F_{\mathrm{c}}$ and $d_{\mathrm{c}}$ results are presented in Fig. 5.34, together with those results obtained earlier for the $\mathrm{Al}-\mathrm{SiO}_{2}-\mathrm{Si}, \mathrm{Al}-\mathrm{Si}_{3} \mathrm{~N}_{4}-\mathrm{Si}, \mathrm{CuTi}-\mathrm{SiO}_{2}-\mathrm{Si}$ and $\mathrm{CuTi}-$ $\mathrm{Si}_{3} \mathrm{~N}_{4}-\mathrm{Si}$ specimens. The mean values of $F_{\mathrm{c}}$ for the $\mathrm{SiO}_{2}-\mathrm{Si}$ and $\mathrm{Si}_{3} \mathrm{~N}_{4}-\mathrm{Si}$ specimens are 
$\sim 2.2$ and $\sim 1.6 \mathrm{~N}$, respectively. The values of $F_{\mathrm{c}}$ are slightly higher than those for the metal-coated specimens, which can be highly attributed by the different intrinsic or residual stresses in the specimen before and after the removal of top metal layer. Nevertheless, this evaluation attests that the $F_{\mathrm{c}}$ is independent of the metal coating applied.

(a)

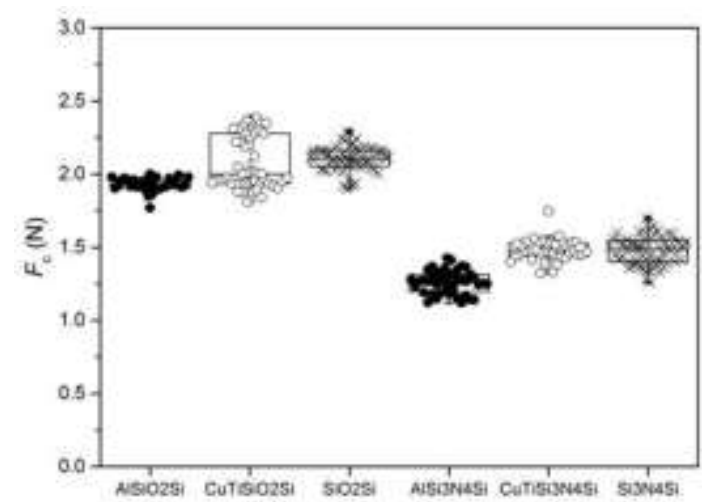

(b)

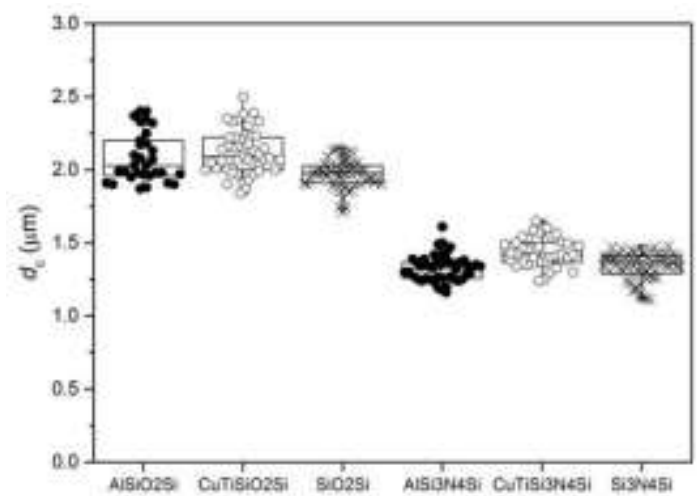

Fig. 5.34: The indentation damage test results for the different thin-film stacked specimens: (a) $F_{\mathrm{c}}$, and (b) $d_{\mathrm{c}}$.

The radial cracking and chipping on the $\mathrm{SiO}_{2}$ surface are observed after the indentation damage tests (Fig 5.35). The cross-sectioning (FIB and SEM) of the specimen reveals the sub-surface cone and lateral cracking in the Si substrate. These failure modes are similar to those observed in the metal-coated $\mathrm{SiO}_{2}$ specimens, where the chipping of the $\mathrm{SiO}_{2}$ layer and/or $\mathrm{Si}$ substrate is a severe failure mode in comparison to a partial "white-ring" observed at the perimeter of the imprinted $\mathrm{SiO}_{2}$ surface (Fig. 5.12(a)).

It was reported that a through-thickness cracking and peeling or delamination of a hard coating layer could occur during the loading stage of an indentation test [90-91, 97, 105]. The damage mechanism was due to high bending stresses at the edges of the buckled thin-coating, which was the result of using a sharp indenter like a Berkovich or 
Vickers tip (Fig. 2.9). However, the damage or cracking behavior and mechanism will be different if a blunt indenter like a sphero-conical tip is used.

(a)

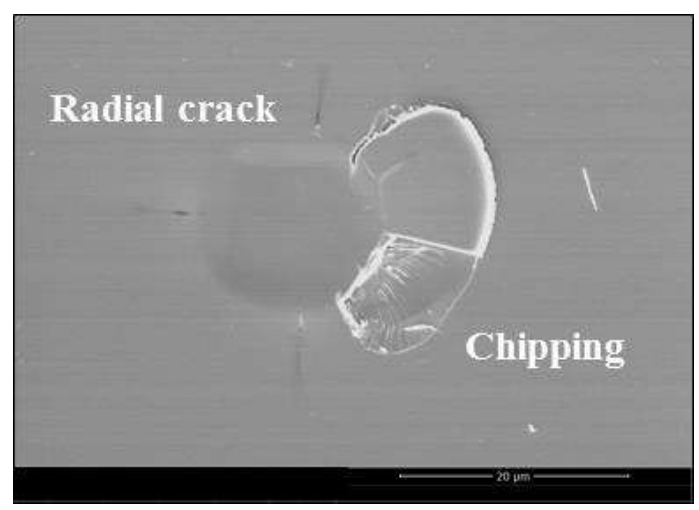

(b)
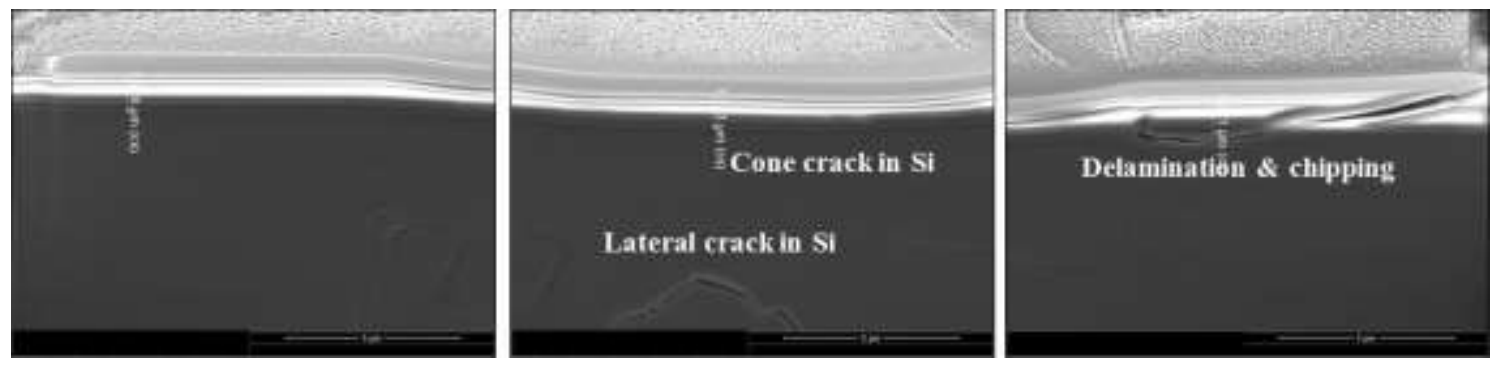

Fig. 5.35: The failure modes of the $\mathrm{SiO}_{2}-\mathrm{Si}$ specimen after the indentation damage test: (a) surface and (b) cross-sectional SEM images.

The damage on the $\mathrm{Si}_{3} \mathrm{~N}_{4}$-Si specimen is similar to those observed on the metal-coated $\mathrm{Si}_{3} \mathrm{~N}_{4}$ specimens, where the median, ring, and radial cracking are also observed on the $\mathrm{Si}_{3} \mathrm{~N}_{4}$ dielectric surface (Fig 5.36). The cross-sectioning (FIB and SEM) of the specimen reveals the through-thickness crack in the $\mathrm{Si}_{3} \mathrm{~N}_{4}$ dielectric layer, and the sub-surface lateral cracking in the Si substrate.

As the $\mathrm{SiO}_{2}$ dielectric has an elastic modulus which is $\sim 3$ times lower than that of $\mathrm{Si}_{3} \mathrm{~N}_{4}$, and thus from the cross-sectional SEM images (Figs. 5.4, 5.12, 5.20, 5.28), the $\mathrm{SiO}_{2}$ dielectric layer experiences a larger deformation or "bending" without any through- 
thickness cracking, as compared to the $\mathrm{Si}_{3} \mathrm{~N}_{4}$ electric layer. This is further evident by a lower $F_{\mathrm{c}}$ usually measured for those specimens with the $\mathrm{Si}_{3} \mathrm{~N}_{4}$ dielectric layer.

(a)

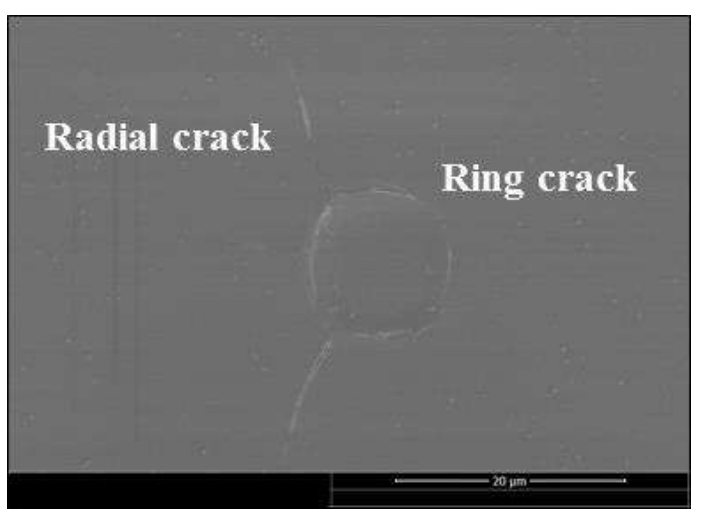

(b)
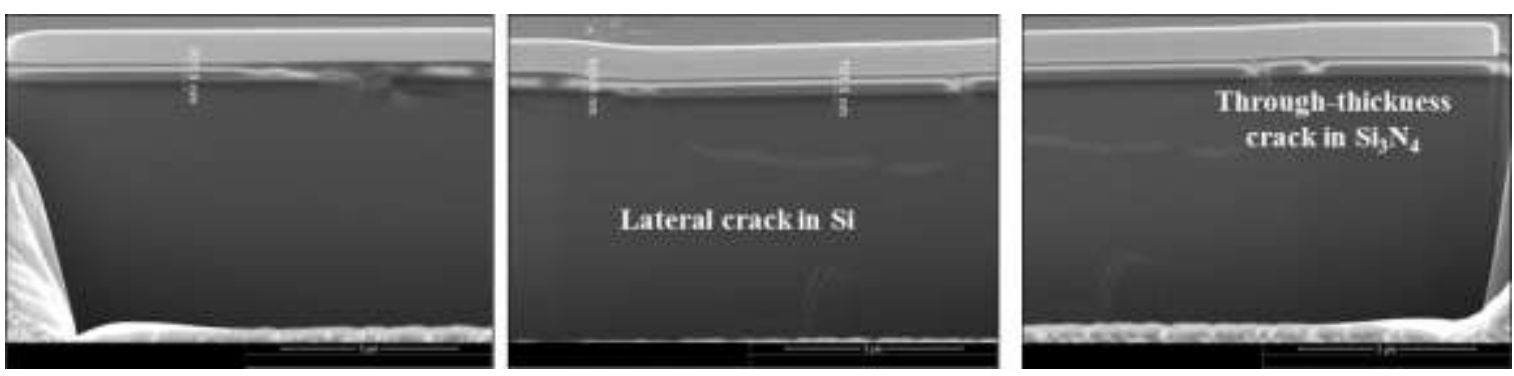

Fig. 5.36: The failure modes of the $\mathrm{Si}_{3} \mathrm{~N}_{4}$ specimen after the indentation damage test: (a) surface and (b) cross-sectional SEM images.

A second $\mathrm{AE}$ event is detected during the unloading stage for the $\mathrm{SiO}_{2}-\mathrm{Si}$ specimen, which is most probably due to the delamination and chipping of the $\mathrm{SiO}_{2}$ layer or/and $\mathrm{Si}$ substrate. During the unloading stage, a large elastic recovery of the highly deformed $\mathrm{SiO}_{2}$ dielectric is expected (higher $F_{\mathrm{c}}$ measured), and results in a large strain energy released through delamination or interfacial cracking between the dielectric layer and Si substrate. If the indentation is conducted on the metal-coated $\mathrm{SiO}_{2}-\mathrm{Si}$ specimen, chipping of the $\mathrm{SiO}_{2}$ layer or/and $\mathrm{Si}$ substrate may be prevented. In addition, a larger elastic recovery from both the metal and dielectric layers is expected, and will yield a higher strain energy 
release during the unloading stage, which is susceptible to delamination between the dielectric layer and Si substrate.

It is observed that the detected $V_{\mathrm{s}}$ of the first $\mathrm{AE}$ event is much larger than that of the second one, which can provide insights to the occurrence of the different damage modes during the loading and unloading stages. As a large ultrasonic wave intensity or $E_{\mathrm{AE}}$ is usually emitted for a sudden cracking, as observed in the Si substrate during the loading stage, and a weak $E_{\mathrm{AE}}$ might account for the delamination failure during the unloading stage. In addition, this weak $E_{\mathrm{AE}}$ detected in the second $\mathrm{AE}$ event could be attenuated further within the damage areas (crack lines and gaps) that are induced during the earlier loading stage.

For the $\mathrm{Si}_{3} \mathrm{~N}_{4}-\mathrm{Si}$ specimen, a negligible second $\mathrm{AE}$ signal is recorded, which is found only on the three indents. This may be highly due to the effect of the contact friction between the diamond indenter tip and the damaged and fragmented $\mathrm{Si}_{3} \mathrm{~N}_{4}$ dielectric layer. Generally, if a through-thickness of the dielectric layer occurs, there will be minimum or no elastic recovery of this dielectric during the unloading stage, and hence delamination will never occur in the metal-coated $\mathrm{Si}_{3} \mathrm{~N}_{4}$-Si specimen.

The damage behavior of the metal-coated thin-films stacked structure during the indentation loading-unloading cycle is presented in Fig. 5.37, where for simplicity the pile-up of the top metallization by the indenter is not drawn. For the metal-coated $\mathrm{SiO}_{2}$ dielectric specimen (Fig. 5.37(a)), the top metal layer undergoes an elastic-plastic deformation during the loading (stage I), while the dielectric layer and the Si substrate are assumed to undergo the elastic deformation. When the first $\mathrm{AE}$ event is detected, the indenter stops immediately (stage II), and $F_{\mathrm{c}}$ is determined that corresponds to the ring 
and radical cracking on the dielectric surface, and the sub-surface cone and the lateral cracking in the Si substrate. Subsequently, the indenter retracts and the stacked structure then undergoes an elastic recovery. As the indentation load reduces, a second AE event occurs, which indicates the occurrence of the delamination or interfacial cracking between the dielectric layer and Si substrate (stage III). When the test is performed on the exposed $\mathrm{SiO}_{2}$ dielectric specimen, chipping or peeling is observed. However, for the metal-coated $\mathrm{Si}_{3} \mathrm{~N}_{4}$ dielectric specimen (Fig. 5.37(b)), the first AE event detected at the loading stage is the results of the median, ring and radial cracking observed on the dielectric surface, including the through-thickness cracking in the dielectric layer, and the sub-surface lateral cracking in the Si substrate.

(a)

I. Loading of indenter.

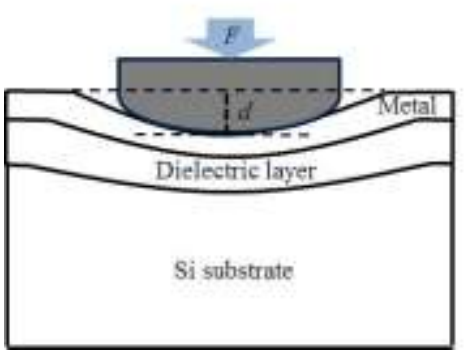

(b)
II. Loading stop when $1^{\text {st }} \mathrm{AE}$ event detected.

III. Unloading of indenter

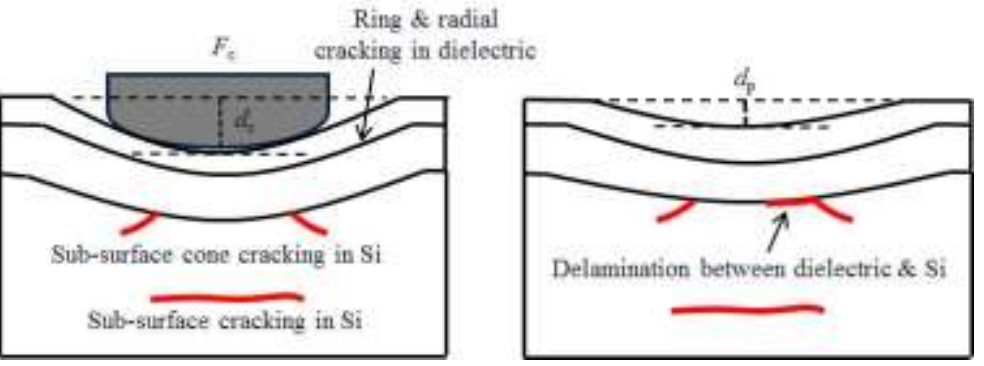

III. Unloading of indenter

II. Loading stop when $1^{\text {st }} \mathrm{AE}$ event detected.

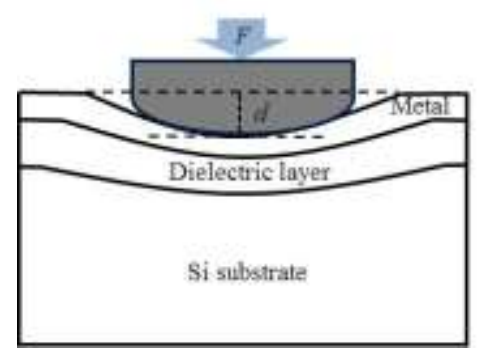

Median, ring \& radial

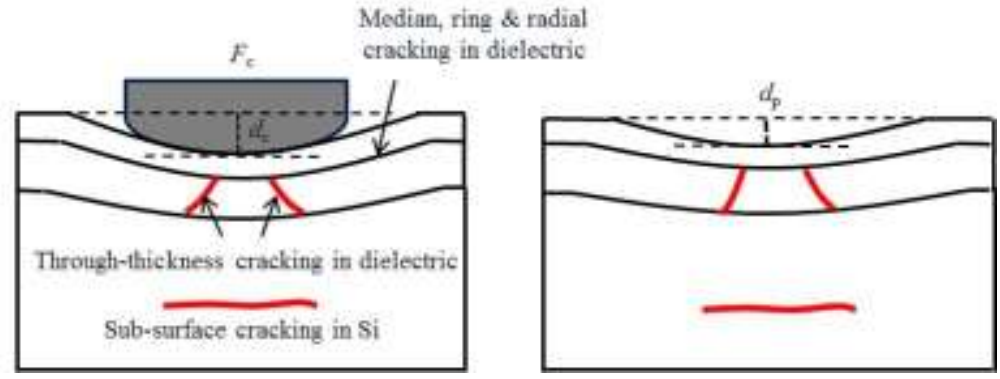

Fig. 5.37: The indentation damage model for: (a) the metal-coated $\mathrm{SiO}_{2}$ dielectric, and (b) the metal-coated $\mathrm{Si}_{3} \mathrm{~N}_{4}$ dielectric on the $\mathrm{Si}$ substrate. 
The real scenario has many multiple cracking failure modes (Fig 1.1), which depend on the failure mechanisms, for examples, ultrasonic, impact or contact load (Chapter 2.1). Fig. 5.37 shows the typically observed cracking modes under the contact loading only, where are interpreted with the experimental obtained $F-d$ curve and AE response.

\subsection{Finite element modelling and simulation results}

As described in Chapter 4, a similar FE modelling approach is used to simulate the indentation test on the thin-film stacked structure without considering the time effect. A three-dimensional (3D) quarter model is built using the solid (SOLID185) and contact pair (TARGE170 and CONTA173) elements, with the applied boundary and displacement loading conditions, as shown in Fig. 5.38. No intrinsic stress from the specimen preparation is considered, and perfect adhesion is assumed at all the interfaces of the thinfilm stacked structure.

The diamond indenter is modelled to have linear-elastic behaviour, where the elastic modulus $E$ and the Poison's ratio $v$ take the values of $1141 \mathrm{GPa}$ and 0.07 , respectively. The Si substrate is described according to the material model developed in Chapter 4, where $E=150 \mathrm{GPa}$, yield stress $Y=7.3 \mathrm{GPa}$, tangent modulus $E_{\mathrm{t}}=0.1 E$, and Poison's ratio $v=0.28$. The $F-d$ response is modelled and curve-fitted to the experimental results to obtain the material parameters $E, Y$ and $E_{\mathrm{t}}$ for the top metal and intermediate dielectric layers. The calibrated model is then employed to simulate the indentation test on the metal-coated thin-film specimens. 

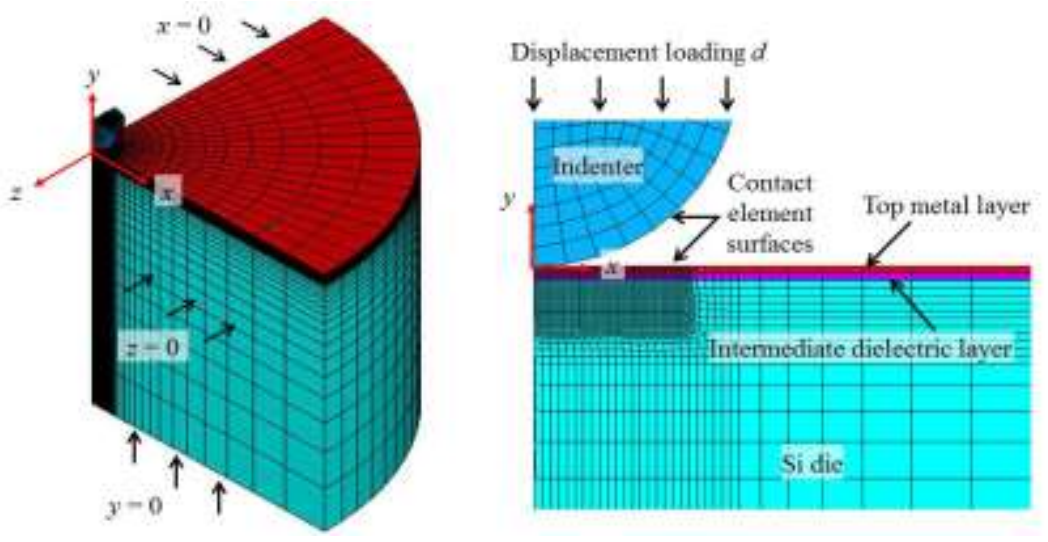

Fig. 5.38: The FE model of the thin-film stacked structure.

\subsubsection{FE model development}

Several features in the typical $F-d$ curve (Fig. 5.39), including (i) the maximum force $F_{\mathrm{m}}$, (ii) the unloading or contact stiffness $S$, (iii) the final displacement $d_{\mathrm{p}}$ after unloading, and (iv) the plastic energy that is defined by the area enclosed between the loading and unloading curves, are employed as the fitting criteria between the experimental and modelling results. The indentation test is simulated at the $1-\mu \mathrm{m}$ displacement loading condition, where no specimen damage is observed in the experiment result. The subsequent results of $F$ - $d$ curves are the averaged data obtained from the experiments.

With the knowledge of the $E, Y$ and $E_{\mathrm{t}}$ of the $\mathrm{Si}$ substrate, both the modelling and experimental testing are then conducted on the system of a single dielectric layer $\mathrm{SiO}_{2}$ or $\mathrm{Si}_{3} \mathrm{~N}_{4}$ on the $\mathrm{Si}$ substrate under indentation. The $E, Y$ and $E_{\mathrm{t}}$ for both $\mathrm{SiO}_{2}$ and $\mathrm{Si}_{3} \mathrm{~N}_{4}$ are determined iteratively by fitting the $F$ - $d$ curves obtained from the modelling to those from the experimental testing (Fig. 5.40). Afterwards, both the modelling and experimental testing are conducted on the system consisting of the top Al or CuTi metal layer, the intermediate $\mathrm{SiO}_{2}$ and $\mathrm{Si}_{3} \mathrm{~N}_{4}$ dielectric layer, and the $\mathrm{Si}$ substrate under indentation. The $E$, 
$Y$ and $E_{\mathrm{t}}$ for $\mathrm{Al}, \mathrm{Cu}$ and $\mathrm{Ti}$ are then determined iteratively through fitting the modelling results with the experimental results of $F$ - $d$ curves (Figs. 5.41-5.43). All the material parameters determined are summarized in Table 5.2. The Poisson's ratios $v$ of the metals and dielectric layers are taken as 0.3 , as $v$ has a negligible effect on the modelling results, as reported by Chen et al [67].

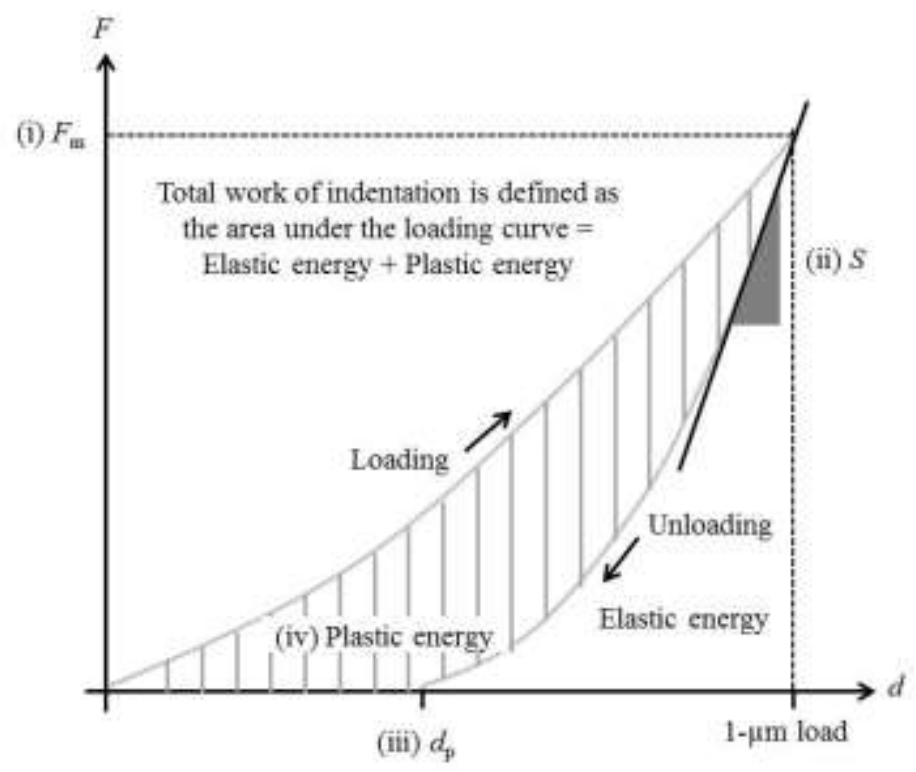

Fig. 5.39: The fitting criterion features in the $F-d$ curve during the indentation testing.

It is observed that the fitting of the initial $F-d$ curve does not match well in all the cases, possibly due to the non-ideal spherical shape of the diamond indenter tip used, as its shape factor effect is not considered in the FE model. The other possible reason could be due to the hard oxidized surface layer of the specimen rather than its original soft metal surface for which the experimental results show a steeper slope during the initial contact.

Generally, a decrease in $E$ of the top-layer material tends to decrease the slopes or reduce the gradients for both the loading and unloading paths of the $F-d$ curve, and thus yields a low contact stiffness $S$ and the maximum force; while a decrease in $Y$ tends to increase the plastic work and the residue displacement. In some cases, the resultant $F$ - $d$ 
curve may not be obvious for different $E$ and/or $Y$ values of the top-layer material, as the interaction effects from the underlying material may be more dominant. It is also observed that $Y$ obtained for the top metal layers is higher than those for bulk specimens of the same material, and this could be due to the existence of fewer defects in the thin-film specimen [138], and the constrained dislocation motion within the thickness of the film or the grains [139].

(a)

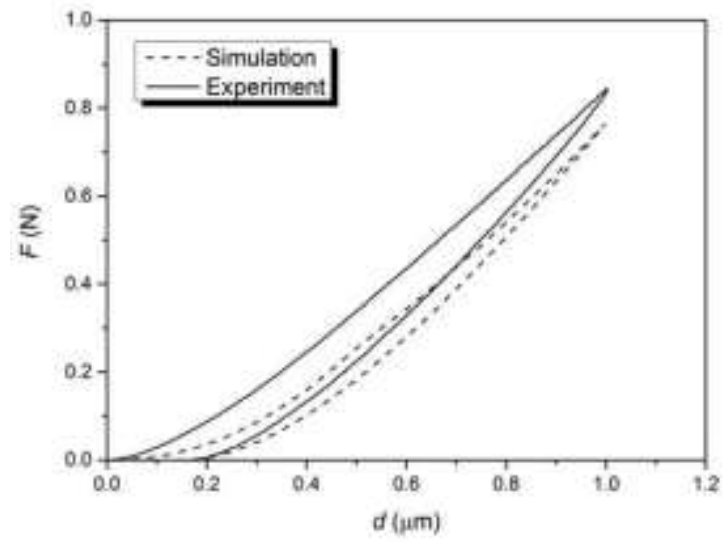

(b)

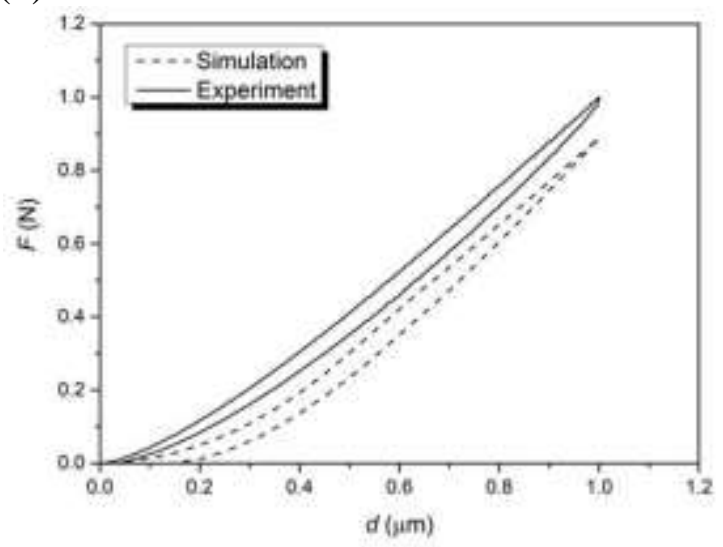

Fig. 5.40: The comparison of the experiment and modelling results for a single dielectric layer on the $\mathrm{Si}$ substrate after the $1-\mu \mathrm{m}$ indentation test: (a) $\mathrm{SiO}_{2}-\mathrm{Si}$ and (b) $\mathrm{Si}_{3} \mathrm{~N}_{4}-\mathrm{Si}$ specimens.

(a)

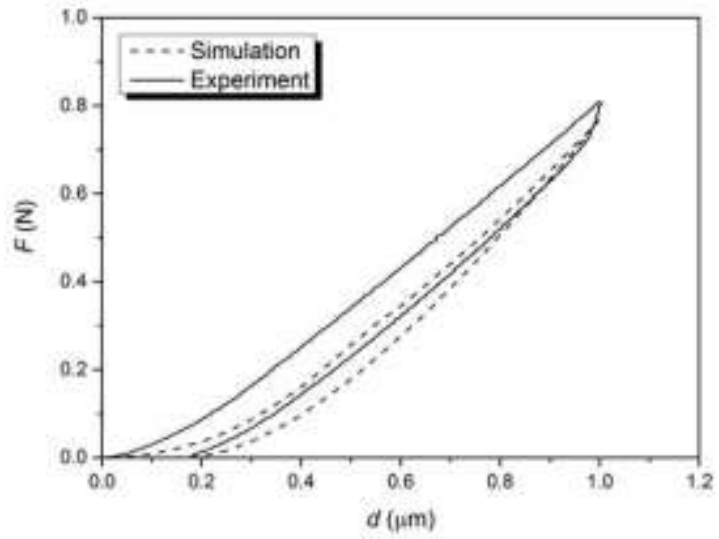

(b)

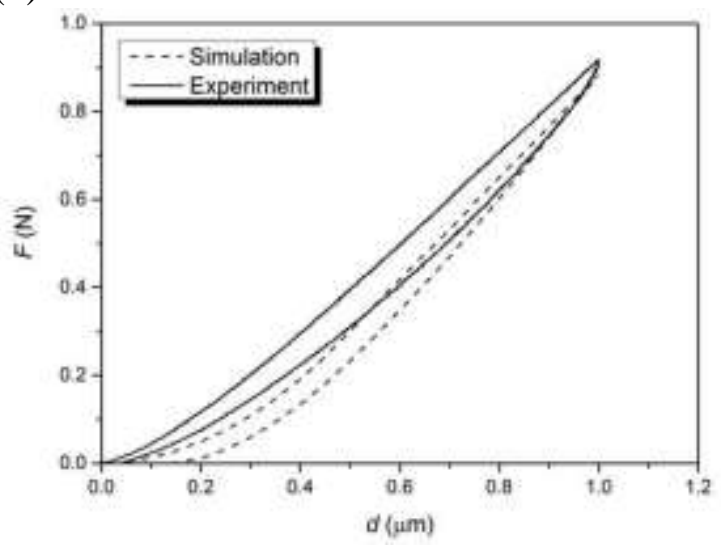

Fig. 5.41: The comparison of the experimental and modelling results for a Ti adhesion layer and an intermediate dielectric layer on the Si substrate after the 1- $\mu \mathrm{m}$ indentation test: (a) $\mathrm{Ti}-\mathrm{SiO}_{2}-\mathrm{Si}$ and (b) $\mathrm{Ti}-\mathrm{Si}_{3} \mathrm{~N}_{4}-\mathrm{Si}$ specimens. 
(a)

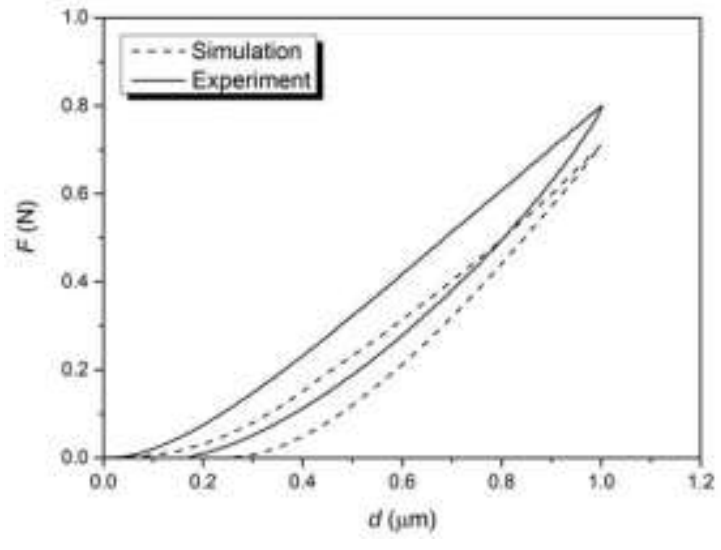

(b)

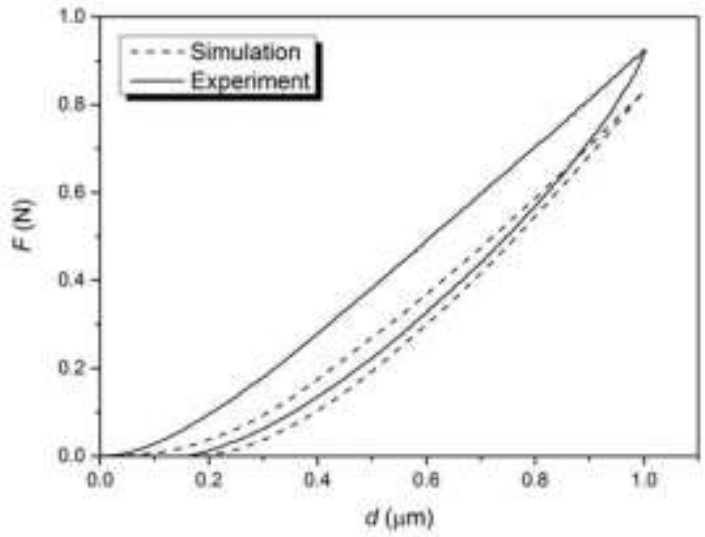

Fig. 5.42: The comparison of the experiment and modelling results for a top Al layer and an intermediate dielectric layer on the Si substrate after the $1-\mu \mathrm{m}$ indentation test: (a) Al$\mathrm{SiO}_{2}-\mathrm{Si}$ and (b) Al- $\mathrm{Si}_{3} \mathrm{~N}_{4}-\mathrm{Si}$ specimens.

(a)

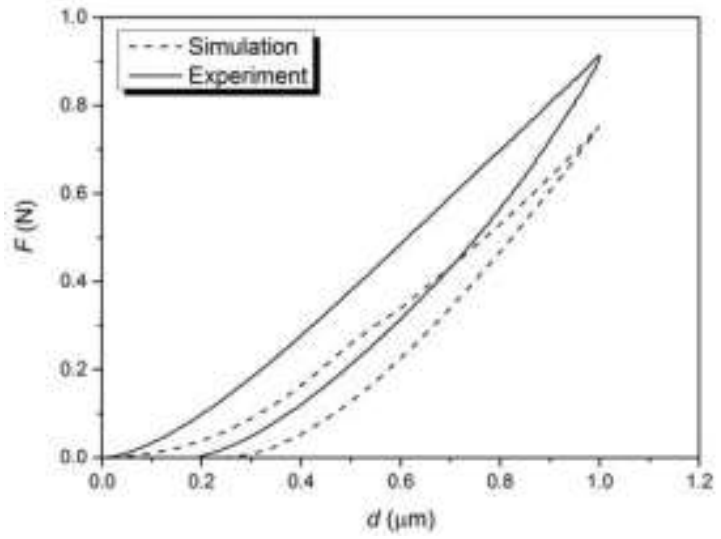

(b)

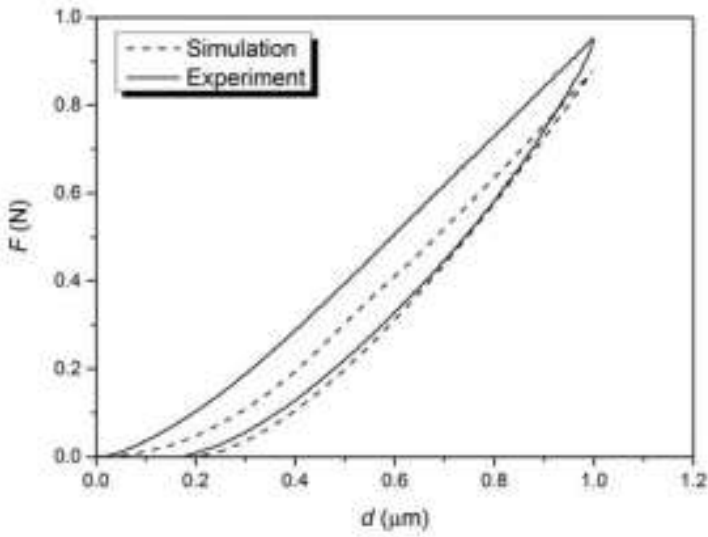

Fig. 5.43: The comparison of the experiment and modelling results for a top $\mathrm{Cu}$ layer and an intermediate dielectric layer on the Si substrate after the 1- $\mu \mathrm{m}$ indentation test: (a) $\mathrm{CuTi}-\mathrm{SiO}_{2}-\mathrm{Si}$ and (b) $\mathrm{CuTi}-\mathrm{Si}_{3} \mathrm{~N}_{4}-\mathrm{Si}$ specimens.

\subsubsection{Stress analysis and damage assessment}

The indentation damage test is simulated on the thin-film stacked specimens that consist of a top $\mathrm{Al}$ or $\mathrm{Cu}$ metal layer, an intermediate $\mathrm{SiO}_{2}$ or $\mathrm{Si}_{3} \mathrm{~N}_{4}$ dielectric layer and a Si substrate, where the material properties are listed in Table 5.2. Both the simulation and experimental results are compared and discussed. From the experiment results, the 
damage observed in the specimens is independent of the top metal layer. Hence, the stress modelling is performed and discussed based on different types of intermediate dielectric layers, and compared with the experimental results.

Table 5.2: Material properties of the thin-film stacked specimens obtained from the combined modelling and experiment methods.

\begin{tabular}{cccc}
\hline Material & $E\left(10^{3} \mathrm{~N} / \mathrm{mm}^{2}\right)$ & $Y\left(10^{3} \mathrm{~N} / \mathrm{mm}^{2}\right)$ & $E_{\mathrm{t}}\left(10^{3} \mathrm{~N} / \mathrm{mm}^{2}\right)$ \\
$\mathrm{Al}$ & 70 & 0.4 & 14 \\
$\mathrm{Cu}$ & 140 & 2 & 14 \\
$\mathrm{Ti}$ & 120 & 1.5 & 12 \\
$\mathrm{SiO}_{2}$ & 80 & 3 & 8 \\
$\mathrm{Si}_{3} \mathrm{~N}_{4}$ & 200 & 5 & 20 \\
$\mathrm{Si}$ & 150 & 7.3 & 15 \\
\hline \hline
\end{tabular}

\subsubsection{Metal-coated $\mathrm{SiO}_{2}$-Si specimens}

The mean value of $d_{\mathrm{c}}$ obtained from the experiment testing is used as the loading condition for the simulation. It is found that the FE model tends to over-estimate $F_{\mathrm{c}}$ by $\sim 30 \%$ and $\sim 20 \%$ for Al- and Cu-coated specimens, respectively (Fig. 5.44). Since the FE model parameters are determined by fitting empirically for a loading condition of $d_{\mathrm{m}}=1$ $\mu \mathrm{m}$, the modelling results are expected to deviate from the experiment when $d>1 \mu \mathrm{m}$, where a higher stiffness is predicted. This deviation could be due to the high-strain hardening effect incorporated in the material models that yield a high tangent modulus $E_{\mathrm{t}}$, and this effect is significant under a large stress-strain condition. Furthermore, a bilinear plastic modelling is employed in the current FE model, which may tend to over-predict 
the stiffness in the $F-d$ curve at higher loading, compared to a model using the multilinear plastic modelling approach.

(a)

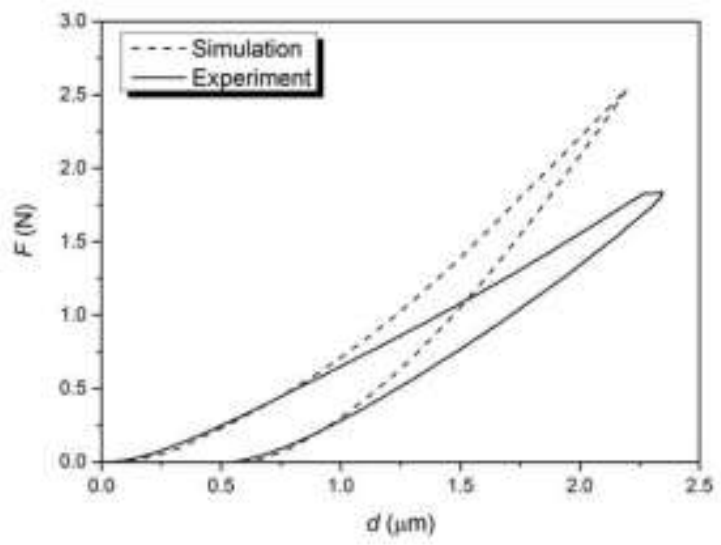

(b)

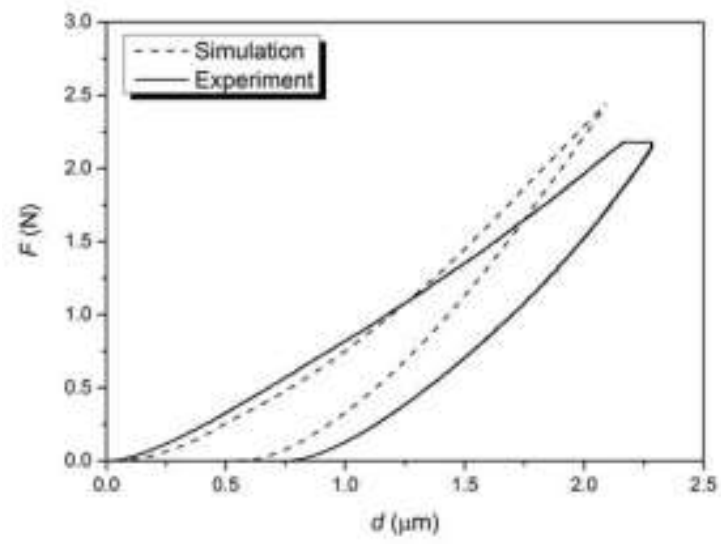

Fig. 5.44: A comparison of the experimental and modelling results after the indentation damage tests: (a) $\mathrm{Al}-\mathrm{SiO}_{2}-\mathrm{Si}$ and (b) $\mathrm{CuTi}-\mathrm{SiO}_{2}-\mathrm{Si}$ specimens.

During the loading stage at $F_{\mathrm{c}}$ or $d_{\mathrm{c}}$, sub-surface cone and lateral cracks are observed in the $\mathrm{Si}$ substrate of the metal-coated $\mathrm{SiO}_{2}-\mathrm{Si}$ specimen. An dimensional analysis is performed on the SEM image of the specimen to determine the locations of those subsurface cracks (Fig. 5.45(a)). The FE modelling results show that the maximum principal tensile stress component $\sigma_{1}$ occurs at Position A, which is located at the surface of the $\mathrm{Si}$ substrate and at a distance of $10.5 \mu \mathrm{m}$ from the indentation centre (Fig. 5.45(b)). In the SEM image, Position A corresponds to somewhere within the sub-surface cone crack region. It is conjectured that the maximum tensile stress at Position A initiates a mode-I crack, which is then driven by the indentation loading to form the cone crack.

The maximum shear stress component $\tau_{13}=0.5\left(\sigma_{1}-\sigma_{3}\right)$ occurs at Position $\mathrm{B}$ that is located $\sim 2 \mu \mathrm{m}$ below the surface of Si substrate (Fig. 5.45(c)). In the SEM image, Position B corresponds to somewhere within the sub-surface lateral crack region. This infers that 
the maximum shear stress at Position B initiates a mode-II crack, which then propagates to form the lateral crack under the indentation loading. The intermediate $\mathrm{SiO}_{2}$ layer has smaller $E$ and $H$ and is more compliant than the Si substrate, and thus is more prone to deformation under a high indentation load. As a result, the stiffer Si layer beneath the $\mathrm{SiO}_{2}$ layer is more prone to cracking.

(a)

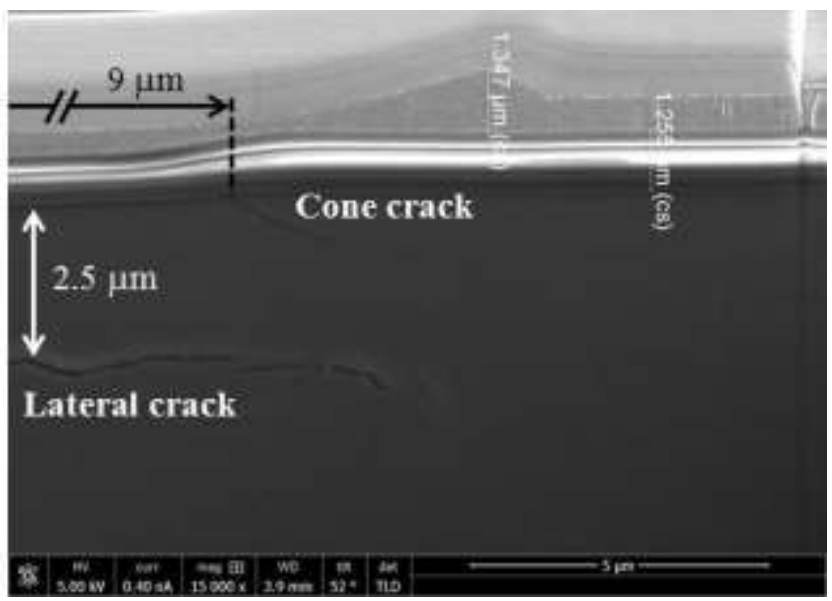

(b)

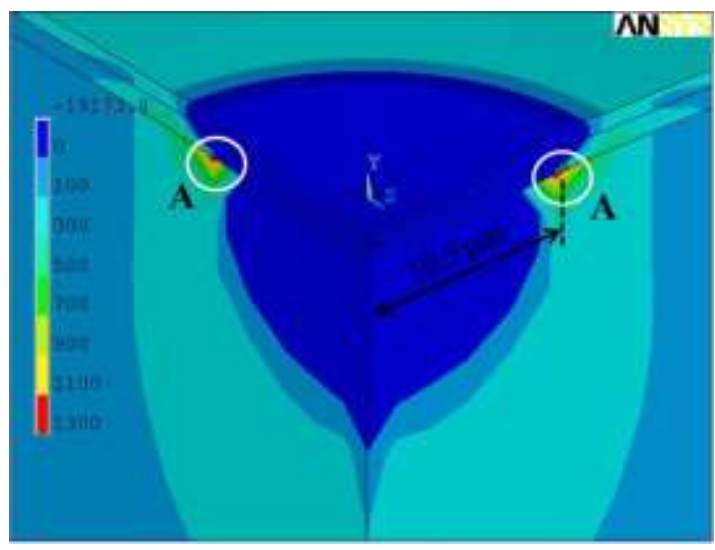

(c)

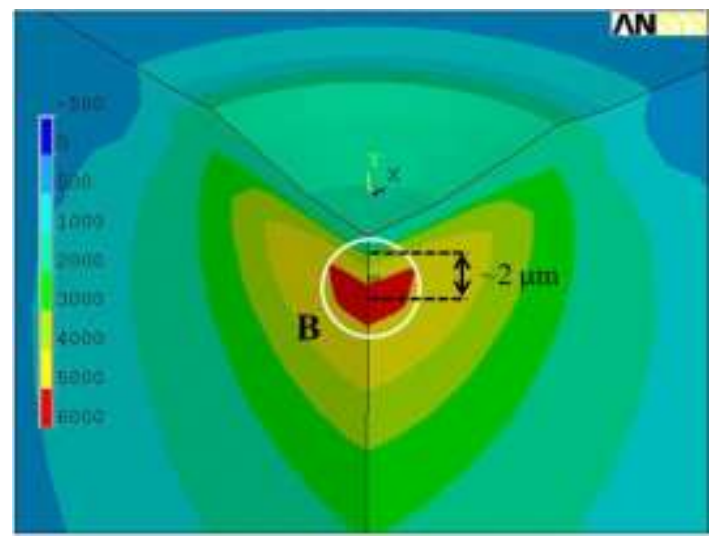

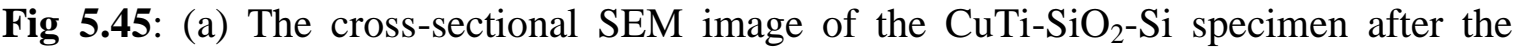
indentation damage test. Stress contours obtained from FE modelling of the same specimen under the $d_{\mathrm{c}}$ loading: (b) principle stress $\sigma_{1}$ and (c) shear stress $\tau_{13}(\mathrm{MPa})$. 
During the unloading stage, a second $\mathrm{AE}$ event is thought to be related to the interfacial crack or delamination between the intermediate $\mathrm{SiO}_{2}$ layer and $\mathrm{Si}$ substrate of the $\mathrm{Al}-\mathrm{SiO}_{2}-\mathrm{Si}$ specimen, as shown in Fig. 5.46(a). The FE modelling results of the same specimen show that the maximum shear stress $\sigma_{x y}$ and normal stress $\sigma_{y}$ occur at Position C, which is located within the delamination region (Fig. 5.46(b) and (c)).It is attested that the delamination observed at this interface could be due to the fracture of mixed modes I and II during the unloading of the indentation test.

(a)

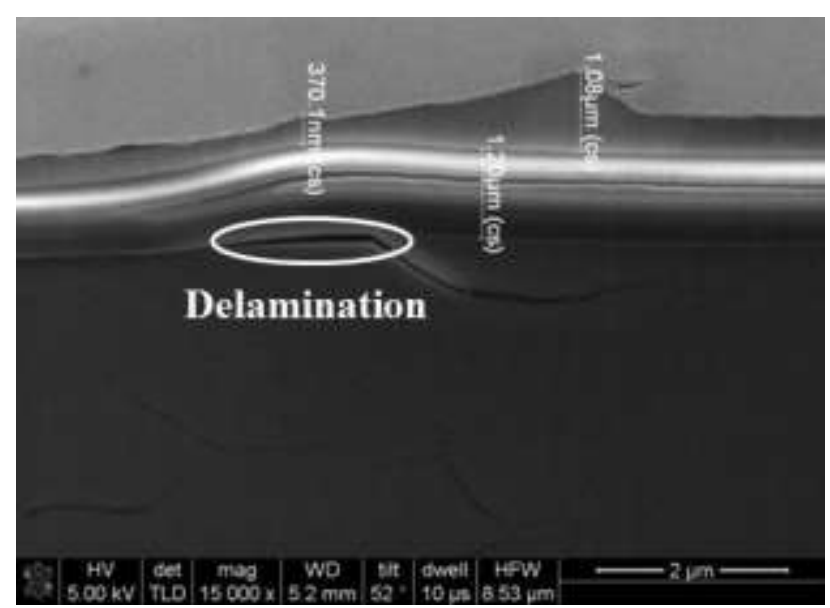

(b)

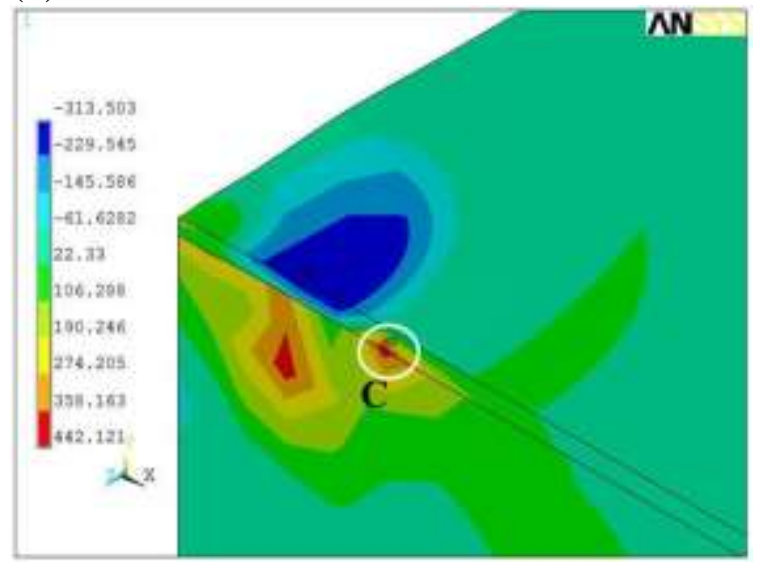

(c)

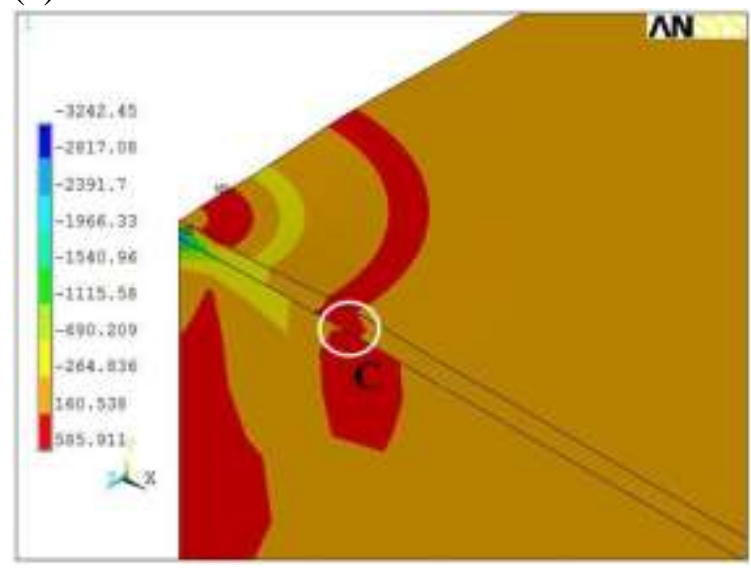

Fig. 5.46: (a) The cross-sectional SEM image of the $\mathrm{Al}-\mathrm{SiO}_{2}-\mathrm{Si}$ specimen after the indentation damage test. The stress contours from the modelling of the same specimen during the unloading stage at an indentation depth of $\sim 1.1 \mu \mathrm{m}$ : (b) shear stress $\sigma_{x y}$ and (c) normal stress $\sigma_{y}(\mathrm{MPa})$. 
It is observed that the second AE event corresponds to a depth of $0.8-1.0 \mu \mathrm{m}$ during the unloading stage for both $\mathrm{Al}-\mathrm{SiO}_{2}-\mathrm{Si}$ and $\mathrm{CuTi}-\mathrm{SiO}_{2}-\mathrm{Si}$ specimens (Fig. 5.47). Figure 5.48 then presents the modelling results of the shear stress $\sigma_{x y}$ and normal stress $\sigma_{y}$ over an indentation loading-unloading cycle that is extracted at Position $\mathrm{C}$ for both specimens. At the loading stage, $\sigma_{x y}$ increases with the indentation load up to $d_{\mathrm{c}}$, and then decreases during the unloading stage until the indenter retracts to a depth of $\sim 1.1 \mu \mathrm{m}$, upon which the maximum stress $\sigma_{y}$ is determined. When the indenter returns to its original position, the residual stresses are presented in the specimens, and the permanent deformation of the top metal and intermediate dielectric layers could be observed after the test (Figs. 5.45(a) and 5.46(a)). It is demonstrated that the simulation result of the maximum stress $\sigma_{y}$ at the depth of $\sim 1.1 \mu \mathrm{m}$ matches closely with the experimental observation of $0.8-1.0 \mu \mathrm{m}$, as evident by the second AE event.

(a)

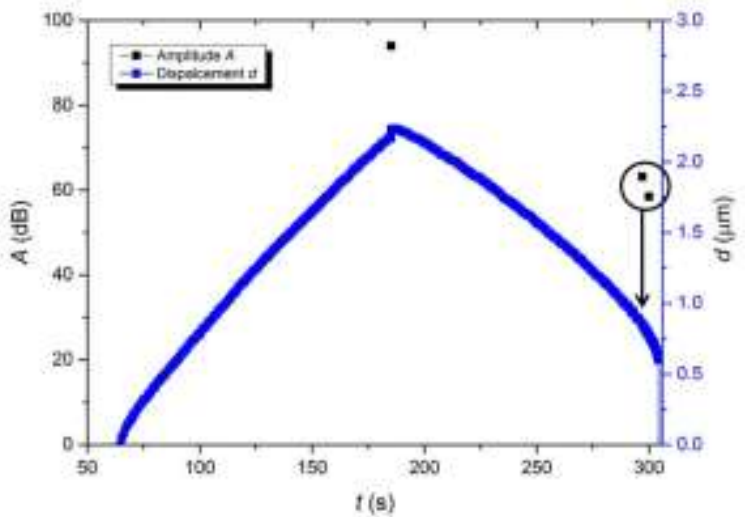

(b)

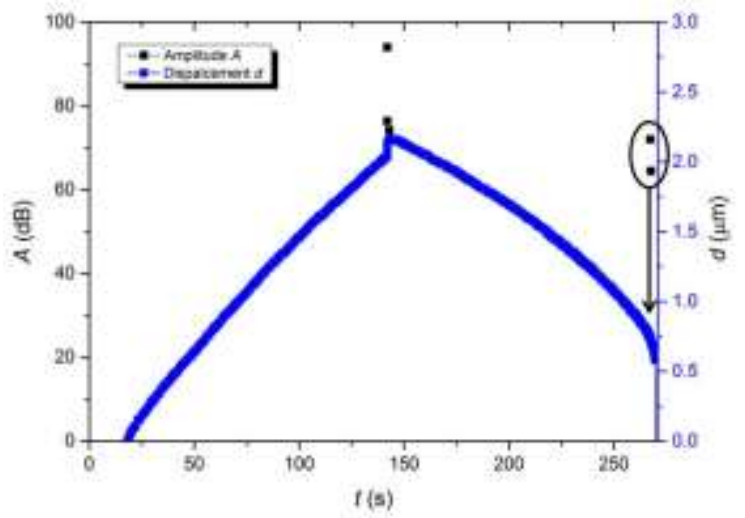

Fig. 5.47: The results of the displacement $d$ and $A$ plotted against $t$ after the indentation damage test for (a) $\mathrm{Al}_{-} \mathrm{SiO}_{2}-\mathrm{Si}$, and (b) $\mathrm{CuTi}_{-} \mathrm{SiO}_{2}-\mathrm{Si}$ specimens. 


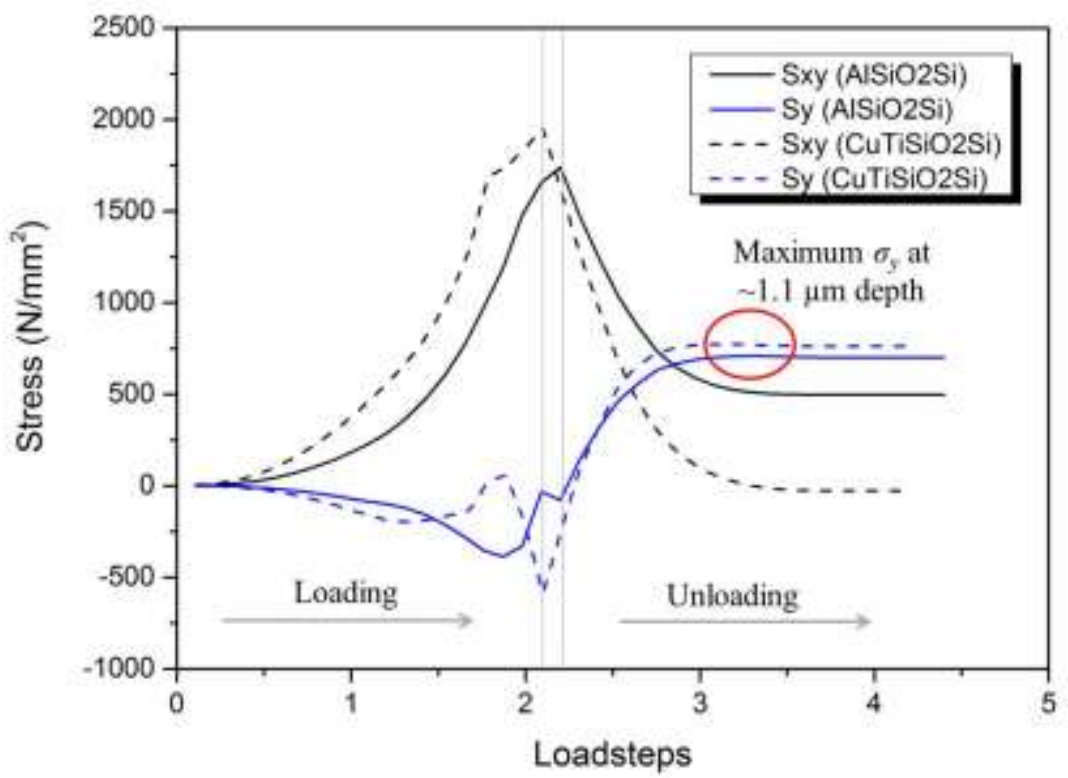

Fig. 5.48: The modelling results of $\sigma_{x y}$ and $\sigma_{y}$ components (extracted at Position $\mathrm{C}$ in Fig. 5.42) during the indentation loading-unloading cycle for both $\mathrm{Al}-\mathrm{SiO}_{2}-\mathrm{Si}$, and $\mathrm{CuTi}-\mathrm{SiO}_{2}-$ Si specimens.

During the unloading stage, the elastic recovery of the stacked specimen may lead to the peeling of the intermediate $\mathrm{SiO}_{2}$ from the damaged $\mathrm{Si}$ substrate at $d_{\mathrm{c}}$. However, during this stage, the FE simulation does not account for any release of the elastic strain energy, and shows that the maximum stresses $\sigma_{x y}$ and $\sigma_{y}$ occur at an indentation depth of $\sim 1.1 \mu \mathrm{m}$, slightly higher than the experimental results of $0.8-1.0 \mu \mathrm{m}$.

\subsubsection{Metal-coated $\mathrm{Si}_{3} \mathrm{~N}_{4}-\mathrm{Si}$ specimens}

A similar approach is employed for the metal-coated $\mathrm{Si}_{3} \mathrm{~N}_{4}-\mathrm{Si}$ specimen, whereby the experimentally obtained mean value of $d_{\mathrm{c}}$ is used as the loading condition for the simulation. The FE model tends to over-estimate $F_{\mathrm{c}}$ slightly (Fig. 5.49), but as compared to the metal-coated $\mathrm{SiO}_{2}$ specimen, it provides a better prediction of $F_{\mathrm{c}}$. This is because the $d_{\mathrm{c}}$ of the metal-coated $\mathrm{Si}_{3} \mathrm{~N}_{4}-\mathrm{Si}$ specimen is near the $d_{\mathrm{m}}(1 \mu \mathrm{m})$ that is used during the 
FE model development. If a multi-linear plastic modelling is adopted, an accurate $F$ - $d$ curve prediction can be achieved.

During the loading stage at the critical displacement $d_{\mathrm{c}}$ or force $F_{\mathrm{c}}$, the sub-surface lateral crack is observed in the $\mathrm{Si}$ substrate of the metal-coated $\mathrm{Si}_{3} \mathrm{~N}_{4}-\mathrm{Si}$ specimen. The dimensional analysis is performed on the SEM image of the damaged specimen to determine the locations of the sub-surface lateral cracks (Fig. 5.50(a)). The FE modelling results show that the maximum shear stress component $\tau_{13}=0.5\left(\sigma_{1}-\sigma_{3}\right)$ occurs at Position $\mathrm{D}$ that is located $\sim 2 \mu \mathrm{m}$ below the surface of the Si substrate (Fig. 5.50(b)). In the SEM image, Position D corresponds to somewhere within the sub-surface lateral crack region. This infers that the maximum shear stress at Position D initiates a mode-II crack, which then propagates to form the lateral crack under the indentation loading.

(a)

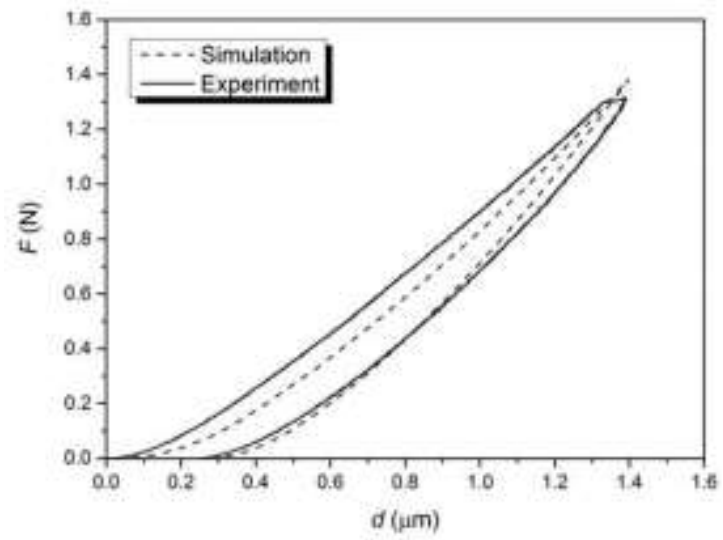

(b)

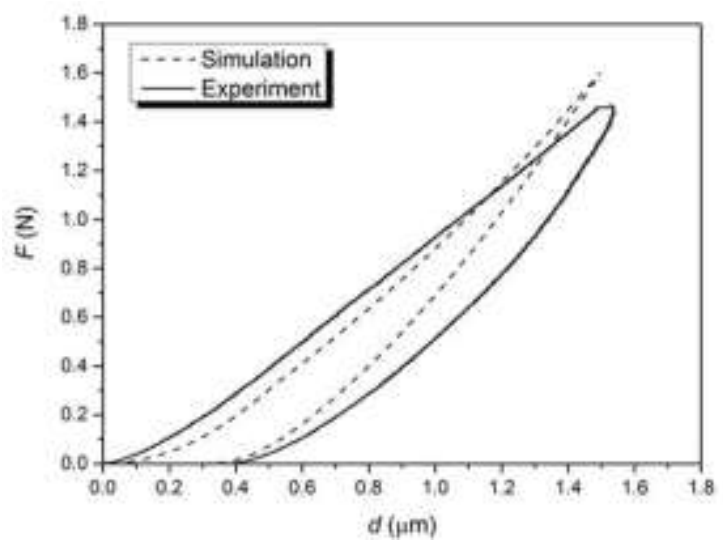

Fig. 5.49: The comparison of the experimental and modelling results after the indentation damage tests: (a) $\mathrm{Al}-\mathrm{Si}_{3} \mathrm{~N}_{4}-\mathrm{Si}$ and (b) $\mathrm{CuTi}-\mathrm{Si}_{3} \mathrm{~N}_{4}-\mathrm{Si}$ specimens. 
(a)

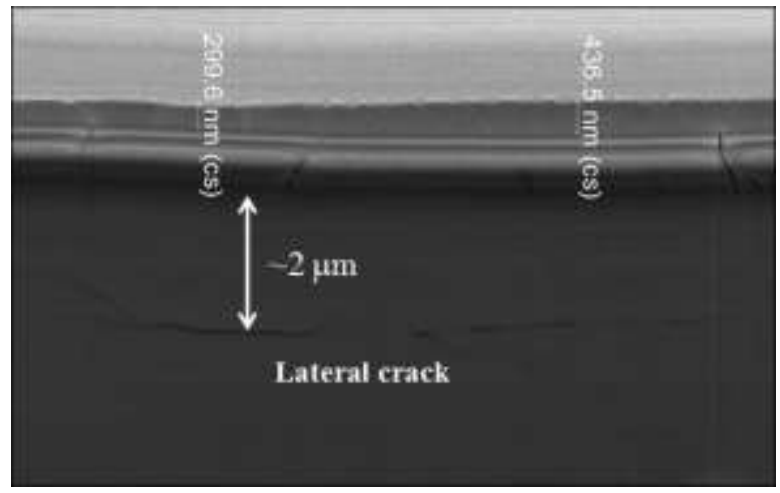

(b)

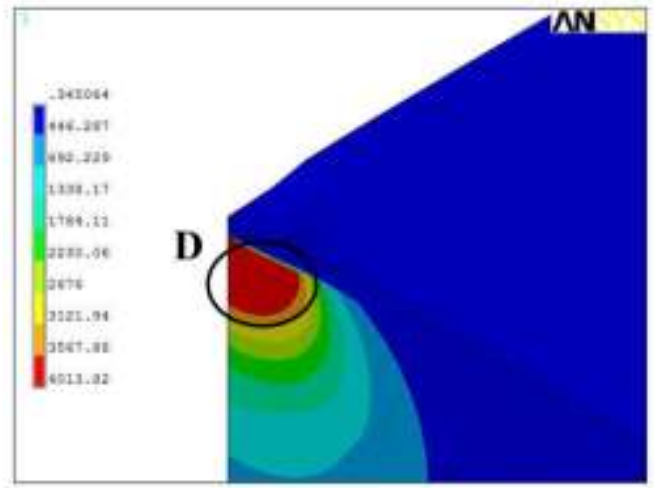

Fig. 5.50: (a) The cross-sectional SEM image of the metal-coated $\mathrm{Si}_{3} \mathrm{~N}_{4}$-Si specimen after the indentation damage test, and (b) the contour plot of the shear stress $\tau_{13}(\mathrm{MPa})$ after the simulation of the same specimen under the $d_{\mathrm{c}}$ loading.

Unlike the metal-coated $\mathrm{SiO}_{2}-\mathrm{Si}$ specimen, no sub-surface cone cracking is observed in the $\mathrm{Si}$ substrate, but a through-thickness crack is found in the intermediate $\mathrm{Si}_{3} \mathrm{~N}_{4}$ layer for both the $\mathrm{Al}-\mathrm{Si}_{3} \mathrm{~N}_{4}-\mathrm{Si}$ and $\mathrm{CuTi}-\mathrm{Si}_{3} \mathrm{~N}_{4}-\mathrm{Si}$ specimens, at a distance of 2-5 $\mu \mathrm{m}$ from the indentation centre (Fig. 5.51(a)). However, the dimensional measurement of this distance could be affected by the cross-sectional plane selected. The FE modelling results show that the maximum shear stress component $\sigma_{x y}$ of the $\mathrm{Si}_{3} \mathrm{~N}_{4}$ layer at Position $\mathrm{E}$ is located within the through-thickness crack region for both the specimens (Figs. 5.51(b)). In addition, Position $\mathrm{E}$ is located $\sim 4 \mu \mathrm{m}$ and $\sim 6 \mu \mathrm{m}$ from the centre of the indentation on the $\mathrm{Al}-\mathrm{Si}_{3} \mathrm{~N}_{4}-\mathrm{Si}$ and $\mathrm{CuTi}-\mathrm{Si}_{3} \mathrm{~N}_{4}-\mathrm{Si}$ specimens, respectively (Fig. 5.52). It is deduced that the through-thickness cracks observed at the intermediate $\mathrm{Si}_{3} \mathrm{~N}_{4}$ layer could be due to the fracture of mode-II during the loading of the indentation test. It is also observed that along the horizontal $x$-axis, $\sigma_{x y}$ in the $\mathrm{Si}_{3} \mathrm{~N}_{4}$ layer increases from the indentation centre to Position E, and then decreases abruptly to a location $\sim 10 \mu \mathrm{m}$ from the centre. This distance is approximately half the length of the residual indention imprint that is shown on the top metal layer after the test (Figs. 5.51(a)). 
(a)
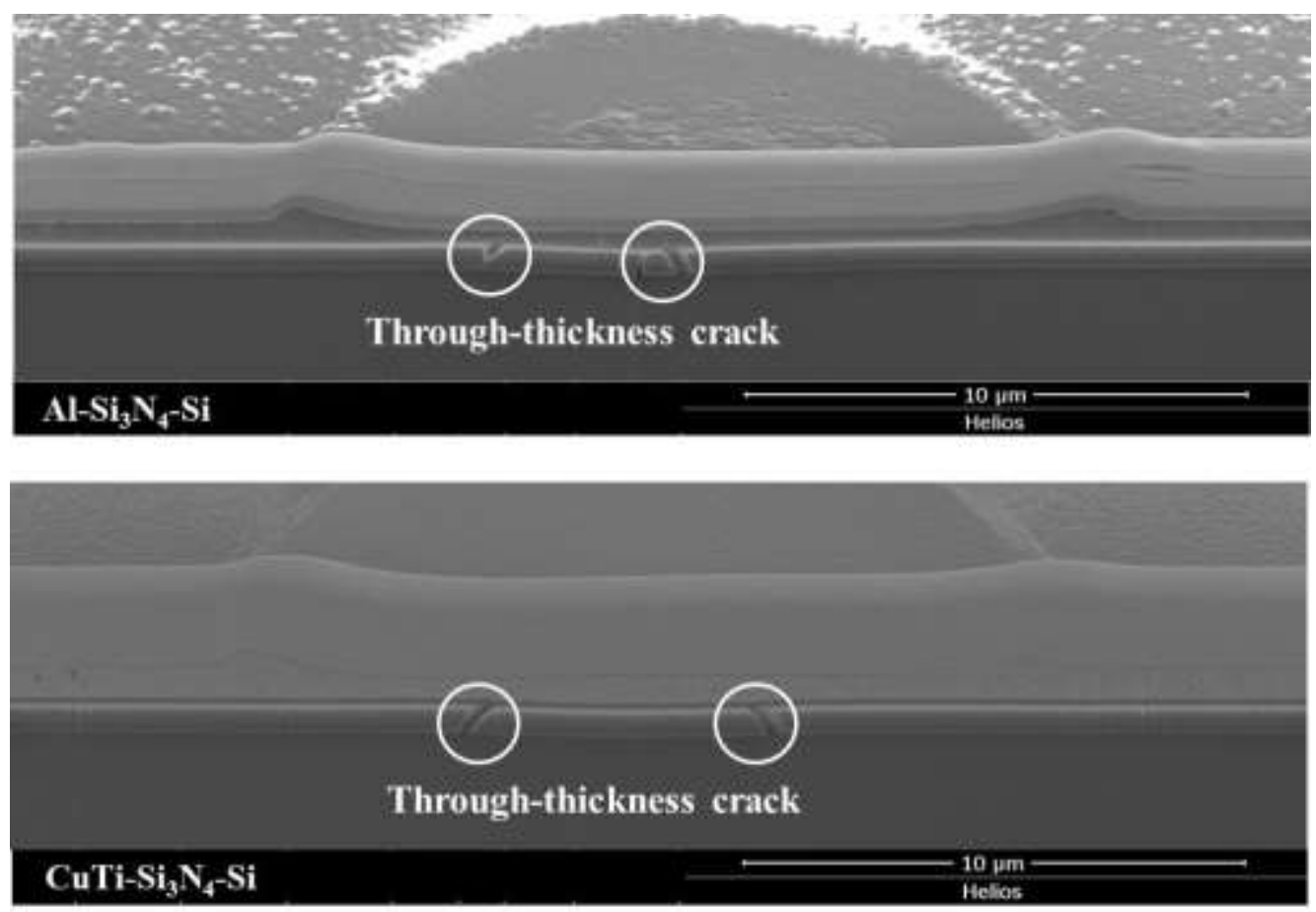

(b)
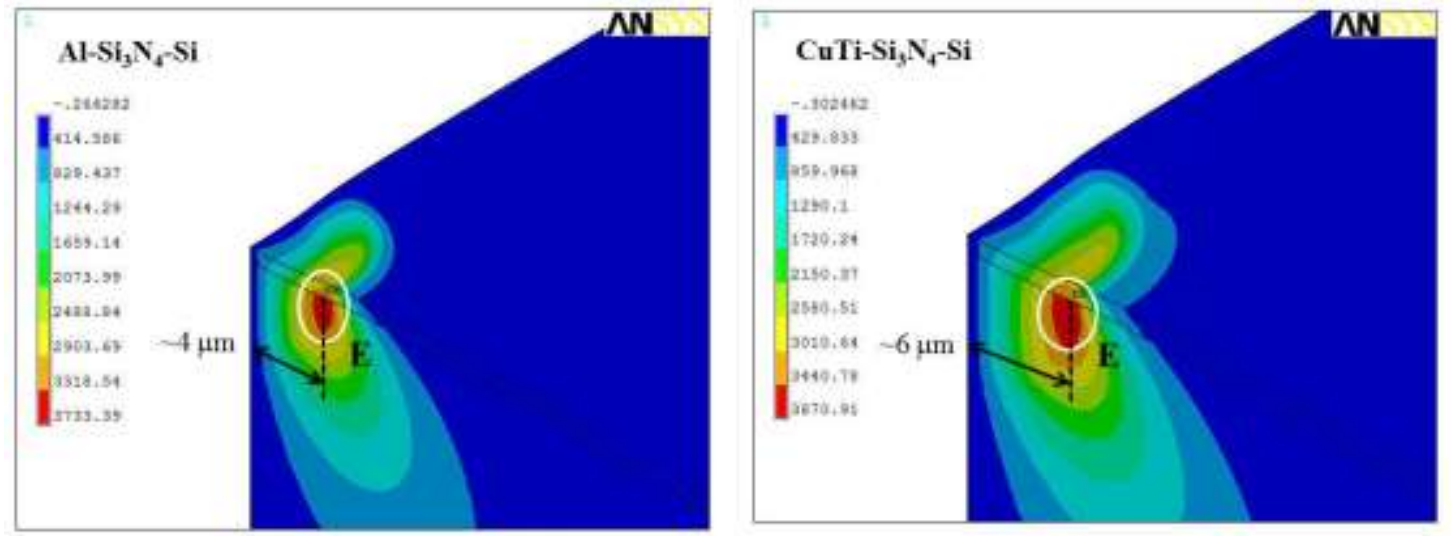

Fig. 5.51: (a) The cross-sectional $\mathrm{SEM}$ images of the metal-coated $\mathrm{Si}_{3} \mathrm{~N}_{4}-\mathrm{Si}$ specimens after the indentation damage test, and (b) the contour plots of the shear stress $\sigma_{x y}(\mathrm{MPa})$ after the simulation of the same specimen under an indentation loading of $d_{\mathrm{c}}$. 


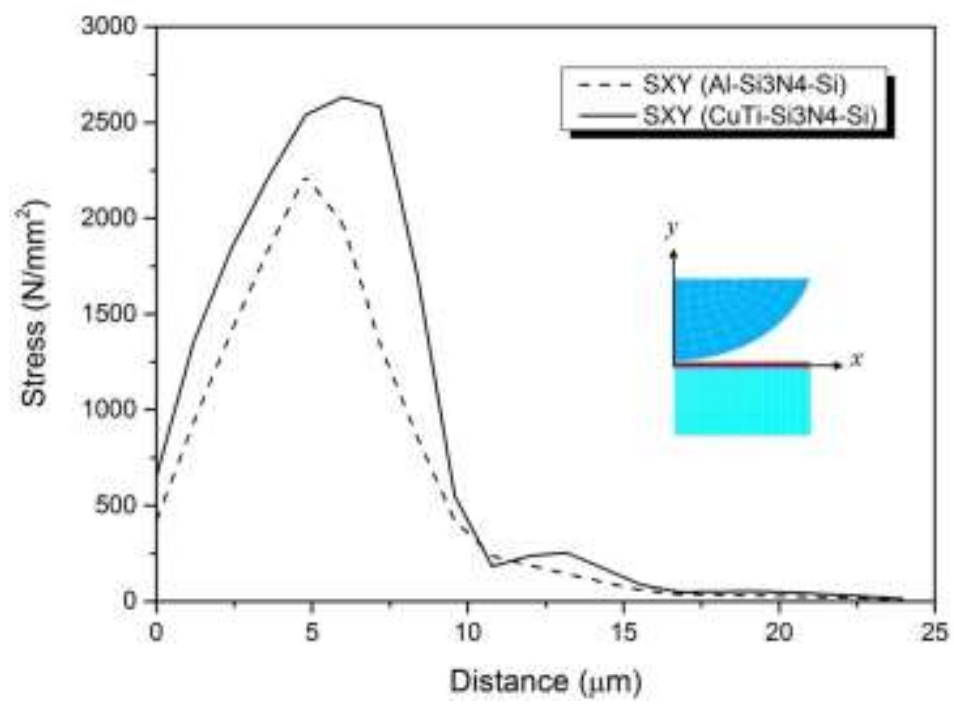

Fig. 5.52: The shear stress component $\sigma_{x y}$ of the intermediate $\mathrm{Si}_{3} \mathrm{~N}_{4}$ layer from right beneath the indentation centre to a length of the indenter radius for both $\mathrm{Al}$ - and $\mathrm{Cu}$ $\mathrm{Si}_{3} \mathrm{~N}_{4}-\mathrm{Si}$ specimens at the $d_{\mathrm{c}}$ loading condition.

The intermediate $\mathrm{Si}_{3} \mathrm{~N}_{4}$ layer has a higher $E$ and is less compliant than the Si substrate, and thus is more prone to cracking under a high indentation load. Furthermore, during the unloading stage, no delamination occurs in the metal-coated $\mathrm{Si}_{3} \mathrm{~N}_{4}-\mathrm{Si}$ specimens, and thus no second AE event that is related to the specimen damage is noted.

Generally, the metal-coated $\mathrm{SiO}_{2}-\mathrm{Si}$ specimen has a higher damage resistance or strength (higher $d_{\mathrm{c}}$ or $F_{\mathrm{c}}$ ) than the metal-coated $\mathrm{Si}_{3} \mathrm{~N}_{4}-\mathrm{Si}$ specimen. This observation is also in agreement with the previous finding by Jung et al. that the strength increases for oxides but decreases for nitrides on the Si substrate, with the residual stress effect being considered [140].

\subsection{Summary}

A damage test methodology invoking the techniques of instrumented indentation testing and AE sensing has been developed to evaluate the damage behavior of the metal- 
coated thin-films stacked structure. Table 5.3 presents a summary of the indentation damage test results based on the detection of the first AE peak signal.

Table 5.3: A summary of the indentation damage test results.

\begin{tabular}{|c|c|c|c|c|c|c|}
\hline \multirow[b]{2}{*}{ Specimen } & \multicolumn{2}{|c|}{ Mechanical response } & \multicolumn{4}{|c|}{ First peak of AE transient signal } \\
\hline & $F_{\mathrm{c}}(\mathrm{N})$ & $d_{\mathrm{c}}(\mu \mathrm{m})$ & $A(d B)$ & $t_{\mathrm{r}}(\mu \mathrm{s})$ & $t_{\mathrm{d}}(\mu \mathrm{s})$ & $\begin{array}{c}E_{\mathrm{AE}} 10^{6}(\mathrm{eu}) \\
1 \mathrm{eu}=10^{-18} \mathrm{~J}\end{array}$ \\
\hline Si (100) die & $1.09-1.26$ & $1.05-1.50$ & $72-91$ & $6.7-12.4$ & $59-186$ & $0.01-0.81$ \\
\hline $\mathrm{Al}-\mathrm{SiO}_{2}-\mathrm{Si}$ & $1.77-2.00$ & $1.87-2.40$ & $87-97$ & $9.3-12.6$ & $123-274$ & $0.22-2.8$ \\
\hline $\mathrm{CuTi}-\mathrm{SiO}_{2}-\mathrm{Si}$ & $1.81-2.39$ & $1.84-2.50$ & $85-102$ & $9.2-12.6$ & $123-911$ & $0.18-9.6$ \\
\hline $\mathrm{Al}-\mathrm{Si}_{3} \mathrm{~N}_{4}-\mathrm{Si}$ & $1.12-1.43$ & $1.16-1.61$ & $81-92$ & $8.8-12.4$ & $119-248$ & $0.07-0.78$ \\
\hline $\mathrm{CuTi}-\mathrm{Si}_{3} \mathrm{~N}_{4}-\mathrm{Si}$ & $1.33-1.75$ & $1.24-1.65$ & 80-91 & $9-12.4$ & $119-214$ & $0.05-0.83$ \\
\hline
\end{tabular}

During the indentation loading stage, $F_{\mathrm{c}}$ corresponds to the first $\mathrm{AE}$ event or peak voltage $V_{\mathrm{s}}$ occurrence, where "pop-in" in the $F$ - $d$ curve is observed. This is mainly due to the brittle cracking in the dielectric layer or/and Si substrate. A lower magnitude of a second AE event is detected during the unloading stage, but no "pop-out" is observed in the $F-d$ curve, which is related to the delamination between the dielectric layer and the $\mathrm{Si}$ substrate. It is observed that higher $A$ and $E_{\mathrm{AE}}$ are recorded for a larger $F_{\mathrm{c}}$ measured, except for $t_{\mathrm{r}}$ that is almost the same for all the specimens, independent of $F_{\mathrm{c}}$. It is also found that $t_{\mathrm{d}}$ recorded in the $\mathrm{CuTi}-\mathrm{SiO}_{2}-\mathrm{Si}$ specimen is much higher than the rest of the specimens, which could be due to the reflected signal of the original AE event, and the reflection plane could be the crack-free Ti layer.

There is no cracking found on the top metal layers for all the thin-film stacked specimens, except a round indented mark and a pile-up around the indented area. 
However, the delayering of those top metal layers reveals the peeling, ring and radial cracking on the $\mathrm{SiO}_{2}$ surfaces, and the medium, ring and radial cracking on the $\mathrm{Si}_{3} \mathrm{~N}_{4}$ surfaces. The cross-sectioning of the damaged metal-coated $\mathrm{SiO}_{2}$-Si specimens reveals the sub-surface cone and lateral cracking in the Si substrate, and delamination between the $\mathrm{SiO}_{2}$ and $\mathrm{Si}$ interface. However, for the metal-coated $\mathrm{Si}_{3} \mathrm{~N}_{4}-\mathrm{Si}$ specimen, the throughthickness cracking is observed in the $\mathrm{Si}_{3} \mathrm{~N}_{4}$ dielectric layer, and the sub-surface lateral cracking in the Si substrate. In general, $F_{\mathrm{c}}$ depends strongly on the intermediate dielectric layer used in the thin-film stacked specimen. A higher $F_{\mathrm{c}}$ is usually obtained in the metalcoated $\mathrm{SiO}_{2}-\mathrm{Si}$ specimen as compared to the metal-coated $\mathrm{Si}_{3} \mathrm{~N}_{4}-\mathrm{Si}$ specimen. Furthermore, the delamination only occurs in the former specimen during the unloading stage of the indentation test.

From the FE simulation study, the locations of the maximum principal normal and shear stresses in the Si substrate are found to be within the Si damage regions as observed in those specimens with the intermediate $\mathrm{SiO}_{2}$ dielectric layer. It is also found that the maximum shear stress component $\sigma_{x y}$ of the $\mathrm{Si}_{3} \mathrm{~N}_{4}$ layer is located within the throughthickness crack region, which suggests that the mode-II fracture is the main damage mechanism for the through-thickness cracks seen in the intermediate $\mathrm{Si}_{3} \mathrm{~N}_{4}$ dielectric layer of the thin-film stacked specimen during the indentation loading. During the unloading stage, the mixed mode I and II fracture is the main damage mechanism responsible for the delamination at the interface between the $\mathrm{SiO}_{2}$ dielectric layer and $\mathrm{Si}$ substrate. 


\section{Chapter 6 Analysis of Indentation Work and Acoustic Emission Energy}

Indentation testing at the various $F_{\mathrm{m}}$ conditions is performed on the same specimens, where the $F_{\mathrm{c}}$ is determined from the indentation damage test. The associated works before and after the damage test are examined from the indentation $F$ - $d$ curve, and the damage mechanisms involved are discussed. An energy-based method is proposed to evaluate the work of indentation fracture for the Si (100) die and the thin-film stacked specimens, which consist of a top metal layer $(\mathrm{Al}$ or $\mathrm{CuTi})$ and an intermediate dielectric $\left(\mathrm{SiO}_{2}\right.$ or $\mathrm{Si}_{3} \mathrm{~N}_{4}$ ) layer on the $\mathrm{Si}(100)$ substrate. Two different approaches are presented to determine the work of indentation fracture. The work of indentation damage and fracture is then discussed with the $E_{\mathrm{AE}}$ measurement.

\subsection{Elastic and total work of indentation}

The total indentation work done on the specimen with no damage induced can be calculated from the total area under the $F-d$ curve. Assuming the energy loss due to the contact friction is negligible, the total work comprises the elastic energy $W_{\mathrm{el}}$ and plastic energy $W_{\mathrm{pl}}$ that are related to the deformation of the specimen and can be written as

$$
W_{\mathrm{T}}=W_{\mathrm{el}}+W_{\mathrm{pl}}
$$

The $W_{\mathrm{el}}$ is associated with the elastic strain recovery of the specimen and represented by the area under the unloading $F-d$ curve, while $W_{\mathrm{pl}}$ is described by the permanent deformation of the specimen and represented by the area enclosed within the loading and unloading curves (Fig. 5.39). 
The ratio of $W_{\mathrm{el}} / W_{\mathrm{T}}$ is determined at different maximum force $F_{\mathrm{m}}$ or displacement $d_{\mathrm{m}}$ loading conditions for the Si (100) die and various thin-film stacked specimens. Each loading condition is repeated five times on each specimen. Generally, $W_{\mathrm{el}} / W_{\mathrm{T}}$ approaches unity for the elastic material, and zero for the plastic or ductile material.

It is observed that $W_{\mathrm{el}} / W_{\mathrm{T}}$ for the Si die is $\sim 0.96$ when $F_{\mathrm{m}} / F_{\mathrm{c}}$ or $d_{\mathrm{m}} / d_{\mathrm{c}}<1$ (Fig. 6.1). If $F_{\mathrm{m}}=F_{\mathrm{c}}$, , i.e., $F_{\mathrm{m}} / F_{\mathrm{c}}$ or $d_{\mathrm{m}} / d_{\mathrm{c}}=1$, the $\mathrm{Si}$ die cracks and a plateau is usually observed in the $F-d$ curve, which results in a decrease of $W_{\mathrm{el}} / W_{\mathrm{T}}$ to $\sim 0.84$. This is expected as the Si die is a brittle material; limited plastic deformation is experienced before cracking under the indentation loading.

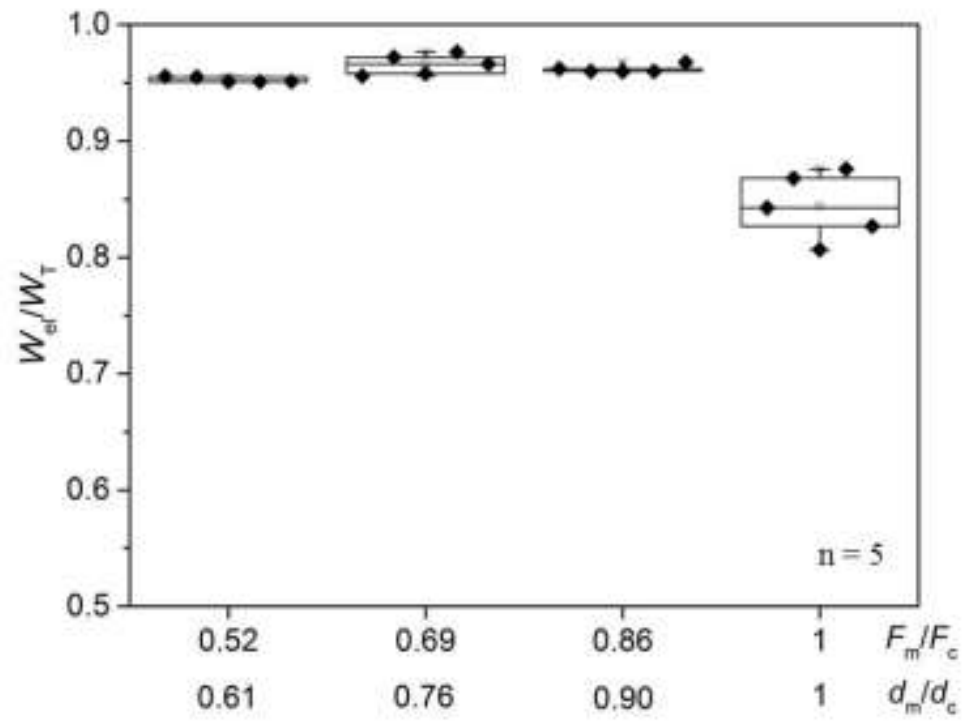

Fig. 6.1: The plots of $W_{\mathrm{el}} / W_{\mathrm{T}}$ against $F_{\mathrm{m}} / F_{\mathrm{c}}$ and $d_{\mathrm{m}} / d_{\mathrm{c}}$ for the Si die specimen.

For the thin-film stacked specimens, $W_{\mathrm{el}} / W_{\mathrm{T}}$ reduces with an increasing load, and eventually becomes relatively constant if $F_{\mathrm{m}} / F_{\mathrm{c}}>0.6$ or $d_{\mathrm{m}} / d_{\mathrm{c}}>0.7$ for the Al-coated specimens, and $F_{\mathrm{m}} / F_{\mathrm{c}}>0.55$ or $d_{\mathrm{m}} / d_{\mathrm{c}}>0.65$ for the $\mathrm{Cu}$-coated specimens (Fig. 6.2). This implies that the plastic deformation or energy experienced by the top metal layer is accumulating with an increasing indentation load. However, at certain point (Al-coated 110 
specimen: $F_{\mathrm{m}} / F_{\mathrm{c}}>0.6$ or $\mathrm{Cu}$-coated specimen: $\left.F_{\mathrm{m}} / F_{\mathrm{c}}>0.55\right)$, any further increase in the load tends to increase both $W_{\mathrm{el}}$ and $W_{\mathrm{pl}}$ proportionally, which yields an insignificant change in $W_{\mathrm{el}} / W_{\mathrm{T}}$. This could be due to the fact that the entire top metal layer underneath the indenter experiences a near or fully plastic strain field.

The values of $W_{\mathrm{el}} / W_{\mathrm{T}}$ for the $\mathrm{Al}-\mathrm{SiO}_{2}-\mathrm{Si}, \mathrm{CuTi}-\mathrm{SiO}_{2}-\mathrm{Si}, \mathrm{Al}-\mathrm{Si}_{3} \mathrm{~N}_{4}-\mathrm{Si}$ and $\mathrm{CuTi}-\mathrm{Si}_{3} \mathrm{~N}_{4}-$ Si specimens are $\sim 0.77, \sim 0.70, \sim 0.79$ and $\sim 0.77$, respectively, before cracking is observed in the specimen (Fig. 6.2). When $F_{\mathrm{m}}=F_{\mathrm{c}}$, a plateau is usually observed in the $F$ - $d$ curve, and $W_{\mathrm{el}} / W_{\mathrm{T}}$ decreases to $\sim 0.71, \sim 0.61, \sim 0.74$ and $\sim 0.7$, respectively. Generally, the Alcoated specimen yields a higher $W_{\mathrm{el}} / W_{\mathrm{T}}$ than the $\mathrm{Cu}$-coated specimen for both before and after the specimen cracking. It is also found that Al-coated specimen has a larger value of $d_{\mathrm{m}} / d_{\mathrm{c}}$ than the $\mathrm{Cu}$-coated specimens before the specimen cracking. This suggests that those specimens with the top Al layer undergo a larger deformation before cracking of the dielectric or/and Si substrate happens. This is evident that the Al remnant thickness is smaller than that of $\mathrm{Cu}$ after the indentation damage test, as shown in Fig. 6.3. Furthermore, the $\mathrm{Al}$ metal has lower $E$ and $Y$ than the $\mathrm{Cu}$, and hence a larger deformation is expected under the indentation loading. 
(a)

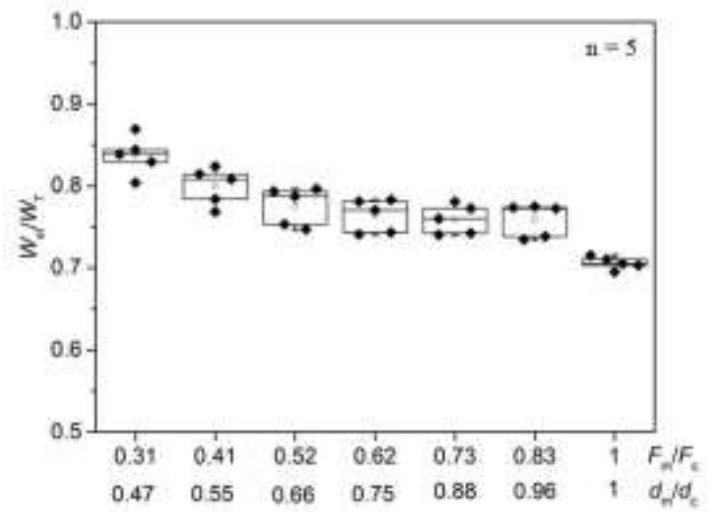

(c)

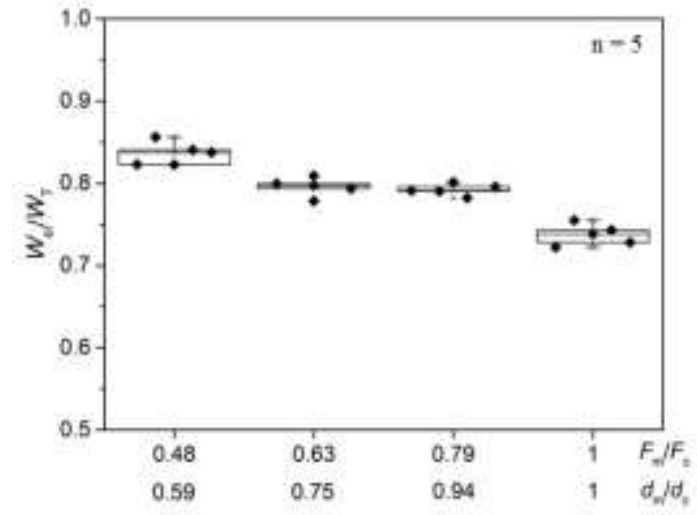

(b)

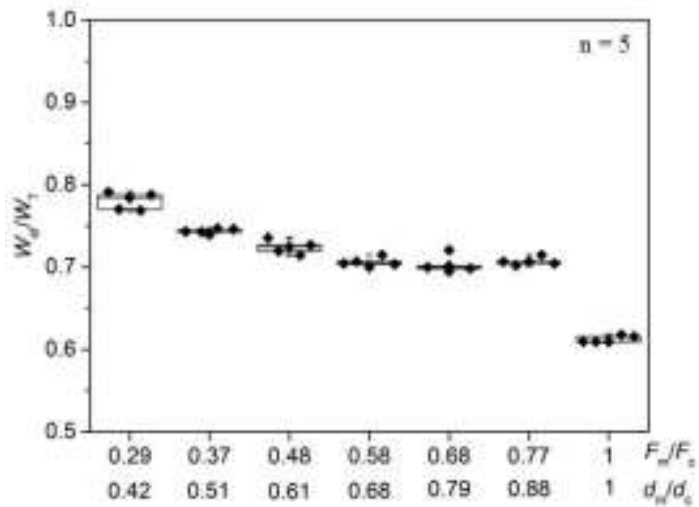

(d)

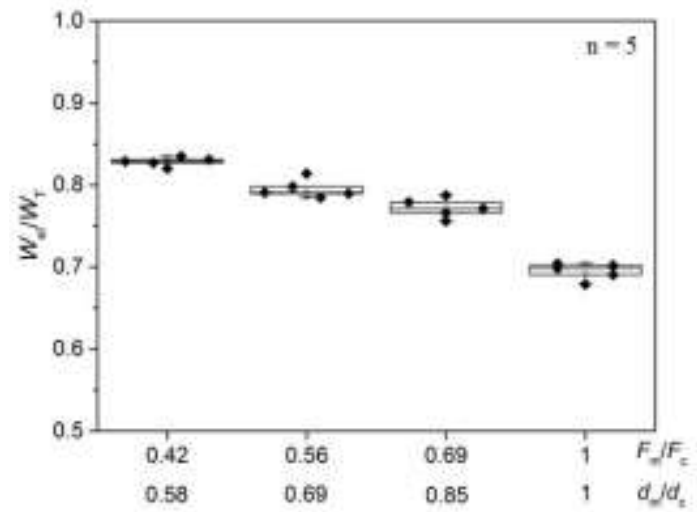

Fig. 6.2: The plots of $W_{\mathrm{el}} / W_{\mathrm{T}}$ against $F_{\mathrm{m}} / F_{\mathrm{c}}$ and $d_{\mathrm{m}} / d_{\mathrm{c}}$ : (a) $\mathrm{Al}-\mathrm{SiO}_{2}-\mathrm{Si}$, (b) $\mathrm{CuTi}-\mathrm{SiO}{ }_{2}-\mathrm{Si}$, (c) $\mathrm{Al}-\mathrm{Si}_{3} \mathrm{~N}_{4}-\mathrm{Si}$, and (d) $\mathrm{CuTi}-\mathrm{Si}_{3} \mathrm{~N}_{4}-\mathrm{Si}$ specimens.

(a)

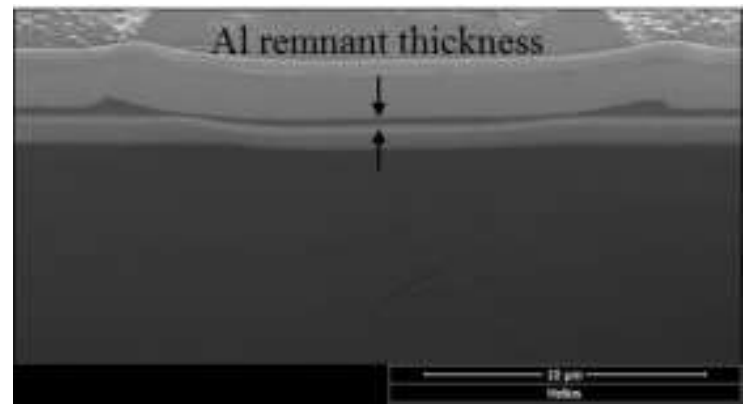

(b)

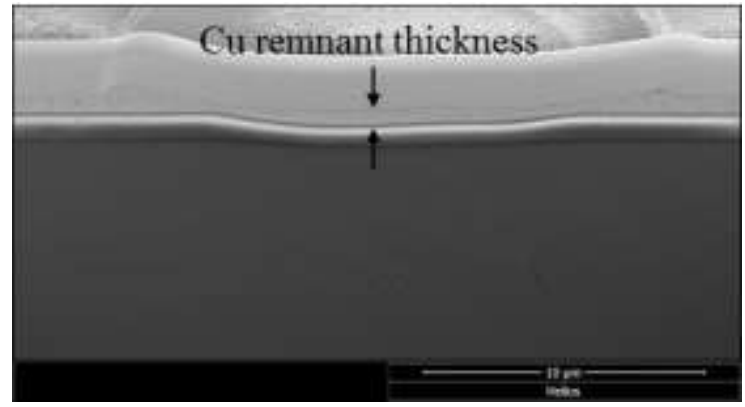

Fig. 6.3: The SEM images showing the deformed top metal layers after the indentation damage testing: (a) $\mathrm{Al}-\mathrm{SiO}_{2}-\mathrm{Si}$, and (b) $\mathrm{CuTi}-\mathrm{SiO}_{2}-\mathrm{Si}$ specimems. 


\subsection{Work of indentation damage and fracture}

The area under the plateau of the $F$ - $d$ curve or the damage energy $W_{\mathrm{d}}$ refers to the work done by the indenter as it penetrates deep into the damaged specimen at a constant load $F_{\mathrm{c}}$ (Fig. 6.4). However, upon the detection of the first AE event at $F_{\mathrm{c}}, W_{\mathrm{d}}$ may consist of some work related to the fracture energy released or work of indentation fracture $W_{\mathrm{f}}$ due to the crack formation in the specimen. The total indentation work in a damage test is represented by the total area under the $F$ - $d$ curve:

$$
W_{\mathrm{T}}^{\mathrm{d}}=W_{\mathrm{el}}^{\mathrm{d}}+W_{\mathrm{pl}}^{\mathrm{d}}+W_{\mathrm{d}},
$$

where $W_{\mathrm{el}}^{\mathrm{d}}$ is the elastic energy that is the area under the unloading $F-d$ curve, and $W_{\mathrm{pl}}^{\mathrm{d}}$ is the plastic energy. Assuming energy loss due to the contact friction between the indenter and specimen or crack surfaces areas, the heat is negligible.
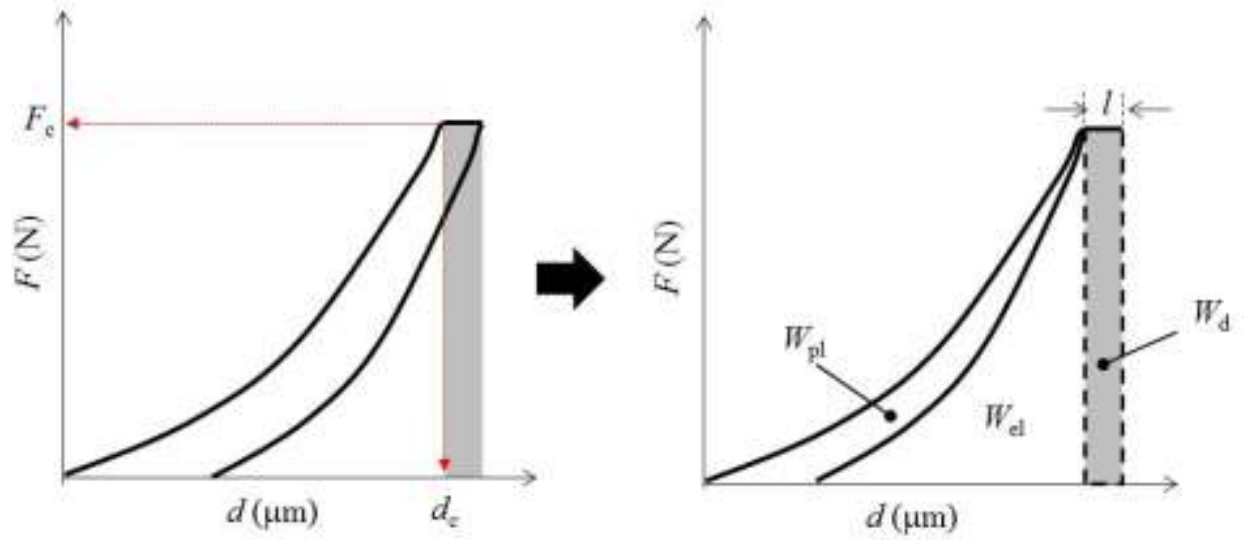

Fig. 6.4: The associated work in the $F-d$ curve after the indentation damage testing.

The $W_{\mathrm{d}}$ can be determined from the $F-d$ curve by multipling $F_{\mathrm{c}}$ with the plateau length $l$, which is measured horizontally from the location $d_{\mathrm{c}}$ to a point where the indentation force starts to decrease, i.e., unloading. In this indentation damage test set-up, an algorithm is developed so that if an $\mathrm{AE}$ event is detected during the indentation loading, 
the indenter would stop immediately, and then retract to its original position. However, a small increase in force, i.e., $<10 \mathrm{mN}$ is usually measured in the $F$ - $d$ curve before the unloading process (Fig. 6.5). This is due to the intrinsic behavior in the electrical signal delay between the $\mathrm{AE}$ measurement system and the micro-mechanical tester. In order to determine $W_{\mathrm{d}}$ accurately, the displacement due to this small increase of force is not take into account for the measurement of $l$.

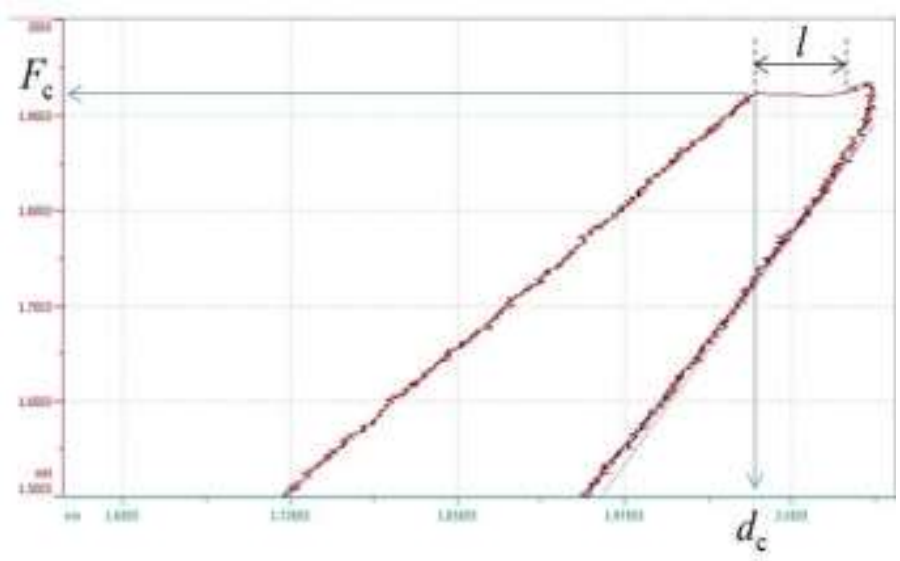

Fig 6.5: The illustration of the $l$ measurement in the $F-d$ curve.

The measurement of $l$ observes a larger variance than that obtained for $F_{\mathrm{c}}$, as shown in Fig. 6.6. This could be due to the displacement of the indenter onto that cracked specimen, which depends strongly on the damage condition of the specimen, which is intrinsic and random. In additional, the thicknesses of those thin-films due to the processing variation can also contribute to the large variance of $l$. It is observed that the $\mathrm{Si}$ die and metalcoated $\mathrm{Si}_{3} \mathrm{~N}_{4}-\mathrm{Si}$ specimens yield a comparable $F_{\mathrm{c}}$, but a larger $l$ is measured for the latter one. This could be explained by the through-thickness cracking of the $\mathrm{Si}_{3} \mathrm{~N}_{4}$ dielectric layer, in addition to the sub-surface cracking of the Si substrate, which causes the indenter to displace further at $F_{\mathrm{c}}$, and thus yields a larger $W_{\mathrm{d}}$. The largest value of $W_{\mathrm{d}}$ is calculated 
in the metal-coated $\mathrm{SiO}_{2}$-Si specimens, which corresponds to the largest values of $F_{\mathrm{c}}$ and $l$ measured.

(a)

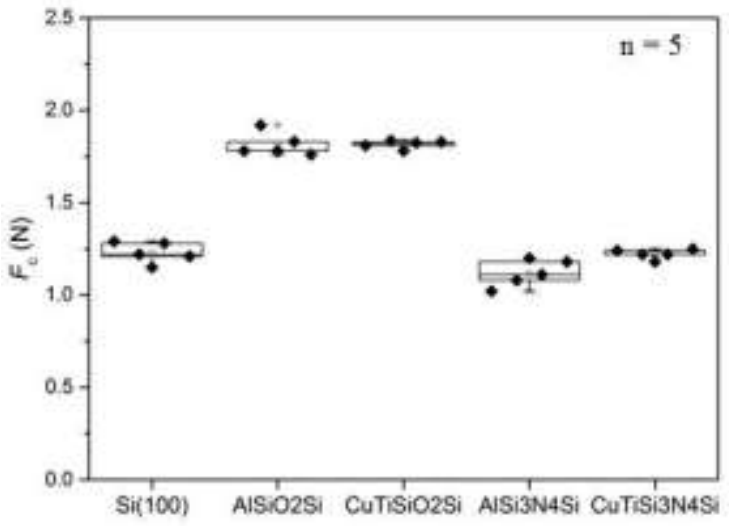

(b)

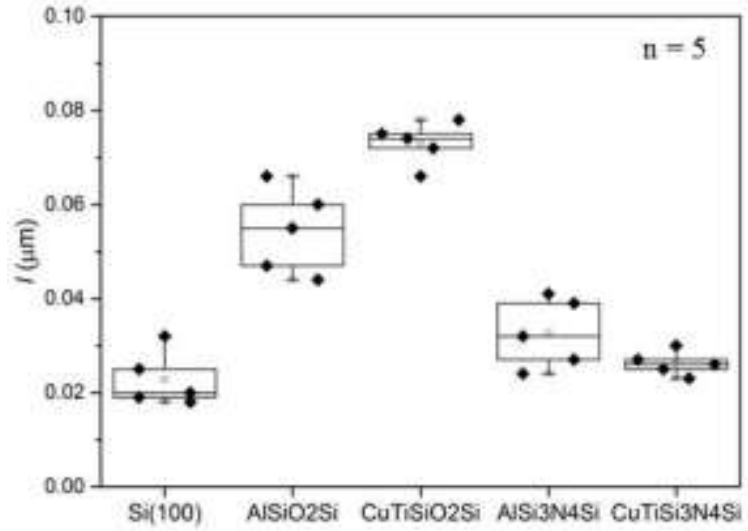

(c)

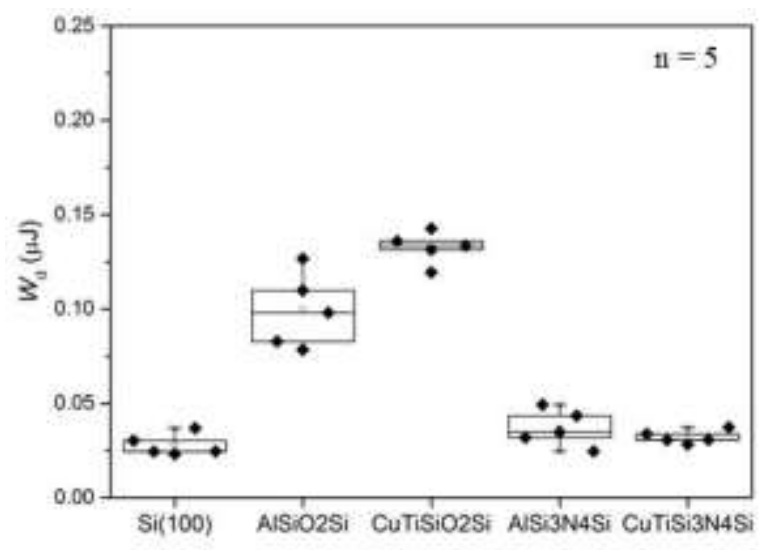

Fig. 6.6: The results of the $\mathrm{Si}$ die and thin-film stacked specimens after the indentation damage testing: (a) $F_{\mathrm{c}}$, (b) $l$ and (c) $W_{\mathrm{d}}$.

Figure 6.7 shows the plots of $F$ and $d$ against $t$, and the observation of the 'pop-in' in the displacement curve is due to a sudden increase in the distance travelled by the indenter when the cracking of the specimen occurs (for a force-controlled indentation) before reaching another resistance point. This suggests that the elastic strain energy in the specimen converted from the work of indentation is released by fracture, and the specimen loses its structural integrity and stiffness at the instance of the 'pop-in' 
occurrence. At this moment, the indentation test system tries to maintain the force at $F_{\mathrm{c}}$ by moving the indenter to meet a reaction force equal to $F_{\mathrm{c}}$, within an acquisition time step. This results in a sudden increase of the displacement of the indenter at $l$. Since $l$ can be influenced by the loading and measurement conditions, and also related to the crack severity state, $W_{\mathrm{d}}=F_{\mathrm{c}} l$ may not be the right physical quantity to assess the fracture released energy in the specimen.

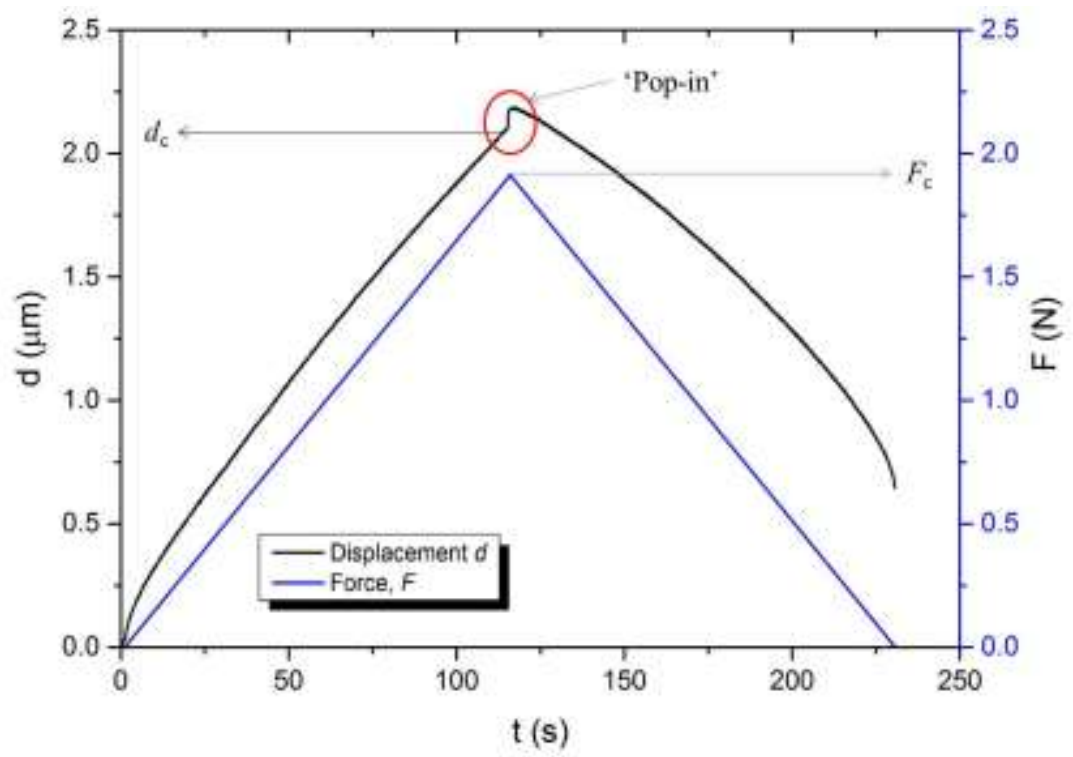

Fig. 6.7: The plots of $F$ and $d$ against $t$ for the $\mathrm{Al}_{-} \mathrm{SiO}_{2}-\mathrm{Si}$ specimen during the indentation damage testing.

In order to determine the actual work related to the cracking or fracture of the specimen, the work of indentation fracture $W_{\mathrm{f}}$ is used. Physically, $W_{\mathrm{f}}$ is the energy responsible for the crack initiation and propagation in the specimen at $F_{\mathrm{c}}$. During the indentation loading, the elastic strain energy is stored in the specimen until cracking occurs at $F_{\mathrm{c}}$, where part of this energy will be released as fracture dissipation energy or work of indentation fracture $W_{\mathrm{f}}$. Based on the difference in the elastic strain recovery between a damaged and a non-damaged specimen at $F_{\mathrm{c}}, W_{\mathrm{f}}$ can then be calculated by 


$$
W_{\mathrm{f}}=W_{\mathrm{el}}^{\prime}-W_{\mathrm{el}}^{\mathrm{d}}
$$

where $W_{\mathrm{el}}^{\prime}$ is the imaginary elastic energy or strain recovery from an indentation load at $F_{\mathrm{c}}$, assuming no cracking in the specimen. This parameter can be estimated from the results obtained from the indentation testing at the $F_{\mathrm{m}}$ condition by using (i) the elastic-to-total work ratio method, or (ii) the integration of the unloading $F$ - $d$ curve method.

\subsubsection{Elastic-to-total work ratio method}

The elastic-to-total work ratio method in calculating the $W_{\mathrm{f}}$ is presented in Fig. 6.8. The area under the loading curve is equivalent to $W_{\mathrm{T}}^{\mathrm{d}}-W_{\mathrm{d}}$ or $W_{\mathrm{el}}^{\mathrm{d}}+W_{\mathrm{pl}}^{\mathrm{d}}$. It is assumed that $W_{\mathrm{el}} / W_{\mathrm{T}}$ obtained from the indentation test at $F_{\mathrm{m}}$ is equivalent to that at $F_{\mathrm{c}}$ (where $F_{\mathrm{m}}$ is near $\left.F_{\mathrm{c}}\right)$, the imaginary elastic energy $W_{\mathrm{el}}^{\prime}$ can be determined from $W_{\mathrm{el}}\left(W_{\mathrm{T}}^{\mathrm{d}}-W_{\mathrm{d}}\right) / W_{\mathrm{T}}$. Finally, $W_{\mathrm{f}}$ obtained from Eq. (6.3) can be rewritten as

$$
W_{\mathrm{f}}=\frac{W_{\mathrm{el}}}{W_{\mathrm{T}}}\left(W_{\mathrm{T}}^{\mathrm{d}}-W_{\mathrm{d}}\right)-W_{\mathrm{el}}^{\mathrm{d}}
$$

The metal-coated $\mathrm{SiO}_{2}-\mathrm{Si}$ specimens yield the higher values of $W_{f}$ than the metalcoated $\mathrm{Si}_{3} \mathrm{~N}_{4}$-Si specimens, as presented in Fig. 6.9. This work of indentation fracture in the former specimen is related to the ring and radial cracking on the $\mathrm{SiO}_{2}$ surfaces, including the sub-surface cone and lateral cracking in the Si substrate, while $W_{f}$ in the latter specimen is related to the ring, radial, medium and through-thickness cracking of the $\mathrm{Si}_{3} \mathrm{~N}_{4}$ layer, and also the subsurface lateral cracking in the Si substrate. 


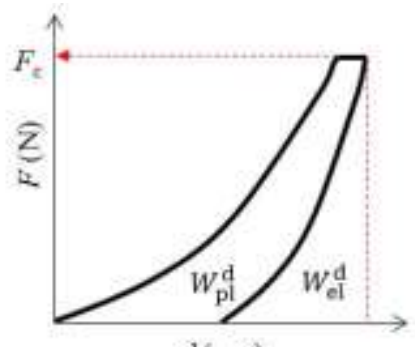

$d(\mu \mathrm{m})$

Damage test $\rightarrow W_{e t}^{d}$

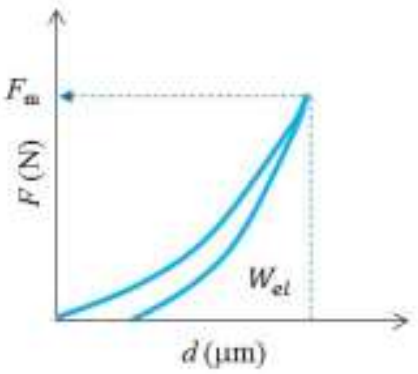

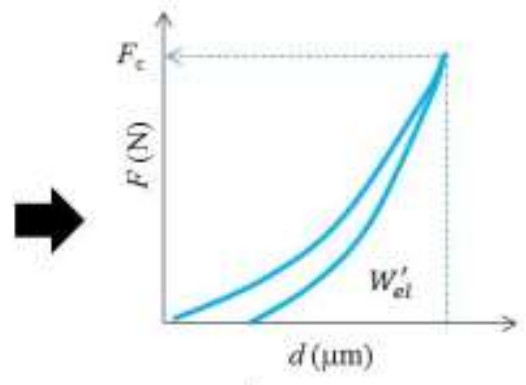

Obtain $\left(W_{\mathrm{T}}^{\mathrm{d}}-W_{\mathrm{d}}\right)$ from the damage test, and multiple by $W_{\mathrm{el}} W_{\mathrm{T}} \rightarrow W_{e l}^{\prime}$

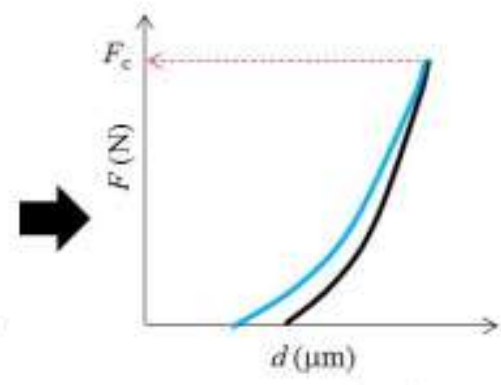

Area enclosed $W_{e t}^{\prime}-W_{e l}^{d} \rightarrow W_{\mathrm{f}}$

Indentation test@ $F_{\mathrm{m}}$ $\rightarrow W_{\mathrm{el}} W_{\mathrm{T}}$

Fig. 6.8: The calculation of $W_{\mathrm{f}}$ by the elastic-to-total work ratio method.

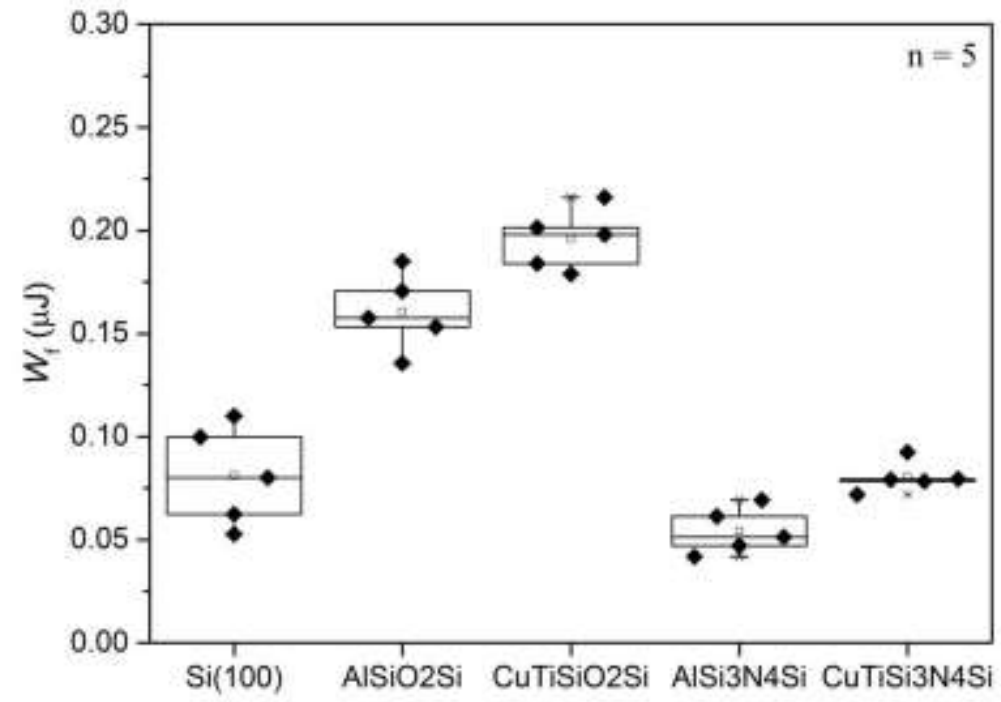

Fig. 6.9: The results of $W_{\mathrm{f}}$ determined from the elastic-to-total work ratio method for the Si die and thin-film stacked specimens. 


\subsubsection{Integration of the unloading $F-d$ curve method}

Another method is proposed to determine the $W_{\mathrm{el}}^{\prime}$ by integrating the unloading $F$ - $d$ curve obtained from an indentation test at $F_{\mathrm{m}}$ for the non-damaged specimen (Fig. 6.10). In order to minimize the error, $F_{\mathrm{m}}$ should be close to $F_{\mathrm{c}}$, and both the indentations should be conducted on the same specimen.

The unloading $F-d$ curve obtained from the indentation test at $F_{\mathrm{m}}$ can be described by a second-order polynomial function:

$$
F=A d^{2}+B d-C,
$$

where $A, B$ and $C$ are the fitted coefficients. By integrating Eq. (6.5) from the residual displacement $d_{\mathrm{p}}$ to the critical displacement $d_{\mathrm{c}}, W_{\mathrm{el}}^{\prime}$ can be determined. The $d_{\mathrm{p}}$ is defined as the plastic residue or deformation after the indenter is fully removed during the indentation test at $F_{\mathrm{m}}$, while $d_{\mathrm{c}}$ is corresponding to $F_{\mathrm{c}}$ that is obtained from the indentation damage test. Finally, $W_{\mathrm{f}}$ can be determined from Eq. (6.3).

Figure 6.11 presents the results of $W_{\mathrm{f}}$ using the integration of the unloading $F$ - $d$ curve method for the Si die and thin-film stacked specimens. A similar trend is observed for both the methods, where the higher values of $W_{\mathrm{f}}$ are obtained for the metal-coated $\mathrm{SiO}_{2^{-}}$ $\mathrm{Si}$, as compared to the metal-coated $\mathrm{Si}_{3} \mathrm{~N}_{4}-\mathrm{Si}$ specimens. 


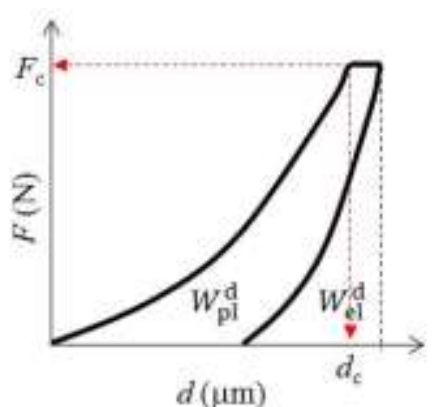

Damage test $\rightarrow W_{e l}^{d}$

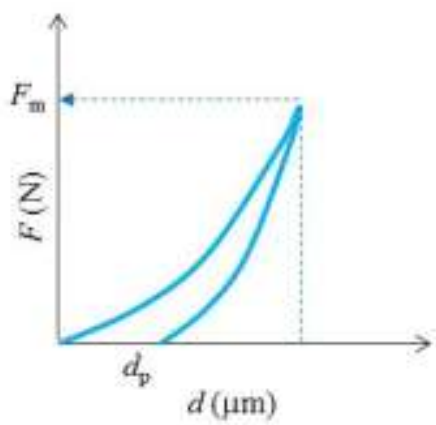

Indentationtest@ $F_{\mathrm{m}} \rightarrow$ unloading $F-d$ curve

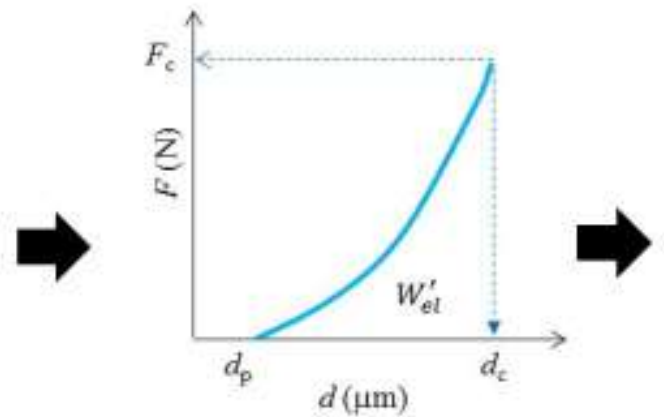

Extrapolate unloading $F-d$ curve from indentation test $@ F_{\mathrm{m}}$ to $F_{\mathrm{c}}$ \& integrate from $d_{\mathrm{p}}$ to $d_{\mathrm{c}} \rightarrow W_{e l}^{\prime}$

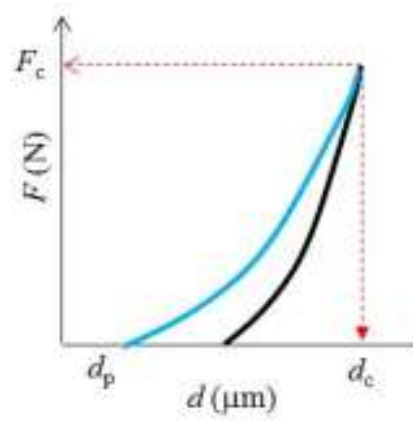

Area enclosed $W_{e l}^{\prime}-W_{e l}^{d} \rightarrow W_{\mathrm{f}}$

Fig. 6.10: The calculation of $W_{\mathrm{f}}$ by integration of the unloading $F$ - $d$ curve method.

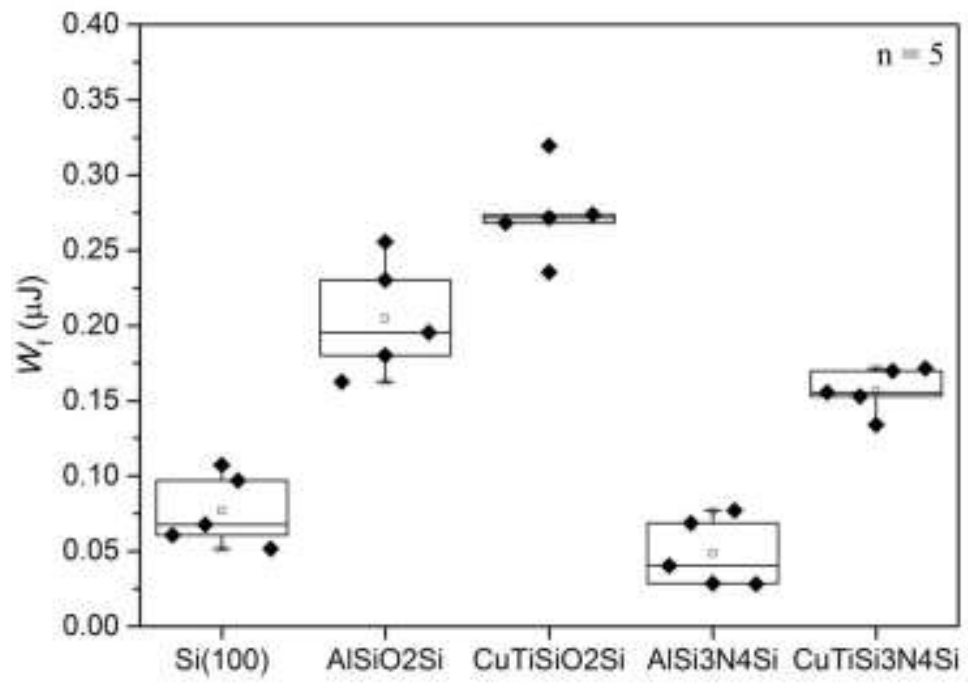

Fig. 6.11: The results of $W_{\mathrm{f}}$ determined from the integration of the unloading $F-d$ curve method for the Si die and thin-film stacked specimens. 
Figure 6.12 summarizes the mean values of $W_{\mathrm{d}}$ and $W_{\mathrm{f}}$ obtained from Figs. 6.6(c), 6.9 and 6.11, and observes $W_{\mathrm{d}}<W_{\mathrm{f}}$ for all the specimens. This implies that the energy required for the crack initiation and propagation in the specimen is much higher than the work done by the indenter at $F_{\mathrm{c}}$. Generally, the elastic-to-total work method calculates the higher values of $W_{\mathrm{f}}$ for both the $\mathrm{Si}$ die and Al-coated specimens, while the integration method calculates the higher values in the $\mathrm{Cu}$-coated specimens. However, the effect of the top metal layer on the results obtained from both the methods remains unclear.

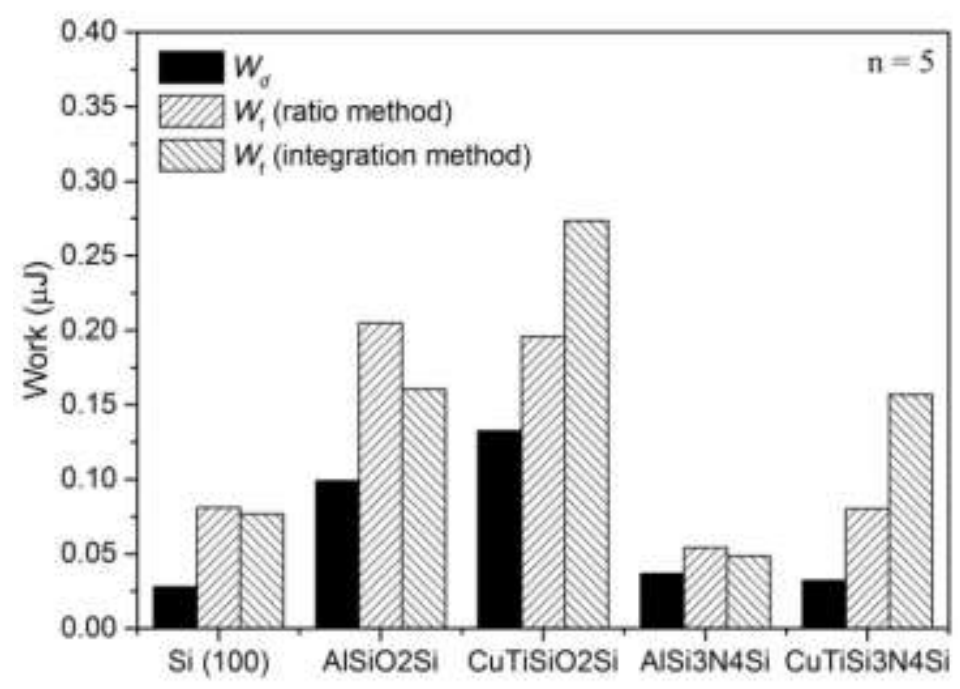

Fig. 6.12: A comparison of $W_{\mathrm{d}}$ and $W_{\mathrm{f}}$ for the Si die and thin-film stacked specimens.

\subsection{Acoustic emission energy measurements}

One of the parameters extracted from the first $\mathrm{AE}$ event or transient signal is the $E_{\mathrm{AE}}$, which is calculated by integrating the square of the digitized AE signal (voltage $V_{i}$ ) during the signal duration, and then divided by a reference resistance $R$, i.e. $E_{\mathrm{i}}=\int V_{i}(t)^{2} d t / R$.

The results of $W_{\mathrm{f}}$ (from the both methods) and its corresponding $E_{\mathrm{AE}}$ measurements are presented in Table 6.1. The lower values of $E_{\mathrm{AE}}$ are measured for both 
the $\mathrm{Al}-\mathrm{Si}_{3} \mathrm{~N}_{4}-\mathrm{Si}$ and $\mathrm{CuTi}-\mathrm{Si}_{3} \mathrm{~N}_{4}-\mathrm{Si}$ specimens, where the radial and through-thickness cracking is observed at the intermediate dielectric layer, and sometimes sub-surface lateral observed in the Si substrate. A slightly higher value of $E_{\mathrm{AE}}$ is observed for the Si die, where the failure mode is typically the sub-surface lateral cracking. Both the $\mathrm{Al}-\mathrm{SiO}_{2}-\mathrm{Si}$ and $\mathrm{CuTi}-\mathrm{SiO}_{2}-\mathrm{Si}$ specimens yield the larger values of $E_{\mathrm{AE}}$ than the metal-coated $\mathrm{Si}_{3} \mathrm{~N}_{4}-\mathrm{Si}$ specimens, where the radial cracking is observed in the intermediate dielectric layer, and also the sub-surface cone and lateral cracking in the $\mathrm{Si}$ substrate. Generally, the observation in these thin-film stacked specimens shows that the lower and higher values of $E_{\mathrm{AE}}$ can be related to the through-thickness cracking in the intermediate dielectric layer and the sub-surface cone cracking in the Si substrate, respectively.

Table 6.1: A summary of $W_{\mathrm{f}}$ and $E_{\mathrm{AE}}$ results.

\begin{tabular}{lccc}
\hline \hline & $\begin{array}{c}\text { Elastic-to-total work } \\
\text { ratio method }\end{array}$ & Integration method & AE measurement \\
Specimen & $W_{\mathrm{f}}(\mu \mathrm{J})$ & $W_{\mathrm{f}}(\mu \mathrm{J})$ & $\begin{array}{c}E_{\mathrm{AE}} 10^{6}(\mathrm{eu}) \\
1 \mathrm{eu}=10^{-18} \mathrm{~J}=10^{-14} \mathrm{~V}^{2} \mathrm{~s}\end{array}$ \\
\hline $\mathrm{Si}(100) \mathrm{die}$ & $0.053-0.110$ & $0.052-0.107$ & $0.18-0.35$ \\
$\mathrm{Al}-\mathrm{SiO}_{2}-\mathrm{Si}$ & $0.162-0.256$ & $0.136-0.185$ & $0.839-1.41$ \\
$\mathrm{CuTi}^{-S i O}{ }_{2}-\mathrm{Si}$ & $0.184-0.216$ & $0.235-0.320$ & $1.06-1.31$ \\
$\mathrm{Al}_{-} \mathrm{Si}_{3} \mathrm{~N}_{4}-\mathrm{Si}$ & $0.042-0.069$ & $0.028-0.077$ & $0.075-0.285$ \\
$\mathrm{CuTi} \mathrm{Si}_{3} \mathrm{~N}_{4}-\mathrm{Si}$ & $0.072-0.092$ & $0.134-0.171$ & $0.048-0.11$ \\
\hline \hline
\end{tabular}

The relationship between the $W_{\mathrm{f}}$ and $E_{\mathrm{AE}}$ for the entire indentation testing is presented in Fig. 6.13. As expected, there is a noticeable proportionality between the $W_{\mathrm{f}}$ and $E_{\mathrm{AE}}$. The challenge with $E_{\mathrm{AE}}$ measurement is that it is not essentially a function of the $\mathrm{AE}$ source alone, but also a function of the measurement system and the structure of the 
specimen. The signal attenuates as it progresses from the AE source (the location of crack) to the sensor. This attenuation effect can be minimized through a proper and consistent experimental set-up, including the amount of coupling medium applied and stand-off height between the specimen and $\mathrm{AE}$ sensor, and the positioning of the specimen on the sensor with the coupling medium.

(a)

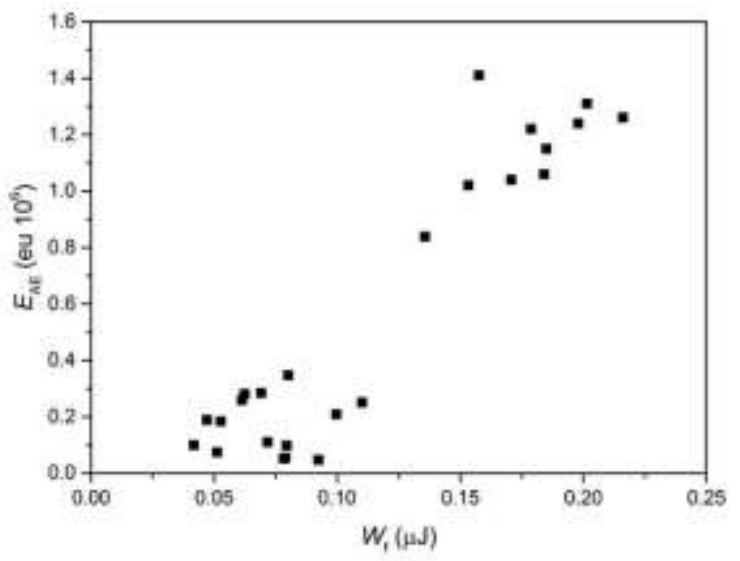

(b)

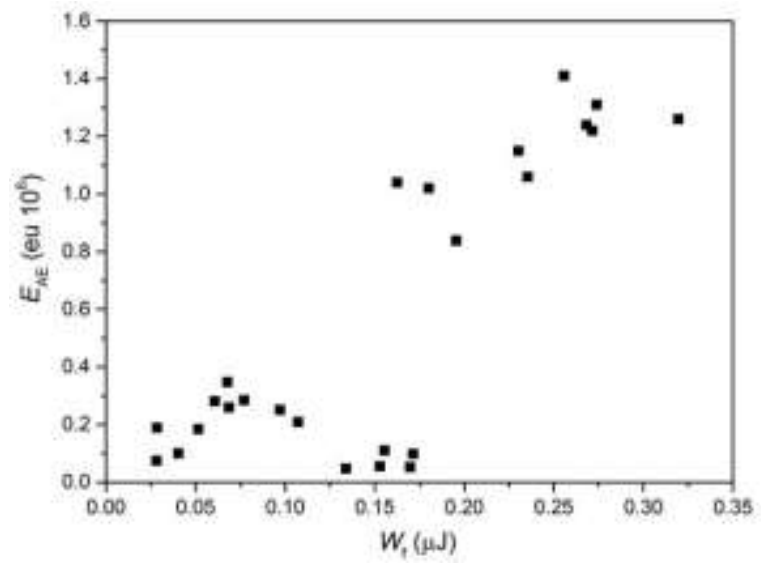

Fig. 6.13: The plots of $E_{\mathrm{AE}}$ against $W_{\mathrm{f}}$ calculated by (a) the elastic-to-total work method, and (b) the integration of $F-d$ curve method.

Ideally, the calculation of $E_{\mathrm{AE}}$ should reveal the true measurement of the energy being transmitted by the elastic waves from the AE source when cracking occurs, and would be in the equivalent units as $W_{\mathrm{f}}[141]$. However, the integral over the AE signal duration is the 'envelope strength' or signal strength, instead of the energy. Nevertheless, it serves the intended purpose as a damage physical quantity that can be related to the mechanical work done for the crack development during the indentation damage test.

\subsection{Summary}

An energy-based model is proposed based on the difference in the elastic strain recovery between damaged and non-damaged specimens during the indentation testing. 
The work of indentation fracture $W_{\mathrm{f}}$ is determined by taking the difference between the elastic energy $W_{e l}^{d}$ and the imaginary elastic energy $W_{e l}^{\prime}$ obtained from the indentation damage test and the indentation test at $F_{\mathrm{m}}$ (near $F_{\mathrm{c}}$ ) of the same specimen, respectively. The latter energy component can then be estimated from the elastic-to-total work or integration of the unloading $F$ - $d$ curve methods.

Generally, a higher value of $W_{\mathrm{f}}$ is determined in the metal-coated $\mathrm{SiO}_{2}-\mathrm{Si}$ specimen that is related to the ring and radial cracking on the $\mathrm{SiO}_{2}$ surfaces, including the subsurface cone and lateral cracking in the $\mathrm{Si}$ substrate. However, for the metal coated $\mathrm{Si}_{3} \mathrm{~N}_{4}-$ Si specimen, the ring, radial, medium and through-thickness cracking is observed in the $\mathrm{Si}_{3} \mathrm{~N}_{4}$ layer, and the sub-surface lateral cracking is also found in the $\mathrm{Si}$ substrate.

It is found that the energy required for crack initiation and propagation in the specimen under the indentation testing is much higher than the work done by the indenter at $F_{\mathrm{c}}$ onto those damaged specimens, i.e. $W_{\mathrm{d}}<W_{\mathrm{f}}$. The difference between $W_{\mathrm{d}}$ and $W_{\mathrm{f}}$ is that the former energy depends on the geometry of the thin-film stacked structure, and also the crack severity or condition, which can affect the plateau length $l$ at $F_{\mathrm{c}}$. Therefore, $W_{\mathrm{f}}$ is an appropriate physical parameter to describe the 'mechanical strength' or threshold load of the thin-film stacked structure. It is observed that $W_{\mathrm{f}}$ varies proportionally with the measurement of $E_{\mathrm{AE}}$. It is also found that the lower and higher values of $E_{\mathrm{AE}}$ obtained from the indentation damage test could be related to the through-thickness cracking in the intermediate dielectric layer and the sub-surface cone cracking in the Si substrate, respectively. 


\section{Chapter 7 Conclusions and Recommendations}

Based on the work conducted during this $\mathrm{PhD}$ study, the main conclusions are drawn and the recommendations are suggested in this chapter.

\subsection{Conclusions}

Firstly, an indentation damage test methodology is established using a micromechanical tester integrated with an $\mathrm{AE}$ sensor for the crack detection in the bulk Si die and in the underlying layer of the thin-film stacked specimens. The AE pulsar test method is employed to investigate the $S / N$ ratio and the measurement sensitivity for the different test condition set-ups. It is concluded that the nail polish used as a couplant medium between the specimen and $\mathrm{AE}$ sensor can improve the $S / N$ ratio by $\sim 10 \mathrm{~dB}$. A further improvement of $S / N$ ratio to $\sim 15 \mathrm{~dB}$ can be achieved by positioning the pulsar at the centre of the specimen or AE sensor. The threshold amplitude of $57 \mathrm{~dB}$ is defined, and employed in the indentation damage test. The measurement of $F-d$ from the micromechanical tester is synchronized with the AE signals, and monitored in real time in the Vallen AMSY-6 system during the indentation testing.

Secondly, the indentation damage test system is used to evaluate both the Si (100) die and $\mathrm{Si}$ (111) die specimens. It is found that the first AE event or peak voltage $V_{\mathrm{s}}$ detected corresponds to the 'pop-in' or plateau in the $F$ - $d$ curve, and the force and displacement at this point are defined as the onset crack force $F_{\mathrm{c}}$ and displacement $d_{\mathrm{c}}$, respectively. The mean values of $F_{\mathrm{c}}$ and $d_{\mathrm{c}}$ for the $\mathrm{Si}(100)$ die specimen are $1.16 \mathrm{~N}$ and $1.24 \mu \mathrm{m}$, respectively, and for the $\mathrm{Si}(111)$ die are $1.49 \mathrm{~N}$ and $1.47 \mu \mathrm{m}$. In general, the larger values 
of $A$ and $E_{\mathrm{AE}}$ are detected if the higher $F_{\mathrm{c}}$ is measured. The major failure mode of the $\mathrm{Si}$ (100) die specimen is the sub-surface lateral cracking, and sometimes surface ring and radial cracking is observed. However, mixed surface ring and radial cracking and subsurface cone and lateral cracking are observed in the $\mathrm{Si}$ (111) die specimen.

The indentation hardness $H_{\mathrm{IT}}$ and modulus $E_{\mathrm{IT}}$ of the $\mathrm{Si}(100)$ die specimen are measured to be $\sim 11 \mathrm{GPa}$ and $\sim 150 \mathrm{MPa}$, respectively, and used in the indentation testing simulation model. The modelling results show that the location of the maximum principle stress component $\sigma_{1}$ occurs within the radial crack region, as observed in the indentation damage test. This suggests that the maximum tensile stress region initiates a mode-I crack, whose propagation is then driven by the indentation loading to form the radial crack. The locations of the maximum shear stress component $\tau_{13}=0.5\left(\sigma_{1}-\sigma_{3}\right)$ correspond to the region within the ring and the sub-surface lateral cracks. This infers that the maximum shear stress region initiates a mode-II crack, which then propagates to form the ring and lateral cracks, under the indentation loading. Generally, the FE modelling shows that the locations of the maximum principle stress and shear stress components correspond to the cracking regions in those $\mathrm{Si}$ die specimens.

Thirdly, the indentation damage test is employed to evaluate on different thin-film stacked systems, which consists of a top metal layer (Al or CuTi) and an intermediate dielectric $\left(\mathrm{SiO}_{2}\right.$ or $\left.\mathrm{Si}_{3} \mathrm{~N}_{4}\right)$ layers on the $\mathrm{Si}(100)$ substrate. The $F_{\mathrm{c}}$ is determined from the first $\mathrm{AE}$ event occurrence, and corresponds to the "pop-in" observed in the F- $d$ curve, which is mainly due to the brittle cracking in the dielectric layer or/and Si substrate. A lower magnitude of a second $\mathrm{AE}$ event is detected during the unloading stage, but no "pop-out" is observed in the $F-d$ curve, which is related to the delamination or interfacial 
cracking between the dielectric layer and the $\mathrm{Si}$ substrate for those metal-coated $\mathrm{SiO}_{2}-\mathrm{Si}$ specimens. It is observed that a higher $F_{\mathrm{c}}$ corresponds to the higher $A$ and $E_{\mathrm{AE}}$ detected in the AE signals, except for the rise time $t_{\mathrm{r}}$ that is almost the same for all the specimens. It is also found that the duration time $t_{\mathrm{r}}$ recorded in the $\mathrm{CuTi}-\mathrm{SiO}_{2}-\mathrm{Si}$ specimen is much longer than the rest of the thin-film stacked specimens, which also observes a higher occurrence of the AE events. There is no cracking found on the top metal layer for all the specimens after the indentation damage test, except a round indented mark and pile-up around the indented area. However, delayering of those top metal layers reveals the peeling, ring and radial cracking on the $\mathrm{SiO}_{2}$ surfaces, and the medium, ring and radial cracking on the $\mathrm{Si}_{3} \mathrm{~N}_{4}$ surfaces. The cross-sectioning of the damaged metal-coated $\mathrm{SiO}_{2}-\mathrm{Si}$ specimens shows the sub-surface cone and lateral cracking in the $\mathrm{Si}$ substrate, and delamination at the interface between the $\mathrm{SiO}_{2}$ and $\mathrm{Si}$. However, for the metal-coated $\mathrm{Si}_{3} \mathrm{~N}_{4}-\mathrm{Si}$ specimen, the through-thickness cracking of the $\mathrm{Si}_{3} \mathrm{~N}_{4}$ dielectric layer and the sub-surface lateral cracking of the Si substrate are observed. Generally, a higher $F_{\mathrm{c}}$ is usually obtained in the metal-coated $\mathrm{SiO}_{2}-\mathrm{Si}$ specimen as compared to the metal-coated $\mathrm{Si}_{3} \mathrm{~N}_{4}-\mathrm{Si}$. Furthermore, delamination only occurs in the former specimen during the unloading stage of the indentation testing.

An FE model of the thin-film stacked structure is established to perform the stress modelling on those specimens under the indentation testing. It is observed that the locations of the maximum principle stress $\sigma_{1}$ and shear stress $\tau_{13}$ at the maximum load condition are within the $\mathrm{Si}$ damage regions, as observed in the experiments. It is found that the mode-II fracture is the main damage mechanism for the through-thickness cracks in the intermediate $\mathrm{Si}_{3} \mathrm{~N}_{4}$-Si dielectric layer of the thin-film stacked specimen during the 
indentation loading. In the unloading stage, the fracture of mixed modes I and II is the main damage mechanism responsible for the delamination at the $\mathrm{SiO}_{2}$ dielectric layer and the Si substrate interface.

Finally, an indentation energy-based approach is proposed to determine the work of indentation damage $W_{\mathrm{d}}$ and fracture $W_{\mathrm{f}}$. The $W_{\mathrm{d}}$ describes the work done by the indenter on the damaged specimen after the crack formation, and is calculated by multipling $F_{\mathrm{c}}$ with the plateau length $l$ obtained from the $F-d$ curve. The $W_{\mathrm{f}}$ describes the energy difference in the elastic strain recovery between a damaged and a non-damaged indentation from the same specimen. The energy calculation approach can only be employed using this indentation damage test set-up, where the unloading stage is triggered upon the detection of the first $\mathrm{AE}$ event at the loading. Two different techniques are proposed to estimate $W_{\mathrm{f}}$, namely, the elastic-to-total work ratio method and the integration of the unloading $F-d$ curve method. Both methods yield similar trends, where a higher $W_{\mathrm{f}}$ is determined for the metal-coated $\mathrm{SiO}_{2}-\mathrm{Si}$ specimen as compared to the metal-coated $\mathrm{Si}_{3} \mathrm{~N}_{4}-\mathrm{Si}$. It is found that the energy required for crack formation in the specimen is much higher than the work done by the indenter at $F_{\mathrm{c}}$ onto those damaged specimens, i.e. $W_{\mathrm{d}}<$ $W_{\mathrm{f}}$. Therefore, $W_{\mathrm{f}}$ should be the appropriate physical parameter to describe the 'mechanical strength' of the specimen under indentation test. It is observed that $W_{\mathrm{f}}$ varies proportionally with the $E_{\mathrm{AE}}$. In addition, a lower and a higher $E_{\mathrm{AE}}$ obtained from the indentation damage test could be closely related to the through-thickness cracking in the intermediate dielectric layer and the sub-surface cone cracking in the $\mathrm{Si}$ substrate, respectively. 
This $\mathrm{PhD}$ work provides an in-depth understanding of the damage mechanisms on a thin-film stacked structure during the indentation loading-unloading cycle. The application can be found in the wafer probing and wire bonding processes, where the damage-sensitive pad can be identified and handled with care. Furthermore, the methodology can be used to optimize the mechanical design of the bond pad, or implement as a mechanical screening tool for wafer quality check, which will eventually enable resilient statements for improving the product quality and reliability of IC chips.

\subsection{Recommendations}

This $\mathrm{PhD}$ study provides a systematic approach in analysing the mechanical behavior of the thin-film stacked specimen under the indentation testing at room temperature. As the wire bonding process is conducted at an elevated temperature, i.e., $>150{ }^{\circ} \mathrm{C}$, the deformation and damage behavior of those thin-film stacked system may be different. Furthermore, the adhesion strength within the thin-film stacked system may vary. However, the implementation of high-temperature testing is not so straight-forward. Besides a high-operating temperature $\mathrm{AE}$ sensor, the thermal drift effect from the system has to be considered and compensated accordingly in order to obtain an accurate measurement of the mechanical response.

The proposed work of indentation fracture model can be extended to determine the fracture toughness $K$ or strain energy release rate $G=K / E$ of the thin-films, if the geometrical detail of the cracks can be characterized. In addition, the delamination observed in the metal-coated $\mathrm{SiO}_{2}-\mathrm{Si}$ specimens during the unloading stage is not considered in the model, which can be included for further work. 


\section{References}

[1] International Technocalogy Roadmap for Semiconductor, Assembly and packaging, 2012.

[2] Solid State Technology Online 2005. Retrieved from http://electroiq.com/blog/2005/07/wire-bond-vs-flip-chip-packaging/

[3] G. G. Harman, Wire Bonding in Microelectronics, $3^{\text {rd }}$ Ed., McCraw-Hill, New York, 2010.

[4] B. I. Lasgesecker, "Effects of Ultrasound on Deformation Characteristics of Metals," IEEE Transactions on Sonics and Ultrasonics, vol. 13(1), pp. 1-8 , 1966.

[5] G. G. Harman and J. Albers, "The ultrasonic welding mechanism as applied to aluminum- and gold-wire bonding in microelectronics," IEEE Transactions on Parts, Hybrids, and packaging, vol. 13(4), pp.406-412, 1977.

[6] J. E. Krzanowski, "A transmission electron microscopy study of ultrasonic wire bonding," IEEE Transactions on Components, Hybrids, and Manufacturing Technology, vol. 13(1), pp. 176-181, 1990.

[7] T. A. Tran, L. Yong, W. Chen, S. Chen and A. Chen, "Fine Pitch Probing and Wirebonding and Reliability of Aluminum Capped Copper Bond Pads," Proceedings of $50^{\text {th }}$ Electronic Components and Technology Conference, pp. 1674-1680, Las Vegas, USA, 2000.

[8] Y. Jeng and J. Horng, "A microcontact approach for ultrasonic wire bonding in microelectronics," Journal of Tribology, vol.123, pp. 725-731, 2001.

[9] G. G. Harman and C. E. Johnson, "Wire bonding to advanced copper, low-K integrated circuits, the metal/dielectric stacks, and materials considerations," IEEE Transactions on Components and Packaging Technologies, vol. 25(4), pp. 677683, 2002.

[10] J. Park, H. J. Cha, B. S. Kim, Y. B. Jo, J. K. Park, S. Y. Kim, S. C. Shin, M. Y. Shin, K. I. Ouh and H. Jeon, "Interfacial degradation mechanism of Au/Al and Alloy/Al bonds under high temperature storage test: Contamination, epoxy molding compound, wire and bonding strength," IEEE Transactions on Components and Packaging Technologies, vol. 30, No. 4, p. 731-744, 2007.

[11] F. L. Wang, Y. Chen and L. Han, "Experiment study of dynamic looping process for thermosonic wire bonding," Microelectronics Reliability, vol. 52, pp. 1105$1111,2012$. 
[12] L. Yang, P. A. Agyakwa and C. M. Johnson, "Calibration of a novel microstructural damage model for wire bonds," IEEE Transactions on Device and Materials Reliability, vol. 14(4), pp. 989-994, 2014.

[13] M. D. Ker and J. J. Peng, "Fully process-compatible layout design on bond pad to improve wire bond reliability in CMOS ICs," IEEE Transactions on Components and Packaging Technologies, vol. 25(2), pp. 309-316, 2002.

[14] K. J. Hess, S. H. Downey, G. B. Hall, T. Lee and L. L. Mercado, "Reliability of

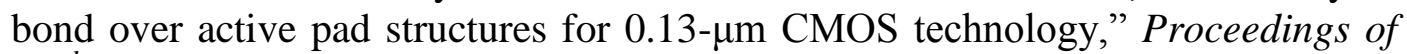
$53^{\text {rd }}$ Electronic Components and Technology Conference, pp. 1344-1349, New Orleans, Louisiana, USA, 2003.

[15] I. Jeon and Q. Chung, "The study on failure mechanisms of bond pad metal peeling: Part A -Experimental investigation," Microelectronics Reliability, vol. 43, pp. 2047-2054, 2003.

[16] I. Jeon, "The study on failure mechanisms of bond pad metal peeling: Part B Numerical analysis," Microelectronics Reliability, vol. 43, pp. 2055-2064, 2003.

[17] C. M. Tan and Z. Gan, "Failure Mechanisms of aluminum bondpad peeling during thermosonic bonding," IEEE Transactions on Device and Materials Reliability, vol. 3(2), pp. 44-50, 2003.

[18] C. Xu, C. D. Breach, T. Sritharan, F. Wulff and S. G. Mhaisalkar, "Oxidation of bulk Au-Al intermetallics,” Thin Solid Films, vol. 462-463, pp. 357-362, 2004.

[19] J. Tan, Z. W. Zhong and H. M. Ho, "Wire-bonding process development for low-k materials," Microelectronic Engineering, vol. 81, pp.75-82, 2005.

[20] L. Shen, V. Gumaste, A. Poddar and L. Nguyen, "Effect of pad stacks on dielectric layer failure during wire bonding," Proceedings of $56^{\text {th }}$ Electronic Components and Technology Conference, pp. 146-150, San Diego, California, USA, 2006.

[21] A. G. K. Viswanath, X. W. Zhang, V. P. Ganesh and L. Chun, "Numerical study of gold wire bonding orocess on Cu/low-k structures," IEEE Transactions on Advanced Packaging, vol. 30 (3), pp. 448-456, 2007.

[22] C. C. Lee, T. Tran and C. Miller, "Overview of metal lifted failure modes during fine-pitch wirebonding low-K/copper dies," Proceedings of $57^{\text {th }}$ Electronic Components and Technology Conference, pp. 1775-1781, Reno, Nevada, USA, 2007.

[23] S. Hunter, A. Mallik, D. Whittaker, R. Alldredge and T. Rodrigues, "Simulation of ball bonding on various bond pad structures." Proceedings of $15^{\text {th }}$ Electronics Packaging Technology Conference, pp. 452-456, Singapore, 2013. 
[24] L. England and T. Jiang, "Reliability of $\mathrm{Cu}$ wire bonding to $\mathrm{Al}$ metallization," Proceedings of $57^{\text {th }}$ Electronic Components and Technology Conference, pp. 1604-1613, Reno, Nevada, USA, 2007.

[25] L. S. Yeoh, "Characterization of intermetallic growth for gold bonding and copper bonding," Proceedings of $9^{\text {th }}$ Electronics Packaging Technology Conference, pp. 731-736, Singapore, 2007.

[26] B. H. Zhang, K. Y. Qian, T. Wang, Y. Q. Cong, M. Zhao, X. Q. Fan and J. J. Wang, "Behaviors of palladium in palladium coated copper wire bonding process," Proceedings of $10^{\text {th }}$ International Conference on Electronic Packaging Technology \& High Density Packaging, pp. 662-665, Beijing, China, 2009.

[27] H. Xu, C. Q. Liu, V. V. Silberschmidt and Z. Chen, "Growth of intermetallic compounds in thermosonic copper wire bonding on aluminium metallization," Journal of Electronic Materials, vol. 39(1), pp. 124-131, 2010.

[28] Y. H. Lu, Y. W. Wang, B. K. Appelt, Y. S. Lai and C. R. Kao, "Growth of CuAl intermetallic compounds in $\mathrm{Cu}$ and $\mathrm{Cu}(\mathrm{Pd})$ wire bonding," Proceedings of $61^{\text {st }}$ Electronic Components and Technology Conference, pp. 1481-1488, Florida, USA, 2011.

[29] F. Y. Hung, T. S. Lui, L. H. Chen and Y. C. Lin, "Electric flame-off characteristics and fracture properties of $20 \mu \mathrm{m}$ thin copper bonding wire," Materials Transactions, vol. 50(2), pp. 293-298, 2009.

[30] H. Xu, C. Liu, V. V. Silberschmidt, S. S. Pramana, T. J. White and Z. Chen, “A reexamination of the mechanism of thermosonic copper ball bonding on aluminium metallization pads," Scripta Materialia, vol. 61, pp.165-168, 2009.

[31] L. England, S. T. Eng, C. Liew and H. H. Lim, "Cu wire bond parameter optimization on various bond pad metallization and barrier layer material schemes," Microelectronics Reliability, vol. 51, pp. 81-87, 2011.

[32] A. Shah , M. Mayer a, Y. Zhou, S.J. Hong and J.T. Moon, "In situ ultrasonic force signals during low-temperature thermosonic copper wire bonding," Microelectronic Engineering, vol. 85, pp. 1851-1857, 2008.

[33] A. Shah, M. Mayer, Y.N. Zhou, S.J. Hong and J.T. Moon, "Low-stress thermosonic copper ball bonding," IEEE Transactions on Electronics Packaging Manufacturing, vol. 32(3), pp. 176-184, 2009.

[34] W. Y. Yong, X. W. Zhang, T. C. Chai, A. Trigg, N. B. Jaafar and G. Q. Lo, "Insitu measurement and stress evaluation for wire bonding using embedded piezoresistive stress sensors," IEEE Transactions on Components, Packaging and Manufacturing Technology, vol. 3(2), pp. 328-335, 2013. 
[35] C. Wang and R. Sun, "The quality test of wire bonding," Modern Applied Science, vol. 3(12), pp. 50-56, 2009.

[36] Wire bond shear test method, JEDEC No.22-B116A, Aug 2009.

[37] Wire bond pull strength, IPC-TM-650, Feb 1998.

[38] D. Echizenyaab., H. Sakamotoa and K. O. Sasakib, "Effect of mechanical surface damage on Silicon wafer strength," Procedia Engineering 10, pp. 1440-1445, 2011.

[39] S. Barnat, H. Frémont, A. Gracia and E. Cadalen, "Evaluation by three-point-bend and ball-on-ring tests of thinning process on silicon die strength," Microelectronics Reliability, vol. 52, pp. 2278-2282, 2012.

[40] S. Saffar, S. Gouttebroze and Z. L. Zhang, "Fracture analysis and distribution of surface cracks in multicrystalline silicon safers," Journal of Solar Energy Engineering, vol. 136 (2), 2013.

[41] Z. Huang, Z. Suo, G. Xu, J. He, J.H. Prevost and N. Sukumar, "Initiation and arrest of an interfacial crack in a four-point bend test," Engineering Fracture Mechanics, vol. 72, pp. 584-2601, 2005.

[42] R. Shaviv, S. Roham and P. Woytowitz, "Optimizing the precision of the fourpoint bend test for the measurement of thin film adhesion," Microelectronic Engineering, vol. 82, pp. 99-112, 2005.

[43] S.J. Bull, "Failure mode maps in the thin film scratch adhesion test," Tribology International, vol. 30(7), pp. 491-498, 1997.

[44] J. Malzbender, J.M.J. den Toonder, A.R. Balkenende and G. de With, "Measuring mechanical properties of coatings: a methodology applied to nano-particle-filled sol-gel coatings on glass," Materials Science and Engineering R, vol. 36, pp. 47103, 2002.

[45] F. Wredenberg and P-L Larsson, "Delamination of thin coatings at scratching: experiments and numerics," Journal of Mechanics of Materials and Structures, vol. 4(6), pp. 1041-1062, 2009.

[46] B. D. Beake, A. J. Harris and T. W. Liskiewicz, "Review of recent progress in nanoscratch testing," Tribology - Materials, Surfaces \& Interfaces, vol. 7(2), 8796, 2013.

[47] J. E. Lee, H. J. Kim and D. E. Kim, "Assessment of adhesion between thin film and silicon based on a scratch test," Journal of Mechanical Science and Technology, vol. 24, pp. 97-101, 2010. 
[48] Online Bruker webinars: Tribological tools and mechanical testers 2015. Retrieved from https://www.bruker.com/service/education-training/webinars/tribology.html

[49] I. N. Sneddon, "The relationship between load and penetration in the axisymmetric Boussinesq problem for a punch of arbitrary profile," International Journal of Engineering Science, vol. 3, pp. 47-57, 1965.

[50] K. L. Johnson, Contact Mechanics, Cambridge University Press, London, 1985.

[51] M. F. Doerner and W. D. Nix, "A method for interpreting the data from depthsensing indentation instruments", Journal of Material Research, vol. 1, pp. 601609, 1986.

[52] W. C. Oliver and G. M. Pharr, "An improved technique for determining hardness and elastic modulus using load and displacement sensing indentation measurements," Journal of Material Reseach, vol. 7 (6), pp. 1564-1583, 1992.

[53] M. Sakai, "Energy principle of the indentation-induced inelastic surface deformation and hardness of brittle materials," Acta Materialia, vol. 41 (6), pp. 1751-1758, 1993.

[54] S. Biwa and B. Storakers, "An analysis of fully plastic Brinell indentation," Journal of Mechanics and Physics of Solids, vol. 43, pp. 1303-1333, 1995.

[55] C. M. Cheng and Y. T. Cheng, "On the initial unloading slope in indentation of elastic-plastic solids by an indenter with an axisymmetric smooth profile," Applied. Physics Leters, vol. 71, pp. 2623, 1997.

[56] X. Z. Hu and B. R. Lawn, "A simple indentation stress-strain relation for contacts with spheres on bilayer structures," Thin Solid Film, vol 322, pp. 225-232, 1998.

[57] Y. T. Cheng and C. M. Cheng, "Relationships between hardness, elastic modulus, and the work of indentation" Applied. Phyics Letters, vol. 73 (5), pp. 614-616, 1998.

[58] S. D. Mesarovic and N. A. Fleck, "Spherical indentation of elastic-plastic solids," Proceedings of the Royal Society of London, pp. 2707-2728, 1999.

[59] J. Alcala', F. Gaudette, S. Suresh and S. Sampath, "Instrumented spherical microindentation of plasma-sprayed coatings," Materials Science and Engineering, vol. 316, pp. 1-10, 2001.

[60] M. R. VanLandingham, "Review of instrumented indentation," Journal of Research of the Nationl. Institute of Standards and Technology, vol. 108, pp. 249$265,2003$. 
[61] W. C. Oliver and G. M. Pharr, "Measurement of hardness and elastic modulus by instrumented indentation: Advances in understanding and refinements to methodology," Journal of Material Reseach, vol. 19 (1), pp. 1-20, 2004.

[62] Y. G. Jung and B. R. Lawn, M. Martyniuk, H. Huang, X. Z. Hu, "Evaluation of elastic modulus and hardness of thin films by nanoindentation," Journal of Material Research, vol. 19 (10), pp. 3076- 3080, 2004.

[63] A. R. Franco Jr., G. Pintaúdeb, A. Sinatoraa, C. E. Pinedoc and A. P. Tschiptschina, "The use of a Vickers indenter in depth sensing indentation for measuring elastic modulus and Vickers hardness," Materials Research, vol. 7 (3), pp. 483-491, 2004.

[64] F. Helvaci and J. Cho, "A nanoindentation study of thermally-grown-oxide films on silicon," Materials Research Society Symposia Proceeding: Materials Research Society, vol. 841, 2005.

[65] L. M. Farrissey and P. E. McHugh, "Determination of elastic and plastic material properties using indentation: Development of method and application to a thin surface coating," Materials Science and Engineering A, vol. 399, pp. 254-266, 2005 .

[66] I. Etsion, Y. Kligerman and Y. Kadin, "Unloading of an elastic-plastic loaded spherical contact," International Journal of Solids and Structures, vol. 42, pp. 3716-3729, 2005

[67] S. Chen, L. Liu and T. Wang, "Investigation of the mechanical properties of thin films by nanoindentation, considering the effects of thickness and different coating-substrate combinations," Journal of Surface \& Coatings Technology, vol. 191, pp. 25-32, 2005.

[68] Y. Y. Lim and M. M. Chaudhri, "Indentation of elastic solids with a rigid Vickers pyramidal indenter," Mechanics of Materials, vol. 38, pp. 1213-1228, 2006.

[69] K. Wang, D. Pan, M. W. Chen, W. Zhang, X. M. Wang and A. Inoue, "Measuring elastic energy density of bulk metallic glasses by nanoindentation," Materials Transactions, vol. 47 (8), pp. 1981-1984, 2006.

[70] S. Kucharski and Z. Mroz, "Identification of yield stress and plastic hardening parameters from a spherical indentation test," International Journal of Mechanical Sciences, vol. 49, pp. 1238-1250, 2007

[71] W. Y. Yan, Q. P. Sun and D. P. Hodgson, "Determination of plastic yield stress from spherical indentation slope curve," Materials Letters, vol. 62, pp. 2260-2262, 2008. 
[72] B. Poon, D. Rittel and G. Ravichandran, "An analysis of nanoindentation in linearly elastic solids," International Journal of Solids and Structures, vol. 45, pp. 6018-6033, 2008.

[73] J. Chen and S. J. Bull, "Investigation of the relationship between work done during indentation and the hardness and Young's modulus obtained by indentation testing," International Journal of Materials Research, vol. 99, No. 8, pp. 852-857, 2008.

[74] L. Ge, N. H. Kim, G. R. Bourne and W. G. Sawyer, "Material property identification and sensitivity analysis using micro-indentation," Journal of Tribology, vol. 131, 2009.

[75] S. K. Kang, J-Y. Kim, C. P. Park, H. U. Kim and D. Kwon, “Conventional Vickers and true instrumented indentation hardness determined by instrumented indentation tests," Journal of Material Research, vol. 25 (2), pp. 337-343, 2010.

[76] A. C. Fischer-Cripps, "Nanoindentation," Mechanical Engineering Series 1, 2011.

[77] Online material hardness article, CALCE, University of Maryland, 2001. Retrieve from http://www.calce.umd.edu/TSFA/Hardness_ad_.htm

[78] B. R. Lawn and D. B. Marshall, "Indentation fracture and strength degradation in ceramics," Fracture Mechanics of Ceramics, vol. 3, pp. 205-229, 1975.

[79] B. R. Lawn and R. Wilshaw, "Review indentation fracture: principles and applications," Journal of Materials Science, vol. 10, pp. 1049-1081, 1975.

[80] B. R. Lawn and D. B. Marshall, "Hardness, toughness, and brittleness: An indentation analysis," Journal of The American Ceramic Society, vol. 62 (7-8), pp. 347-350, 1979.

[81] B. R. Lawn, A. G. Evans and D. B. Marshall, "Elastic/plastic indentation damage in ceramics: the median/radial crack system," Journal of the Amercian Ceramic Society, vol. 63 (9-10), pp. 574-581, 1980

[82] B. R. Lawn, D. B. Marshall and P. Chantikul, "Mechanics of strength - degrading contact flaws in silicon," Journal of Materials Science, vol. 16, pp. 1769-1775, 1981.

[83] G. R. Anstis, P. Chantikul, B. R. Lawn and D. B. Marshall, "A critical evaluation of indentation techniques for measuring fracture toughness. I. Direct crack measurements," Journal of American Ceramic Society, vol. 64 (9), pp. 533-538, 1981. 
[84] G. R. Anstis, P. Chantikul, B. R. Lawn and D. B. Marshall, "A critical evaluation of indentation techniques for measuring fracture toughness. II. Strength method," Journal of American Ceramic Society, vol. 64 (9), pp. 539-543, 1981.

[85] B. R. Lawn, Fracture of Brittle Solids, Cambridge University Press, London, $2^{\text {nd }}$ edition 1993,

[86] D. S. Harding, W. C. Oliver and G. M. Pharr, "Cracking during nanoindentation and its use in the measurement of fracture toughness," Materials Research Society Proceedings, vol. 356, 1995.

[87] D. Broek, Elementary Engineering Fracture Mechanics, Kluwer Academic Publishers, $4^{\text {th }}$ revised edition 1997.

[88] Y. Tang, A. Yonezu, N. Ogasawara, N. Chiba and X. Chen, "On radial crack and half-penny crack induced by Vickers indentation" Proceedings of the Royal Society A, vol. 464, pp. 2967-2984, 2008.

[89] J. J. Kruzica, D. K. Kimb, K. J. Koesterc and R.O. Ritchiec, "Indentation techniques for evaluating the fracture toughness of biomaterials and hard tissues," Journal of The Mechanical Behavior of Biomedical Materials, vol. 2, pp. 384-395, 2009.

[90] X. Li, D. Diao and B. Bhushan, "Fracture mechanisms of thin amorphous carbon films in nanoindentation," Acta Materialia, vol. 45 (11), pp. 4453-4461, 1997.

[91] X. Li and B Bhushan, "Measurement of fracture toughness of ultra-thin amorphous carbon films," Thin Solid Films, vol. 315 (1), pp. 214-221, 1998.

[92] G. M. Pharr, "Measurement of mechanical properties by ultra-low load indentation," Materials Science and Engineering A, vol. 253, pp. 151-159, 1998.

[93] J.S. Field, M.V. Swain and J.D. Dukino, "Determination of fracture toughness from the extra penetration produced by indentation pop-in," Journal of Materials Research, vol. 18 (6), pp. 1412-1416, 2003.

[94] A. A. Volinsky, B. J. Vella and W. W. Gerberich, "Fracture toughness, adhesion and mechanical properties of low- $k$ dielectric thin films measured by nanoindentation," Thin Solid Films, vol. 429, pp. 201-210, 2003.

[95] Z. H. Xia, W. A. Curtin and B.W. Sheldon, "A new method to evaluate the fracture toughness of thin films," Acta Materialia, vol. 52, pp. 3507-3517, 2004.

[96] F. Sergejev and M. Antonov, "Comparative study on indentation fracture toughness measurements of cemented carbides," Proceedings of the Estonian Academic of Science - Engineering, vol. 12 (4), pp. 388-398, 2006. 
[97] M. D. Michel, L. V. Muhlen, C. A. Achete and C. M. Lepienski, "Fracture toughness, hardness and elastic modulus of hydrogenated amorphous carbon films deposited by chemical vapor deposition," Thin Solid Films, vol. 496 (2), pp. 481488, 2006.

[98] S. Lee, J. Jang, B. W. Lee, Y. Choi, S. G. Lee and D. Kwon, “An instrumented indentation technique for estimating fracture toughness of ductile materials: A critical indentation energy model based on continuum damage mechanics," Acta Materialia, vol. 54, pp. 1101-1109, 2006.

[99] J. Chen and S. J. Bull, "Assessment of the toughness of thin coatings using nanoindentation under displacement control," Thin Solid Films, vol. 494 (1-2), pp. 1-7, 2006.

[100] J. Chen and S. J. Bull, "An energy based model to estimate coating toughness in the case that there is no excursion in the load-displacement curve," Proceedings of Materials Science \& Technology Conference, pp. 3251 - 3260, 2006.

[101] J. Chen and S. J. Bull, "Indentation fracture and toughness assessment for thin optical coatings on glass," Journal of Physics D: Applied Physics, vol. 40 (18), pp. 5401-5417, 2007.

[102] V. Hatty, H. Kahn and H. A. Heuer, "Fracture toughness, fracture strength, and stress corrosion cracking of silicon dioxide thin films," Journal of Microelectromechanical Systems, vol. 17 (4), pp. 943-947, 2008.

[103] J. Chen and S.J. Bull, "Modelling the limits of coating toughness in brittle coated systems," Thin Solid Films, vol. 517 (9), pp. 2945- 2952, 2009.

[104] J. Chen, "Indentation-based methods to assess fracture toughness for thin coatings," Journal of Physics D: Applied Physics, vol. 45 (20), pp. 1-14, 2012.

[105] S. Zhang and X. M. Zhang, "Toughness evaluation of hard coatings and thin films," Thin Solid Films, vol. 520, pp. 2375-2389, 2012.

[106] M. M. Silvaa, A. R. Vazb, S. A. Moshkalevb and J. W. Swart, "Electrical characterization of platinum thin films deposited by focused ion beam," ECS Transactions, vol. 9 (1), pp. 235-241, 2007.

[107] G. P. Panta and D. P. Subedi, "Electrical characterization of aluminum (Al) thin films measured by using four-point probe method," Journal of Science, Engineering and Technology, vol. 8 (2), pp. 31-36, 2012.

[108] B. J. Kim, H. A. S. Shin, I. S. Choi and Y. C. Joo, "Electrical failure and damage analysis of multi-layer metal films on flexible substrate during cyclic bending 
deformation," Proceedings from the 37th International Symposium for Testing and Failure Analysis, San Jose, CA, USA, 2011.

[109] T. Fourcade, A. Broue, J. Dehnnin, J. M. Desmarres, C. Seguineau, O. Dalverny, J. Alexis and T. Masri, "Validation of mechanical damage monitoring on aluminium freestanding thin films using electrical measurements," Key Engineering Materials, vol. 550, pp. 157-164, 2013.

[110] Y. Singh, "Electrical resistivity measurements: A Review," International Journal of Modern Physics: Conference Series, Vol. 22, pp. 745-756, 2013.

[111] G. G. Harman, "The use of acoustic emission in a test for beam-lead, TAB, and hybrid chip capacitor bond integrity," IEEE Transactions on Parts, Hybrids, and Packaging, vol. 13 (2), pp. 116-126, 1977.

[112] P. J. Whalen and J. B. Blum, "Practical adhesion of an Ag-Pd thick-film conductor: An acoustic emission study of pull tests - Part I, Monitoring system and initial adhesion," IEEE Transactions on Components, Hybrids, and Manufacturing Technology, vol. 9 (2), pp. 161-167, 1986

[113] W. H. Prosser, K. E. Jackson, S. Kellas, B. T. Smith, J. McKeon and A. Friedman, "Advanced, waveform based acoustic emission detection of matrix cracking in composites," Materials Evaluation, vol. 53 (9), pp. 1052-1058, 1995.

[114] M. Huang, L. Jiang, P. K. Liaw, C. R. Brooks, R. Seeley and D. L. Klarstrom, "Using acoustic emission in fatigue and fracture materials research," Journal of Minerals, Metals, and Materials Society, vol. 50 (11), 1998.

[115] A.A. Volinsky and W.W. Gerberich, "Acoustic emission analysis of fracture events in Cu films with W overlayers," Material Research Soceity Symposium Proceedings, Materials Reliability in Microelectronics IX, vol. 563, 1999.

[116] H. Cho, K. Fukaura and K. Ono, "Micro-crakcing and breakdown of Kaiser effect in ultra high strength steels," Journal of Acoustic Emission, vol. 21, pp. 112-119, 2003.

[117] B. Mi, T. E. Michaels and J. E. Michaels, "In-situ ultrasonic monitoring of crack growth under static and dynamic loadings," Proceedings of SPIE, Nondestructive Evaluation and Health Monitoring of Aerospace Materials, Composites, and Civil Infrastructure IV, vol. 5767, pp. 1-9, 2005.

[118] A. Schiavi, G. Niccolini, P. Tarizzo, A. Carpinteri, G. Lacidogna and A. Manuello, "Acoustic emissions at high and low frequencies during compression tests in brittle materials," An International Journal for Experimental Mechanics, Strain, vol. 47, pp. 105-110, 2011. 
[119] Z. W. Li, S. Yuyama, M. Yamada, K. Sekine, S. Kitsukawa, H. Maruyama and S. Konno, "Investigation on AE signal/noise processing in corrosion damage evaluation of tank bottom," Journal of Acoustic Emission, vol. 23, pp. 233-242, 2005.

[120] T. Shiotani, X. Luo and H. Haya, "Damage diagnosis of railway concrete structures by means of one-dimensional AE sources," Journal Acoustic Emission, vol. 24, pp. 205-214, 2006.

[121] K. Ono, "Structural integrity evaluation using acoustic emission," Journal of Acoustic Emission, vol. 25, 2007

[122] B. Muravin, "Acoustic Emission Science and Technology," Journal of Building and Infrastructure Engineering of the Israeli Association of Engineers and Architects, 2009.

[123] D. G. Aggelis, T. Shiotani, S. Momoki and A. Hirama, "Acoustic emission and ultrasound for damage characterization of concrete elements," American Concrete Institute Materials Journal, pp. 1-6, 2009.

[124] L. C. Lynnworth, "Industrial application of ultrasound: Measurements, test, and process control using low-intensity ultrasound," IEEE Transactions of Sonics and Ultrasonics, vol. 22 (2), pp. 71-101, 1975.

[125] J. Choi and D. E. Lee, "In-situ acoustic emission monitoring of surface chemical reactions for copper CMP," Laboratory for Manufacturing and Sustinability, University of California, Berkeley, Technical Repository 2005.

[126] M. Helu, J. Chien and D. Dornfeld, "In-situ CMP endpoint detection using acoustic emission," Procedia CIRP, pp. 454-459, 2014.

[127] H.M. Tensi, "The Kaiser-effect and its scientific background," Proceedings of European Working Group on Acoustic Emission Conference, pp.31-42, 2004.

[128] T.D. Rossing, Handbook of Acoustic, Springer Dordrecht Heidelberg London New York, $2^{\text {nd }}$ Edition, 2014.

[129] Online NDT educational materials 2002. Retrieve from https://www.ndeed.org/EducationResources/CommunityCollege/Other\%20Methods/AE/AE_Index .php

[130] B. Muravin, Online acoustic emission articles and presentations 2003. Retrieve from http://www.muravin.com/

[131] Online Vallen systeme products and applications. Retrieve from http://www.vallen.de/ 
[132] L. Chang and L.C. Zhang, "Deformation mechanisms at pop-out in monocrystalline silicon under nanoindentation," Acta Materialia 57, pp. 21482153, 2009.

[133] T. H. Wang, T. H. Fang and Y. C Lin, "A numerical study of factors affecting the characterization of nanoindentation on silicon," Materials Science and Engineering A, vol. 447, pp. 244-253, 2007.

[134] L. Kogut, and I. Etsion, "Elastic-plastic contact analysis of a sphere and a rigid flat," Journal of Applied Mechanics, vol. 69, pp.657-662, 2002.

[135] M. Liu, C. Lu, K. A. Tieu, and K. Zhou, "Crystal plasticity FEM study of nanoindentation behaviors of $\mathrm{Cu}$ bicrystals and $\mathrm{Cu}-\mathrm{Al}$ bicrystals," Journal of Materials Research, vol. 30, pp. 2485-2499, 2015.

[136] K. E. Petersen, "Silicon as a mechanical material," Proceedings of the IEEE, vol. 70 (5), pp. 420-457, 1982.

[137] Sami Franssila, Introduction to Microfabrication, $2^{\text {nd }}$ Ed., John Wiley \& Sons, Ltd, 2010.

[138] M. H. Gordon, W. F. Schmidt, Q. Qiao, B. Huang, and S. S. Ang, "A simple technique for determining yield strength of thin films," Experimental Mechanics, vol. 42 (3), pp. 232-236, 2002.

[139] Y. Choi, and S. Suresh, "Size effects on the mechanical properties of thin polycrystalline metal films on substrates," Acta Materialia, vol. 50, pp. 1881-1893, 2002.

[140] Y. G. Jung, A. Pajares and B. R. Lawn, "Effect of oxide and nitride films on strength of silicon: a study using controlled small-scale flaws," Journal of Material Research, vol. 19, pp. 3569-3575, 2004.

[141] E. N. Landis and L. Baillon, "Acoustic emission measurements of fracture energy," Proceedings of Fracture Mechanics of Concrete Structures, pp. 389-394, 2001. 


\section{List of Publications}

[1] A. Yeo, E. Yong and K. Zhou, "Compliance compensation analysis micromechanical tester integrated with acoustic emission sensors," IEEE Transactions on Device and Materials Reliability, vol. 14 (3), pp. 898-903, 2014.

[2] A. Yeo, M. Liu and K. Zhou, "Indentation damage evaluation on metal-coated thin-films stacked structure," Journal of Material Research, vol. 20 (11), pp. 3071-3083, 2015.

[3] A. Yeo, Y. S. Chan, F. Che, M. Liu and K. Zhou, "A combined experimental and modelling study of indentation damage test on thin-film stacked structures," Thin Soild Films, vol. 615, pp. 74-83, 2016.

[4] A. Yeo, Yang, F. Che, and K. Zhou, "Study on damage and fracture of thin-film stacked structures through indentation test with acoustic emission sensing," International Journal of Mechanical Sciences, vol. 128-129, pp. 159-167, 2017. 